\title{
Development of the Table of Initial Isolation and Protective Action Distances for the 2000 Emergency Response Guidebook
}

by D.F. Brown, A.J. Policastro, W.E. Dunn ${ }^{\star} R . A$. Carhart, ${ }^{*}$ M.A. Lazaro, ${ }^{*}$

W.A. Freeman, ${ }^{*}$ and M. Krumpolc*

Decision and Information Sciences Division

Argonne National Laboratory, 9700 South Cass Avenue, Argonne, Illinois 60439

October 2000

Work sponsored by U.S. Department of Transportation, Research and Special Programs Administration, Office of Hazardous Materials Technology

${ }^{*}$ Dunn is affiliated with the University of Illinois, Urbana, Illinois; Carhart, Freeman, and Krumpolc are affiliated with the University of Illinois at Chicago; and Lazaro is affiliated with Argonne's Environmental Assessment Division. 
This report is printed on recycled paper. 


\section{Contents}

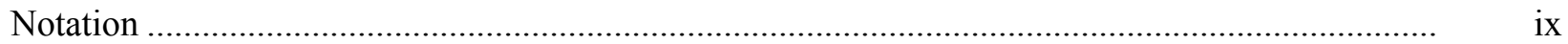

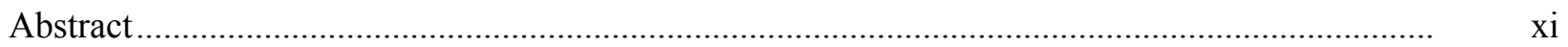

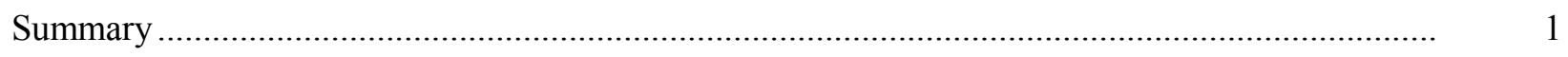

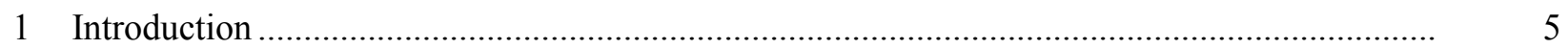

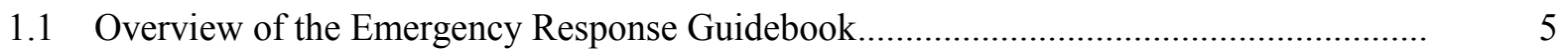

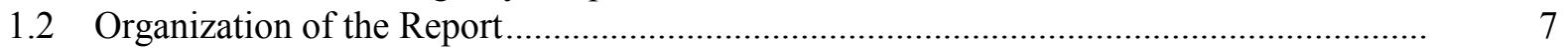

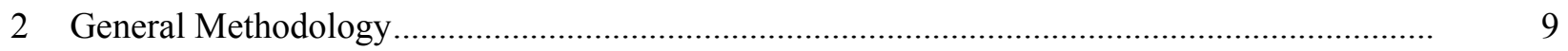

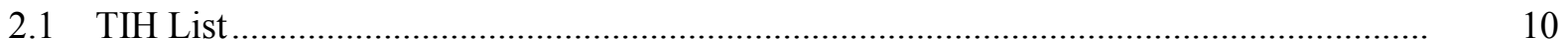

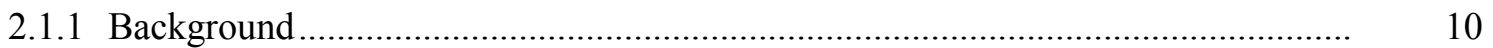

2.1.2 Changes in the Table for the 2000ERG ............................................................... 11

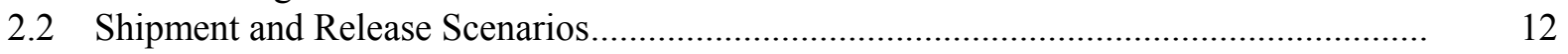

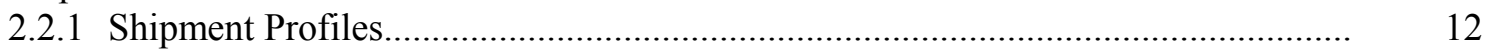

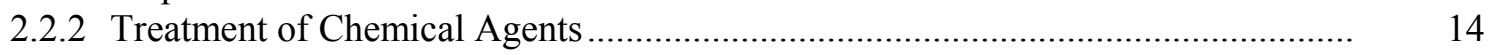

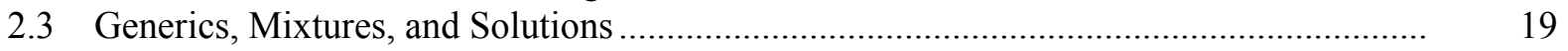

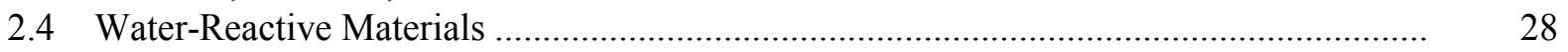

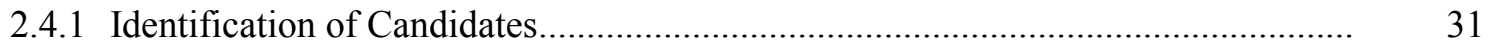

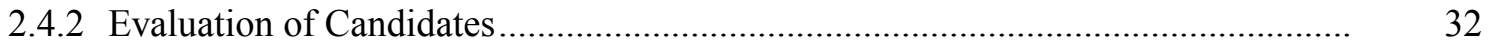

2.5 Determination of Initial Isolation Distances ................................................................. 35

3 Statistical Accident Scenario Analysis and CASRAM ........................................................ 37

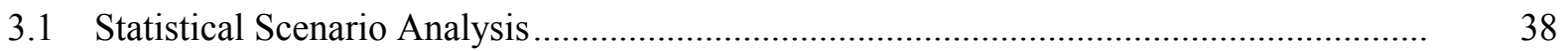

3.1.1 Overview of Analysis Steps........................................................................ 38

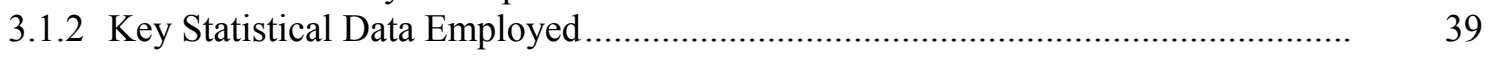

3.2 Meteorological Database Used to Prepare the Guidebook .............................................

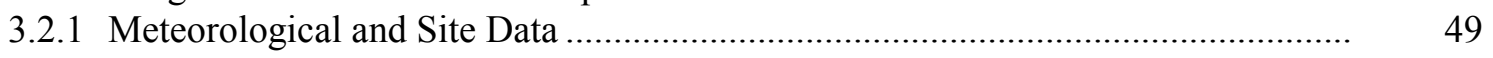

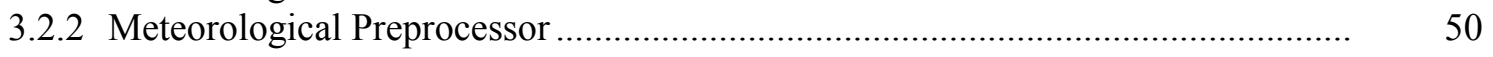

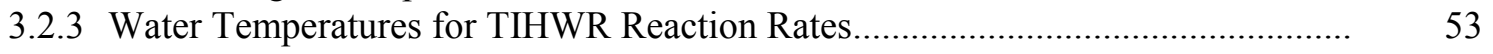

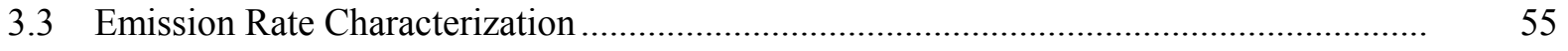

3.3.1 Overview of Release Types ............................................................................ 55

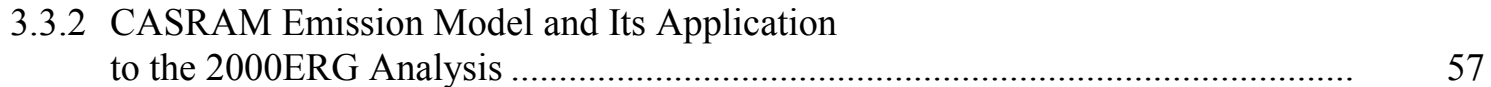

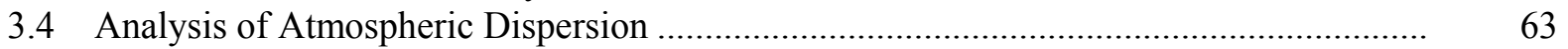

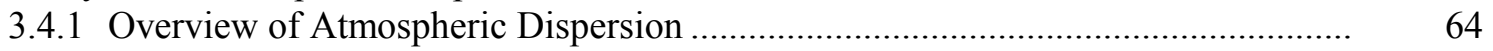

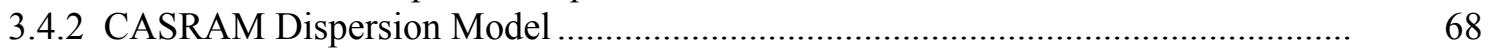




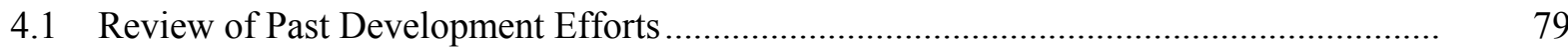

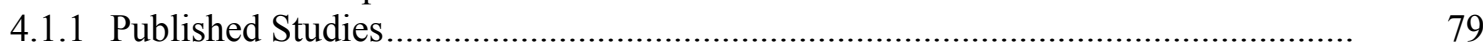

4.1.2 Expert Panel Review................................................................................. 80

4.2 Overview of the Procedure Used to Develop Health Criteria ........................................... 81

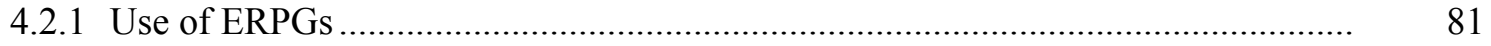

4.2.2 Use of Acute Inhalation Lethality Data in Animals .......................................... 81

4.2.3 Use of Alternative Health Criteria .........................................................................

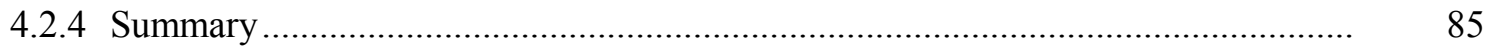

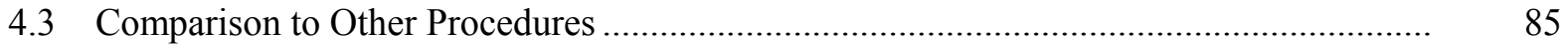

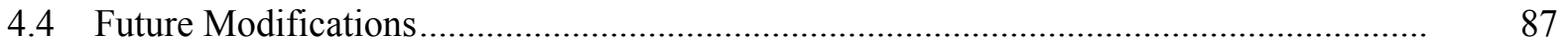

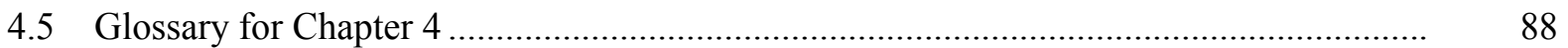

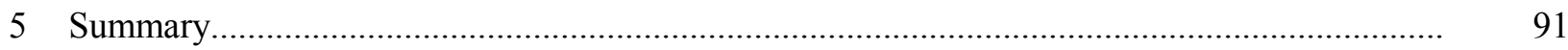

5.1 Safe Distance Distributions and Protective Action Distances ...................................... 91

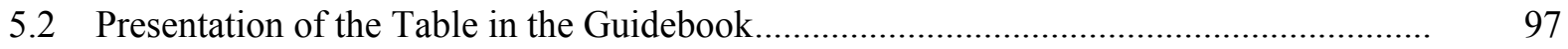

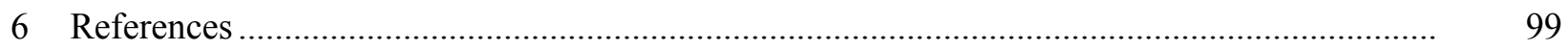

\section{Appendixes}

Appendix A: Table of Initial Isolation and Protective Action Distances

in the 2000 Emegency Response Guidebook.

Appendix B: Chemicals Analyzed in the 2000 Emergency Response

Guidebook Analysis

Appendix C: Experimental Program Conducted to Support the Water

Reactivity Analysis

Appendix D: Additional Details on Water-Reactive Materials

\section{Figures}

1.1 Illustration Showing How the 2000ERG Defines the Initial Isolation and

Protective Action Zones for Use by a First Responder

2.1 Schematic of the Methodology Used to Prepare the 2000ERG Table of Initial Isolation and Protective Action Distances

3.1 Hourly Distribution of Highway-Transportation-Related Hazardous Material Releases 


\section{Figures (Cont.)}

3.2 Monthly Distribution of Highway-Transportation-Related Hazardous Material

Releases

3.3 Hourly Distribution of Rail-Transportation-Related Hazardous Material Releases

3.4 Monthly Distribution of Rail-Transportation-Related Hazardous Material Releases

3.5 Discharge Fraction Cumulative Probability for Bulk Nonpressurized and

Low-Pressure Containers as Derived from the HMIS Database

3.6 Discharge Fraction Cumulative Probability for Bulk Pressurized Containers

as Derived from the HMIS Database

3.7 Discharge Fraction Cumulative Probability for Package Freight Containers

3.8 Locations of the 105 National Weather Service Stations Used for Statistical

Meteorological Characterization

3.9 Water Quality Network Stations Used to Determine Variations of Average Water

Temperature by Julian Day and Location...

3.10 Important Source Types for Inhalation Risk Considered in the 2000ERG Analysis ...........

3.11 Typical Daytime Convective Boundary Layer Showing (a) an Instantaneous

Wind Field and (b) an Instantaneous Material Concentration Field from a

Ground-Level Release

3.12 Typical Nighttime Stable Boundary Layer Showing (a) an Instantaneous

Wind Field and (b) an Instantaneous Material Concentration Field from a

Ground-Level Release

4.1 Histograms Comparing the Frequencies of ERPG-2 and TLV-TWA and Frequencies of ERPG-2 and TLV-C.

5.1 Frequency of Safe Distances for Small Nighttime Chlorine Spills as Determined in the 2000ERG Analysis

5.2 Frequency of Safe Distances for Large Nighttime Chlorine Spills as Determined in the 2000ERG Analysis

5.3 Frequency of Safe Distances for Small Daytime Chlorine Spills as Determined in the 2000ERG Analysis

5.4 Frequency of Safe Distances for Large Daytime Chlorine Spills as Determined in the 2000ERG Analysis 


\section{Figures (Cont.)}

5.5 Frequency of Safe Distances for Small Nighttime Aluminum Phosphide Spills

into Water as Determined in the 2000ERG Analysis

5.6 Frequency of Safe Distances for Large Nighttime Aluminum Phosphide Spills

into Water as Determined in the 2000ERG Analysis

5.7 Frequency of Safe Distances for Small Daytime Aluminum Phosphide Spills

into Water as Determined in the 2000ERG Analysis

5.8 Frequency of Safe Distances for Large Daytime Aluminum Phosphide Spills

into Water as Determined in the 2000ERG Analysis

C.1 Diagram of the Apparatus for Measuring the Rate and Amount of TIH Gases

Released When a Material Reacts with Water

\section{Tables}

2.1 Chemicals Removed from the TIH List to Prepare the 2000ERG.................................... 12

2.2 Ratio of En Route/Nonaccident Releases to Accident-Related Releases for Various

Container Types as Derived from the HMIS Database for 1990-1995.

2.3 Mixed Rail and Highway Shipment Profile Data for Liquids

2.4 Mixed Rail and Highway Shipment Profile Data for Gases

2.5 Chemical Agents Added to the 2000ERG Table of Initial Isolation and Protective Action Distances

2.6 Shipment Profile Data for Chemical Warfare Agents Transported by the Military.

2.7 Chemical Warfare Agents Added to the 2000ERG Table of Initial Isolation and

Protective Action Distances

2.8 Chemicals Used to Determine Initial Isolation and Protective Action Distances

for the Generic Material Described as Liquefied Gas, Poisonous, Flammable, n.o.s..........

2.9 Summary of Generic Compounds in the DOT TIH List and Corresponding

Surrogates Used for 2000ERG.

2.10 Summary of Mixtures and Solutions in the DOT TIH List and How They Were Modeled for 2000ERG. 


\section{Tables (Cont.)}

3.1 Geographic Distribution of Highway and Rail Transportation Incidents Modeled in the 2000ERG Analysis, by Percentage

4.1 Order of Acute Lethality Data for Estimating Health Criteria ..........................................

4.2 Summary of the Basis for Health Criteria Used to Prepare 2000ERG ............................... 86

5.1 Safe Distances at Several Percentiles for Chlorine Releases as Determined in the 2000ERG Analysis

5.2 Safe Distances at Several Percentiles for Aluminum Phosphide Releases into Water as Determined in the 2000ERG Analysis

5.3 Safe Distances at Several Percentiles for Land-Based Phosphorous Trichloride Releases as Determined in the 2000ERG Analysis

5.4 Safe Distances at Several Percentiles for Ethylene Oxide Releases as Determined in the 2000ERG Analysis

A.1 Table of Initial Isolation and Protective Action Distances

B.1 Chemicals Analyzed in the 2000ERG Analysis

D.1 Supplementary Information on Water-Reactive Materials in the 2000 Emergency Response Guidebook 
$\Delta$ 
The following is a list of the acronyms, initialisms, and abbreviations (including units of measure) used in this document. Acronyms and abbreviations used only in tables and figures are defined in the respective tables and figures.

\section{Acronyms and Abbreviations}

$\begin{array}{ll}\text { ABL } & \text { atmospheric boundary layer } \\ \text { ACGIH } & \text { American Conference of Governmental Industrial Hygienists } \\ \text { AEGL } & \text { acute exposure guidance level (National Advisory Committee) } \\ \text { AIHA } & \text { American Industrial Hygiene Association } \\ \text { CAS } & \text { Chemical Abstracts Services } \\ \text { CASRAM } & \text { Chemical Accident Statistical Risk Assessment Model } \\ \text { CBL } & \text { convective boundary layer } \\ \text { CFR } & \text { Code of Federal Regulations } \\ \text { CWI } & \text { crosswind-integrated concentration } \\ \text { DOD } & \text { U.S. Department of Defense } \\ \text { DOE } & \text { U.S. Department of Energy } \\ \text { DOT } & \text { U.S. Department of Transportation } \\ \text { EEGL } & \text { emergency exposure guidance level (National Research Council) } \\ \text { EEL } & \text { Emergency Exposure Level (AIHA Journal) } \\ \text { EPA } & \text { U.S. Environmental Protection Agency } \\ \text { ERG } & \text { Emergency Response Guidebook } \\ \text { ERPG } & \text { Emergency Response Planning Guideline (AIHA) } \\ \text { ERPG-1 } & \text { ERPG Level 1 } \\ \text { ERPG-2 } & \text { ERPG Level 2 } \\ \text { ERPG-3 } & \text { ERPG Level 3 } \\ \text { GDP } & \text { gross domestic product } \\ \text { GLB } & \text { Great Lakes Buoy } \\ \text { HCl } & \text { hydrogen chloride } \\ \text { HF } & \text { hydrogen fluoride } \\ \text { HMIS } & \text { Hazardous Materials Information System } \\ \text { HSE } & \text { Health and Safety Executive } \\ \text { IDLH } & \text { immediately dangerous to life and health (NIOSH level) } \\ \text { LC } & \text { lethal concentration to 50\% of the exposed population; } \\ & \text { median lethal concentration } \\ \text { LC } & \text { lowest reported lethal concentration } \\ \text { LOC } & \text { level of concern (EPA) } \\ \text { NIOSH } & \text { National Institute for Occupational Safety and Health } \\ \mathrm{N}_{2} \mathrm{O}_{4} & \text { nitrogen tetroxide } \\ \text { NOAA } & \text { National Oceanic and Atmospheric Administration } \\ \text { n.o.s. } & \text { not otherwise specified } \\ & \end{array}$


OSHA Occupational Safety and Health Administration

PAD Protective Action Distance

PEL permissible exposure limit (OSHA)

$\mathrm{RD}_{50} \quad 50 \%$ decrease in mean respiratory rate

SBL stratified boundary layer

SEB surface energy budget

SEBMET Surface Energy Budget Meteorological (model)

SLOT specified level of toxicity (HSE)

$\mathrm{SO}_{3} \quad$ sulfur trioxide

STC Secretariat of Transport and Communications of Mexico

STEL short-term exposure limit (ACGIH)

Table Table of Initial Isolation and Protective Action Distances (in 2000ERG)

$\mathrm{TIH} \quad$ toxic by inhalation

TIHWR toxic by inhalation by water reactivity

TLV threshold limit value (ACGIH)

TLV-C ceiling TLV

TLV-TWA time-weighted average TLV

UN United Nations

USGS U.S. Geological Survey

WQN Water Quality Network

2000ERG 2000 Emergency Response Guidebook

\section{Units of Measure}

$\begin{array}{ll}{ }^{\circ} \mathrm{C} & \text { degree(s) Celsius } \\ \mathrm{cm} & \text { centimeter(s) } \\ \mathrm{ft} & \text { foot (feet) } \\ \mathrm{g} & \text { gram(s) } \\ \text { gal } & \text { gallon(s) } \\ \mathrm{h} & \text { hour(s) } \\ \mathrm{K} & \text { degree(s) Kelvin } \\ \mathrm{kg} & \text { kilogram(s) } \\ \mathrm{kPa} & \text { kilopascal(s) } \\ \mathrm{m} & \text { meter(s) } \\ \mathrm{m}^{2} & \text { square meter(s) } \\ \mathrm{m}^{3} & \text { cubic meter(s) } \\ \mu \mathrm{m} & \text { micrometer(s) } \\ \mathrm{mi} & \text { mile(s) } \\ \mathrm{min} & \text { minute(s) } \\ \mathrm{mL} & \text { milliliter(s) } \\ \mathrm{mmol} & \text { millimole(s) } \\ \mathrm{Pa} & \text { Pascal(s) } \\ \mathrm{ppm} & \text { part(s) per million } \\ \mathrm{s} & \text { second(s) }\end{array}$




\section{Abstract}

This report provides technical documentation for values in the Table of Initial Isolation and Protective Action Distances (PADs) in the 2000 Emergency Response Guidebook (2000ERG). The objective for choosing the PADs specified in the 2000ERG was to balance the need to adequately protect the public from exposure to potentially harmful substances against the risks and expenses that could result from overreacting to a spill. To quantify this balance, a statistical approach was adopted, whereby the best available information was used to conduct an accident scenario analysis and develop a set of up to 100,000 hypothetical incidents. The set accounted for differences in the types of containers, types of incidents, severities of accidents (i.e., amounts released), locations, times of day, times of year, and meteorological conditions involved. Each scenario was analyzed by using detailed emission rate and atmospheric dispersion models to calculate the downwind chemical concentrations. The safe distance for each incident, defined as the distance downwind from the source at which the chemical concentration falls below the health criteria, was determined. The health criteria used were the American Industrial Hygiene Association's Emergency Response Planning Guideline Level 2 (ERPG-2) or equivalent criteria. The statistical sample of safe distance values for all incidents considered in the analysis was separated into four categories: small spill/daytime release, small spill/nighttime release, large spill/daytime release, and large spill/nighttime release. The 90-percentile safe distance values for each of these groups became the PADs that appear in the 2000ERG table. 
$\Delta$ 


\section{Summary}

Chemical spills resulting from the transport of toxic materials can pose substantial hazards to the general public and to first responders. To address these hazards, first responders can consult the Emergency Response Guidebook (ERG), which helps them determine whether a spill is potentially hazardous and what actions to take. The year 2000 edition of this guidebook, entitled 2000 Emergency Response Guidebook (i.e., 2000ERG), was prepared by the U.S. Department of Transportation (DOT), Transport Canada, and the Secretariat of Transport and Communications of Mexico.

The ERG provides information on fire-fighting and mitigation strategies as well as on potential health effects associated with various chemicals, which it lists under their proper shipping names and four-digit United Nations identification numbers. The ERG also provides Initial Isolation Distances and Protective Action Distances (PADs) for a subset of the chemicals it lists: chemicals that are toxic by inhalation (TIH chemicals) and chemicals that react with water to produce TIH gases (TIHWR chemicals). The Initial Isolation Distance identifies the radius of a zone around the release from which all people not directly involved in emergency response are to be kept away. The PAD is the downwind distance from the release that defines a zone in which persons should be either evacuated or sheltered-in-place, depending on the nature of the population at risk (e.g., density, age, health) and the severity of the incident.

This report provides the technical documentation for the values in the 2000ERG Table of Initial Isolation and Protective Action Distances (hereafter referred to as the Table). The objective for choosing the PADs specified in the 2000ERG was to balance the need to adequately protect the public from exposure to potentially harmful substances against the risks and expenses that could result from overreacting to a spill. To quantify this balance, a "level of protection" was defined. The level represents the probability that the listed PAD will allow sufficient protection of the public. A $90 \%$ level of protection was selected for the 2000ERG.

Quantitative analysis of the level of protection required a statistical approach to specify the PAD. To achieve this objective, the best available information was used to conduct an accident scenario analysis to develop a set of up to 100,000 hypothetical incidents for each material. The set accounted for differences in the types of containers, types of incidents, severities of accidents (i.e., amounts released), locations, times of day, times of year, and meteorological conditions involved. Each scenario was analyzed by using detailed emission rate and atmospheric dispersion models to calculate the downwind chemical concentrations. The "safe distance" for each incident, defined as the distance downwind from the source at which the chemical concentration falls below the health criteria, was determined. The health criteria used were the American Industrial Hygiene Association's Emergency Response Planning Guideline Level 2 (ERPG-2) or 
equivalent criteria. The ERPG-2 criteria denote the highest chemical concentration at which persons will suffer no irreversible or other serious health effects that could impair their ability to take protective action. The statistical sample of safe distance values for all incidents for each material was separated into four categories: small spill/daytime release, small spill/nighttime release, large spill/daytime release, and large spill/ nighttime release. The 90-percentile safe distance values for each of these groups became the PADs that appear in the Table.

Several changes from earlier versions of the Table were made to produce the Table that appears in the 2000ERG. Specific improvements and changes are listed below, and their influences on PADs are discussed.

1. The methodology for modeling TIHWR releases was substantially improved, allowing them to be treated at the same level of detail as land-based TIH releases. As a result, in the 2000ERG, water-reactive materials are listed together with TIH materials in the Table. A key factor in developing this methodology was an experimental program that provided important reaction data on 21 candidate materials. As a result of the experiments and detailed literature reviews, 36 new materials were added to the TIHWR list, which had contained 37 materials in the 1996 edition of the ERG. In addition, 3 of the 37 materials on the old list were removed. Thus, the number of TIHWR materials in the 2000ERG list totals 70 .

2. Twenty chemicals recognized as chemical warfare agents were added to the Table for cases in which they would be used as a weapon, since release scenarios for weapons-related incidents are very different from release scenarios for transportation-related TIH incidents. Ten of the 20 new chemicals also met the criteria for being TIH chemicals, so they were also entered in the Table for cases in which they would be released in transportation-related incidents. In addition, new entries for several other industrial chemicals already on the TIH list (e.g., hydrocyanic acid, phosgene) were created for cases in which they would be used as a weapon.

3. Shipment profiles were developed for each TIH chemical so the types of containers and transport modes (e.g., rail, highway) used to ship the chemicals would be more closely reflected. The shipment profiles specified the bulk and package freight containers typically used to transport the material, as well as the relative frequency at which each type of container is involved in incidents. Using shipment profiles resulted in some substantial changes in PADs. For many chemicals, the PADs for small spills became shorter than they were in the two previous editions of the ERG because the estimates for those releases were less conservative. However, since the shipment profiles provided a more realistic split between rail and highway transportation than had been considered before, the PADs for large spills of some liquefied gases became somewhat longer than they were in the 1996 ERG. 
4. The database on chemical properties that is used for calculating emission rates was substantially updated. Improved techniques were used to estimate some properties that had not been known or were crudely approximated in earlier versions of the ERG. This effort resulted in large changes for some chemicals but no changes for chemicals that had been well characterized in past ERGs (chlorine, ammonia, sulfur dioxide, etc.).

5. A dense gas dispersion algorithm was added to CASRAM, the risk assessment model used to determine Initial Isolation Distances and PADs. The special consideration of dense gas effects did not greatly influence the final PADs, except for the PADs for liquefied gases with low to moderate toxicity. For this class of materials, inclusion of dense gas effects shortened PADs by up to $15 \%$.

6. Accidents in Canada and Mexico, in addition to those in the United States, were considered in the statistical release and dispersion analysis. The inclusion of these accidents had a relatively small impact on the PADs because (1) most accidents (89\%) occur in the United States and (2) the effects of meteorological conditions (chiefly temperature) in Canada and Mexico tended to offset each other. 
$\Delta$ 


\section{Section 1 Introduction}

Chemical spills that occur during the transport of toxic materials can pose significant hazards to the general public and to emergency response personnel who are the first to arrive at the scene. To help first responders determine whether a shipment is potentially hazardous and decide what actions should be taken if a toxic spill did occur, an Emergency Response Guidebook (ERG) is periodically published and updated. The U.S. Department of Transportation (DOT), Transport Canada (TC), and Secretariat of Transport and Communications of Mexico (STC) published the 2000 edition of the ERG (DOT et al. 2000). It is titled 2000 Emergency Response Guidebook (hereafter referred to as 2000ERG). The ERG provides essential information on fire fighting, spill response, and potential public health effects. The ERG provides Initial Isolation Distances and Protective Action Distances (PADs) for a subset of the chemicals that are listed in the book: chemicals that are toxic by inhalation (TIH chemicals) and chemicals that produce TIH gases upon reaction with water (TIHWR chemicals). The Initial Isolation Distance defines the radius of the zone around the spill that should be accessed solely by people who are directly involved in emergency response. The PAD is the distance downwind from the source of the release that defines a zone in which persons should be either evacuated or sheltered-in-place, depending on the severity of the incident and the nature of the population (e.g., density, age, health).

This report was prepared to document and discuss the methodology used to prepare the 2000ERG Table of Initial Isolation and Protective Action Distances (hereafter referred to as the Table). The PADs in the Table were calculated to balance the need to adequately protect the public from exposure to potentially harmful substances against the risks and expenses that could result from overreacting to a spill. In determining the PADs, this balance was quantified in terms of a level of protection (i.e., the probability that the listed PAD will allow sufficient protection of the public). The level of protection adopted for the ERG was $90 \%$. Clearly, a quantitative analysis of the level of protection requires a statistical approach to specify the $\mathrm{PAD}$. The underlying technical basis for this statistical methodology is described in this report.

\subsection{Overview of the Emergency Response Guidebook}

Figure 1.1 illustrates the basic information presented in the ERG. As shown, the ERG is designed to be used by a first responder to determine the appropriate level of action during the first 30 minutes after a transportation accident involving hazardous materials. Although knowledgeable in the field of law enforcement and public protection, a first responder is usually not an expert in the transport of hazardous materials. Thus, the ERG is a compact source of essential information to use as a basis for making reasonable decisions, often under difficult conditions. 

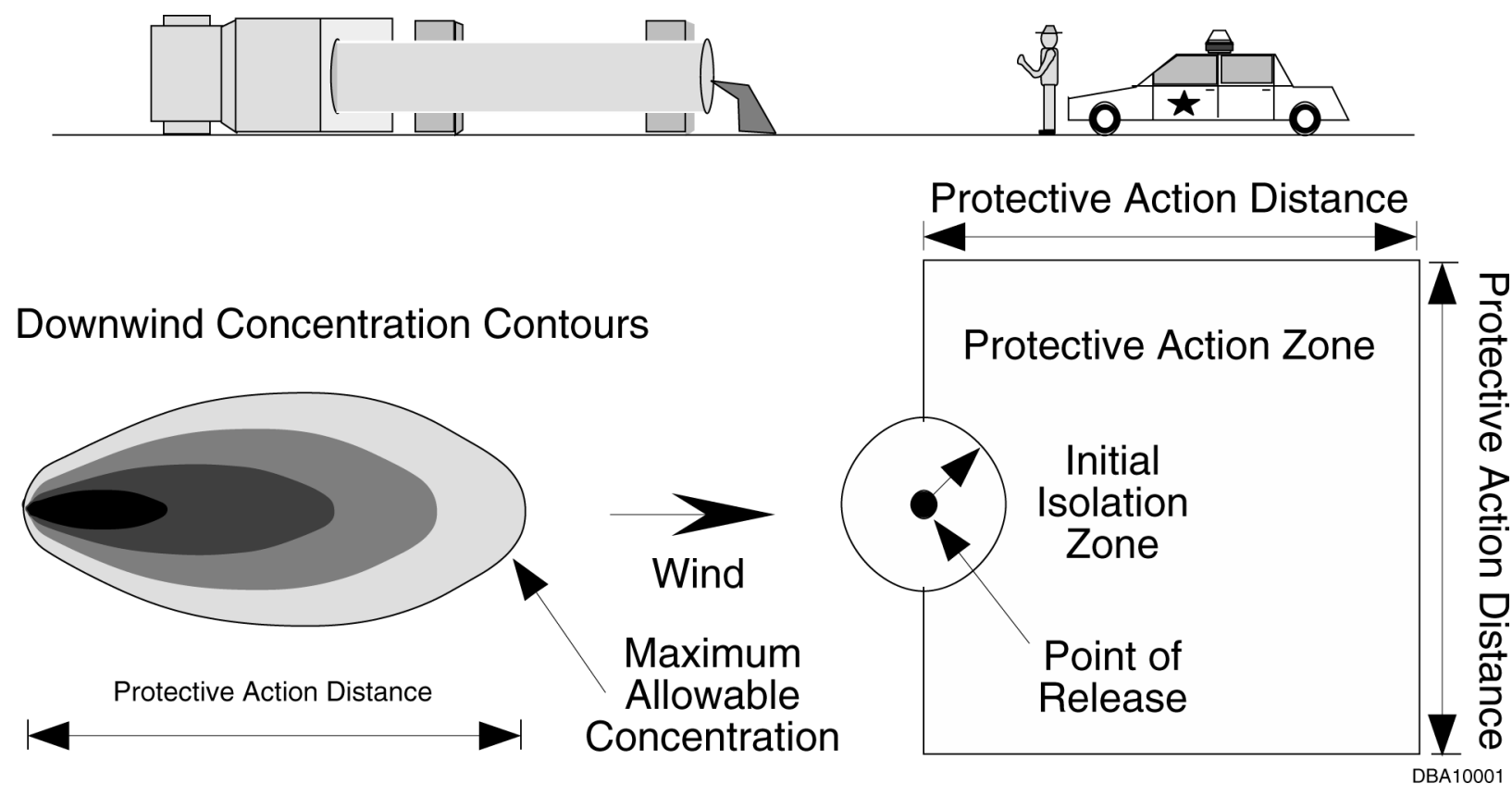

Figure 1.1 Illustration Showing How the 2000ERG Defines the Initial Isolation and Protective Action Zones for Use by a First Responder

To properly use the Table, a responder must determine the following:

- United Nations (UN) identification number and/or proper shipping name of the material being transported;

- Direction of the prevailing wind;

- Size of the release, i.e., a small (55 gal or less) spill or large (more than 55 gal) spill;

- Time of day or night; and

- Any special conditions that could preclude the use of the values given in the Table.

As illustrated by the contours shown in Figure 1.1, the downwind concentrations of vapor decrease as distance increases. At some distance downwind from the source of the release, the concentration reaches a level that no longer requires protective action. This distance is called the Protective Action Distance (PAD). The term Protective Action Zone refers to a square region that has side dimensions equal to the PAD and lies downwind and symmetrically about the accident location. The square shape was chosen to provide a simple, familiar way to define the zone and, more important, to account for the uncertainty in the plume trajectory, which is caused by the variability in wind direction and the possible effects of topographical features. The Table also provides an Initial Isolation Distance, which defines the radius of a circular zone that surrounds the accident site. Persons who are not involved in response activities should not be permitted within this Initial Isolation Zone. They could be exposed to life-threatening health 
effects downwind of the accident site and to dangerous concentrations upwind in the case of variable wind direction.

\subsection{Organization of the Report}

Section 2 presents a detailed overview of the methodology used to calculate the Initial Isolation Distances and PADs. Included in this discussion is an examination of issues related to the $\mathrm{TIH}$ list; treatment of generic compounds, mixtures, and solutions; treatment of chemical warfare agents (a new class added in the 2000ERG); and treatment of water-reactive materials. Section 3 provides details on the statistical scenario analysis applied to materials in the Table, as well as technical details on the consequence models used. Section 4 documents the health criteria, or threshold chemical concentrations, used to specify the Initial Isolation and Protective Action Distances. Section 5 discusses the safe distance distributions developed as a result of the analysis and describes how the PADs were determined from these distributions. Appendix A provides the $2000 \mathrm{ERG}$ Table of Initial Isolation and Protective Distances (DOT et al. 2000). Appendixes B-D contain details about chemical-specific data, including experiments conducted to identify and quantify TIH gas emission rates from water-reactive materials. 
$\Delta$ 


\section{Section 2 General Methodology}

The methodology used in preparing the Table for the 2000ERG is illustrated schematically in Figure 2.1. The starting point for the analysis of the methodology is a list of TIH materials developed by DOT (see discussion in Section 2.1). This list was modified slightly from the 1996 ERG in that it now includes various chemical agents that are either transported by the U.S. Department of Defense (DOD) or could be used as weapons. For each material in the list, the authorized mode of shipping, as outlined in the Code of Federal Regulations (CFR), is combined with commodity flow information

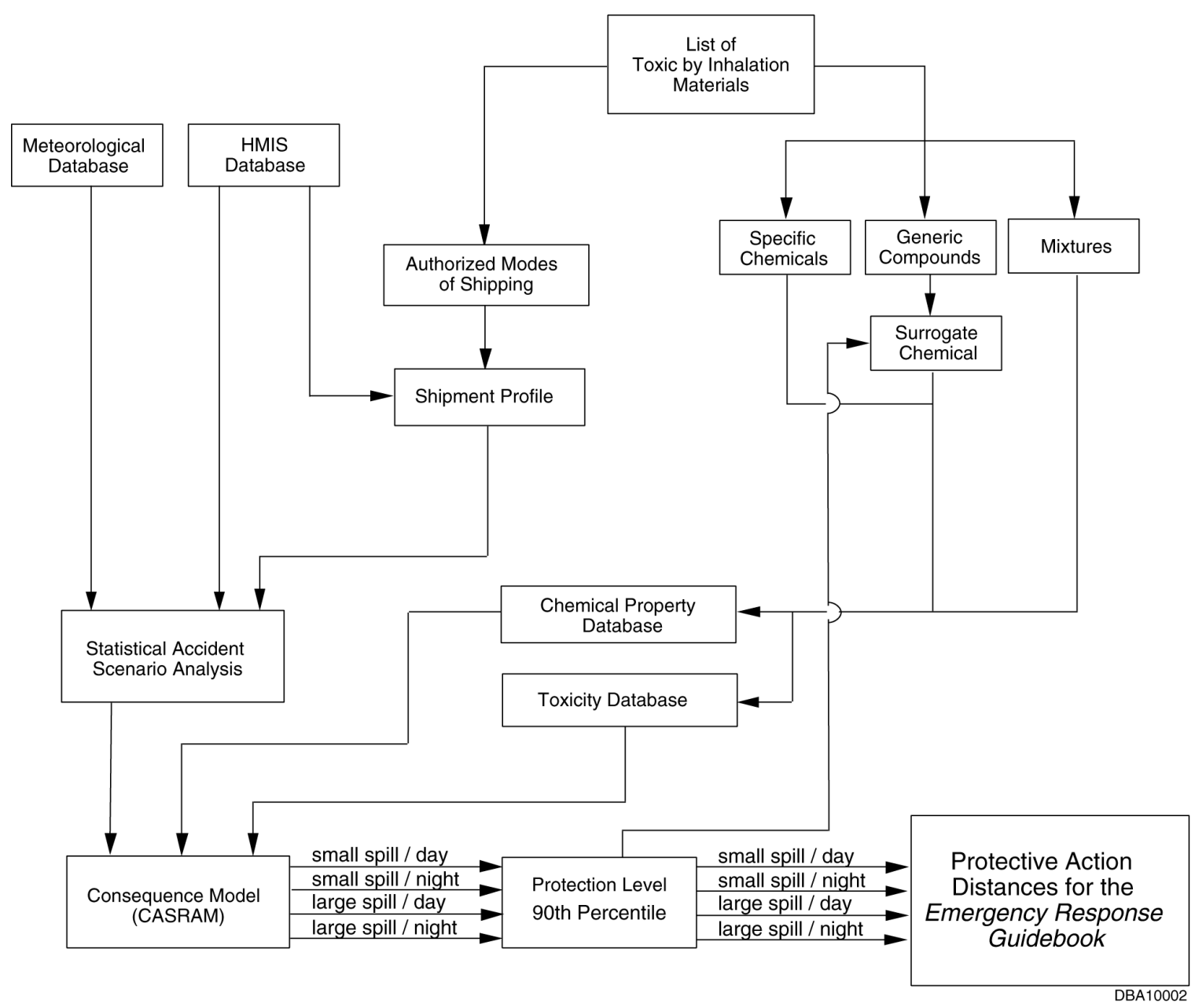

Figure 2.1 Schematic of the Methodology Used to Prepare the 2000ERG Table of Initial Isolation and Protective Action Distances 
and historical incident data to develop a "shipment profile." Shipment profiles, which are discussed in Section 2.2.1, are used in the analysis to determine the types of incidents that could occur for particular materials or classes of materials.

The shipment profiles are then used to conduct a statistical analysis of accident scenarios. The result of this analysis is a set of up to 100,000 hypothetical incidents based on the best available statistical information, which takes into account variability in container type, incident type, accident severity (i.e., release amount), location, time of day, time of year, and meteorology. Several of the important release parameters are selected from statistical distributions from transportation-related hazardous materials releases cataloged in the Hazardous Materials Information System (HMIS) database maintained by the DOT Research and Special Programs Administration.

Each scenario is then analyzed by using detailed emission rate and atmospheric dispersion models to calculate an estimated downwind chemical concentration footprint. The safe distance for a specific scenario is then chosen as the furthest downwind distance that the health criteria for the chemical involved in the incident is exceeded. The health criteria, which are exposure-time-dependent threshold concentrations, are based on American Industrial Hygiene Association (AIHA) Emergency Response Planning Guideline Level 2 (ERPG-2) or an equivalent guideline (see Section 4). The safe distance estimates for the entire set of hypothetical incidents considered in the analysis provide a distribution of safe distances that correspond to the many transportation-related releases that could occur. Incidents are then categorized by time (day, night) and spill size $(55 \mathrm{gal}$ or less $=$ small, more than $55 \mathrm{gal}=$ large $)$. The PADs provided in the 2000ERG are then selected as the $90^{\text {th }}$ percentile values for these individual categories. The Initial Isolation Zones are calculated in a similar manner on the basis of health criteria for life-threatening effects.

\subsection{TIH List}

\subsubsection{Background}

The analysis begins with the TIH list provided by DOT. The materials in the TIH list are designated by UN number and proper shipping name, although the UN numbers are not unique. The list can be divided into several categories of chemicals: (1) single chemicals, (2) mixtures, (3) solutions, and (4) generics. Altogether, the TIH list for 2000ERG includes 152 single chemicals, 16 mixtures, 5 solutions, and 24 generics. As is explained later, generic compounds are divided into subcategories on the basis of hazard zone designation, as defined in Title 49, Part 173, Section 133 of the CFR (49 CFR 173.133). Hazard Zones A, B, C, and D are for gases; Hazard Zones A and B are for liquids). In addition, 70 water-reactive materials, defined here as materials that emit a $\mathrm{TIH}$ gas upon contact with water, are included. Of the water-reactive materials in the Table, 12 are also TIH compounds, which produce a secondary, sometimes more toxic, $\mathrm{TIH}$ gas upon reaction with water. 
Each category is handled individually. Single chemicals are specified according to a Chemical Abstracts Services (CAS) number, which is a unique numerical identifier for each chemical compound. A unique identifier is necessary to avoid problems with chemical name synonyms. Mixtures are treated by considering the individual components in the mixture. Generics are modeled by using a surrogate compound, with the surrogate being the worst case of the materials considered for the particular generic description and hazard zone. Water-reactive materials are treated in a manner similar to regular TIH materials, with the water reactivity being treated in the emission rate analysis. The treatment of water reactivity is discussed in Section 2.4 and Appendixes C and D.

\subsubsection{Changes in the Table for the 2000ERG}

New materials were added to the Table for the 2000ERG. Twenty of the new materials are classified as chemical warfare agents and were included in the Table because they could be released as weapons (see Section 2.2.2). Ten of the new materials also have entries for standard transportation-related releases associated with legal activities. In addition, weapons-related entries were added for several other industrial TIH chemicals already on the TIH list (e.g., hydrocyanic acid, phosgene). Some of these materials have several synonyms for which entries were also added. The list of new materials is included in Section 2.2.2 in the discussion related to the treatment of chemical warfare agents.

The other substantial change made to the Table was to include materials that emit a TIH gas upon reaction with water throughout the table where appropriate; previously, these materials had been listed separately at the end of the Table. To make this change, individual distances were calculated for these materials by using a methodology similar to that employed for land-based spills. In addition, 37 new materials were added to the TIH by water reactivity (TIHWR) list, and 4 materials were removed, partially on the basis of results from experimental studies conducted for the 2000ERG analysis. The treatment of water-reactive materials is discussed in depth in Section 2.4 and Appendixes $\mathrm{C}$ and D.

In addition to the variety of new materials added to the Table, 17 new entries that are synonymous with materials already listed were added to the Table.

The two chemicals listed in Table 2.1 were removed from the TIH list because of their low volatility. These chemicals are liquids that fall into Hazard Zone $\mathrm{C}$ per the definitions in 49 CFR 173.133. The calculated PADs for these materials are less than $0.2 \mathrm{mi}$. Acetone cyanohydrin, however, is a water-reactive material and therefore is retained in the Table, but only for spills into water. 
Table 2.1 Chemicals Removed from the TIH List to Prepare the 2000ERGa

\begin{tabular}{|lccc|}
\hline \multicolumn{1}{c}{ Chemical } & UN No. & LC $_{\mathbf{5 0}}$ (ppm) & $\mathbf{P}_{\text {vap }}$ at $\mathbf{2 0}^{\circ} \mathbf{C} \mathbf{( P a )}$ \\
\hline Acetone cyanohydrin & 1541 & 126 & 29.4 \\
Phenylcarbylamine chloride & 1672 & 300 est. & 41.4 est. \\
\hline
\end{tabular}

a $\mathrm{LC}_{50}=$ lethal concentration to $50 \%$ the population; ppm = parts per million; est. $=$ estimated.

\subsection{Shipment and Release Scenarios}

Associated with each entry in the TIH list are authorized modes of shipping as specified in 49 CFR 172.101 and associated subsections. These specifications substantially influence the amount of material that could be released in a transportrelated accident. For example, many Division 2.3 gases under Hazard Zone A cannot be transported in bulk form. Consequently, such materials are shipped only in package freight containers (drums, cylinders). The resultant total shipping volumes are thus much less than those associated with a typical bulk shipment. Packaging authorizations also govern container type. This factor is important to remember when considering not only shipping volumes but also discharge fractions (the amount of material released in an incident relative to the container capacity).

\subsubsection{Shipment Profiles}

For the ERG2000 analysis, we used packaging authorizations together with data on commodity flow and hazardous material incidents to develop shipment profiles for each material considered. Shipment profiles specify bulk and package freight containers typically used in transporting the material as well as the relative frequency that each container is involved in an incident. In this method, each chemical is assigned a set of representative shipments that reflect its transportation in the United States, Canada, and Mexico. For almost all chemicals, the shipment profile fell into one of the following nine general classes:

1. Gases dominated by rail transportation,

2. Gases with mixed rail and highway transportation,

3. Gases dominated by highway transportation,

4. Liquids dominated by rail transportation,

5. Liquids with mixed rail and highway transportation, 
6. Liquids dominated by highway transportation,

7. Bulk-forbidden gases and liquids authorized under 49 CFR 173.192,

8. Bulk-forbidden gases and liquids authorized under 49 CFR 173.302, and

9. Organophosphates authorized under 49 CFR 173.334.

Chemicals with a 49 CFR 173.245 authorization for bulk transportation are included in the bulk-forbidden classes. For these chemicals (and the ones for which bulk is forbidden), the PADs for large spills were estimated from shipments containing up to 25 cylinders or drums. A release from this number of package freight containers is equivalent to a release from a small bulk cargo tank (e.g., 1,500 g). Larger containers were not included in this analysis because it was believed that they would add an unrealistic degree of conservatism to the results, since the probability of these materials being shipped in true bulk form appears to be very low.

A shipment was designated as being either rail- or highway-dominated on the basis of available commodity flow data (these data are available for a few widely shipped chemicals) and a survey of incidents from the HMIS database. If no information other than data on packing authorizations within 49 CFR was known and if the material was authorized for bulk transport, the mixed rail and highway shipment profile was used. These shipment profiles were used with the Chemical Accident Statistical Risk Assessment Model (CASRAM) to simulate tens of thousands of accidents for each chemical in a fashion similar to that used by Brown et al. (1999).

For each class of shipment, analyses were conducted for releases that occurred (1) during a traffic accident or train derailment and (2) during transport en route from the point of origin to the destination but not during an accident or derailment. These release types are referred to as accident-related releases and en route/nonaccident releases, respectively. Nonaccident releases include releases that occur as a result of cargo shifts, valve failures, corrosion-induced container failure, and so forth. Nonaccident releases are much more common than accident-related releases, as shown by the HMIS incident data summarized in Table 2.2. However, most en route/nonaccident releases are minor.

An example of a mixed rail and highway shipment profile is provided in Table 2.3 for liquids and in Table 2.4 for gases. Three classes of shipments are listed for each profile: bulk rail transportation, bulk highway transportation, and package freight transportation. To provide some perspective on the relative influence of the shipment classes and release types on releases modeled in the 2000ERG analysis, the percentage of total releases represented by each type is listed for all releases, releases of 5 through 55 gal, and releases of more than $55 \mathrm{gal}$. When all releases are considered, en route/nonaccident incidents makeup the majority of releases modeled for the shipment profiles given in Tables 2.3 and 2.4. However, in considering releases of more than 55 gal (i.e., "large spills" in the Table), accident-related incidents makeup the majority of cases. For such 
Table 2.2 Ratio of En Route/Nonaccident Releases to AccidentRelated Releases for Various Container Types as Derived from the HMIS Database for 1990-1995

\begin{tabular}{|cc|}
\hline Container Type & $\begin{array}{c}\text { Ratio of En Route/Nonaccident } \\
\text { Releases to Accident-Related } \\
\text { Releases }\end{array}$ \\
\hline 111AW tank car & 25 \\
112JW and 105A tank car & 40 \\
MC306 cargo tank & 0.25 \\
MC307 cargo tank & 2.5 \\
MC312 cargo tank & 3.5 \\
MC330/331 cargo tank & 0.5 \\
Portable tank & 10 \\
Small and medium drum & 25 \\
Large drum & 7 \\
Cylinder & 7 \\
Miscellaneous package freight & 50 \\
\hline
\end{tabular}

Source: Brown et al. (1999).

releases, package freight incidents contributed the most releases, whereas bulk highway incidents contributed the least. Because PADs are set by the 90-percentile value, incidents involving bulk containers had a far greater influence on PAD values than did incidents involving package freight containers, since bulk containers usually involved larger release amounts.

\subsubsection{Treatment of Chemical Agents}

One of the major changes in the Table in the 2000ERG from previous versions is that it now includes chemical warfare agents. Entries are given for two release scenarios:

(1) transportation-related release scenarios, which are for other materials in the Table, and (2) weapons-related release scenarios, which model a criminal or terrorist act. Each scenario is analyzed in the following sections.

\subsubsection{Transportation-Related Releases}

Previous editions of the ERG listed various industrial chemicals that are classic chemical warfare agents, including hydrogen cyanide, phosgene, diphosgene, cyanogen chloride, arsine, methyldichloroarsine, and ethyldichloroarsine. Because these materials 
Table 2.3 Mixed Rail and Highway Shipment Profile Data for Liquidsa

\begin{tabular}{|c|c|c|c|c|c|c|c|}
\hline \multirow[b]{2}{*}{ Shipment } & \multirow[b]{2}{*}{$\begin{array}{l}\text { Transport } \\
\text { Mode }\end{array}$} & \multirow[b]{2}{*}{ Container } & \multirow[b]{2}{*}{$\begin{array}{l}\text { Shipment } \\
\text { Amount }\end{array}$} & \multirow[b]{2}{*}{$\begin{array}{l}\text { Release } \\
\text { Type }\end{array}$} & \multicolumn{3}{|c|}{$\begin{array}{c}\text { Percent of Total Releases by Type, } \\
\text { Listed by Release Amount }\end{array}$} \\
\hline & & & & & $\begin{array}{c}\text { All } \\
\text { Releases }\end{array}$ & $5-55 \mathrm{gal}^{\mathrm{b}}$ & $>55 \mathrm{gal}^{\mathrm{b}}$ \\
\hline \multirow[t]{2}{*}{1} & \multirow[t]{2}{*}{ Rail } & \multirow{2}{*}{$\begin{array}{l}\text { DOT Class } \\
112 \text { tank car }\end{array}$} & \multirow[t]{2}{*}{$80,000 \mathrm{~kg}$} & $A$ & 1.5 & 0.6 & 19.8 \\
\hline & & & & $E$ & 30.5 & 6.8 & 14.6 \\
\hline \multirow[t]{2}{*}{2} & \multirow[t]{2}{*}{ Highway } & \multirow{2}{*}{$\begin{array}{l}\text { MC312 cargo } \\
\text { tank }\end{array}$} & \multirow[t]{2}{*}{$25,000 \mathrm{~kg}$} & $A$ & 0.8 & 0.3 & 11.2 \\
\hline & & & & $E$ & 3.1 & 2.9 & 2.5 \\
\hline \multirow[t]{2}{*}{3} & \multirow[t]{2}{*}{ Highway } & \multirow{2}{*}{$\begin{array}{l}\text { Ten } 55-\text { gal } \\
5 \mathrm{C} \text { drums }\end{array}$} & \multirow[t]{2}{*}{550 gal } & $A$ & 3.1 & 3.7 & 27.9 \\
\hline & & & & $E$ & 61.0 & 85.7 & 24.0 \\
\hline
\end{tabular}

a This profile covers three shipment classes and two release types, accident-related $(A)$ and en route/nonaccident $(E)$. Percentages are provided for the total number of incidents that occurred in the various shipment classes and release types. Percentages are given for all releases, releases of 5 through $55 \mathrm{gal}$, and releases of more than $55 \mathrm{gal}$.

b Data provided for allylamine (UN 2334). Other materials with this profile would have similar results.

Table 2.4 Mixed Rail and Highway Shipment Profile Data for Gasesa

\begin{tabular}{|c|c|c|c|c|c|c|c|}
\hline \multirow[b]{2}{*}{ Shipment } & \multirow[b]{2}{*}{$\begin{array}{l}\text { Transport } \\
\text { Mode }\end{array}$} & \multirow[b]{2}{*}{ Container } & \multirow[b]{2}{*}{$\begin{array}{l}\text { Shipment } \\
\text { Amount }\end{array}$} & \multirow[b]{2}{*}{$\begin{array}{l}\text { Release } \\
\text { Type }\end{array}$} & \multicolumn{3}{|c|}{$\begin{array}{c}\text { Percent of Total Releases by Type, } \\
\text { Listed by Release Amount }\end{array}$} \\
\hline & & & & & $\begin{array}{c}\text { All } \\
\text { Releases }\end{array}$ & $5-55 \mathrm{gal}^{\mathrm{b}}$ & $>55 \mathrm{gal}^{\mathrm{b}}$ \\
\hline \multirow[t]{2}{*}{1} & \multirow[t]{2}{*}{ Rail } & \multirow{2}{*}{$\begin{array}{l}\text { DOT Class } \\
\text { 105, } 112 \text { tank } \\
\text { car }\end{array}$} & \multirow[t]{2}{*}{$80,000 \mathrm{~kg}$} & $A$ & 1.7 & 0.70 & 21.7 \\
\hline & & & & $E$ & 69.3 & 19.7 & 17.9 \\
\hline \multirow[t]{2}{*}{2} & \multirow[t]{2}{*}{ Highway } & \multirow{2}{*}{$\begin{array}{l}\text { MC331 cargo } \\
\text { tank }\end{array}$} & \multirow[t]{2}{*}{$25,000 \mathrm{~kg}$} & $A$ & 0.8 & 0.7 & 8.8 \\
\hline & & & & $E$ & 0.4 & 0.5 & 2.2 \\
\hline \multirow[t]{2}{*}{3} & \multirow[t]{2}{*}{ Highway } & \multirow{2}{*}{$\begin{array}{c}\text { Fifteen } \\
19-g a l \\
3 \mathrm{~A} \text { or } 4 \mathrm{~A} \\
\text { cylinders }\end{array}$} & \multirow[t]{2}{*}{$285 \mathrm{gal}$} & $A$ & 3.5 & 7.1 & 34.0 \\
\hline & & & & $E$ & 24.3 & 71.3 & 15.4 \\
\hline
\end{tabular}

a This profile covers three shipment classes and two release types, accident-related $(A)$ and en route/nonaccident $(E)$. Percentages are provided for the total number of incidents that occurred in the various shipment classes and release types. Percentages are given for all releases, releases of 5 through $55 \mathrm{gal}$, and releases of more than $55 \mathrm{gal}$.

b Data provided for chlorine trifluoride (UN 1749). Other materials with this profile would have similar results. 
are transported for industrial purposes, they are listed in 49 CFR 173.101 and were included in the standard shipment profile methodology.

For the 2000ERG, some nerve and blister agents transported in small quantities by military agencies were added to this list (see Table 2.5). Release scenarios for these materials are somewhat different than those for the other materials in the Table. Military agencies primarily ship these agents in very small quantities (less than $2 \mathrm{~kg}$ ). In rare circumstances, small munitions are also transported for disposal. Because of overpacking, small leaks (primarily in en route/nonaccident incidents) are contained. As a result, only accident-related incidents were studied in this analysis. "Ton cylinders" however, were also included in the analysis. These containers are used to store blister and nerve agents at a few military bases. Although such containers have not been transported off site in the past several years, they were included to provide PAD values for large spills, because the other shipments fall well below this size limit, and ton cylinders would be a likely container to be involved in such a release. The containers and release amounts modeled for nerve and blister agents are summarized in Table 2.6.

It is important to note that although blister and nerve agents are extremely toxic, most are nonvolatile liquids (except for isopropyl methylphosphonofluoridate). Consequently, their PAD values are actually small relative to those of other highly hazardous materials in the Table.

Table 2.5 Chemical Agents Added to the 2000ERG Table of Initial Isolation and Protective Action Distances

\begin{tabular}{|c|c|c|}
\hline UN No. & Chemical Name & $\begin{array}{c}\text { Agent } \\
\text { Synonym }\end{array}$ \\
\hline 2810 & Bis-(2-chloroethyl) sulfide & $\mathrm{H}, \mathrm{HD}$, Mustard \\
\hline 2810 & Bis-(2-chloroethyl) ethylamine & $\mathrm{HN}-1$ \\
\hline 2810 & Bis-(2-chloroethyl) methylamine & $\mathrm{HN}-2$ \\
\hline 2810 & Tris-(2-chloroethyl) amine & $\mathrm{HN}-3$ \\
\hline 2810 & Dichloro-(2-chlorovinyl) arsine & L, Lewisite \\
\hline 2810 & Ethyl N,N-dimethylphosphoramidocyanidate & GA, Tabun \\
\hline 2810 & Isopropyl methylphosphonofluoridate & GB, Sarin \\
\hline 2810 & Pinacolyl methylphosphonofluoridate & GD \\
\hline 2810 & Cyclohexyl methylphosphonofluoridate & GF \\
\hline 2810 & $\begin{array}{l}\text { O-Ethyl S-(2-diisopropylaminoethyl) } \\
\text { methylphosphonothiolate }\end{array}$ & VX \\
\hline
\end{tabular}


Table 2.6 Shipment Profile Data for Chemical Warfare Agents Transported by the Military

\begin{tabular}{|ccccc|}
\hline Shipment & $\begin{array}{c}\text { Transport } \\
\text { Mode }\end{array}$ & Container & $\begin{array}{c}\text { Shipment } \\
\text { Amount }\end{array}$ & $\begin{array}{c}\text { Total Release } \\
\text { by Category } \\
\text { (\%) }\end{array}$ \\
\hline 1 & Highway & $\begin{array}{c}\text { Glass vial overpacked with } \\
\text { vermiculite }\end{array}$ & $2 \mathrm{~kg}$ & 90 \\
2 & Highway & $\begin{array}{c}\text { Chemical munition } \\
\text { overpacked with } \\
\text { vermiculite }\end{array}$ & 25 gal & 5 \\
3 & Highway & Ton cylinder & 200 gal & 5 \\
\hline
\end{tabular}

\subsubsection{Weapons-Related Releases}

The first-response community has become more aware of the potential threat from the malicious use of chemical and biological agents. For this reason, the 2000ERG now includes Initial Isolation and Protective Action Distances for various chemical agents that could be used as weapons. In addition, a separate new section entitled Criminal/Terrorist Use of Chemical/Biological Agents (page 368 of the 2000ERG) provides information on identification, response, and decontamination strategies for personnel who must respond to a suspected chemical or biological agent release.

Table 2.7 lists 26 chemical compounds for which Initial Isolation and Protective Action Distances were calculated for cases in which they would be used as a weapon. (The table shows 36 chemical warfare agent names for the 26 compounds.) Accordingly, entries in the 2000ERG Table for these materials include the statement "when used as a weapon." Many of these materials are also industrial chemicals that appear separately in 2000ERG as transportation-related releases. (In general, if the material represents a TIH hazard, it is also listed separately as a transportation-related release in 2000ERG.) Entries for weapons-related use of chemical agents, however, are listed under the common or military name for the compound, not the chemical name. For example, for weapons-related entries, one compound is listed as sarin and GB, whereas for transportation-related entries, this same compound is listed as isopropyl methylphosphonofluoridate. All three terms refer to the same compound.

The accident scenarios for weapons-related incidents differ from those for transportation-related incidents because they involve deliberate releases. Two maximum release sizes were used for each material considered in the analysis (Table 2.7). In the statistical analysis, release amounts were uniformly distributed between 50 and $100 \%$ of these maximum release amounts. Various release types were modeled, depending on the material being released. The release types are denoted in Table 2.7 by two-letter codes. The codes AL and AS refer to aerosolized liquid and aerosolized solid release mechanisms, respectively. It is assumed that $\mathrm{AL}$ and $\mathrm{AS}$ would be dispersed in 
Table 2.7 Chemical Warfare Agents Added to the 2000ERG Table of Initial Isolation and Protective Action Distances

\begin{tabular}{|c|c|c|c|c|c|}
\hline $\begin{array}{l}\text { UN } \\
\text { No. }\end{array}$ & $\begin{array}{c}\text { Chemical } \\
\text { Warfare Agent } \\
\text { Name }\end{array}$ & Chemical Compound Name & $\begin{array}{c}\text { Small } \\
(\mathbf{k g})\end{array}$ & $\begin{array}{c}\text { Large } \\
(\mathbf{k g})\end{array}$ & Type $^{a}$ \\
\hline 1051 & $A C$ & Hydrogen cyanide & 60 & 30,000 & $\mathrm{SH}$ \\
\hline 1076 & DP & Diphosgene & 30 & 500 & $\mathrm{AL}$ \\
\hline 1076 & CG & Phosgene & 60 & 1,500 & $\mathrm{SH}$ \\
\hline 1556 & MD & Methyldichloroarsine & 30 & 500 & $\overline{A L}$ \\
\hline 1556 & PD & Phenyldichloroarsine & 30 & 500 & $\overline{A L}$ \\
\hline 1589 & $\mathrm{CK}$ & Cyanogen chloride & 30 & 500 & $\mathrm{AL}$ \\
\hline 1694 & $\mathrm{CA}$ & Bromobenzyl cyanides & 10 & 500 & AS \\
\hline 1697 & $\mathrm{CN}$ & Chloroacetophenone & 10 & 500 & AS \\
\hline 1698 & DM & \multirow{2}{*}{ Diphenylamine chloroarsine } & \multirow{2}{*}{10} & \multirow{2}{*}{500} & \multirow{2}{*}{ AS } \\
\hline 1698 & Adamsite & & & & \\
\hline 1699 & DA & Diphenylchloroarsine & 10 & 500 & AS \\
\hline 1892 & ED & Ethyldichloroarsine & 30 & 500 & $\mathrm{AL}$ \\
\hline 2188 & SA & Arsine & 60 & 1,500 & $\mathrm{SH}$ \\
\hline 2810 & $\mathrm{H}$ & \multirow[b]{2}{*}{ Bis-(2-chloroethyl) sulfide } & \multirow[b]{2}{*}{2} & \multirow[b]{2}{*}{100} & \multirow[b]{2}{*}{ SP } \\
\hline $2810^{-}$ & Mustard & & & & \\
\hline 2810 & $\mathrm{HN}-1$ & Bis-(2-chloroethyl) ethylamine & 2 & 100 & $\mathrm{SP}$ \\
\hline 2810 & $\mathrm{HN}-2$ & Bis-(2-chloroethyl) methylamine & 2 & 100 & SP \\
\hline 2810 & $\mathrm{HN}-3$ & Tris-(2-chloroethyl) amine & 2 & 100 & SP \\
\hline 2810 & $L$ & \multirow{4}{*}{ Dichloro-(2-chlorovinyl) arsine } & \multirow{4}{*}{2} & \multirow{4}{*}{100} & \multirow{4}{*}{ SP } \\
\hline 2810 & Lewisite & & & & \\
\hline $2810^{-1}$ & $\mathrm{HL}^{\mathrm{b}}$ & & & & \\
\hline $2810^{--}$ & Mustard Lewisite & & & & \\
\hline 2810 & $B Z$ & \multirow{2}{*}{ 3-Quinuclidinylbenzilate } & \multirow{2}{*}{10} & \multirow{2}{*}{500} & \multirow{2}{*}{ AS } \\
\hline $2810^{-}$ & Buzz & & & & \\
\hline 2810 & $\mathrm{CS}$ & o-Chlorobenzylidene malononitrile & 10 & 500 & AS \\
\hline 2810 & $\mathrm{DC}$ & Diphenylcyanoarsine & 10 & 500 & AS \\
\hline 2810 & GA & \multirow{2}{*}{ Ethyl N,N-dimethylphos-phoramidocyanidate } & \multirow{2}{*}{2} & \multirow{2}{*}{100} & \multirow{2}{*}{ SP } \\
\hline 2810 & Tabun & & & & \\
\hline 2810 & GB & \multirow{2}{*}{ Isopropyl methylphosphonofluoridate } & \multirow{2}{*}{2} & \multirow{2}{*}{100} & \multirow{2}{*}{ SP } \\
\hline 2810 & Sarin & & & & \\
\hline 2810 & GD & \multirow{2}{*}{ Pinacolyl methylphosphonofluoridate } & \multirow{2}{*}{2} & \multirow{2}{*}{100} & \multirow{2}{*}{ SP } \\
\hline $2810^{-}$ & Soman & & & & \\
\hline 2810 & GF & Cyclohexyl methylphosphonofluoridate & 2 & 100 & SP \\
\hline 2810 & VX & $\begin{array}{l}\text { O-Ethyl S-(2-diisopropylaminoethyl) } \\
\text { methylphosphonothiolate }\end{array}$ & 2 & 100 & SP \\
\hline 2811 & $C X$ & Phosgene oxime & 10 & 500 & AS \\
\hline
\end{tabular}

a $\mathrm{SH}=$ releases by shipment sabotage; $\mathrm{AL}=$ aerosolized liquid; $\mathrm{AS}=$ aerosolized solid; $\mathrm{SP}=$ spray or explosive release.

b Because of uncertainties in defining the composition, $\mathrm{HL}$ and mustard lewisite were treated as standard lewisite (L). 
aerosolized form with a $2-$ to $5-\mu \mathrm{m}$ particle size. This release mechanism is used for solid materials or for materials that have very slow evaporation rates; thus, aerosolization is the only way to disseminate them effectively. The code SP refers to a spray or explosive release. This release mechanism is considered the most likely one to be used to disperse nerve and blister agents, since they are typically thick liquids not readily amenable to direct aerosolization. In the scenario used in this analysis, the spray quickly settled to the ground to a depth up to $0.25 \mathrm{~mm}$ and then evaporated. The evaporation rate for these materials is limited by their low vapor pressures. The code SH refers to releases by shipment sabotage. This release mechanism is used for volatile TIH materials. For example, the large release scenario for hydrogen cyanide involves the sabotage of a large bulk container such as a small rail car. Small release amounts for these materials correspond to the release of a standard gas cylinder.

\subsection{Generics, Mixtures, and Solutions}

The Table lists a variety of compounds that are generic in nature. Two examples are liquefied gas, flammable, poisonous, n.o.s. (Inhalation Hazard Zone B) (UN 3160) and toxic liquid, corrosive, organic, n.o.s. (UN 2927). (The abbreviation n.o.s. stands for not otherwise specified.) Each generic compound can represent many chemicals that fit that description but are not individually listed in the 2000ERG or the Table. In the 2000ERG, Initial Isolation and Protective Action Distances for generic compounds are based on the worst-case compound from the pool of chemicals in the overall analysis that matches that generic description. As an example of this process, the generic compound described as liquefied gas, flammable, poisonous, n.o.s. (Inhalation Hazard Zone B) (UN 1953), which is also listed in the Table as liquefied gas, toxic, flammable, n.o.s. (Inhalation Hazard Zone B) (UN 3160), is considered below. The six chemicals analyzed in the 2000ERG analysis that are included in this category are listed in Table 2.8. Cyanogen (UN 1026) yields the maximum distances for large spills, whereas phosphorus pentafluoride (UN 2198) yields the maximum distances for small spills (shown in bold in Table 2.8). Also provided are eight entries for this generic category that reflect the variations in wording in the Table. These entries are rounded up to the nearest $0.1 \mathrm{mi}$ (100 ft for Initial Isolation Zones) to reflect their appearance in the Table.

Table 2.9 lists all the generic compounds included in the Table and provides the subset of chemicals from which their distances were calculated. Synonyms are not listed in Table 2.9; each entry in Table 2.9 may have several corresponding entries in the Table of Protective Action and Initial Isolation Distances. For categories that had fewer than three chemicals from which to pick the worst-case example, the selection pool was enlarged to include materials from the next less restrictive designation. For instance, the pool for the generic category described as compressed gas, poisonous, oxidizing, corrosive, n.o.s. (Inhalation Hazard Zones C and D) included all corrosive gases in Hazard Zones $\mathrm{C}$ and $\mathrm{D}$, respectively, because no corrosive, oxidizing gases with those hazard zone designations were identified in the analysis pool. 
Table 2.8 Chemicals Used to Determine Initial Isolation and Protective Action Distances for the Generic Material Described as Liquefied Gas, Poisonous, Flammable, n.o.s. (Inhalation Hazard Zone B) (UN 1953, UN 3160)

\begin{tabular}{|c|c|c|c|c|c|c|c|}
\hline \multirow[b]{3}{*}{ UN No. } & \multirow[b]{3}{*}{ Name of Material } & \multicolumn{3}{|c|}{ Small Spills } & \multicolumn{3}{|c|}{ Large Spills } \\
\hline & & \multirow{2}{*}{$\begin{array}{c}\text { First } \\
\text { Isolate in } \\
\text { All Direc- } \\
\text { tions (ft) }\end{array}$} & \multicolumn{2}{|c|}{$\begin{array}{l}\text { Then Protect } \\
\text { Persons } \\
\text { Downwind } \\
\text { during }\end{array}$} & \multirow{2}{*}{$\begin{array}{l}\text { First } \\
\text { Isolate in } \\
\text { All Direc- } \\
\text { tions (ft) }\end{array}$} & \multicolumn{2}{|c|}{$\begin{array}{l}\text { Then Protect } \\
\text { Persons } \\
\text { Downwind } \\
\text { during }\end{array}$} \\
\hline & & & $\begin{array}{l}\text { Day } \\
\text { (mi) }\end{array}$ & $\begin{array}{l}\text { Night } \\
(\mathrm{mi})\end{array}$ & & $\begin{array}{l}\text { Day } \\
\text { (mi) }\end{array}$ & $\begin{array}{l}\text { Night } \\
\text { (mi) }\end{array}$ \\
\hline \multicolumn{8}{|c|}{ Potential Surrogate Compounds } \\
\hline 1026 & Cyanogen & 58.1 & 0.11 & 0.61 & 966 & 1.83 & 4.80 \\
\hline 1053 & Hydrogen sulfide & 31.6 & 0.04 & 0.19 & 644 & 0.82 & 2.63 \\
\hline 2189 & Dichlorosilane & 58.1 & 0.11 & 0.56 & 787 & 1.49 & 3.84 \\
\hline 2192 & Germane & 47.5 & 0.09 & 0.49 & 869 & 1.64 & 4.09 \\
\hline 2198 & Phosphorus pentafluoride & 68.6 & 0.13 & 0.63 & 322 & 0.61 & 2.15 \\
\hline 2204 & Carbonyl sulfide & 31.7 & 0.06 & 0.31 & 602 & 1.14 & 3.45 \\
\hline \multicolumn{8}{|c|}{ Synonymous Entries for Generic Compound Categories } \\
\hline 1953 & $\begin{array}{l}\text { Compressed gas, flammable, } \\
\text { poisonous, n.o.s. (Inhalation Hazard } \\
\text { Zone B) }\end{array}$ & 100 & 0.2 & 0.7 & 1,000 & 1.9 & 4.8 \\
\hline 1953 & $\begin{array}{l}\text { Compressed gas, flammable, toxic, } \\
\text { n.o.s. (Inhalation Hazard Zone B) }\end{array}$ & 100 & 0.2 & 0.7 & 1,000 & 1.9 & 4.8 \\
\hline 1953 & $\begin{array}{l}\text { Compressed gas, poisonous, } \\
\text { flammable, n.o.s. (Inhalation Hazard } \\
\text { Zone B) }\end{array}$ & 100 & 0.2 & 0.7 & 1,000 & 1.9 & 4.8 \\
\hline 1953 & $\begin{array}{l}\text { Compressed gas, toxic, flammable, } \\
\text { n.o.s. (Inhalation Hazard Zone B) }\end{array}$ & 100 & 0.2 & 0.7 & 1,000 & 1.9 & 4.8 \\
\hline 1953 & $\begin{array}{l}\text { Liquefied gas, flammable, poisonous, } \\
\text { n.o.s. (Inhalation Hazard Zone B) }\end{array}$ & 100 & 0.2 & 0.7 & 1,000 & 1.9 & 4.8 \\
\hline 1953 & $\begin{array}{l}\text { Liquefied gas, flammable, toxic, n.o.s. } \\
\text { (Inhalation Hazard Zone B) }\end{array}$ & 100 & 0.2 & 0.7 & 1,000 & 1.9 & 4.8 \\
\hline 3160 & $\begin{array}{l}\text { Liquefied gas, poisonous, flammable, } \\
\text { n.o.s. (Inhalation Hazard Zone B) }\end{array}$ & 100 & 0.2 & 0.7 & 1,000 & 1.9 & 4.8 \\
\hline 3160 & $\begin{array}{l}\text { Liquefied gas, toxic, flammable, n.o.s. } \\
\text { (Inhalation Hazard Zone B) }\end{array}$ & 100 & 0.2 & 0.7 & 1,000 & 1.9 & 4.8 \\
\hline
\end{tabular}

a This table provides distance estimates for all applicable entries in the 2000ERG Table of Initial Isolation and Protective Action Distances (DOT et al. 2000). The worst-case (maximum) distances for small spills and large spills for each column are shown in bold. 
Table 2.9 Summary of Generic Compounds in the DOT TIH List and Corresponding Surrogates Used for 2000ERG (A different surrogate material can be used for each release category)

\begin{tabular}{|c|c|c|}
\hline $\begin{array}{l}\text { UN } \\
\text { No. }\end{array}$ & Proper Shipping Name & Surrogate \\
\hline 1953 & Liquefied gas, poisonous, flammable, n.o.s. & Worst cases among all TIH, flammable gases \\
\hline 1953 & $\begin{array}{l}\text { Liquefied gas, poisonous, flammable, n.o.s. (Inhalation Hazard } \\
\text { Zone A) }\end{array}$ & Worst cases among all TIH, flammable Hazard Zone A gases \\
\hline 1953 & $\begin{array}{l}\text { Liquefied gas, poisonous, flammable, n.o.s. (Inhalation Hazard } \\
\text { Zone B) }\end{array}$ & Worst cases among all TIH, flammable Hazard Zone B gases \\
\hline 1953 & $\begin{array}{l}\text { Liquefied gas, poisonous, flammable, n.o.s. (Inhalation Hazard } \\
\text { Zone C) }\end{array}$ & Worst cases among all $\mathrm{TIH}$, flammable Hazard Zone $\mathrm{C}$ gases \\
\hline 1953 & $\begin{array}{l}\text { Liquefied gas, poisonous, flammable, n.o.s. (Inhalation Hazard } \\
\text { Zone D) }\end{array}$ & Worst cases among all TIH, Hazard Zone D gases \\
\hline 1955 & Liquefied gas, poisonous, n.o.s. & Worst cases among all TIH gases \\
\hline 1955 & Liquefied gas, poisonous, n.o.s. (Inhalation Hazard Zone A) & Worst cases among all TIH, Hazard Zone A gases \\
\hline 1955 & Liquefied gas, poisonous, n.o.s. (Inhalation Hazard Zone B) & Worst cases among all TIH, Hazard Zone B gases \\
\hline 1955 & Liquefied gas, poisonous, n.o.s. (Inhalation Hazard Zone C) & Worst cases among all TIH, Hazard Zone C gases \\
\hline 1955 & Liquefied gas, poisonous, n.o.s. (Inhalation Hazard Zone D) & Worst cases among all TIH, Hazard Zone D gases \\
\hline 1955 & Organic phosphate mixed with compressed gas & Worst cases among all organic phosphate/gompressed gas mixtures \\
\hline 1967 & Insecticide gas, poisonous, n.o.s. & Worst cases among all insecticide gases \\
\hline 2810 & Poisonous liquid, n.o.s. & Worst cases among all TIH liquids \\
\hline 2810 & Poisonous liquid, n.o.s. (Inhalation Hazard Zone A) & Worst cases among all TIH Hazard Zone A liquids \\
\hline 2810 & Poisonous liquid, n.o.s. (Inhalation Hazard Zone B) & Worst cases among all TIH Hazard Zone B liquids \\
\hline 2810 & Poisonous liquid, organic, n.o.s. & Worst cases among all TIH organic liquids \\
\hline 2810 & Poisonous liquid, organic, n.o.s. (Inhalation Hazard Zone A) & Worst cases among all TIH, organic, Hazard Zone A liquids \\
\hline 2810 & Poisonous liquid, organic, n.o.s. (Inhalation Hazard Zone B) & Worst cases among all TIH, organic, Hazard Zone B liquids \\
\hline
\end{tabular}

Continued 
Table 2.9 Summary of Generic Compounds in the DOT TIH List and Corresponding Surrogates Used for 2000ERG (A different surrogate material can be used for each release category) (Cont.)

\begin{tabular}{|c|c|c|}
\hline $\begin{array}{l}\text { UN } \\
\text { No. }\end{array}$ & Proper Shipping Name & Surrogate \\
\hline 2927 & Poisonous liquid, corrosive, n.o.s. & Worst cases among all TIH corrosive liquids \\
\hline 2927 & Poisonous liquid, corrosive, n.o.s. (Inhalation Hazard Zone A) & Worst cases among all TIH, corrosive, Hazard Zone A liquids \\
\hline 2927 & Poisonous liquid, corrosive, n.o.s. (Inhalation Hazard Zone B) & Worst cases among all TIH, corrosive, Hazard Zone B liquids \\
\hline 2927 & Toxic liquid, corrosive, organic, n.o.s. & Worst cases among all TIH corrosive, organic liquids \\
\hline 2927 & Toxic liquid, corrosive, organic, n.o.s. (Inhalation Hazard Zone A) & Worst cases among all TIH, corrosive, organic Hazard Zone A liquids \\
\hline 2927 & Toxic liquid, corrosive, organic, n.o.s. (Inhalation Hazard Zone B) & Worst cases among all TIH, corrosive, organic, Hazard Zone B liquids \\
\hline 2929 & Poisonous liquid, flammable, n.o.s. & Worst cases among all TIH flammable liquids \\
\hline 2929 & Poisonous liquid, flammable, n.o.s. (Inhalation Hazard Zone A) & Worst cases among all TIH, flammable, Hazard Zone A liquids \\
\hline 2929 & Poisonous liquid, flammable, n.o.s. (Inhalation Hazard Zone B) & Worst cases among all TIH, flammable, Hazard Zone B liquids \\
\hline 2929 & Poisonous liquid, flammable, organic, n.o.s. & Worst cases among all TIH flammable, organic, liquids \\
\hline 2929 & $\begin{array}{l}\text { Poisonous liquid, flammable, organic, n.o.s. (Inhalation Hazard } \\
\text { Zone A) }\end{array}$ & Worst cases among all TIH, flammable, organic, Hazard Zone A liquids \\
\hline 2929 & $\begin{array}{l}\text { Poisonous liquid, flammable, organic, n.o.s. (Inhalation Hazard } \\
\text { Zone B) }\end{array}$ & Worst cases among all TIH, flammable, organic, Hazard Zone B liquids \\
\hline 3122 & Poisonous liquid, oxidizing, n.o.s. & Worst cases among all TIH, flammable, liquids \\
\hline 3122 & Poisonous liquids, oxidizing, n.o.s. (Inhalation Hazard Zone A) & Worst cases among all TIH, flammable, Hazard Zone A liquids \\
\hline 3122 & Poisonous liquids, oxidizing, n.o.s. (Inhalation Hazard Zone B) & Worst cases among all TIH, oxidizing, Hazard Zone B liquids \\
\hline 3123 & Poisonous liquid, water-reactive, n.o.s. & Worst cases among all TIH liquids \\
\hline 3123 & Poisonous liquid, water-reactive, n.o.s. (Inhalation Hazard Zone A) & Worst cases among all TIH Hazard Zone A liquids \\
\hline 3123 & Poisonous liquid, water-reactive, n.o.s. (Inhalation Hazard Zone B) & Worst cases among all TIH Hazard Zone B liquids \\
\hline 3123 & $\begin{array}{l}\text { Poisonous liquid, which in contact with water emits flammable } \\
\text { gases, n.o.s. }\end{array}$ & Worst cases among all TIH flammable liquids \\
\hline 3123 & $\begin{array}{l}\text { Poisonous liquid, which in contact with water emits flammable } \\
\text { gases, n.o.s. (Inhalation Hazard Zone A) }\end{array}$ & Worst cases among all TIH, flammable, Hazard Zone A liquids \\
\hline 3123 & $\begin{array}{l}\text { Poisonous liquid, which in contact with water emits flammable } \\
\text { gases, n.o.s. (Inhalation Hazard Zone B) }\end{array}$ & Worst cases among all TIH, flammable, Hazard Zone B liquids \\
\hline
\end{tabular}


Table 2.9 Summary of Generic Compounds in the DOT TIH List and Corresponding Surrogates Used for 2000ERG (A different surrogate material can be used for each release category) (Cont.)

\begin{tabular}{|c|c|c|}
\hline $\begin{array}{l}\text { UN } \\
\text { No. }\end{array}$ & Proper Shipping Name & Surrogate \\
\hline 3160 & Liquefied gas, poisonous, flammable, n.o.s. & Worst cases among all TIH, flammable gases \\
\hline 3160 & $\begin{array}{l}\text { Liquefied gas, poisonous, flammable, n.o.s. (Inhalation Hazard } \\
\text { Zone A) }\end{array}$ & Worst cases among all TIH, flammable Hazard Zone A gases \\
\hline 3160 & $\begin{array}{l}\text { Liquefied gas, poisonous, flammable, n.o.s. (Inhalation Hazard } \\
\text { Zone B) }\end{array}$ & Worst cases among all TIH, flammable Hazard Zone B gases \\
\hline 3160 & $\begin{array}{l}\text { Liquefied gas, poisonous, flammable, n.o.s. (Inhalation Hazard } \\
\text { Zone C) }\end{array}$ & Worst cases among all TIH, flammable Hazard Zone C gases \\
\hline 3160 & $\begin{array}{l}\text { Liquefied gas, poisonous, flammable, n.o.s. (Inhalation Hazard } \\
\text { Zone D) }\end{array}$ & Worst cases among all TIH, flammable Hazard Zone D gases \\
\hline 3162 & Liquefied gas, poisonous, n.o.s. & Worst cases among all TIH gases \\
\hline 3162 & Liquefied gas, poisonous, n.o.s. (Inhalation Hazard Zone A) & Worst cases among all TIH Hazard Zone A gases \\
\hline 3162 & Liquefied gas, poisonous, n.o.s. (Inhalation Hazard Zone B) & Worst cases among all TIH Hazard Zone B gases \\
\hline 3162 & Liquefied gas, poisonous, n.o.s. (Inhalation Hazard Zone C) & Worst cases among all TIH Hazard Zone C gases \\
\hline 3162 & Liquefied gas, poisonous, n.o.s. (Inhalation Hazard Zone D) & Worst cases among all TIH Hazard Zone D gases \\
\hline 3275 & Nitriles, poisonous, flammable, n.o.s. & Worst case among TIH flammable nitriles \\
\hline 3276 & Nitriles, poisonous, n.o.s. & Worst case among TIH nitriles \\
\hline 3278 & Organophosphorus compound, poisonous, n.o.s. & Worst cases among all organophosphorus compounds \\
\hline 3279 & Organophosphorus compound, poisonous, flammable, n.o.s. & Worst cases among all organophosphorus compounds \\
\hline 3280 & Organoarsenic compound, n.o.s. & Worst cases among all organoarsenic compounds \\
\hline 3281 & Metal carbonyls, n.o.s. & Worst cases among all metal carbonyls \\
\hline 3287 & Poisonous liquid, inorganic, n.o.s. & Worst cases among all TIH inorganic liquids \\
\hline 3287 & Poisonous liquid, inorganic, n.o.s. (Inhalation Hazard Zone A) & Worst cases among all TIH, inorganic, Hazard Zone A liquids \\
\hline 3287 & Poisonous liquid, inorganic, n.o.s. (Inhalation Hazard Zone B) & Worst cases among all TIH, inorganic, Hazard Zone B liquids \\
\hline
\end{tabular}


Table 2.9 Summary of Generic Compounds in the DOT TIH List and Corresponding Surrogates Used for 2000ERG (A different surrogate material can be used for each release category) (Cont.)

\begin{tabular}{|c|c|c|}
\hline $\begin{array}{l}\text { UN } \\
\text { No. }\end{array}$ & Proper Shipping Name & Surrogate \\
\hline 3289 & Poisonous liquid, corrosive, inorganic, n.o.s. & Worst cases among all TIH, corrosive, inorganic liquids \\
\hline 3289 & $\begin{array}{l}\text { Poisonous liquid, corrosive, inorganic, n.o.s. (Inhalation Hazard } \\
\text { Zone A) }\end{array}$ & $\begin{array}{l}\text { Worst cases among all TIH, corrosive, inorganic, Hazard Zone A } \\
\text { liquids }\end{array}$ \\
\hline 3289 & $\begin{array}{l}\text { Poisonous liquid, corrosive, inorganic, n.o.s. (Inhalation Hazard } \\
\text { Zone B) }\end{array}$ & $\begin{array}{l}\text { Worst cases among all TIH, corrosive, inorganic, Hazard Zone B } \\
\text { liquids }\end{array}$ \\
\hline 3303 & Compressed gas, poisonous, oxidizing, n.o.s. & Worst cases among all TIH, oxidizing gases \\
\hline 3303 & $\begin{array}{l}\text { Compressed gas, poisonous, oxidizing, n.o.s. (Inhalation Hazard } \\
\text { Zone A) }\end{array}$ & Worst cases among all TIH, Hazard Zone A, oxidizing gases \\
\hline 3303 & $\begin{array}{l}\text { Compressed gas, poisonous, oxidizing, n.o.s. (Inhalation Hazard } \\
\text { Zone B) }\end{array}$ & Worst cases among all TIH, Hazard Zone B, oxidizing gases \\
\hline 3303 & $\begin{array}{l}\text { Compressed gas, poisonous, oxidizing, n.o.s. (Inhalation Hazard } \\
\text { Zone C) }\end{array}$ & Worst cases among all TIH, Hazard Zone $\mathrm{C}$ gases \\
\hline 3303 & $\begin{array}{l}\text { Compressed gas, poisonous, oxidizing, n.o.s. (Inhalation Hazard } \\
\text { Zone D) }\end{array}$ & Worst cases among all TIH, Hazard Zone D gases \\
\hline 3304 & Compressed gas, poisonous, corrosive, n.o.s. & Worst cases among all TIH, corrosive gases \\
\hline 3304 & $\begin{array}{l}\text { Compressed gas, poisonous, corrosive, n.o.s. (Inhalation Hazard } \\
\text { Zone A) }\end{array}$ & Worst cases among all TIH, corrosive, Hazard Zone A gases \\
\hline 3304 & $\begin{array}{l}\text { Compressed gas, poisonous, corrosive, n.o.s. (Inhalation Hazard } \\
\text { Zone B) }\end{array}$ & Worst cases among all TIH, corrosive, Hazard Zone B gases \\
\hline 3304 & $\begin{array}{l}\text { Compressed gas, poisonous, corrosive, n.o.s. (Inhalation Hazard } \\
\text { Zone C) }\end{array}$ & Worst cases among all $\mathrm{TIH}$, corrosive, Hazard Zone $\mathrm{C}$ gases \\
\hline 3304 & $\begin{array}{l}\text { Compressed gas, poisonous, corrosive, n.o.s. (Inhalation Hazard } \\
\text { Zone D) }\end{array}$ & Worst cases among all TIH, corrosive, Hazard Zone D gases \\
\hline
\end{tabular}


Table 2.9 Summary of Generic Compounds in the DOT TIH List and Corresponding Surrogates Used for 2000ERG (A different surrogate material can be used for each release category) (Cont.)

\begin{tabular}{|c|c|c|}
\hline $\begin{array}{l}\text { UN } \\
\text { No. }\end{array}$ & Proper Shipping Name & Surrogate \\
\hline 3305 & Compressed gas, poisonous, flammable, corrosive, n.o.s. & Worst cases among all TIH, corrosive gases \\
\hline 3305 & $\begin{array}{l}\text { Compressed gas, poisonous, flammable, corrosive, n.o.s. (Inh. } \\
\text { Hazard Zone A) }\end{array}$ & Worst cases among all $\mathrm{TIH}$, corrosive, Hazard Zone A gases \\
\hline 3305 & $\begin{array}{l}\text { Compressed gas, poisonous, flammable, corrosive, n.o.s. (Inh. } \\
\text { Hazard Zone B) }\end{array}$ & Worst cases among all TIH, corrosive, Hazard Zone B gases \\
\hline 3305 & $\begin{array}{l}\text { Compressed gas, poisonous, flammable, corrosive, n.o.s. (Inh. } \\
\text { Hazard Zone C) }\end{array}$ & Worst cases among all TIH, corrosive, Hazard Zone $\mathrm{C}$ gases \\
\hline 3305 & $\begin{array}{l}\text { Compressed gas, poisonous, flammable, corrosive, n.o.s. (Inh. } \\
\text { Hazard Zone D) }\end{array}$ & Worst cases among all TIH, corrosive, Hazard Zone D gases \\
\hline 3306 & Compressed gas, poisonous, oxidizing, corrosive, n.o.s. & Worst cases among all TIH, oxidizing, corrosive gases \\
\hline 3306 & $\begin{array}{l}\text { Compressed gas, poisonous, oxidizing, corrosive, n.o.s. (Inh. Hazard } \\
\text { Zone A) }\end{array}$ & Worst cases among all TIH, oxidizing, corrosive, Hazard Zone A gases \\
\hline 3306 & $\begin{array}{l}\text { Compressed gas, poisonous, oxidizing, corrosive, n.o.s. (Inh. Hazard } \\
\text { Zone B) }\end{array}$ & Worst cases among all TIH, oxidizing, corrosive, Hazard Zone B gases \\
\hline 3306 & $\begin{array}{l}\text { Compressed gas, poisonous, oxidizing, corrosive, n.o.s. (Inh. Hazard } \\
\text { Zone C) }\end{array}$ & Worst cases among all TIH, corrosive, Hazard Zone $\mathrm{C}$ gases \\
\hline 3306 & $\begin{array}{l}\text { Compressed gas, poisonous, oxidizing, corrosive, n.o.s. (Inh. Hazard } \\
\text { Zone D) }\end{array}$ & Worst cases among all TIH, corrosive, Hazard Zone D gases \\
\hline 3307 & Liquefied gas, poisonous, oxidizing, n.o.s. & Worst cases among all TIH, oxidizing gases \\
\hline 3307 & $\begin{array}{l}\text { Liquefied gas, poisonous, oxidizing, n.o.s. (Inhalation Hazard } \\
\text { Zone A) }\end{array}$ & Worst cases among all TIH, Hazard Zone A, oxidizing gases \\
\hline 3307 & $\begin{array}{l}\text { Liquefied gas, poisonous, oxidizing, n.o.s. (Inhalation Hazard } \\
\text { Zone B) }\end{array}$ & Worst cases among all TIH, Hazard Zone B, oxidizing gases \\
\hline 3307 & $\begin{array}{l}\text { Liquefied gas, poisonous, oxidizing, n.o.s. (Inhalation Hazard } \\
\text { Zone C) }\end{array}$ & Worst cases among all TIH, Hazard Zone $\mathrm{C}$, oxidizing gases \\
\hline 3307 & $\begin{array}{l}\text { Liquefied gas, poisonous, oxidizing, n.o.s. (Inhalation Hazard } \\
\text { Zone D) }\end{array}$ & Worst cases among all TIH, Hazard Zone D, oxidizing gases \\
\hline
\end{tabular}


Table 2.9 Summary of Generic Compounds in the DOT TIH List and Corresponding Surrogates Used for 2000ERG (A different surrogate material can be used for each release category) (Cont.)

\begin{tabular}{|c|c|c|}
\hline $\begin{array}{l}\text { UN } \\
\text { No. }\end{array}$ & Proper Shipping Name & Surrogate \\
\hline 3308 & Liquefied gas, poisonous, corrosive, n.o.s. & Worst cases among all TIH, corrosive gases \\
\hline 3308 & $\begin{array}{l}\text { Liquefied gas, poisonous, corrosive, n.o.s. (Inhalation Hazard } \\
\text { Zone A) }\end{array}$ & Worst cases among all $\mathrm{TIH}$, corrosive, Hazard Zone A gases \\
\hline 3308 & $\begin{array}{l}\text { Liquefied gas, poisonous, corrosive, n.o.s. (Inhalation Hazard } \\
\text { Zone B) }\end{array}$ & Worst cases among all TIH, corrosive, Hazard Zone B gases \\
\hline 3308 & $\begin{array}{l}\text { Liquefied gas, poisonous, corrosive, n.o.s. (Inhalation Hazard } \\
\text { Zone } C \text { ) }\end{array}$ & Worst cases among all $\mathrm{TIH}$, corrosive, Hazard Zone $\mathrm{C}$ gases \\
\hline 3308 & $\begin{array}{l}\text { Liquefied gas, poisonous, corrosive, n.o.s. (Inhalation Hazard } \\
\text { Zone D) }\end{array}$ & Worst cases among all TIH, corrosive, Hazard Zone D gases \\
\hline 3309 & Liquefied gas, poisonous, flammable, corrosive, n.o.s. & Worst cases among all TIH, corrosive gases \\
\hline 3309 & $\begin{array}{l}\text { Liquefied gas, poisonous, flammable, corrosive, n.o.s. (Inhalation } \\
\text { Hazard Zone A) }\end{array}$ & Worst cases among all TIH, corrosive, Hazard Zone A gases \\
\hline 3309 & $\begin{array}{l}\text { Liquefied gas, poisonous, flammable, corrosive, n.o.s. (Inhalation } \\
\text { Hazard Zone B) }\end{array}$ & Worst cases among all TIH, corrosive, Hazard Zone B gases \\
\hline 3309 & $\begin{array}{l}\text { Liquefied gas, poisonous, flammable, corrosive, n.o.s. (Inhalation } \\
\text { Hazard Zone C) }\end{array}$ & Worst cases among all $\mathrm{TIH}$, corrosive, Hazard Zone $\mathrm{C}$ gases \\
\hline 3309 & $\begin{array}{l}\text { Liquefied gas, poisonous, flammable, corrosive, n.o.s. (Inhalation } \\
\text { Hazard Zone D) }\end{array}$ & Worst cases among all TIH, corrosive, Hazard Zone D gases \\
\hline 3310 & Liquefied gas, poisonous, oxidizing, corrosive, n.o.s. & Worst cases among all TIH, oxidizing, corrosive gases \\
\hline 3310 & $\begin{array}{l}\text { Liquefied gas, poisonous, oxidizing, corrosive, n.o.s. (Inhalation } \\
\text { Hazard Zone A) }\end{array}$ & Worst cases among all TIH, oxidizing, corrosive, Hazard Zone A gases \\
\hline 3310 & $\begin{array}{l}\text { Liquefied gas, poisonous, oxidizing, corrosive, n.o.s. (Inhalation } \\
\text { Hazard Zone B) }\end{array}$ & Worst cases among all TIH, oxidizing, corrosive, Hazard Zone B gases \\
\hline 3310 & $\begin{array}{l}\text { Liquefied gas, poisonous, oxidizing, corrosive, n.o.s. (Inhalation } \\
\text { Hazard Zone C) }\end{array}$ & Worst cases among all TIH, corrosive, Hazard Zone $\mathrm{C}$ gases \\
\hline 3310 & $\begin{array}{l}\text { Liquefied gas, poisonous, oxidizing, corrosive, n.o.s. (Inhalation } \\
\text { Hazard Zone D) }\end{array}$ & Worst cases among all TIH, corrosive, Hazard Zone D gases \\
\hline
\end{tabular}


Table 2.9 Summary of Generic Compounds in the DOT TIH List and Corresponding Surrogates Used for 2000ERG (A different surrogate material can be used for each release category) (Cont.)

\begin{tabular}{|c|c|c|}
\hline $\begin{array}{l}\text { UN } \\
\text { No. }\end{array}$ & Proper Shipping Name & Surrogate \\
\hline 3355 & Insecticide gas, poisonous, flammable, n.o.s & Worst cases among all flammable, insecticide gases \\
\hline 3355 & $\begin{array}{l}\text { Insecticide gas, poisonous, flammable, n.o.s. (Inhalation Hazard } \\
\text { Zone A) }\end{array}$ & Worst cases among all flammable, insecticide, Hazard Zone A gases \\
\hline 3355 & $\begin{array}{l}\text { Insecticide gas, poisonous, flammable, n.o.s. (Inhalation Hazard } \\
\text { Zone B) }\end{array}$ & Worst cases among all flammable, insecticide, Hazard Zone B gases \\
\hline 3355 & $\begin{array}{l}\text { Insecticide gas, poisonous, flammable, n.o.s. (Inhalation Hazard } \\
\text { Zone C) }\end{array}$ & Worst cases among all flammable, insecticide, Hazard Zone $\mathrm{C}$ gases \\
\hline 3355 & $\begin{array}{l}\text { Insecticide gas, poisonous, flammable, n.o.s. (Inhalation Hazard } \\
\text { Zone D) }\end{array}$ & Worst cases among all flammable, insecticide, Hazard Zone D gases \\
\hline
\end{tabular}


Table 2.10 lists the mixtures and solutions treated in the 2000ERG analysis and indicates how they were modeled. In general, the distances for mixtures were determined by (1) selecting a surrogate compound, (2) considering the toxic effects of a single hazardous constituent, or (3) considering the toxic effects of multiple hazardous constituents. Surrogates were chosen when the mixture composition was not specified. For these cases, the surrogate was chosen as the worst-case chemical or potential composition in that mixture. As an example, consider chlorosulfonic acid and sulfur trioxide mixtures (UN 1754). In these mixtures, sulfur trioxide is the more hazardous component, primarily because of its higher vapor pressure. The addition of chlorosulfonic acid will act to lower the vapor pressure, so a $100 \%$ sulfur trioxide mixture is the worst case and was chosen for analysis. A single hazardous constituent was modeled for several cases involving mixtures in compressed gases and solutions (e.g., diborane, tetraethyl pyrophosphate, hydrocyanic acid solutions). For each case, the worst case as specified in 49 CFR or by the description was modeled. The third class of mixtures involves compounds with more than one hazardous component. For instance, in chloropicrin and methyl bromide mixtures (UN 1581), chloropicrin is dissolved in methyl bromide at 2 or $5 \%$ by volume. Therefore, toxic effects of both constituents are taken into account. The result is a mixture that behaves almost identically to pure methyl bromide in terms of release rate and dispersion. However, the mixture is much more toxic than pure methyl bromide as a result of the high toxicity of chloropicrin, so the PAD is longer than that for pure methyl bromide.

\subsection{Water-Reactive Materials}

Trucks and rail cars that transport hazardous chemicals can have accidents in which their solid or liquid cargo spills into some body of water such as a water-filled roadside ditch, stream, river, pond, lake, or body of saline water connected to an ocean. A subset of the hazardous materials carried routinely on highways and railway lines can emit TIH gases that react with water (TIHWR gases). An example is silicon tetrachloride, which is not listed as a TIH material but produces airborne hydrogen chloride $(\mathrm{HCl})$ and $\mathrm{HCl}$ mist upon water reaction. Even heavy rainfall at the time of an accident or airborne water vapor can cause the emission of TIHWR gases. The well-known Chicago spill of "siltet" from a storage tank in 1976 is an example. At one point in the eight-day episode, heavy rainfall led to a significant increase in emissions and sudden damage to the surroundings because additional $\mathrm{HCl}$ was released into the atmosphere. The same problem, though of less magnitude, would occur if a truck or tank car spilled siltet into water or had an accident during a heavy rainstorm.

Until recently, little attention was directed to materials that emit gases into the atmosphere when accidentally released into water. Kapias and Griffiths (1999) presented a limited discussion of water-reactive chemicals and the modeling of accidental releases. They used the example of silicon tetrachloride, which is a strong $\mathrm{HCl}$ emitter, as a result of either reacting with liquid water or scavenging atmospheric water vapor. 
Table 2.10 Summary of Mixtures and Solutions in the DOT TIH List and How They Were Modeled for 2000ERG

\begin{tabular}{|c|c|c|c|}
\hline ID No. & Category & Proper Shipping Name & Modeled as \\
\hline \multicolumn{4}{|c|}{ Mixtures and Solutions Modeled as Single Toxic Species } \\
\hline 1040 & Mixture & Ethylene oxide with nitrogen & $100 \%$ ethylene oxide \\
\hline 1051 & Solution & Hydrocyanic acid, aqueous solutions, with more than $20 \%$ hydrogen cyanide & $100 \%$ hydrogen cyanide \\
\hline 1911 & Mixture & Diborane & $7 \%$ diborane \\
\hline 1955 & Mixture & Methyl bromide and nonflammable, nonliquefied compressed gas mixtures & $100 \%$ methyl bromide \\
\hline 1612 & Mixture & Hexaethyltetraphosphate and compressed gas mixtures & $20 \%$ hexaethyltetraphosphate \\
\hline 1613 & Solution & Hydrocyanic acid, aqueous solution, with not more than $20 \%$ hydrogen cyanide & $20 \%$ hydrogen cyanide solution in water \\
\hline 1703 & Mixture & Tetraethyl dithiopyrophosphate and gases, in solution & $20 \%$ tetraethyl dithiopyrophosphate \\
\hline 1705 & Mixture & Tetraethyl pyrophosphate and compressed gas mixtures & $20 \%$ tetraethyl pyrophosphate \\
\hline 1744 & Solution & Bromine solutions & $100 \%$ bromine \\
\hline 1754 & Mixture & Chlorosulfonic acid and sulfur trioxide mixture & $100 \%$ sulfur trioxide \\
\hline 1967 & Mixture & Parathion and compressed gas mixtures & $20 \%$ parathion \\
\hline 1975 & Mixture & Nitric oxide and dinitrogen tetroxide mixtures & $100 \%$ nitric oxide \\
\hline 2600 & Mixture & Carbon monoxide and hydrogen mixtures & $100 \%$ carbon monoxide \\
\hline 3294 & Solution & Hydrogen cyanide, solution in alcohol, with not more than $45 \%$ hydrogen cyanide & $45 \%$ hydrogen cyanide solution in alcohol \\
\hline 3300 & Mixture & Carbon dioxide and ethylene oxide mixture, with more than $87 \%$ ethylene oxide & $100 \%$ ethylene oxide \\
\hline 3318 & Solution & Ammonia solution, with more than $50 \%$ ammonia & $100 \%$ ammonia \\
\hline \multicolumn{4}{|c|}{ Mixtures Modeled with Multiple Toxic Chemical Species } \\
\hline 1581 & Mixture & Chloropicrin and methyl bromide mixtures & $\begin{array}{l}\text { (a) } 2 \% \text { chloropicrin and (b) } 98 \% \text { methyl } \\
\text { bromide }\end{array}$ \\
\hline 1581 & Mixture & Methyl bromide and more than $2 \%$ chloropicrin mixture, liquid & $\begin{array}{l}\text { (a) } 5 \% \text { chloropicrin and (b) } 95 \% \text { methyl } \\
\text { bromide }\end{array}$ \\
\hline 1582 & Mixture & Chloropicrin and methyl chloride mixtures & $\begin{array}{l}\text { (a) } 2 \% \text { chloropicrin and (b) } 98 \% \text { methyl } \\
\text { chloride }\end{array}$ \\
\hline
\end{tabular}


Table 2.10 Summary of Mixtures and Solutions in the DOT TIH List and How They Were Modeled for 2000ERG (Cont.)

\begin{tabular}{|c|l|l|l|l|}
\hline ID No. & Category & \multicolumn{1}{|c|}{ Proper Shipping Name } & \multicolumn{1}{c|}{ Modeled as } \\
\hline 1023 & Mixture & Coal gas & $\begin{array}{l}\text { (a) 48\% hydrogen, (b) 27\% methane, } \\
\text { (c) 10\% carbon monoxide, (d) } 5 \% \text { carbon } \\
\text { dioxide, and (e) 6\% nitrogen }\end{array}$ \\
\hline 1071 & Mixture & Oil gas & $\begin{array}{l}\text { (a) 55\% hydrogen, (b) 25\% methane, } \\
\text { (c) 11\% carbon monoxide, (d) } 3 \% \text { carbon } \\
\text { dioxide, (e) 2\% ethylene, and (f) } 2 \% \\
\text { benzene }\end{array}$ \\
\hline
\end{tabular}


In the following discussions, materials are considered water-reactive if they are likely to generate substantial quantities of toxic gases fairly rapidly after a spill into water. To compile the recommended list of water-reactive materials for the 2000ERG, general principles of chemical reactivity, specific reactivity information from the chemical literature, and comparisons of such information among related compounds were considered. Experiments were also conducted in which 21 compounds were mixed with water and the evolution of TIH gases was measured as a function of time.

This section discusses the identification of the candidate chemicals and the evaluation of these materials with regard to their water-reactivity hazard. The technical aspects of how the TIH emission rates from these materials were modeled and how they were treated in the statistical analysis as part of the 2000ERG study are detailed in Section 3.3.2.3.

\subsubsection{Identification of Candidates}

A large number of certain materials could emit TIH gases upon their reaction with water. For this reason, screening started with the 208 chemically distinct materials previously found by Carhart et al. (1996) to be capable of producing TIH gases if spilled into a river, lake, or other body of surface water. The 37 materials that make up the 1996 North American ERG "List of Dangerous Water-Reactive Materials" are a subset of these 208. The following materials were then considered as possible additions to this list of 208 candidates:

- Forty-nine materials produced by Nuessler were listed as dangerous water reactives in correspondence from Dieter Nuessler (Chief Fire Officer, Aachen Germany) to DOT. However, most of the materials on the list are active metals, metal alkyls, and metal hydrides (e.g., cesium, diethylzinc, calcium hydride) that generate flammable, low-toxicity gases, such as hydrogen or methane, when mixed with water. Although the gaseous products from the materials are generally serious fire or explosion hazards, they are not TIH hazards, so the materials were rejected as plausible candidates for the list.

Fourteen water-reactive materials on Nuessler's list were found to be suitable TIHWR candidates, however. The reason most of these materials had been previously omitted from the Table is because they were incompletely chemically specified. The 14 suitable candidates are listed below:

UN1730

UN1827

UN 2985

UN 2986

UN 2987

UN 3049

UN 3052

UN 3129

antimony pentachloride

tin tetrachloride

chlorosilanes n.o.s.

chlorosilanes, flammable, corrosive n.o.s

chlorosilanes, corrosive n.o.s.

metal alkyl halides n.o.s.

aluminum alkyl halides

water-reactive substances, liquid, corrosive n.o.s. 
UN 3130

UN 3131

UN 3134

UN 3148

UN 3203

UN 3207 water-reactive liquid, toxic n.o.s.

water-reactive solid, corrosive n.o.s.

substances which in contact with water emit flammable gases, solid, poisonous, n.o.s

water-reactive substances, liquid, n.o.s

pyrophoric organometallic compound n.o.s.

organometallic compound solution water-reactive, flammable n.o.s.

- Seven materials that did not appear in the 1996 North American ERG were proposed by DOT for inclusion.

UN1026 cyanogen chloride

UN1340 phosphorus pentasulfide

UN1394 aluminum carbide

UN1402 calcium carbide

UN1809 phosphorus trichloride

UN1827 titanium tetrachloride

UN1831 oleum

Two of these compounds, cyanogen chloride and titanium tetrachloride, were found to be suitable candidates. Three of the seven materials (phosphorus pentasulfide, phosphorus trichloride, and oleum) were already included in the starting set of 208. Calcium carbide and aluminum carbide were rejected because their reaction with water generates acetylene, a gas that is flammable but is not a TIH hazard.

\subsubsection{Evaluation of Candidates}

The final initial list of 224 candidate materials $(208+14+2)$ was carefully evaluated to determine which ones provided sufficient hazards to warrant their inclusion in the Table. The evaluation process consisted of the following steps:

1. Consider general patterns of reactivity.

2. Examine the primary literature.

3. Examine standard secondary sources such as Kroschwitz (1991-1996) and Lewis (1966).

4. Perform experimental tests on 21 compounds at the University of Illinois at Chicago to estimate the yield and rate of production of toxic gases when mixed with water.

Steps 1 through 3 are similar to the process used to generate the 1996 TIHWR list. Step 4, however, is a new element in the overall analysis. In addition to qualitative descriptions and professional judgment, this experimental program was included in the TIHWR analysis framework to provide a more empirical basis for TIHWR hazard 
estimates. The program consisted of a series of small-scale experiments with representative materials. The need for such experimental data is underscored by the fact that quantitative observations of TIH gas evolution from hazardous chemicals added to water do not exist in the chemical literature. Experiments were conducted for 21 substances. About one-quarter of the total TIHWR list was examined, with heavy emphasis on members of the large class of $\mathrm{HCl}$ emitters.

Water-reactive materials were tested for the generation of gases by mixing small amounts (about 1 millimole [mmol]) of the material with water in a closed system. A diagram of this apparatus is given in Figure C.1 in Appendix C. The release of gas was followed over time by observing the displacement of a manometer. For example, when gaseous $\mathrm{HCl}$ was generated, $\mathrm{HCl}$ vapor was displaced into a buret held at an angle of about 15 degrees from the horizontal. This arrangement allowed for substantial increases in the volume of the closed system while limiting the increase in the pressure within the system to less than $15 \mathrm{kPa}$. Two experiments that used different amounts of water (stoichiometric and five-fold molar excess) were conducted for each material considered. The experimental procedure and resulting data are more fully discussed in Appendix C.

Additional issues associated with the evaluation process are specifically discussed here.

- In an independent study, Nuessler omitted 19 substances that appear in the 1996 North American ERG "List of Dangerous Water-Reactive Materials." This difference occurred because the purposes of the two lists differed. Nuessler's list focused on fire safety and omitted the 19 substances because the gases (such as ammonia or $\mathrm{HCl}$ ) generated when these substances react with water are not very flammable. These 19 materials were retained for the 2000 TIHWR list because ammonia and $\mathrm{HCl}$ are $\mathrm{TIH}$ hazards.

- Materials that undergo highly exothermic reactions with water can generate mist when released into water. For such compounds, water in contact with the material boils violently, emitting a mist of fine particles of hydrated or partially hydrated material. For example, in contact with water, oleum (UN 1831) raises a toxic fume containing $\mathrm{SO}_{3} \cdot \mathrm{H}_{2} \mathrm{O}, \mathrm{H}_{2} \mathrm{SO}_{4}$, and other sulfur-containing species. Such mists present a clear toxic inhalation hazard. The possibility of acidic mists also exists for spills into water of phosphorus pentoxide (UN 1807), leading to a mist of phosphoric acid; sulfur trioxide (UN 1829), emitting a mist of $\mathrm{SO}_{3} \cdot \mathrm{H}_{2} \mathrm{O}$ and $\mathrm{H}_{2} \mathrm{SO}_{4}$; and sulfuryl chloride (UN 1834), generating a mist of $\mathrm{SO}_{3} \cdot \mathrm{H}_{2} \mathrm{O}$ and $\mathrm{H}_{2} \mathrm{SO}_{4}$, plus gaseous $\mathrm{HCl}$.

- Some materials in 2000ERG are not sufficiently described chemically to allow a complete assessment of their behavior when spilled into water. Such materials were not recommended for inclusion unless there was a positive indication that a TIH gas might develop in a spill into water. Thus, pyrophoric organometallic compound n.o.s. (UN 3203) and organometallic compound solution water-reactive, flammable, n.o.s (UN 3207), which would almost certainly evolve only weakly toxic hydrocarbons or hydrogen when spilled into water, were not recommended. Similarly, water-reactive 
substances, liquid, corrosive, n.o.s. (UN 3129); water-reactive solid, corrosive, n.o.s. (UN 3131); water-reactive substances, liquid, n.o.s, (UN 3148); water-reactive liquid, toxic, n.o.s. (UN 3130); and substances which in contact with water emit flammable gases, solid, poisonous, n.o.s. (UN 3134) were not recommended for inclusion.

On the other hand, alkyl halides and chlorosilanes might generate sufficient gaseous $\mathrm{HCl}$ or another hydrogen halide to qualify as TIHWR materials. For this reason, aluminum alkyl halides (UN 3052); metal alkyl halides, n.o.s. (UN 3049); chlorosilanes, n.o.s. (UN 2985); chlorosilanes, flammable, corrosive, n.o.s. (UN 2986); and chlorosilanes, corrosive, n.o.s. (UN 2987 ) were recommended for inclusion.

- Materials that are gases at ordinary conditions (with boiling points below $0^{\circ} \mathrm{C}$ at atmospheric pressure) were uniformly not recommended for inclusion. An example is trifluoroacetyl chloride, which boils at $-18^{\circ} \mathrm{C}$. Such compounds would probably boil away too rapidly to cause a significant reaction with surface water under most atmospheric conditions.

- Liquids boiling in the range of ordinary environmental temperature $\left(0\right.$ to $\left.30^{\circ} \mathrm{C}\right)$ presented problems, in part because they can exist as a liquid or a gas depending on water temperature. Cyanogen chloride was rejected because it is a gas at temperatures above most of this range (boiling point $13.1^{\circ} \mathrm{C}$ ) and because it does not require a spill into water to pose a $\mathrm{TIH}$ hazard. On the other hand, $\mathrm{BCl}_{3}$ is included despite being a gas at $20^{\circ} \mathrm{C}$, because the reaction of the spilled chemical with water rapidly generates $\mathrm{HCl}$ gas, which is more toxic than the parent compound. Also, since its boiling point is $12.5^{\circ} \mathrm{C}$, the material frequently remains in the liquid state when spilled in water. In addition, $\mathrm{BCl}_{3}$ is frequently purveyed in solution in an organic solvent.

- DOT representatives proposed removing calcium hypochlorite (UN 1748), which appears in the 1996 North American ERG. Because of the uncertainties that are associated with both this material and lithium hypochlorite (UN 1471), the former was among the 21 materials chosen for experimental studies. Under the conditions of these experiments, no gases evolved when calcium hypochlorite was mixed with water. Therefore, a recommendation was made to remove both calcium hypochlorite and lithium hypochlorite from the TIHWR list. Calcium hypochlorite had previously been recommended for inclusion because instances of heating and subsequent decomposition to $\mathrm{Cl}_{2}$ with some $\mathrm{HCl}$ upon mixing with a restricted quantity of water had been reported (Lewis [1966], p. 707). However, this scenario appeared too unlikely to justify continued inclusion of the material in the TIHWR list. The results of this analysis also concur with the DOT-proposed omission of nitrosylsulfuric acid (UN 2308) and ammonium hydrosulfide solution (UN 2638).

As a result of the steps and considerations detailed above, 37 new materials were proposed for inclusion in the 2000ERG. This list is presented in Appendix D, along with 
a brief summary of reasons for the inclusion of each material. Table D.1 provides the full list of TIHWR materials with these 37 additions. It also provides important parameters associated with each material such as the (1) state in which the material is shipped,

(2) density of the material, (3) stoichiometric yield, (4) effectiveness factor, and

(5) primary rate constant.

\subsection{Determination of Initial Isolation Distances}

The Initial Isolation Distance denotes the length of the radius of a circular Initial Isolation Zone around the accident site from which people are to be kept away. Establishment of an Initial Isolation Zone serves two purposes. First, it provides a protective barrier upwind to protect against exposures due to wind direction variations. Second, it defines a zone downwind where life-threatening effects might be expected. The latter is a more stringent requirement for most cases, so that purpose is used to define the Initial Isolation Distance. For TIH materials that are also flammable or oxidizers, the Initial Isolation Distance does not account for the explosive or flammable nature of the material. Therefore, the Initial Isolation Distance can be less than the suggested evacuation distances specified in the 2000ERG.

The Initial Isolation Distance is calculated in a manner similar to that used for the PAD. Here, the life-threatening health criterion is defined as an ERPG-3, together with a 5-min exposure time. For chemicals for which an ERPG-3 does not exist, the health criterion is $0.1 \times \mathrm{LC}_{50}$. For such materials, this criterion is 10 times the health criterion used to define the PAD (i.e., the ERPG-2 surrogate). The 5-min exposure time accounts for both the meander of the plume close to the source and the fact that people would not remain in this zone unless they became incapacitated. 
$\Delta$ 


\section{Section 3 \\ Statistical Accident Scenario Analysis and CASRAM}

CASRAM is a quantitative risk assessment model for analyzing hazardous material transportation accidents. This model lies at the core of the 2000ERG analysis. It predicts distributions of hazard zones (i.e., areas in which a threshold chemical concentration is exceeded) and distributions of affected populations as a result of releases associated with hazardous material transportation or storage. The model uses various shipment attributes together with an extensive meteorological database to statistically generate and analyze hazardous material release scenarios. For a given health end-point (i.e., toxicological threshold concentration), distributions of hazard zones are generated stochastically through Monte Carlo sampling of accident scenario parameters (e.g., time, location, release amount, meteorology) and detailed consequence modeling of the hypothetical releases. CASRAM is specifically designed for the statistical analysis of hazardous material release problems. This feature, in particular, separates CASRAM from many other hazardous material release models. Rather than specifying a deterministic measure of risk, CASRAM determines the distribution of possible outcomes, thus allowing identification of the probability of a particular consequence within the limits of the statistical data.

CASRAM is primarily a routing-based risk assessment model that requires shipment attributes (e.g., materials, containers) and shipment routes as inputs. It provides distributions of affected persons as outputs (e.g., Brown et al. 1999). However, it is equally applicable to a geographically based incident distribution system. A geographically based system is required for the ERG analysis because the Table must reflect releases that occur anywhere in North America. The statistical accident scenario analysis (see Figure 2.1) combines the shipment profile information discussed in Section 2.2, meteorological observations from a preprocessed meteorological database, and statistical information from the HMIS database to provide a large distribution of incidents. These incidents are then modeled by using the consequence models within CASRAM. The overall goal of this analysis is to identify the distributions of safe distance (i.e., hazard zone length) associated with the transport within North America of all materials that are given in the Table. The Protective Action and Initial Isolation Distances in the Table are the 90-percentile values of these safe-distance distributions.

This section first discusses the statistical scenario analysis and then the meteorological database used in the 2000ERG study. The emission rate modeling and dispersion modeling within CASRAM, which make up the consequence modeling effort to determine PADs, are then outlined. 


\subsection{Statistical Scenario Analysis}

\subsubsection{Overview of Analysis Steps}

For each material in the Table, CASRAM was used to model between 40,000 and 100,000 separate incidents. For this analysis, incidents were distributed among different transportation modes (e.g., highway, rail), container types (e.g., DOT class 105 tank car, MC 330 cargo tank), and release types (e.g., accident-related, en route/nonaccident) specified in the shipment profile. Examples of incident distributions among these release categories are provided in Section 2.2.1. Incidents were also distributed geographically and temporally on the basis of transportation mode and release type. Geographic and temporal effects have a large influence on meteorology, which in turn directly affects the safe distance calculation. The location of the incident affects the general climate and land use (e.g., dry desert, temperate farmland), whereas the time of day and month affect the weather at that locale.

Each release modeled in the analysis is assigned a random date, time, and location. The locations for U.S.-based accidents are chosen probabilistically on the basis of state distributions of accidents in the HMIS database. Separate distributions are used for accident-related and en route/nonaccident releases for both highway and rail. Locations for Canada and Mexico are based on population density. Date and time are assigned on the basis of month-of-year and time-of-day distributions for incidents in the HMIS database following Brown et al. (1999), where the year is assigned in a five-year window that corresponds to observations in the meteorological database (1985-1989).

The emission rate model in CASRAM uses the shipment information and meteorology as specified above to determine the rate at which specific materials are released into the atmosphere. The first step is to estimate the discharge fraction on the basis of historical statistical distributions generated from analysis of HMIS database incidents. The emission rates of the material to the atmosphere are then calculated by using physical models for discharge, flashing, and evaporation applicable to that release. Within the emission rate model, the total amount of material spilled (discharge fraction) and pool size are treated stochastically.

By using the emission rates for the chemical(s) involved and the ambient meteorology, the dispersion model within CASRAM then determines the affected areas. Calculation of dispersion in CASRAM is basically a two-step process. Step 1 involves characterizing the meteorology from the available surface observations. Step 2 involves estimating the transport and dispersion from the applicable meteorological parameters. Step 1 is accomplished with a meteorological preprocessor, which consists of a series of algorithms that take raw meteorological data (e.g., wind speed, temperature, humidity, cloud cover) and site information (e.g., land cover type, roughness length) and calculate parameters necessary for estimating dispersion. While this analysis is usually closely associated with dispersion modeling, the atmospheric parameters calculated are also used in estimating source emission rates. Traditionally, these parameters have been

represented as stability classes; however, in this analysis, the turbulence of the 
atmospheric boundary layer was represented by more fundamental turbulence measures, such as friction velocity, surface heat flux, and inversion height. Step 2 is accomplished by using a Lagrangian integral dispersion model for passive releases, coupled with a dense gas dispersion model to address large releases of liquefied gases where heavierthan-air plumes form. The physical relationships that makeup the emission rate and dispersion models are outlined in Sections 3.3 and 3.4, respectively.

\subsubsection{Key Statistical Data Employed}

\subsubsection{Geographic Incident Distributions}

In the 2000ERG analysis, accidents are distributed across all 50 states in the United States, the southern Canadian provinces, and Mexico. Within the United States, the accident distribution is based on incident distributions in the HMIS database for 1985 through 1995, and separate geographic distributions are used for highway and rail. The distribution of accidents among the United States, Canada, and Mexico is based on the total gross domestic product (GDP) for 1997. The total GDP was selected as a measure for hazardous materials incidents because detailed data on these incidents in Canada and Mexico are not available. For the United States and Canada, the relative GDP for chemical and chemical products is similar to the total GDP, but because the industryspecific GDP was not available for Mexico, and because Canadian and U.S. chemicalspecific GDPs are calculated slightly differently, the total GDP was considered to be the more robust indicator. On the basis of this breakdown, $89 \%$ of incidents modeled in the 2000ERG analysis occurred in the United States, 7\% occurred in Canada, and 4\% occurred in Mexico. Within Canada and Mexico, incidents were distributed into regions on the basis of population. Canada was divided by province. In this process, New Brunswick, Newfoundland, Nova Scotia, and Prince Edward Island were combined as the "Atlantic Provinces," and the Yukon and Northwest Territories were excluded because of their small populations (more than $0.5 \%$ of total Canadian population). Mexico was divided into three regions: Northern (above $22^{\circ} \mathrm{N}$ latitude), Central (between 18 and $22^{\circ} \mathrm{N}$ latitude), and Southern (below $18^{\circ} \mathrm{N}$ latitude, including the Yucatan Peninsula). A breakdown of the geographic distribution of incidents in the 2000ERG analysis for highway and rail transportation is provided in Table 3.1.

\subsubsection{Temporal Incident Distributions}

Temporal release distributions are important in determining meteorology. In some risk assessment studies, temporal variables also influence the population at risk because the number of people at a particular location may change throughout the day and because more people may be outside during the day. Two temporal variables are defined in the analysis: hour of day and day (or month) of year. With regard to meteorology, the hour of day is critical because of the diurnal cycle of the atmospheric boundary layer, and the day of year is important because of seasonal effects on wind speed, temperature, cloud cover, and daytime mixing height. Note that wind speed and temperature affect not only dispersion but also the emission rate of spilled liquids to the atmosphere. 
Table 3.1 Geographic Distribution of Highway and Rail Transportation Incidents Modeled in the 2000ERG Analysis, by Percentage

\begin{tabular}{|c|c|c|c|c|c|}
\hline State/Province & Highway & Rail & State/Province & Highway & Rail \\
\hline Alabama & 1.85 & 2.76 & New Mexico & 1.45 & 0.68 \\
\hline Alaska & 0.12 & 0.40 & New York & 2.61 & 1.10 \\
\hline Arizona & 1.51 & 0.88 & North Carolina & 2.42 & 2.33 \\
\hline Arkansas & 2.56 & 3.33 & North Dakota & 0.22 & 0.12 \\
\hline California & 4.62 & 8.62 & Ohio & 6.10 & 4.93 \\
\hline Colorado & 1.60 & 1.21 & Oklahoma & 1.30 & 0.95 \\
\hline Connecticut & 0.79 & 0.04 & Oregon & 1.22 & 1.55 \\
\hline District of Columbia & 0.04 & 0.00 & Pennsylvania & 6.51 & 1.82 \\
\hline Delaware & 0.26 & 0.12 & Rhode Island & 0.18 & 0.03 \\
\hline Florida & 2.02 & 1.83 & South Carolina & 1.09 & 0.74 \\
\hline Georgia & 2.43 & 2.91 & South Dakota & 0.18 & 0.00 \\
\hline Hawaii & 0.02 & 0.00 & Tennessee & 3.20 & 1.94 \\
\hline Idaho & 0.46 & 1.00 & Texas & 6.98 & 11.54 \\
\hline Illinois & 5.54 & 5.40 & Utah & 0.94 & 1.97 \\
\hline Indiana & 2.49 & 1.74 & Vermont & 0.16 & 0.01 \\
\hline lowa & 1.27 & 0.63 & Virginia & 1.75 & 1.46 \\
\hline Kansas & 1.78 & 2.34 & Washington & 1.35 & 1.54 \\
\hline Kentucky & 2.00 & 1.38 & West Virginia & 1.08 & 0.66 \\
\hline Louisiana & 3.20 & 5.52 & Wisconsin & 1.35 & 0.23 \\
\hline Massachusetts & 1.25 & 0.21 & Wyoming & 0.63 & 2.40 \\
\hline Maryland & 1.45 & 0.64 & \multicolumn{3}{|c|}{ Canada and Mexico } \\
\hline Maine & 0.28 & 0.12 & British Columbia, Can. & 0.82 & 0.82 \\
\hline Michigan & 1.83 & 3.55 & Alberta & 0.63 & 0.63 \\
\hline Minnesota & 1.52 & 0.42 & Saskatchewan & 0.25 & 0.25 \\
\hline Mississippi & 1.24 & 0.84 & Manitoba & 0.27 & 0.27 \\
\hline Missouri & 2.51 & 2.85 & Ontaria & 2.51 & 2.51 \\
\hline Montana & 0.33 & 0.58 & Quebec & 1.71 & 1.71 \\
\hline Nebraska & 0.63 & 1.85 & Atlantic Provinces & 0.58 & 0.58 \\
\hline Nevada & 0.48 & 0.68 & Northern Mexico & 1.03 & 1.03 \\
\hline New Hampshire & 0.17 & 0.00 & Central Mexico & 2.69 & 2.69 \\
\hline New Jersey & 1.80 & 0.90 & Southern Mexico & 0.76 & 0.76 \\
\hline
\end{tabular}

Temporal incident variations in the 2000ERG analysis are based on statistical data from the HMIS database as presented by Brown et al. (1999) and shown in Figures 3.13.4. Temporal distributions are separated by time of day and month of year. The accident rate is assumed to be uniform on a day-of-month basis. The temporal distributions are further delineated by transport mode (highway or rail) and by type of release (accidentrelated or en route/nonaccident).

\subsubsection{Discharge Fraction Distributions}

In the CASRAM emission model, the discharge fraction is estimated by using statistical distributions developed from an analysis of the HMIS database maintained by 


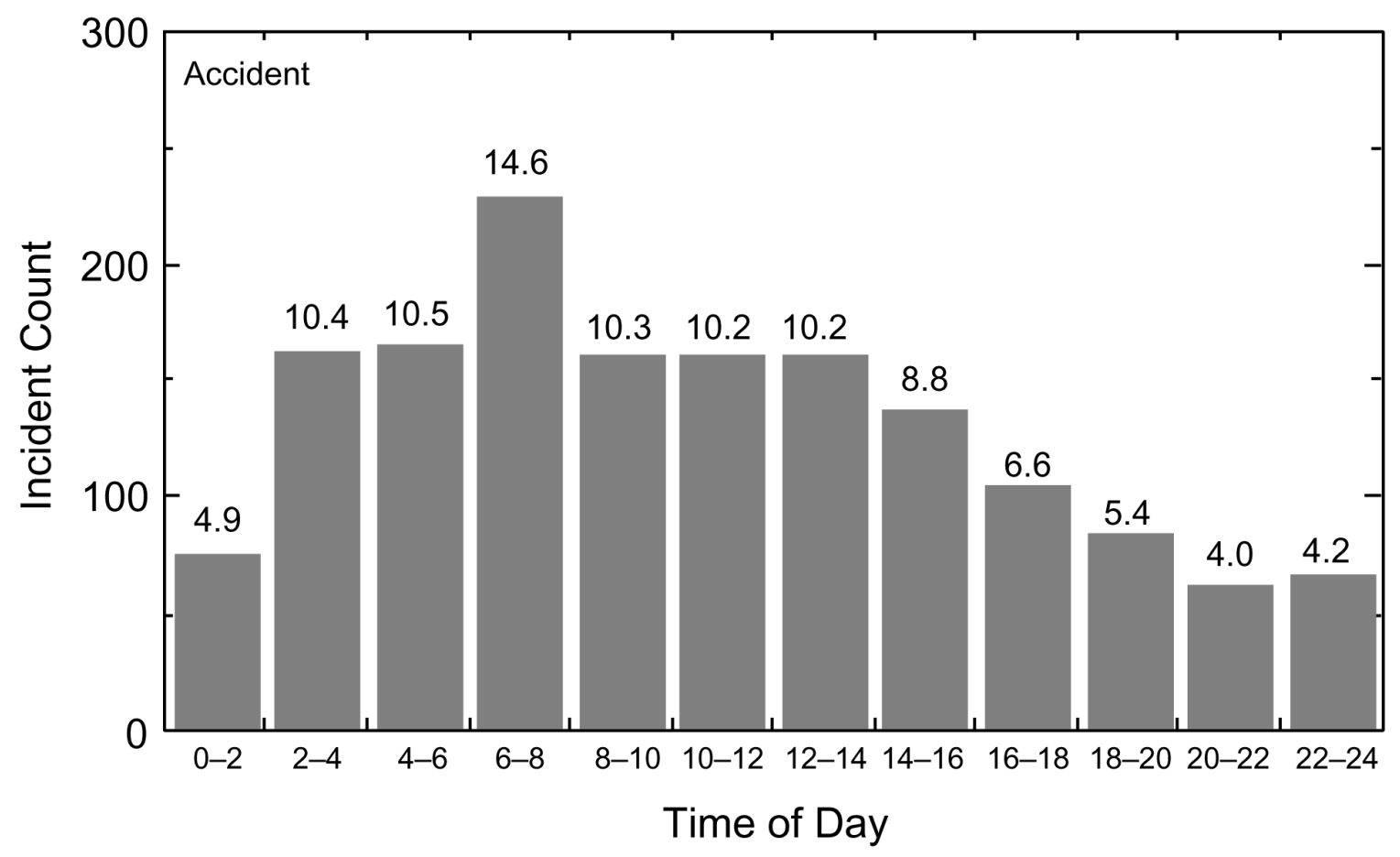

(a)

DBA10003

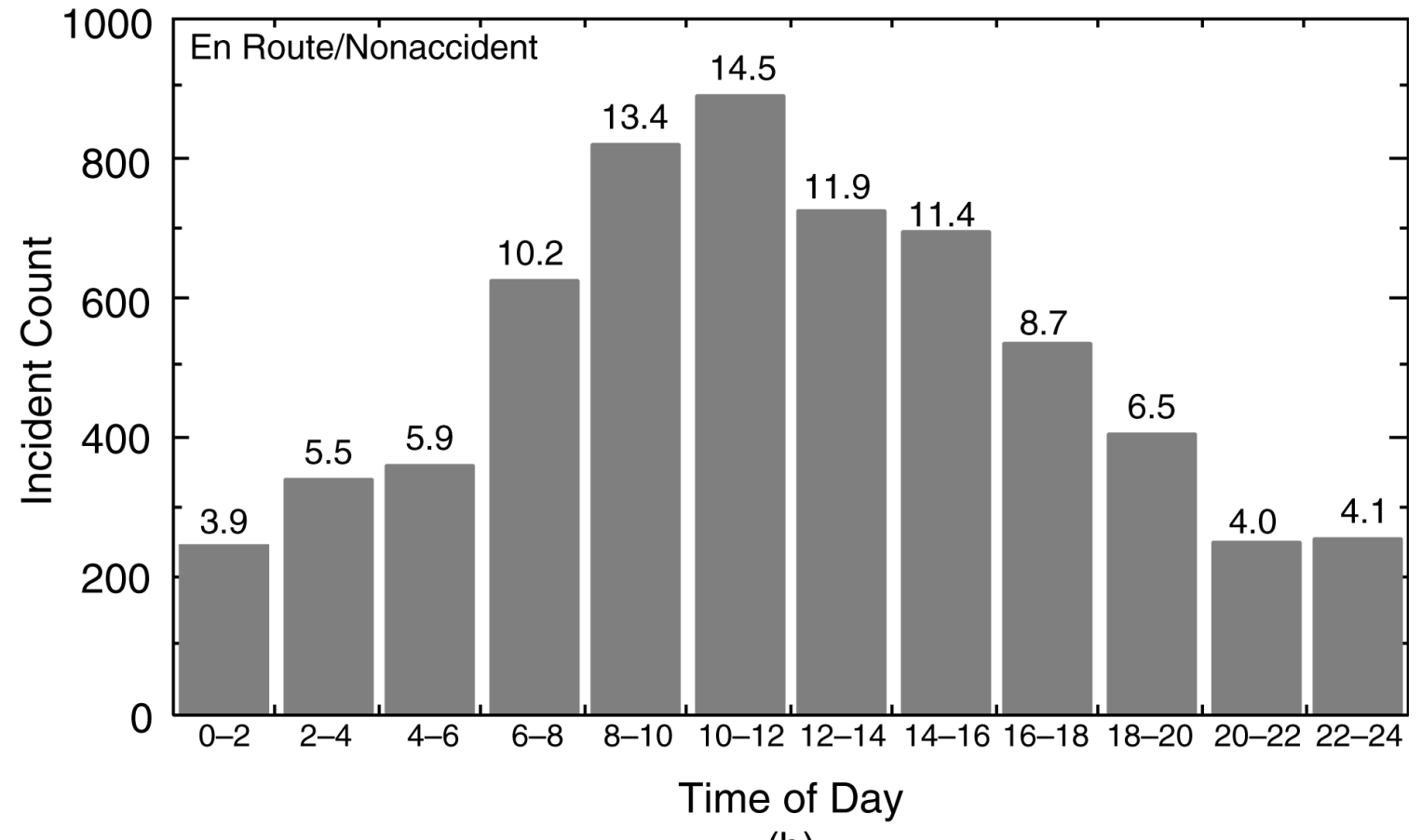

(b)

DBA10004

Figure 3.1 Hourly Distribution of Highway-Transportation-Related Hazardous Material Releases $(a=$ releases during vehicle accidents and $b=$ releases during en route/ nonaccident incidents as calculated by Brown et al. [1999] and used in the 2000ERG analysis) 


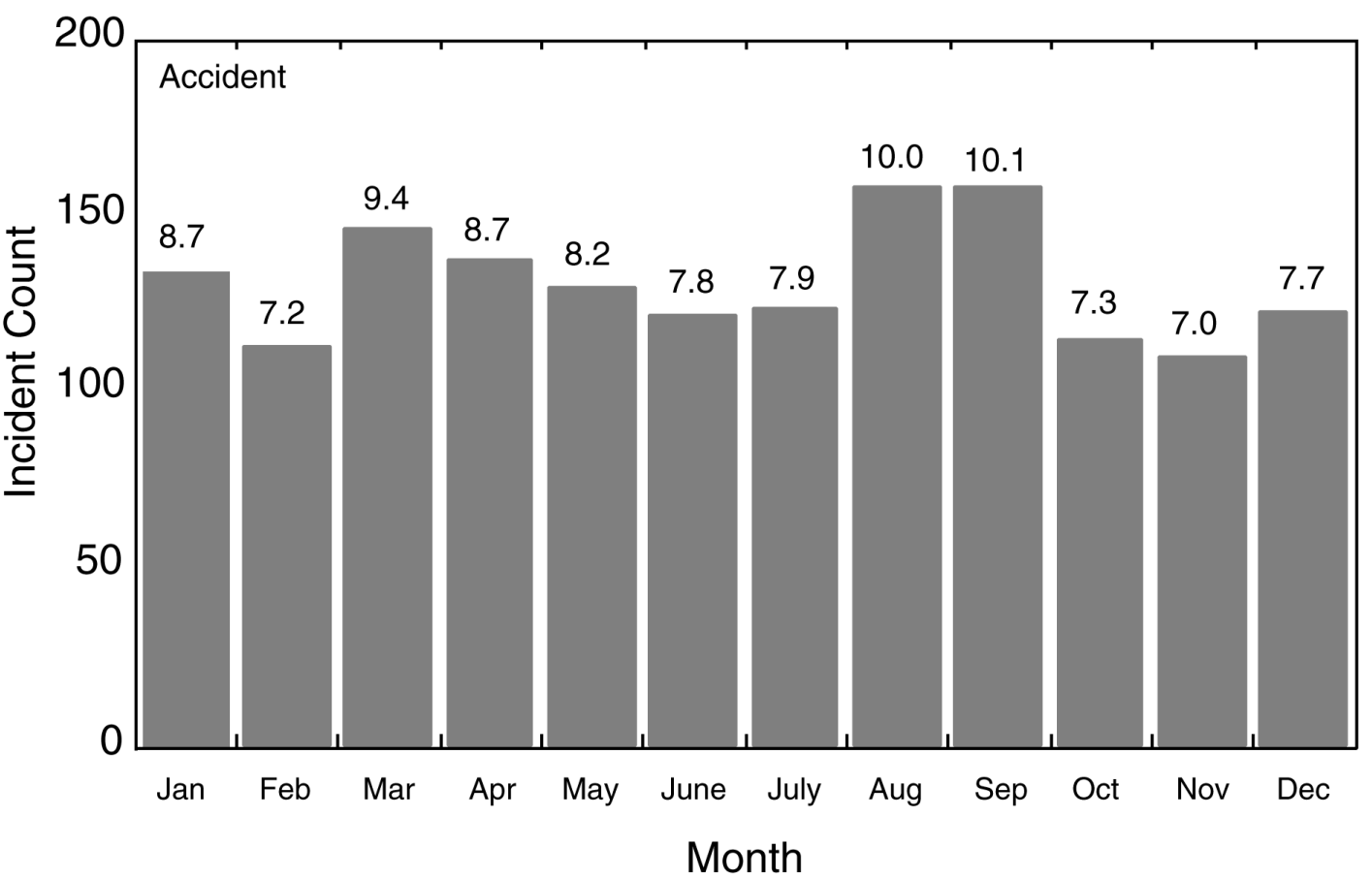

(a)

DBA10005

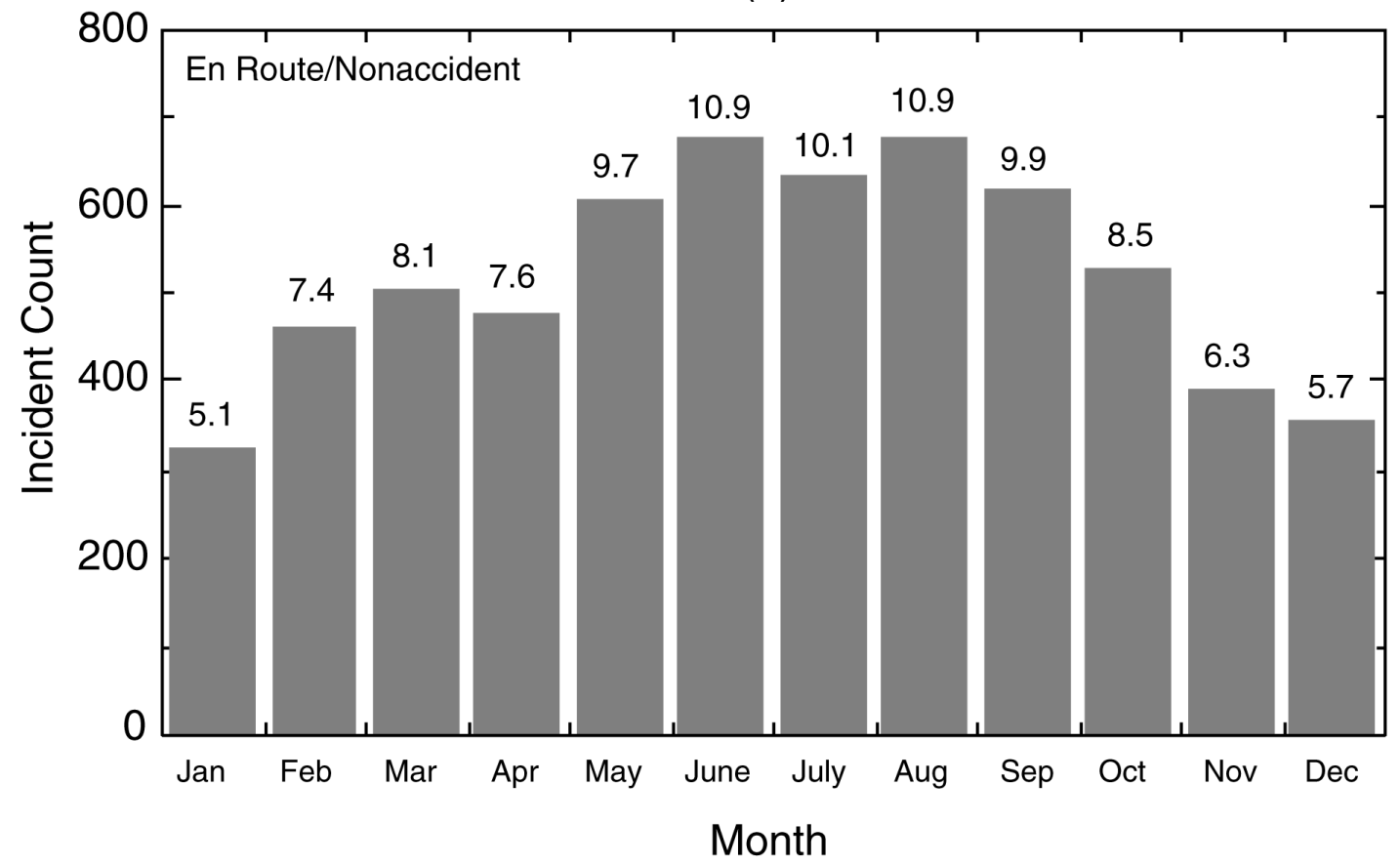

(b)

DBA10006

Figure 3.2 Monthly Distribution of Highway-Transportation-Related Hazardous Material Releases $(a=$ releases during vehicle accidents and $b=$ releases during en route/ nonaccident incidents as calculated by Brown et al. [1999] and used in the 2000ERG analysis) 


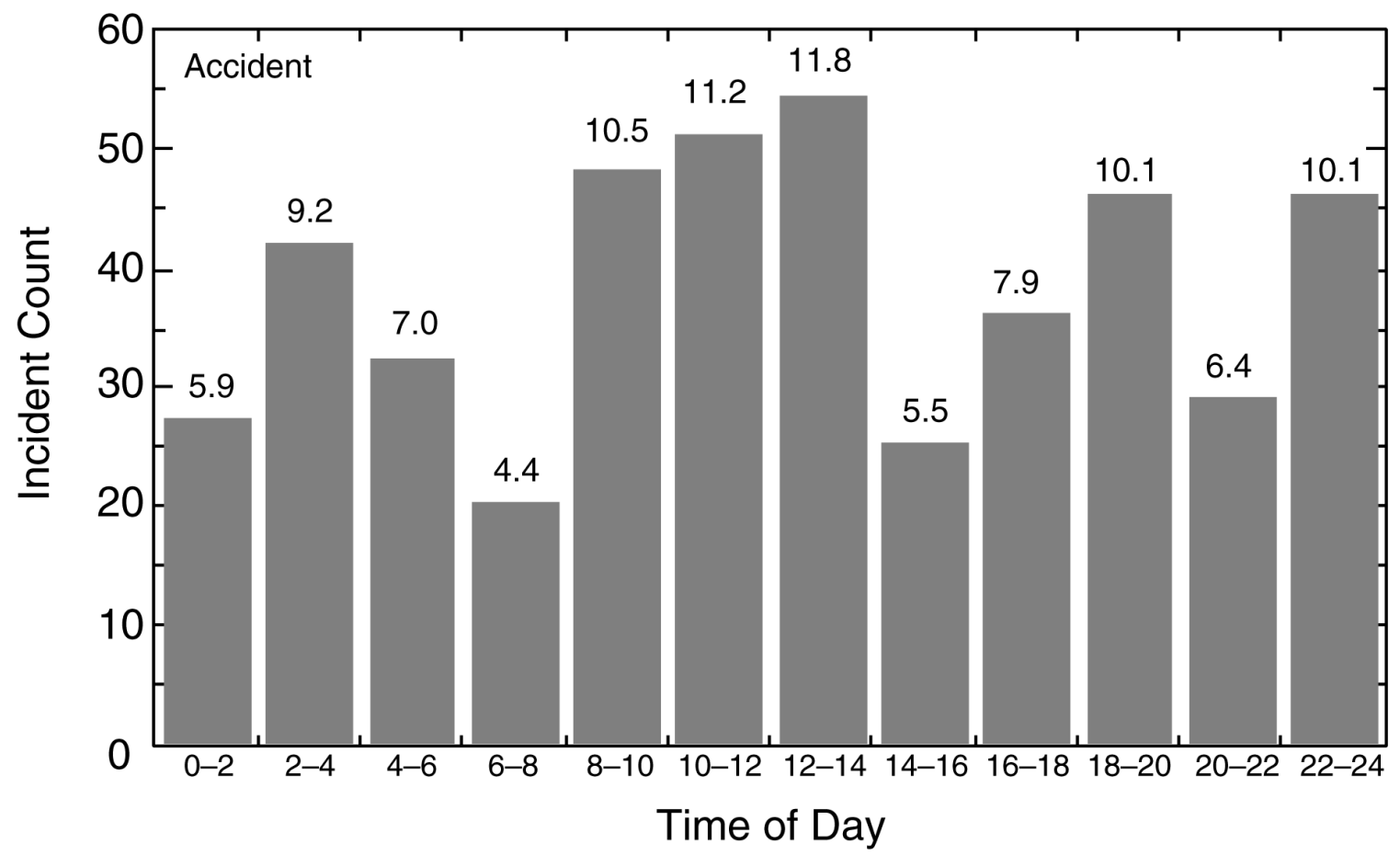

(a)

DBA 10007

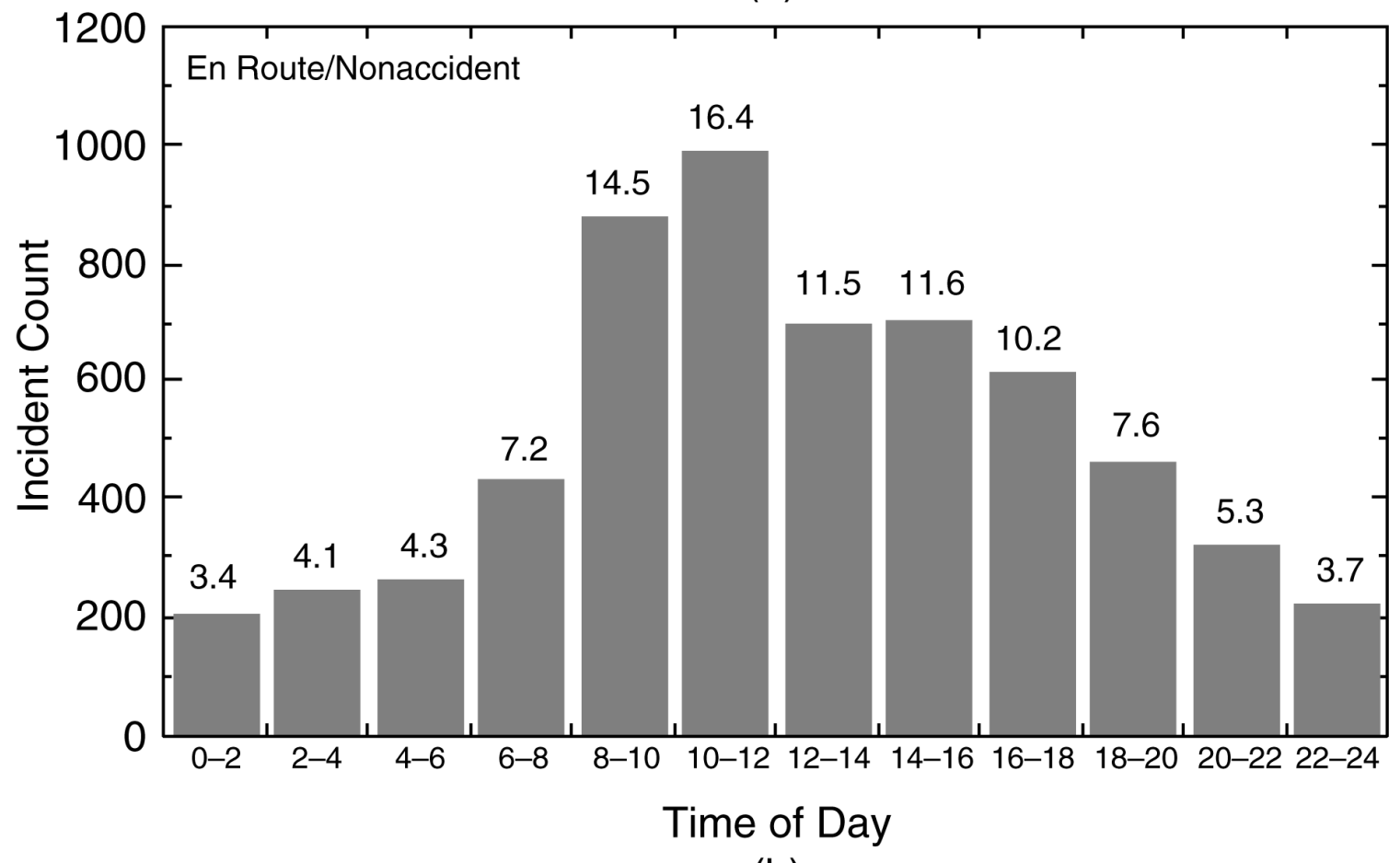

(b)

DBA10008

Figure 3.3 Hourly Distribution of Rail-Transportation-Related Hazardous Material Releases $(a=$ releases during vehicle accidents and $b=$ releases during en route/nonaccident incidents as calculated by Brown et al. [1999] and used in the 2000ERG analysis) 


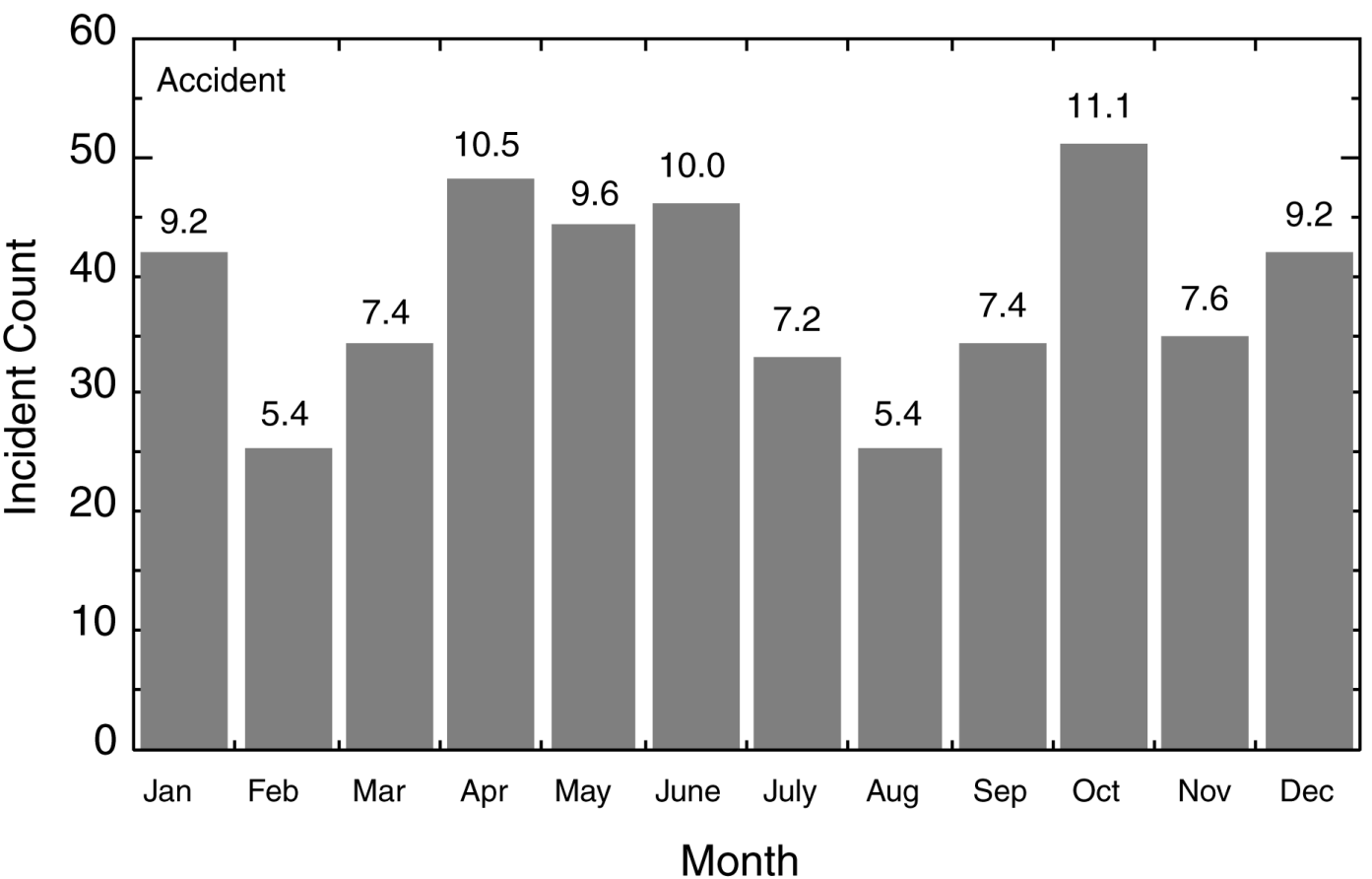

(a)

DBA10009

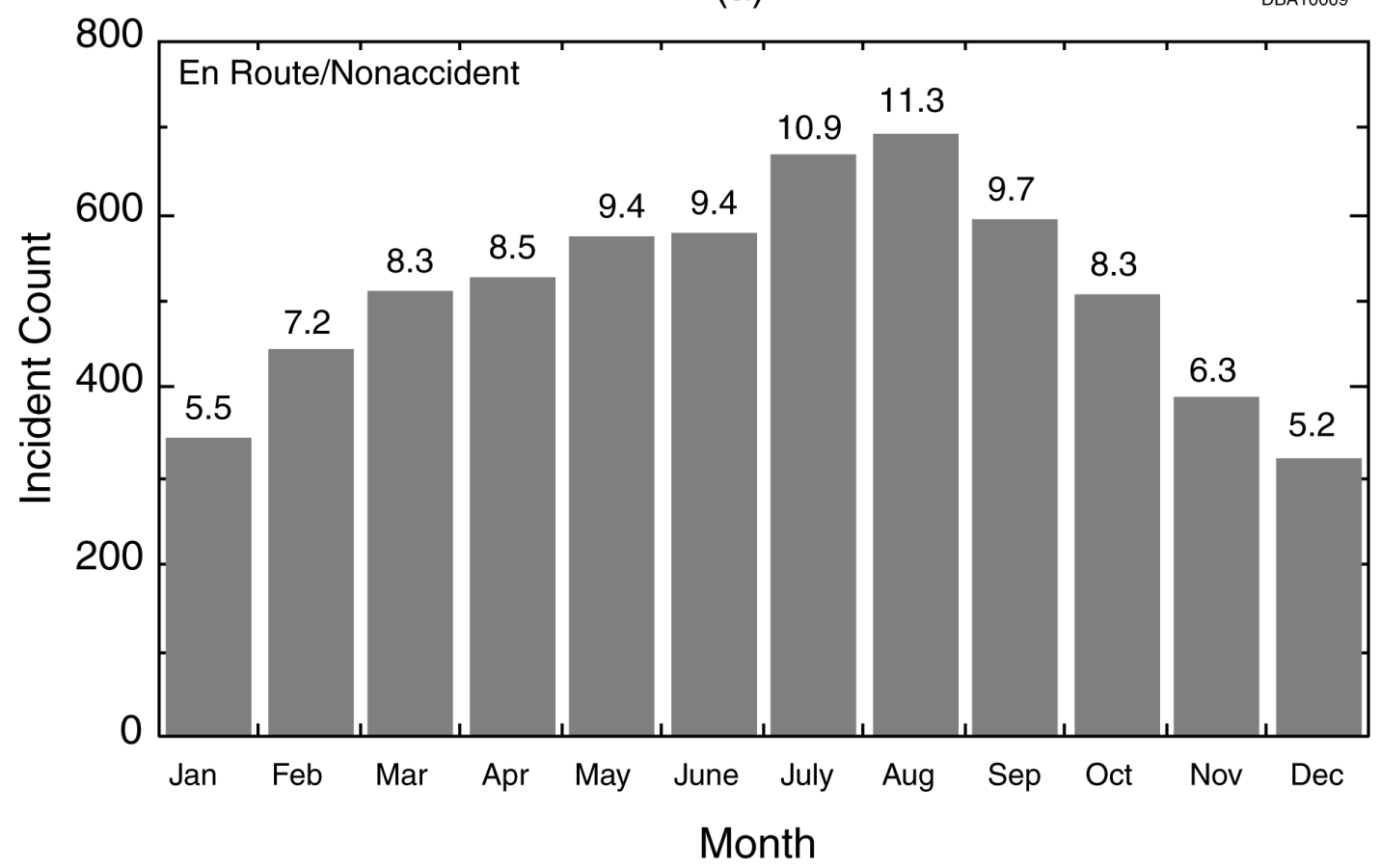

(b)

DBA10010

Figure 3.4 Monthly Distribution of Rail-Transportation-Related Hazardous Material Releases $(a=$ releases during vehicle accidents and $b=$ releases during en routel nonaccident incidents as calculated by Brown et al. [1999] and used in the 2000ERG analysis) 
DOT, following the analysis of Brown et al. (1999). The HMIS database consists of coded information collected from U.S. transportation-related incidents involving hazardous materials. It is the best available source of information about container failures and release amounts. For each incident cataloged in the HMIS database, information includes (1) name of chemical shipped, (2) container type, (3) number of containers shipped, (4) number of containers that failed, and (5) amount of material released. In characterizing the amount of a release, the fraction of the container's capacity that was released appears to be the most robust statistic in terms of both aggregating data from a wide variety of containers and ease of use in subsequent risk assessment studies. This fraction of the total container capacity that is released is defined here as the discharge fraction. In constructing distributions for the discharge fraction for various container types, the amount that was shipped is inferred by multiplying the number of containers by the container capacity. Since the amount of material actually shipped is not currently provided in the HMIS database, the container capacity provides the best estimate of the amount shipped. As an example, consider a vehicular accident that involves the shipment of four 10-gal drums of acetone and in which 1.6 gal is released. The discharge fraction would be 0.04 , i.e., 1.6/(4×10). As is discussed later, this incident would be grouped with all other incidents involving drums with capacities of less than 20 gal to construct the discharge fraction distributions for accident-related releases. The discharge fraction for package freight containers involved in en route/ nonaccident releases and in loading and unloading mishaps is calculated on the basis of the capacity of a single container. When the above example is used again, the discharge fraction would be 0.16 , i.e., 1.6/10 if the release occurred while en route but not during an accident or during loading or unloading of the drums.

In the CASRAM source model, discharge fraction statistics are segregated according to container type. In general, these container types can be classified according to whether they are used for bulk or package freight. Discharge fraction statistics for bulk containers are shown in Figures 3.5 and 3.6. Figure 3.5 shows discharge fraction distributions for containers that are used for nonpressurized and low-pressure materials. Figure 3.6 shows the distributions for containers that are used for high-pressure materials. Discharge fraction distributions are provided for the two transportation-related phases considered in the ERG2000 analysis: accident-related and en route/nonaccident releases. Discharge fraction statistics for bulk package freight were developed for a specific container type (Type 111A tank cars, MC306 tanks, etc.) when sufficient statistical data were available (i.e., data on at least 25 incidents). In practice, discharge fractions for other container types for which data are insufficient could be estimated by using a surrogate for a similar container type for which data do exist. For example, the surrogate discharge fraction distribution for Type 103 tank cars would be that for Type 111A tank cars, and the surrogate for MC338 cargo tanks would be MC330/331 cargo tanks.

The discharge fraction statistics for accident-related and en route/nonaccident releases for package freight containers and portable tanks are shown in Figure 3.7. 


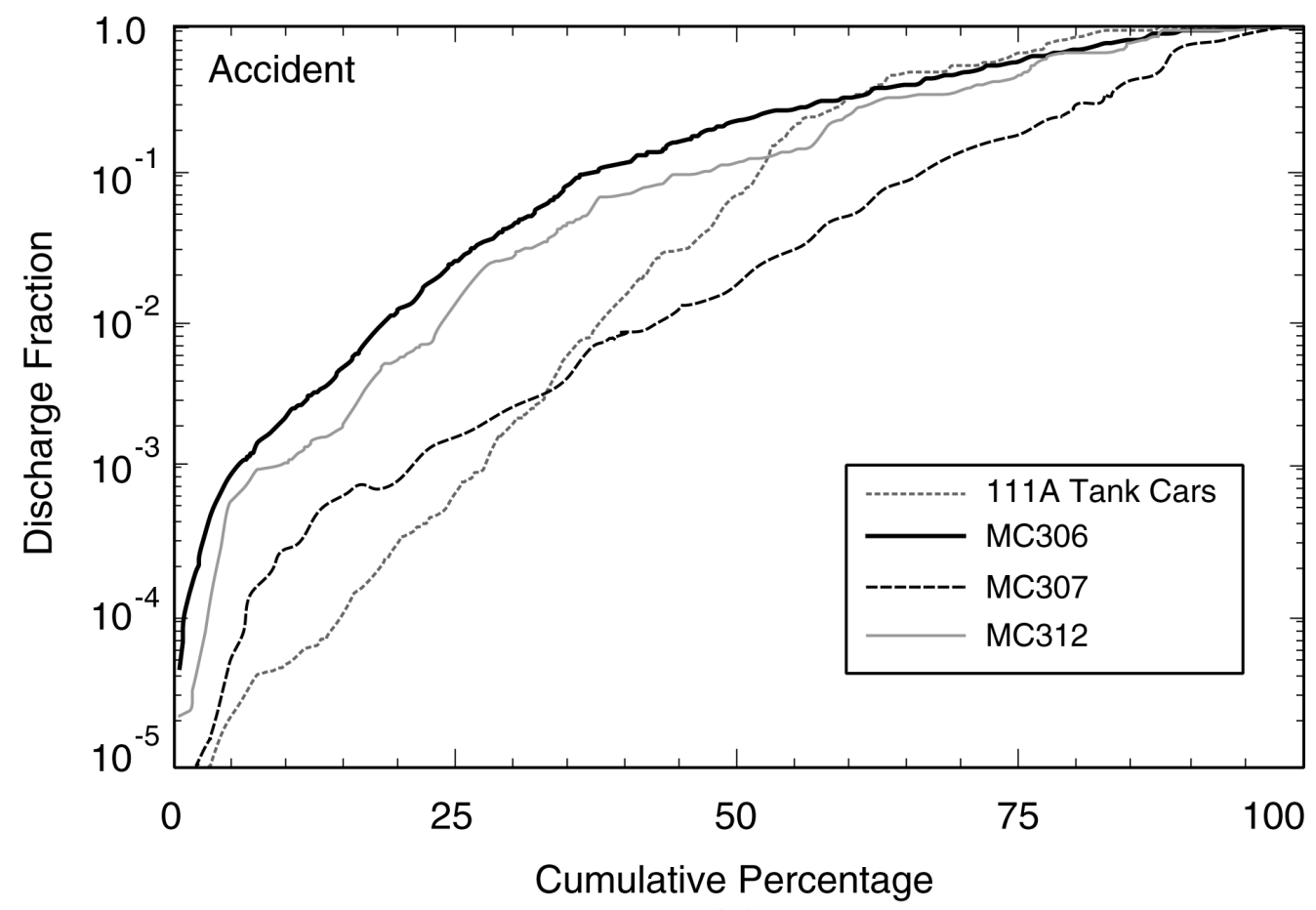

(a)

DBA10011

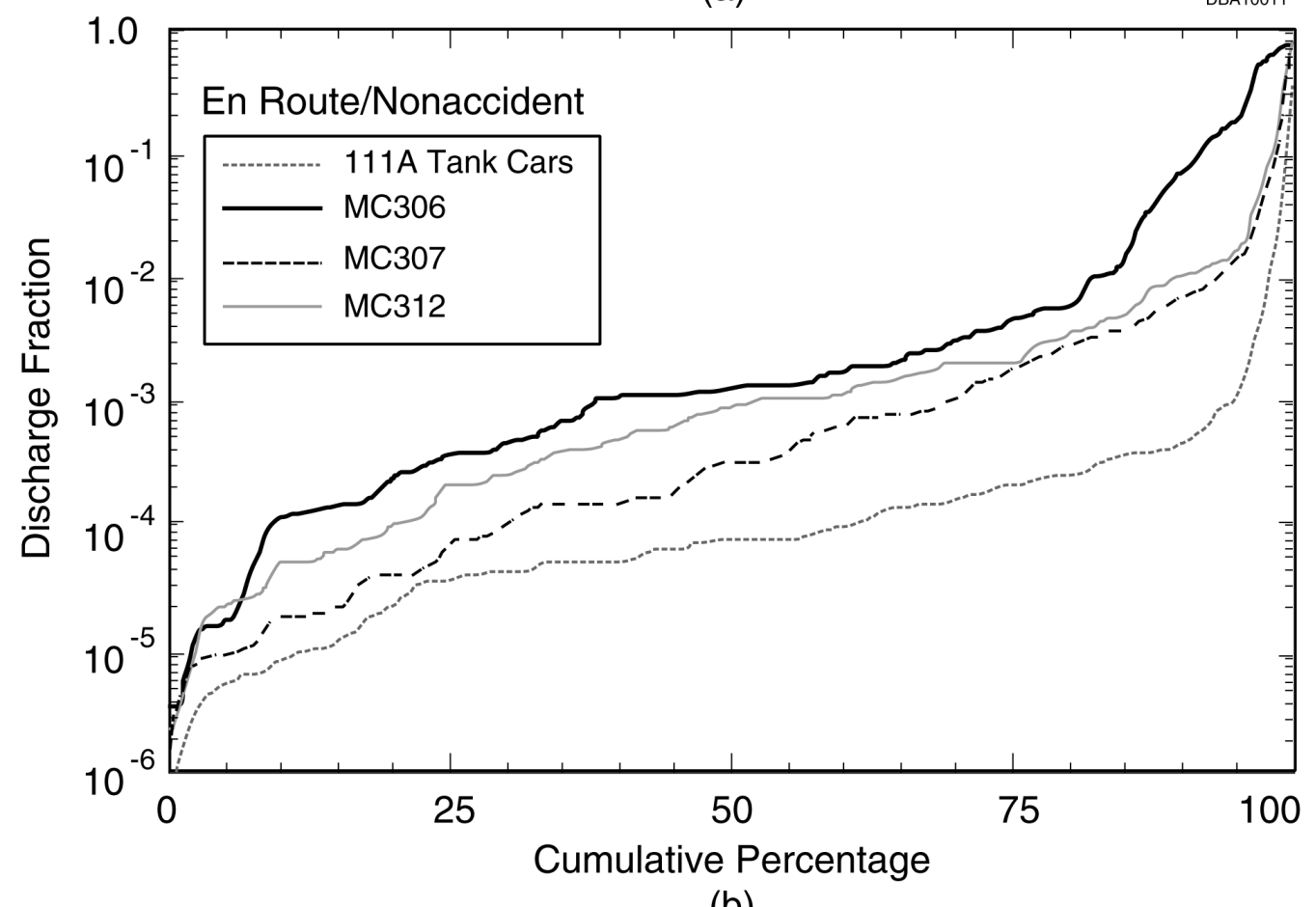

(b)

DBA10012

Figure 3.5 Discharge Fraction Cumulative Probability for Bulk Nonpressurized and Low-Pressure Containers as Derived from the HMIS Database $(a=$ accidentrelated releases and $b=$ en route/nonaccident releases; discharge fraction is fraction of container capacity that was released) (Source: Brown et al. 1999) 


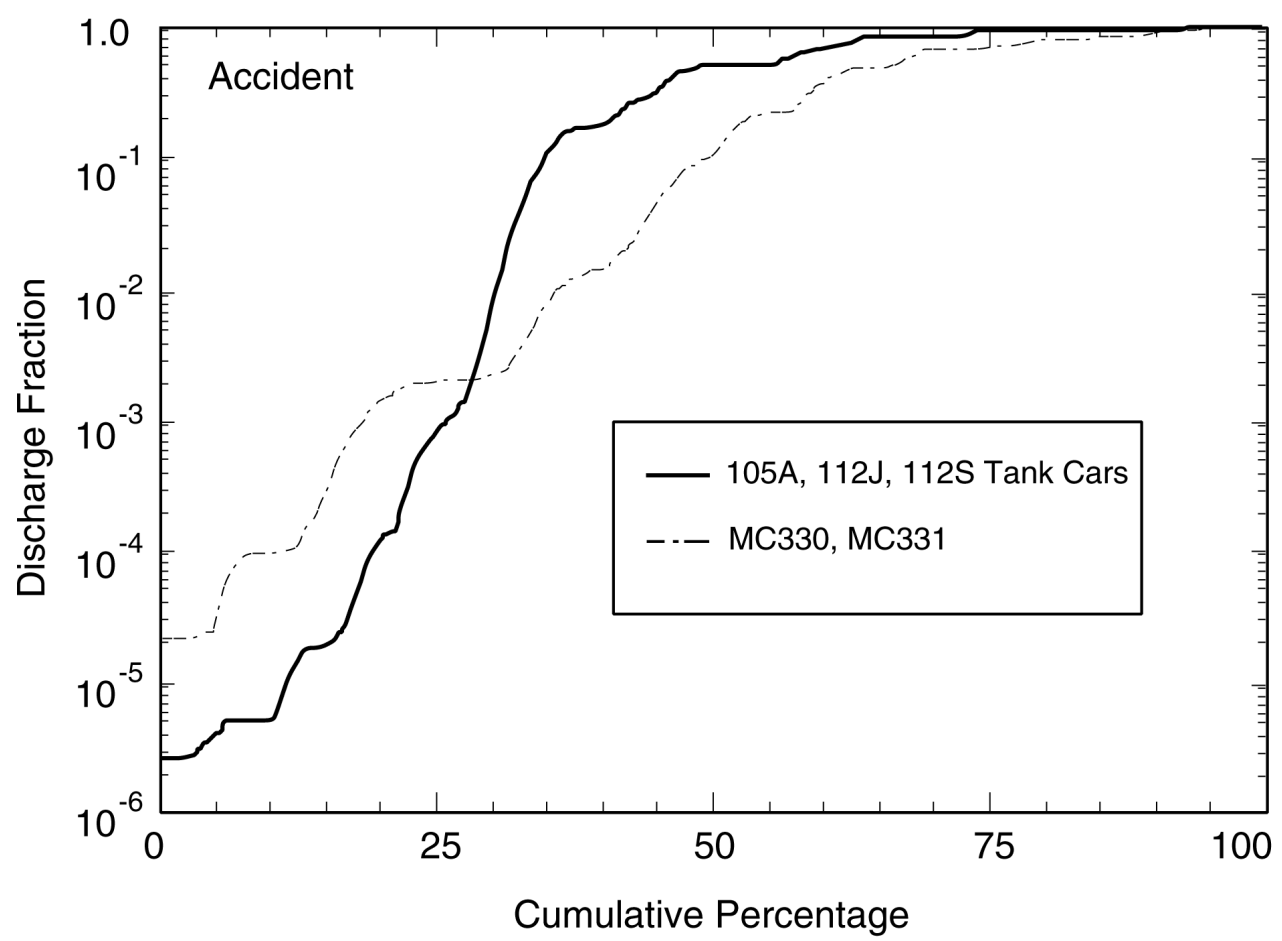

(a)

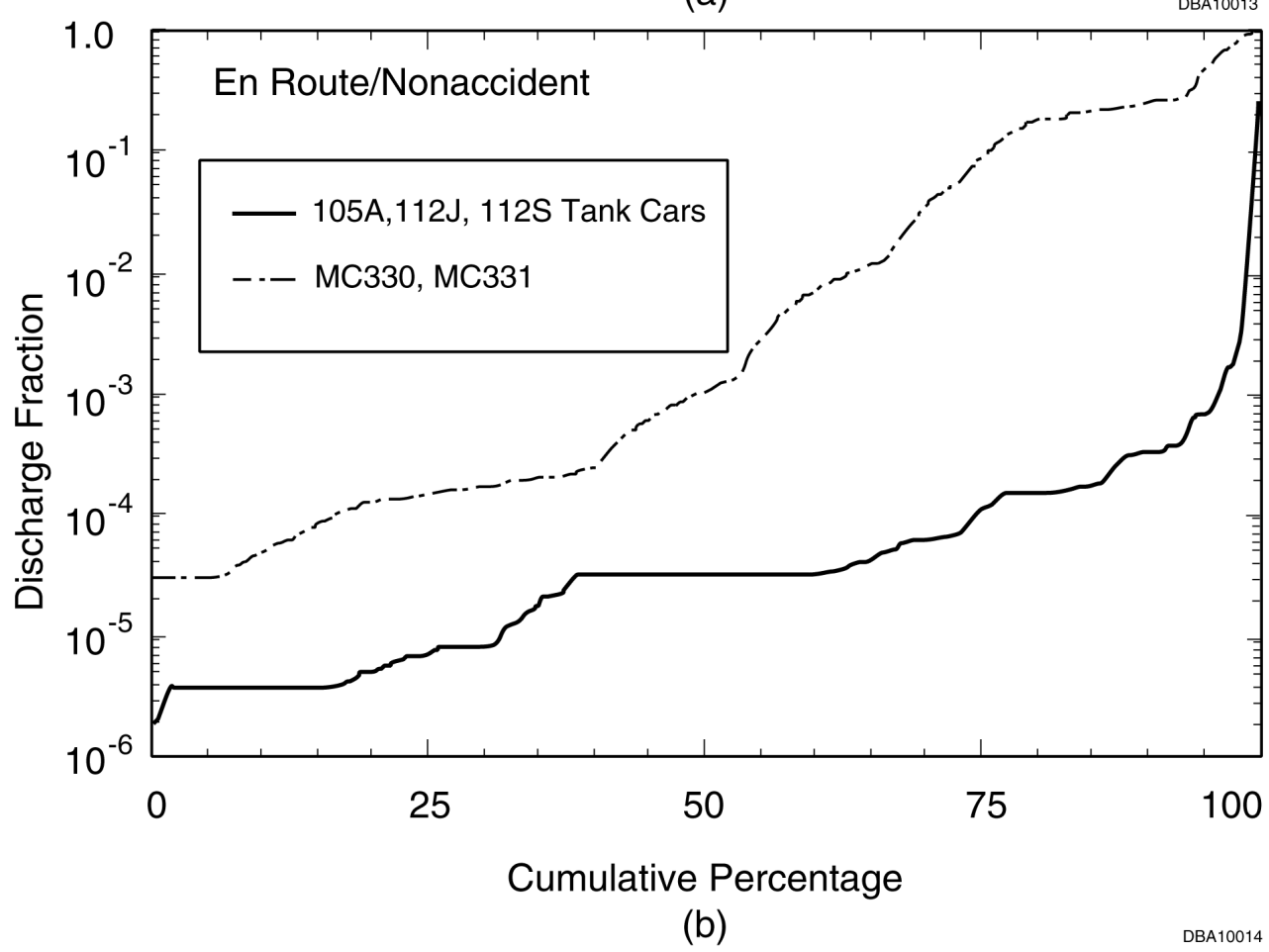

Figure 3.6 Discharge Fraction Cumulative Probability for Bulk Pressurized Containers as Derived from the HMIS Database $(a=$ accident-related releases and $b=$ en route/nonaccident releases; discharge fraction is fraction of container capacity that was released) (Source: Brown et al. 1999) 


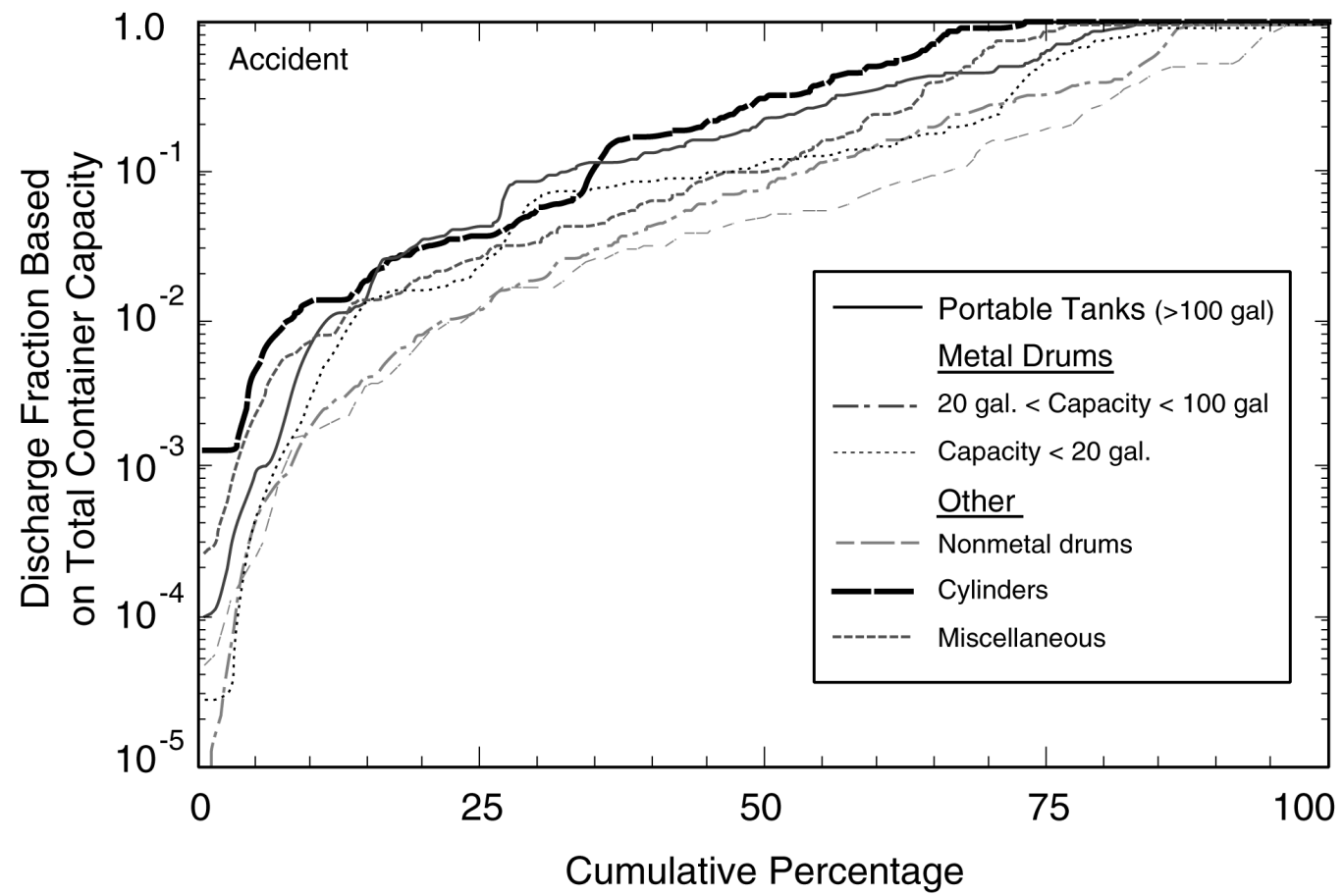

(a)

DBA10015

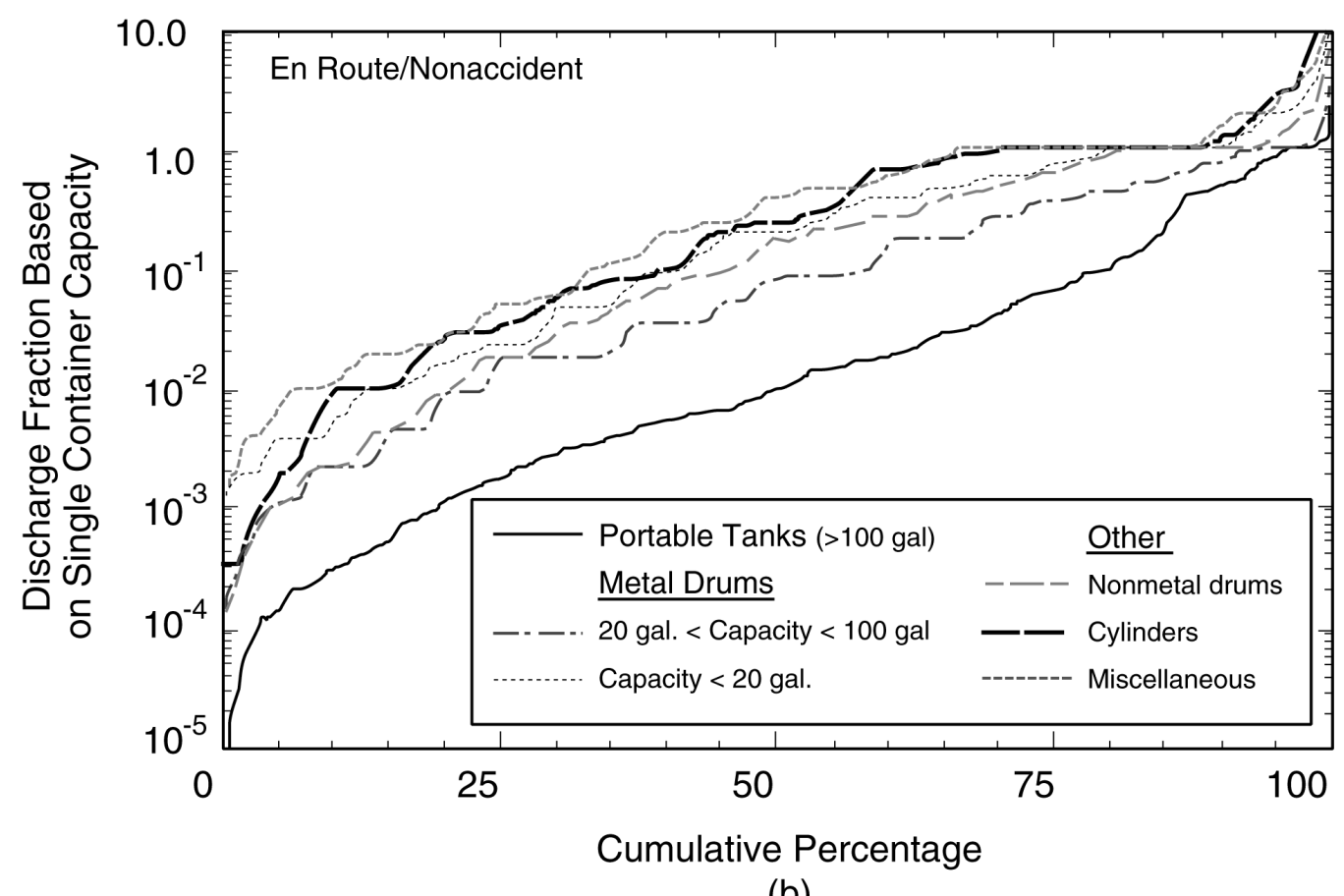

Figure 3.7 Discharge Fraction Cumulative Probability for Package Freight Containers (including portable tanks) as Derived from the HMIS Database ( $a=$ accident-related releases and $b=$ en route/nonaccident releases; for $a$, discharge fraction is fraction of total capacity of all containers that were released; for $b$, it is fraction of a single container that was released) (Source: Brown et al. 1999) 
Because the number of container types was so large, the types were grouped into several categories: (a) portable tanks (including metal drums with capacities greater than 100 gal), (b) metal drums with capacities less than 100 gal but greater than 20 gal, (c) metal drums with capacities of 20 gal or less, (d) nonmetal drums, (e) metal cylinders, and (f) miscellaneous containers. The miscellaneous category includes cans, bottles, pails, jerricans, carboys, and kegs/barrels. The discharge fraction distributions for accident-related releases are given in terms of the amount released as a fraction of the total container capacity (i.e., capacity of all containers combined). In contrast, the discharge fraction distributions for en route/nonaccident releases are given in terms of the amount released as a fraction of an individual container's capacity. Through trial and error, it was found that this was the most reliable method of scaling discharge fraction statistics over a variety of shipment sizes, since en route/nonaccident releases as well as loading and unloading releases frequently involve damage to only a single container. One drawback of this release fraction normalization is that for a few of the container categories, the distributions do not properly represent shipments that contain only few containers. A method for treating these cases is outlined in Brown et al. (1999).

\subsection{Meteorological Database Used to Prepare the Guidebook}

The meteorological database is a critical component of the ERG2000 analysis since it provides the historical meteorological data necessary to model hazardous material incidents anywhere in the United States, Canada, and Mexico. This database was generated directly from five years of observational data from 105 cities in the United States and from supplemental data from several stations in Canada and Mexico. The data were first preprocessed by using the Surface Energy Budget Meteorological (SEBMET) model (Brown 1997; Brown and Dunn 1998). This meteorological preprocessor was designed for use with dispersion studies such as the ERG2000 analyses. A meteorological preprocessor contains a series of algorithms that use routinely measured observations of wind speed, temperature, humidity, and cloud cover, along with upper-air temperature soundings, to calculate the key atmospheric-boundary-layer parameters necessary for modeling source thermodynamics, transport, and dispersion. The following sections first discuss the raw meteorological data used in the analysis and then provide a brief overview of SEBMET's methodology. They then describe a companion database employed to estimate water temperature for analysis of water-reactive spills.

\subsubsection{Meteorological and Site Data}

For the ERG2000 analysis, CASRAM uses a meteorological database that includes hourly meteorological parameters from 105 U.S. cities in 1985 through 1989 (as illustrated in Figure 3.8) and supplemental data from several stations in Canada and Mexico. The stations were chosen to provide a roughly uniform coverage area. Raw meteorological data included yearly surface files listing hourly values of wind speed, temperature, cloud cover (height and fraction), dew point temperature, pressure, and visibility, among other variables. In addition, upper air data from 80 stations across North America were employed to evaluate the atmospheric temperature profile up to the 7,000-m altitude necessary for determining the daytime mixing height. Site 

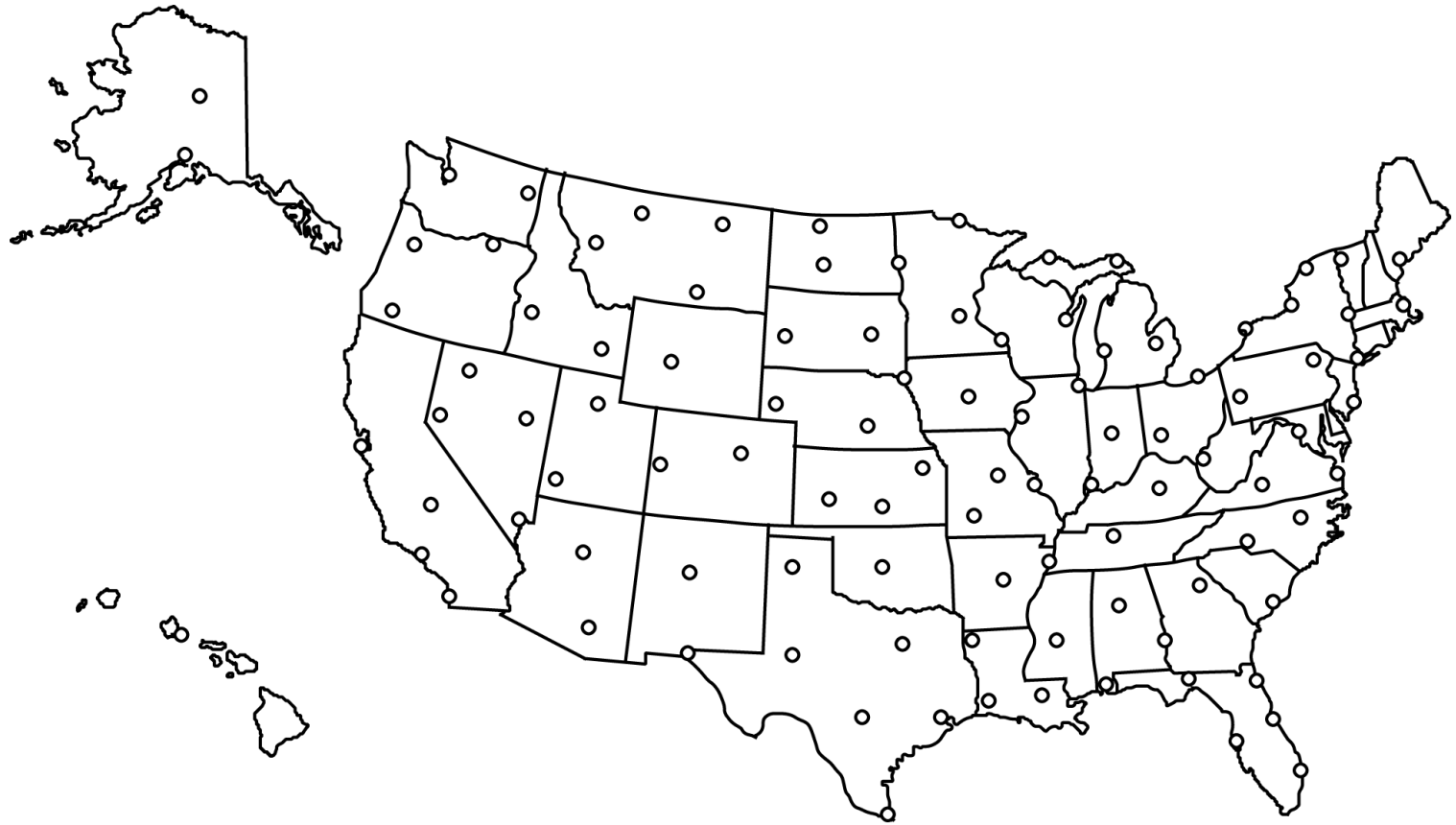

DBA10017

Figure 3.8 Locations of the 105 National Weather Service Stations Used for Statistical Meteorological Characterization

characteristics determined for each station included land cover, vegetative types, the monthly leaf area index (a measure of the canopy density) for each vegetative type, roughness length, albedo, and soil types. These site-specific parameters were determined through a climatological study of the areas surrounding each site.

\subsubsection{Meteorological Preprocessor}

The meteorological preprocessor contains two primary components: a surface energy budget (SEB) model that determines the surface-layer turbulence parameters and an integral model determines inversion height in convective conditions. Each component is briefly outlined below. Brown (1997) and Brown and Dunn (1998) contain additional information on the meteorological preprocessor, including details on its development and validation.

\subsubsection{Surface Turbulence Parameters}

The surface-layer parameters are determined by using a SEB model that consists of parameterizations of the various SEB components and well-known flux-profile relationships. The goal of this modeling approach is to isolate the sensible heat flux $H$ from the other energy budget components. The starting point for this analysis is the SEB 
at the ground. When advection, photosynthesis, and snow melt are neglected, the SEB is most simply represented as follows:

$$
Q^{*}=H+\lambda E_{w}+G+Q_{a}
$$

where

$$
\begin{aligned}
& Q^{*}=\text { net surface radiative heat flux, } \\
& G=\text { conductive soil heat flux, } \\
& \lambda=\text { heat of vaporization for water, } \\
& E=\text { evaporation rate (together, } \lambda E_{\mathrm{w}} \text { is the latent heat flux), and } \\
& Q_{a}=\text { anthropogenic heat flux. }
\end{aligned}
$$

The net surface radiative heat flux is the residual from the absorbed solar radiation $S$, incoming long-wave radiation $L^{+}$, and outgoing long-wave radiation $\varepsilon \sigma T_{\mathrm{S}}^{4}$. It is written as follows:

$$
Q^{*}=\left(1-\alpha_{s}\right) S+L^{+}+\varepsilon_{s} \sigma T_{s}^{4}
$$

where

$$
\begin{aligned}
& \alpha_{S}=\text { surface albedo, } \\
& \varepsilon_{S}=\text { surface emissivity, } \\
& \sigma=\text { Boltzmann constant, and } \\
& T_{S}=\text { surface temperature. }
\end{aligned}
$$

At the surface, the short-wave balance is always positive, while the outgoing longwave radiation generally exceeds incoming long-wave radiation. The model is constructed by parameterizing each of the components in the SEB in terms of routinely observed meteorological observations and site characteristics. A brief description of the SEB component parameterizations is presented below.

Incoming solar radiation at the surface is determined by using a variation of the Parameterization C model (Iqbal 1983). In this model, the solar radiation incident on top of the atmosphere is determined from earth-sun relationships and then adjusted via transmittance functions to account for atmospheric absorption and scattering. Separate transmittances are specified for (1) absorption due to (a) ozone, (b) water vapor, and (c) aerosols and for (2) scattering due to (a) Rayleigh particles (molecules) and 
(b) aerosols. In addition, the model accounts for multiple reflections of solar radiation between the ground and the atmosphere, which significantly increase solar radiation when the surface albedo is high (e.g., deserts or snow cover). Along with data on location and time, the model requires data on (1) local atmospheric pressure; (2) surface albedo; (3) visibility; (4) precipitable water content, which is derived from upper-air data; and (5) ozone amount, which is estimated from latitudinal-seasonal averages. Attenuation due to cloud cover is estimated from the opaque and total cloud cover and cloud height by a semi-empirical model that was developed by Brown (1997) from an analysis of the National Solar Radiation Database (National Renewable Energy Laboratory 1993).

Net long-wave radiation at the surface is determined by using data on surface temperature, emissivity, near-surface temperature profiles, and humidity profiles. In particular, incoming long-wave radiation is estimated on the basis of a semi-empirical relationship developed from parameterizing long-wave radiation estimates from a detailed narrow-band radiation model. This relationship relies on data on the near-ground temperature profile, 10-m water vapor pressure, cloud fraction, and cloud height. Outgoing long-wave radiation is calculated directly from ground and foliage temperatures.

At the surface, the solar radiation and incoming long-wave radiation are balanced against the (1) sensible heat transfer, (2) latent heat transfer, (3) ground conduction heat transfer, and (4) outgoing long-wave radiation. To provide a physical, unified treatment valid under both daytime and nighttime conditions, SEBMET employs a two-layer canopy model that evaluates energy transfer components from both the ground and the vegetative layer. The model is formulated by writing separate energy-balance relationships for the ground and the vegetative canopy similar to Equations 3.1 and 3.2 and by parameterizing the energy transfer components in terms of available meteorological measurements and known vegetation and ground characteristics. The vegetative layer is characterized by the leaf area index and the bulk stomatal resistance, which is a measure of the latent heat transfer resistance. The key parameter is the bulk stomatal resistance, which embodies the physiological response of the vegetation to the ambient environment. In the SEBMET canopy model, this parameter is estimated by modeling the stomatal responses to (1) ambient temperature, (2) vapor pressure deficit, (3) solar radiation, and (4) moisture stress. Evaporation from the soil is considered by defining a moisture store in the soil layer that is reduced through evaporation and replenished by precipitation. The outgoing long-wave radiation is estimated directly from the canopy and ground temperatures and the canopy coverage percentage. Heat conduction into the ground is estimated by using a numerical, finite-difference algorithm that allows the dependence of soil properties and the insulating effect of overlying vegetation and snow to be explicitly treated. Such a scheme allows the ground temperature profile to be saved for use in pool evaporation calculations in the CASRAM emission rate model. 


\subsubsection{Inversion Height and Boundary Layer Height}

The inversion height in convective condition is estimated with a one-dimensional model of the atmospheric boundary layer based on the Driedonks slab model (Driedonks 1982). In the Driedonks model, as in similar models, the surface turbulence fluxes $u *$ and $H$ are integrated over time so the boundary layer evolves from an initial early morning height. The Driedonks model was chosen because of its comprehensive treatment of dynamics at the inversion, favorable comparison with field data, and ease of inclusion in the preprocessor.

In neutral and stable conditions, the boundary layer height is less well defined. Generally, the boundary layer height, at least in stable conditions, is taken to be the height at which surface-induced turbulence drops to a negligible value. Here, the diagnostic relations for stable conditions defined by Nieuwstadt (1981) and provided by the neutral limit ( $h=0.3 u * / f$, where $f$ is the Coriolis force) are used, following the recommendations of Hanna and Paine (1989). (Hanna and Paine recommend that the neutral relation be used when $L$ is greater than or equal to 100 and that Nieuwstadt's relation be used when $L$ is more than zero but less than 100.)

\subsubsection{Water Temperature for TIHWR Reaction Rates}

As discussed in Section 3.3.3, water temperature has a significant influence on the reaction rates of water-reactive materials. In fact, the reaction rate of many materials roughly doubles for every $10^{\circ} \mathrm{C}$ increase in temperature. To account for this effect in our statistical hazardous materials analysis, we developed a database for water temperature as a function of location and Julian day. We investigated the following three sources of water temperature data.

1. Great Lakes Buoys (GLBs). Data were available from eight buoys scattered throughout the Great Lakes, whose reported temperatures yielded a multiyear average that was parameterized as a function of Julian day (Lesht and Brandner 1992).

2. U.S. Geological Survey (USGS) Water Quality Network (WQN). The USGS gathered data on stream water temperatures for periods of up to 30 years before 1990 at about 680 water stations (the WQN data). The data were for uneven durations and taken at uneven frequencies. In the best cases, monthly temperature values were recorded for a period of 20 years or more. For most stations, the day of the month and the time of day on which measurements were recorded varied, and about one month elapsed between measurements.

3. National Oceanic and Atmospheric (NOAA) Ocean Harbor Buoys. Data from a series of harbor buoys along the Atlantic and Pacific Coasts were recorded for years. Data from a representative set of locations were examined and found to substantively agree with the USGS data as a function of latitude. Therefore, the harbor buoy data were not specifically used for this study. 
We selected a set of $35 \mathrm{WQN}$ stations on the basis of several criteria. We wanted the network of stations to cover the United States evenly, or, if concentrated, to represent population centers. We needed data from a period of 20 years to permit meaningful climatological modeling. In actuality, while the target was about 240 temperature values, we chose stations that had recorded between about 150 and 450 values. With the addition of the 8 GLB stations, the total number of temperature stations we chose was 43 . The locations of the temperature stations are shown in Figure 3.9.

We used a special parameterization of average GLB values by Julian day published by Lesht and Brandner (1992) for this study. For each WQN station or harbor buoy, the full set of values was fitted to the following equation:

$$
T(J)=T_{a v g}+(\Delta T) \sin \left(2 \pi \frac{J-J_{o}}{365}\right)
$$

The values of $T_{a v g}, \Delta T$, and $J_{o}$ were fitted to all of the values. The GLBs were fitted with a six-parameter function given by Lesht and Brandner (1992). Because the formula has six adjustable constants and is somewhat detailed, it is not provided here; the original Lesht and Brandner (1992) article can be reviewed.

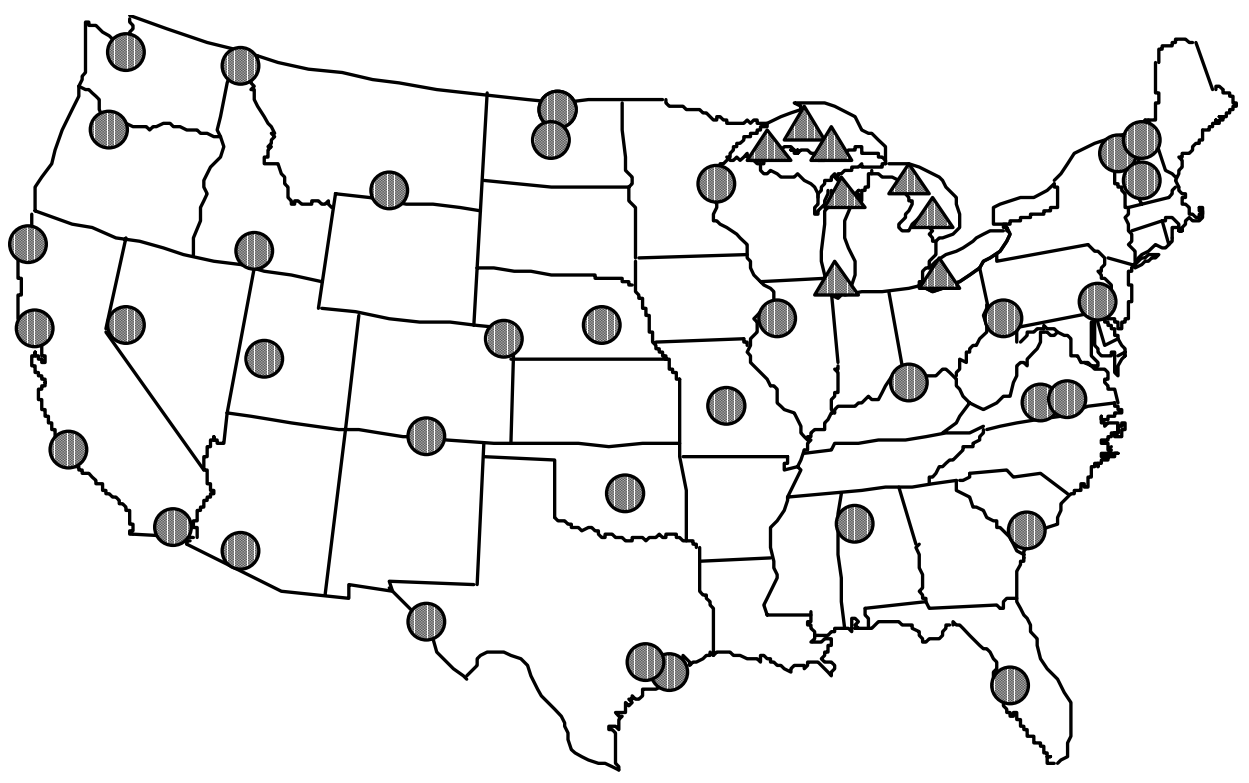

Figure 3.9 Water Quality Network Stations Used to Determine Variations of Average Water Temperature by Julian Day and Location (circles $=35$ land-based sampling sites; triangles $=8$ GLBs) 


\subsection{Emission Rate Characterization}

\subsubsection{Overview of Release Types}

Materials are shipped as solids, ordinary liquids, compressed gases or liquefied gases. The emission rate of the material to the atmosphere largely depends on the shipment state. Because of their low volatility, solids typically exhibit low emission rates. Consequently, with few exceptions, non-water-reactive materials appearing on the TIH list are liquids and gases at atmospheric pressure. The remaining shipment states and water-reactive materials are illustrated in Figure 3.10 and discussed below.

Liquid materials are emitted to the atmosphere through pool evaporation (Figure 3.10a). The pool evaporation rate depends on many factors. For volatile liquids, the governing factors, in approximate order of importance, include (1) vapor pressure of the liquid, (2) available energy, (3) wind speed, and (4) atmospheric stability. In the case of low-volatility liquids (i.e., those characterized by low vapor pressure), meteorology replaces available energy in relative importance. Highly volatile liquids can evaporate very quickly (within minutes), cooling the pool in excess of $30^{\circ} \mathrm{C}$ below the ambient

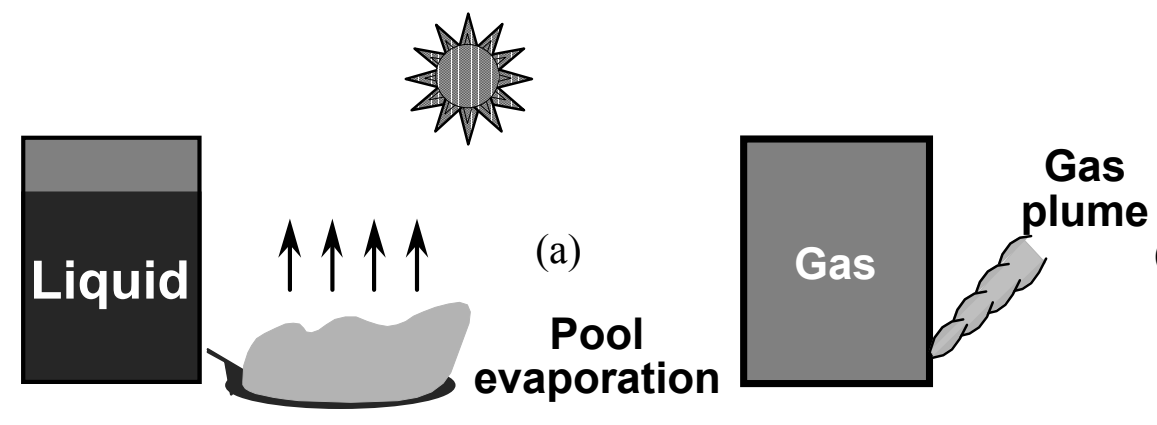

(b)

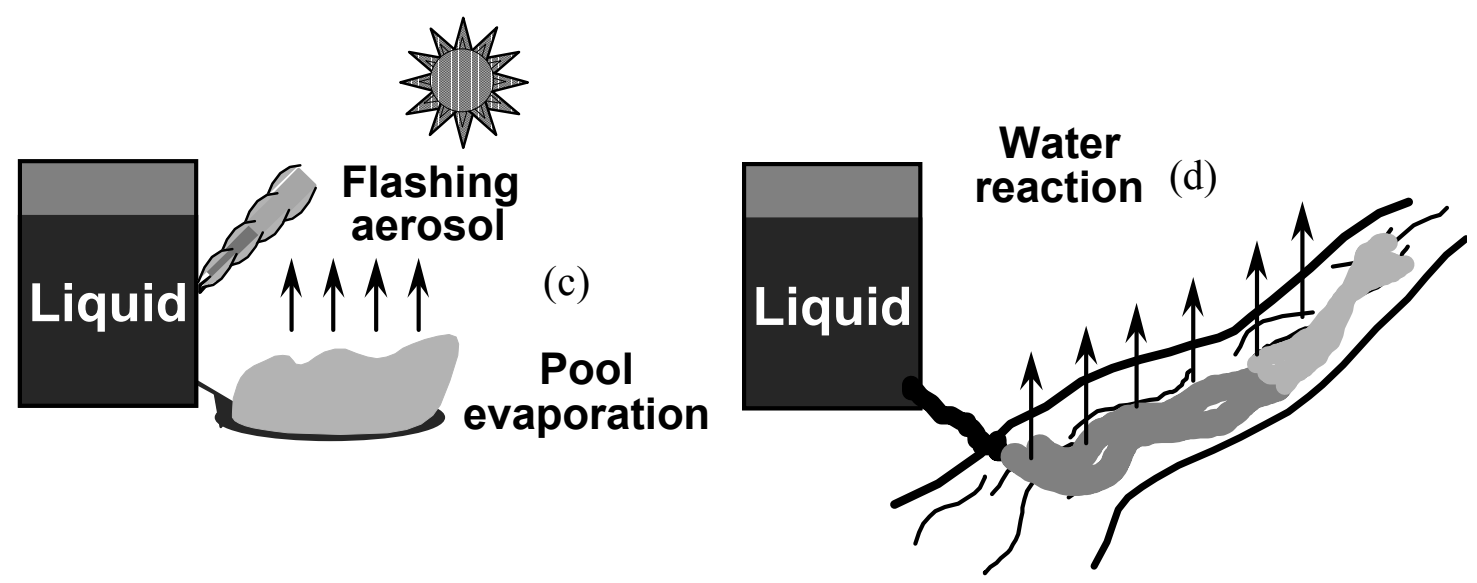

Figure 3.10 Important Source Types for Inhalation Risk Considered in the 2000ERG Analysis $(a=$ ordinary liquids, $b=$ compressed gases, $c=$ liquefied gases, $d=$ waterreactive materials) 
temperature. In such cases, the evaporating material can actually freeze, thereby lowering the evaporation rate.

Compressed gases are released in a so-called blowdown process (Figure 3.10b). This process usually empties the container rapidly and, in the case of severe accidents, may result in an almost instantaneous release. All else being equal, release rates of compressed gases are many times faster than those of ordinary liquids. The exceptions are valve leaks and minor cracks, for which release rates may be very slow. For compressed gases, valve failures are the most common release mechanism for en route/nonaccident releases.

The most catastrophic form of release involves liquefied gases (Figure 3.10c). Here, the release is broken into two phases. In the initial phase, denoted as the flashing and entrainment phase, a fraction of the material (usually 0 to $30 \%$ of the total) is instantaneously vaporized upon exiting the vessel as a result of the sudden reduction in pressure. Because the material expands rapidly, much of the remaining liquid exiting the vessel is broken into tiny drops, forming an aerosol. The vapor typically entrains substantial quantities of this aerosol with the larger droplets quickly settling to the ground or "raining out." This aerosol usually evaporates quickly when exposed to air, cooling the vapor/air mixture to a point at which the density of the mixture can become considerably heavier than air. The liquid remaining on the ground or surrounding surfaces is then released through evaporation. Since the vapor pressures for such materials are usually well above atmospheric pressure, the evaporation phase is usually short, especially in comparison with the pool evaporation phase for materials that are liquids at atmospheric pressure. Because of the large quantities of material typically involved, release rates of liquefied gases are usually higher than those of liquids and compressed gases.

An additional class of materials discussed throughout this report and treated in the 2000ERG analysis is water-reactive materials. These materials release toxic gases to the atmosphere through the reaction of a parent chemical with water. Therefore, a water-way entry or an additional water exposure mechanism is required for them to become an inhalation risk problem. Although the release rate of the toxic by-product to the atmosphere depends primarily on chemical reactivity, many other factors also influence the reaction rate. For example, whether the parent chemical is heavier or lighter than water (solids and some liquids) will affect the mixing rate and therefore the reaction rate. Highly exothermic water reactions will result in faster reactions, more turbulent mixing of water with the chemical, and more rapid introduction of the TIHWR gas to the atmosphere. Rivers are generally more turbulent than some other bodies of water, thus enhancing mixing. Chemicals that spill into nonflowing water bodies also undergo turbulent mixing, but it results from other, generally weaker, mechanisms, such as turbulence produced by heat release in exothermic reactions or wave-generated turbulence due to wind. The reaction rates of these materials also depend rather strongly on water temperature and secondarily on water acidity. 


\subsubsection{CASRAM Emission Model and Its Application to the 2000ERG Analysis}

The source component of CASRAM determines hazardous material release rates for each of the spill and/or vaporization scenarios described above. Information on the shipment, location, and meteorology are employed in the emission rate model to determine the amount of material spilled and the release rate. First the discharge fraction is estimated by using statistical distributions generated from analysis of HMIS database incidents, as discussed in Section 3.1.2. Then one or more physical models are employed to estimate chemical discharge rates and evaporation rates.

\subsubsection{Assumptions Used to Develop Accident Scenarios}

In developing the accident scenarios, the following assumptions were used:

- For accident-related releases from rail shipments (i.e., tank cars) involving a container breach ( $60 \%$ of total), the release rate of material from the container is regulated by the size of the hole, which is specified statistically according to hole size distributions presented by Raj and Turner (1993). Since no comparable data exist for highway transportation, the hole size distributions for highway bulk containers are set to those for tank car types having similar specifications (wall thickness, insulation). Total release amounts are limited to conform with discharge fraction distributions in the HMIS database by varying the location of the hole in the container.

- For en route/nonaccident incidents and for package freight accident-related incidents, release amounts are determined directly from the HMIS database release fraction distributions. For these incidents, the release is assumed to occur uniformly over a period of $15 \mathrm{~min}$. This method overpredicts the impacts from slow leaks. However, this overprediction has little effect on PAD values, since slow vapor releases typically involve the release of small amounts of material and fall well below the 90-percentile level of protection cutoff.

- Liquids released from the container that are not flashed or entrained with the flashed liquid form a pool on the ground that expands and contracts in response to gravitydriven fluid flow and evaporation. For highway-related releases, $50 \%$ of spills are assumed to occur on paved surfaces. For rail releases, $25 \%$ of spills are assumed to occur on pavement or roadbed. All other spills are assumed to occur on natural surfaces characteristic of the accident locale. Ground temperature profiles to a depth of $1 \mathrm{~m}$ are provided in the preprocessed meteorological database.

- The discharge rate of water-reactive materials from their containers is varied so that $18 \%, 40 \%, 60 \%$, and $95 \%$ of the total release amount is discharged in the first 5,15 , 30 , and $60 \mathrm{~min}$, respectively. The total release amounts are selected to conform with discharge fraction distributions in the HMIS database. The time-dependent emission 
rate of the TIH by-product from the water is calculated from the container release rate and the reaction rate of the chemical with water.

- Except for the reaction of water-reactive materials to produce TIH by-products, chemical transformation is not considered.

- The temperature of the material upon release is taken as a weighted average of the air temperature and $290 \mathrm{~K}$, with the exact weight depending on the container type.

\subsubsection{Physical Considerations}

\section{Discharge from Tanks}

In CASRAM, tanks that are punctured below the liquid line release their contents according to the Bernoulli equation (Perry et al. 1984); namely,

$$
Q=c_{o} A_{h} \rho_{l}\left[2 g \Delta h+2\left(\frac{P_{t}-P_{a}}{\rho_{l}}\right)\right]^{\frac{1}{2}},
$$

where

$$
\begin{aligned}
& Q=\text { liquid release rate }(\mathrm{kg} / \mathrm{s}), \\
& c_{O}=\text { discharge coefficient, } \\
& A_{h}=\text { hole area }\left(\mathrm{m}^{2}\right), \\
& \rho_{l}=\text { liquid density }\left(\mathrm{kg} / \mathrm{m}^{3}\right), \\
& g=\text { gravitational acceleration }\left(9.81 \mathrm{~m} / \mathrm{s}^{2}\right), \\
& \Delta h=\text { height of liquid above the hole }(\mathrm{m}), \\
& P_{t}=\text { tank pressure }(\mathrm{Pa}), \text { and } \\
& P_{a}=\text { atmospheric pressure }(\mathrm{Pa}) .
\end{aligned}
$$

In CASRAM, $c_{o}$ is set to 0.6 for all releases.

Equation 3.4 is used to calculate the discharge rates from all bulk containers in CASRAM, where $A_{h}$ is provided by the hole size distributions given by Raj and Turner (1993). If the material is a liquid, it forms a pool on the ground or pavement, which expands and contracts in response to gravity-driven fluid flow and evaporation. Liquefied gases, on the other hand, equilibrate to atmospheric pressure through flashing (explosive evaporation of a fraction of the released material). A fraction of the remaining 
material is aerosolized and entrained in the flashed vapor, and the remaining material falls to the ground and evaporates.

\section{Pool Evaporation}

The release rate of material from an evaporating pool is represented such that

$$
Q=A_{p} E_{c}
$$

where

$$
\begin{aligned}
& A_{p}=\text { pool area }\left(\mathrm{m}^{2}\right) \text { and } \\
& E_{c}=\text { evaporation rate from the pool }\left(\mathrm{kg} / \mathrm{m}^{2}\right) .
\end{aligned}
$$

Pool evaporation in CASRAM is determined by using a time-dependent, energy budget model that considers heat transfer to and from the pool via radiation, convection, conduction, and evaporation. Conductive heat flux from the ground is especially important and is often the dominant source of available energy, especially for very volatile liquids. Treating conduction correctly, especially the initial and boundary conditions, was a principal motivation in the development of the CASRAM evaporation model.

The energy budget of the pool is a balance between solar radiation $S$, incoming longwave radiation $L^{+}$, outgoing long-wave radiation $\varepsilon_{p} \sigma T_{p}^{4}$, convective heat transfer $H_{p}$, latent heat transfer of water vapor from plant material $\lambda E_{w p}$, conductive heat transfer to ground $G_{p}$, chemical evaporation rate $h_{f g} E_{c}$ (subscript $p$ variables refer to pool-specific quantities), and energy storage $\mathrm{mc}_{\mathrm{p}}\left(\mathrm{dT}_{\mathrm{p}} / \mathrm{dt}\right)$. Therefore, the pool energy budget is

$$
Q_{p}^{*}=H_{p}+\lambda E_{w p}+G_{p}+h_{f g} E_{c}+m c_{p} \frac{d T_{p}}{d t},
$$

where

$$
\begin{aligned}
& m=\text { liquid mass of pool }\left(\mathrm{kg} / \mathrm{m}^{2}\right) \text { and } \\
& c_{p}=\text { specific heat of liquid }(\mathrm{kJ} /[\mathrm{kg} \times \mathrm{K}])
\end{aligned}
$$

and where $Q_{p}^{*}$ is the net radiation given by

$$
Q_{p}^{*}=\left(1-\alpha_{\mathrm{p}}\right) S+L^{+}+\varepsilon_{p} \sigma T_{p}^{4}
$$

and $G_{p}$ is the ground heat flux to the pool given by Fourier's law as 


$$
G_{p}=-k_{g}\left(\frac{d T}{d z}\right)_{z=0}
$$

In these relationships, $\varepsilon_{p}$ is the pool emissivity, $\alpha_{p}$ is the pool albedo, and $k_{g}$ is the ground or surface conductivity. The necessary transfer coefficients for evaporation are provided by a chemical property database and the preprocessed meteorological database discussed in the Section 3.2. In particular, the meteorological quantities of interest include aerodynamic resistances based on stability and wind speed, air temperature, incoming solar and long-wave radiation, and the initial ground temperature profile.

\section{Compressed Gas Releases}

In CASRAM, compressed gas releases are modeled by using semi-empirical blowdown relationships based on compressible-flow theory. Releases are assumed to be isentropic rather than isenthalpic. The isentropic assumption is that heat transfer to the vessel is negligible, which is a reasonable approximation for most accidental releases. The isenthalpic approximation, on the other hand, requires sufficient heat transfer to maintain isothermal conditions (assuming $c_{p}$ is constant).

For compressed gas releases, the release rate is calculated on the basis of hole size, tank pressure, and gas density such that

$$
Q=c_{o} A_{h}\left[P_{t} \rho_{g} \gamma\left(\frac{2}{\gamma+1}\right)^{\frac{\gamma+1}{\gamma-1}}\right]^{\frac{1}{2}}
$$

where $\gamma$ is the specific heat ratio $c_{p} / c_{v}$. As in the case of liquid releases, $c_{0}$ is set to 0.6 for all releases.

Equation 3.9 is applicable until the tank pressure drops below a critical value, given as

$$
P_{r}=\left(\frac{\gamma+1}{2}\right)^{\frac{\gamma}{\gamma-1}}
$$

where $P_{r}$ is ratio of the tank pressure to atmospheric pressure. After this criterion is reached, the discharge rate is given by

$$
Q=c_{o} A_{h}\left[P_{t} \rho_{g}\left(\frac{2 \gamma}{\gamma-1}\right)\left(P_{r}^{-\frac{2}{\gamma}}-P_{r}^{-\frac{\gamma+1}{\gamma}}\right)\right]^{\frac{1}{2}} .
$$

Calculations are conducted iteratively by adjusting the tank pressure and density at each time step with the isentropic assumption. 


\section{Liquefied Gas Releases}

Liquefied gas releases are treated by first calculating the liquid release rate from the container given by Equation 3.4. As discussed previously, this material either flashes to vapor, is aerosolized and entrained with the vapor, or remains liquid and falls to the ground. This flash fraction $f$ is given by

$$
f=\frac{c_{p}\left(T_{t}-T_{b}\right)}{h_{f g}},
$$

where $T_{t}$ is the tank temperature and $T_{b}$ is the boiling point. This fraction of remaining material that is aerosolized and entrained into the flashed vapor is calculated by using empirical relationships based on the discharge kinetic energy of the two-phase mixture. Released material that does not flash to vapor or become entrained in the vapor clouds is deposited on the ground. Evaporation of the remaining material is then estimated by using the pool evaporation algorithms.

\subsubsection{Water-Reactive Materials}

For water-reactive materials, a different method is needed to estimate TIH emission rates to the atmosphere. Because of the myriad of water body types, reaction scenarios, and release mechanisms; the general lack of historical data on water entry releases; the inadequate characterizations of water body turbulence and mixing; and the lack of experimental data to validate sophisticated water reactivity models, treatment of all possible incident scenarios is not possible. It was therefore necessary to develop a simplified general approach for assessing the level of public protection required for each spill. This general framework will be expanded in future work, as new data on water reaction rates and accident scenarios become available.

The basic formula employed to compute the release rate of the TIHWR gas is

$$
Q=M_{o} f_{S} \varepsilon C\left(1-e^{-C t}\right),
$$

where

$$
\begin{aligned}
& Q=\text { release rate of TIHWR product }(\mathrm{kg} / \mathrm{s}), \\
& M_{O}=\text { initial mass of parent chemical released into water, } \\
& f_{S}=\text { maximum stoichiometric yield }(\mathrm{kg} \text { TIHWR } / \mathrm{kg} \text { parent chemical), } \\
& \varepsilon=\text { efficiency factor for the reaction }(0 \leq \varepsilon \leq 1), \text { and } \\
& C=\text { primary rate coefficient for water reaction }\left(\mathrm{s}^{-1}\right)
\end{aligned}
$$


If the parent chemical is released over a significant period of time rather than suddenly, this formula yields values for $\Delta Q$ that result from the appropriate time decay for each $\Delta M(t)$ released.

Experimental data for $\varepsilon$ or $C$ in Equation 3.13 are very rare in the chemical literature. An extensive search of the literature at libraries and through on-line Chemical Abstracts yielded only qualitative descriptions of water reactivity for most of the TIHWR materials identified. Such descriptions allow only a crude estimate of either parameter, good to perhaps a level of 0.2 or 0.3 in a range from 0 to 1.0. Moreover, troubling inconsistencies in these qualitative descriptions were found in different literature sources. In several cases, the descriptions disagreed with the direct experience of at least one of the authors. We could not find any examples in which the deliberate release of a bulk chemical into a relatively large amount of water had been followed by the measurement of TIHWR production amounts.

Consequently, we conducted a modest series of direct experiments on 21 representative chemicals to shed light on classes of TIHWR chemicals. Of necessity, these experiments were small in scale and ignored important issues that would need to be addressed if results were to be scaled up to the size of transportation spills. Nevertheless, the experiments greatly increased the accuracy of estimates of $\varepsilon$. They also provided a direct measure of $C$, which is even harder to estimate from the qualitative descriptions.

On the basis of results from the experiments, we were able to delete about 10 chemicals from the TIHWR list, either because no reaction was observed or because the $\mathrm{TIH}$ gas that was released was readily reabsorbed into the water. This latter effect may not occur when large quantities are involved, and future experiments could show the net amount of TIHWR that would escape would require protective action. However, since TIHWR gas is absorbed so rapidly in small quantities, we expect that larger quantities would not pose great danger.

A review of literature on TIHWR chemicals showed that only two aspects of water quality seemed likely to influence their reactions in water: acidity and temperature. For a few chemicals, the presence of acidity was reported to increase the speed and degree of the reaction. However, the characterization of these effects was not well developed. Because of the poor characterization of these effects and the difficulty of obtaining water acidity data for natural water bodies, we did not attempt to account for water acidity variations in the 2000ERG analysis. The effect of temperature is substantially stronger than acidity, however. The reaction rate of many materials roughly doubles for every $10^{\circ} \mathrm{C}$ increase in temperature. Fortunately, the temperature of natural water bodies is well characterized by a network of water quality stations and buoys, as discussed in Section 3.2.3. The temperature dependence of the primary rate constant $C$ was included in the analysis via the Arrhenius equation, written as

$$
C=C_{o} \exp \left[-6610\left(\frac{1}{T_{w}}-\frac{1}{T_{o}}\right)\right],
$$


where $T_{o}=20^{\circ} \mathrm{C}$ and $T_{w}$ is water temperature determined by the procedures outlined in Section 3.2.3. The chemical-specific constant $C_{o}$ was determined experimentally. In applying this relationship, the rate constant $C$ for a given hypothetical spill was specified by finding $T_{w}$ on the Julian day of the simulated accident at the nearest WQN or GLB station. Then the Arrhenius formula was applied to the rate constant listed as the constant $C_{O}$ in Table D. 1 in Appendix D.

\subsection{Analysis of Atmospheric Dispersion}

Hazardous material releases that occur during transportation accidents are typically at ground level. The ground-level concentration that occurs downwind of the release site decreases with distance as the plume (or puff in the case of instantaneous releases) spreads horizontally and vertically. In the dispersion modeling phase of the problem, the emission rate and the prevailing meteorology are employed to estimate the chemical concentration field downwind of the release point. For this study, the maximum concentration, which occurs on the plume centerline, is of primary interest, since it governs the required PADs for a given material.

For passive dispersion (i.e., dispersion in which buoyancy of the plume is insignificant), downwind concentrations are linearly related to (1) the release rate if the release is continuous or (2) the release amount of the release is instantaneous. The dependence of meteorology on dispersion is modeled by evaluating the effects of wind, temperature, cloud cover, solar radiation, and other factors on critical turbulence and structural parameters of the atmospheric boundary layer. The key parameters include wind speed, friction velocity, surface heat flux, and boundary layer or inversion height.

The dispersion method used in the 2000ERG analysis differs substantially from the method that was used in preparing the 1996 ERG. First, for the later analysis, we adopted the vertical dispersion model of Brown (1997), which is applicable for calculating ground-level concentrations from near-ground releases. This passive dispersion model is considerably more sophisticated than the one employed in the 1996 analysis and results in predictions that are significantly different on an individual (case-by-case) basis. However, on a total basis (when the entire spectrum of incidents considered in the analysis of PAD values is considered), these differences are relatively minor and do not change the PAD values by more than $10 \%$. A second significant difference in the two methods involves the incorporation of a dense gas dispersion module into the CASRAM framework for the 2000ERG analysis. The dense gas model is employed mainly for those liquefied gas releases in which cooling of the plume and aerosol entrainment increase the plume density to the point where the passive dispersion assumption is no longer valid. For many liquefied gases, especially those that are highly toxic, dense gas dispersion models provide results very similar to those from passive gas dispersion models in terms of PADs. For a narrow class of less toxic liquefied gases such as ammonia, implementation of the dense gas model does have a more substantial effect. 


\subsubsection{Overview of Atmospheric Dispersion}

\subsubsection{Diurnal Aspects of Plume Dispersion}

The physical processes governing the development and maintenance of the atmospheric boundary layer (ABL) are very different during day and night, leading to boundary layers with extremely different sizes and characters. These marked differences substantially influence the ability of the ABL to disperse pollutants released near the ground, thereby giving rise to the pronounced differences in downwind concentrations and therefore in PAD values appearing in the Table. This section briefly describes the characteristics that distinguish the daytime and nighttime ABLs and elucidates how these variations lead to the differences in PAD values between the two cases.

The unstable or convective boundary layer (CBL), typical of daytime conditions, is shown in Figure 3.11a. The boundary layer structure is a result of the surface heating caused by solar radiation. This heating destabilizes the lower layers of the ABL, producing large convective cells. These convective cells extend vertically to the lowest temperature inversion, and they efficiently transport heat, momentum, and any material contaminants released into the atmosphere. As the day progresses, the temperature inversion marking the top of the boundary layer rises from near the ground to between 0.5 and $4 \mathrm{~km}$ above the surface as a result of the entrainment of stably stratified air above the inversion into the cooler air of the boundary layer below.

An example of a dispersing plume in a typical CBL is pictured in Figure 3.11b. Experimental observations, most notably those of Willis and Deardorff (1976), have indicated that vigorous convection, which typifies the CBL, results in a "rising centerline" phenomenon. In this process, energetic thermals lift the plume or cloud off the ground faster than it disperses downward. This consequence of dispersion in a fully convective boundary layer is primarily responsible for the rapid decay of material concentrations downwind from ground-level sources when the release occurs in the middle of the day.

In the absence of solar heating, the nighttime ABL structure is driven by cooling at the surface as heat is radiated to space. This situation leads to the development of a stably stratified boundary layer (SBL), which is typically much shallower and less energetic than its unstable counterpart, as illustrated in Figure 3.12a. The surface cooling strongly stratifies the low-level air, thereby creating a tenuous balance between the turbulence produced by wind shear and turbulent energy dissipation. The rapid dissipation of turbulent energy greatly limits the vertical eddy size and restricts vertical mixing.

Dispersion in a typical SBL is pictured in Figure 3.12b. The vertical stability and shallow depth profoundly affect dispersion processes by confining material contaminants 

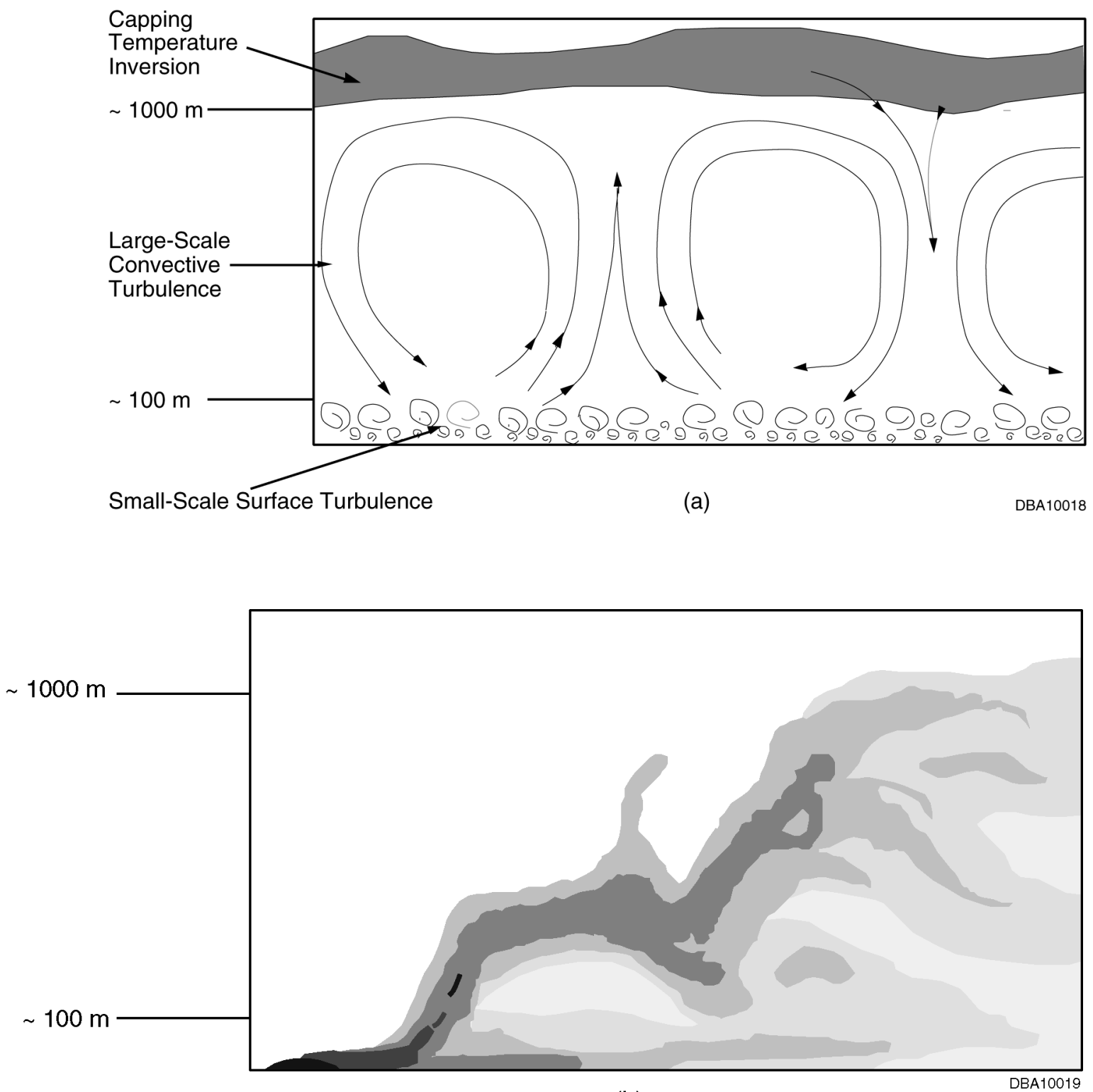

(b)

Figure 3.11 Typical Daytime Convective Boundary Layer Showing (a) an Instantaneous Wind Field and (b) an Instantaneous Material Concentration Field from a Ground-Level Release (characteristic height of about $1,000 \mathrm{~m}$ for the boundary layer and about $\mathbf{1 0 0} \mathrm{m}$ for the surface layer provided for reference) 


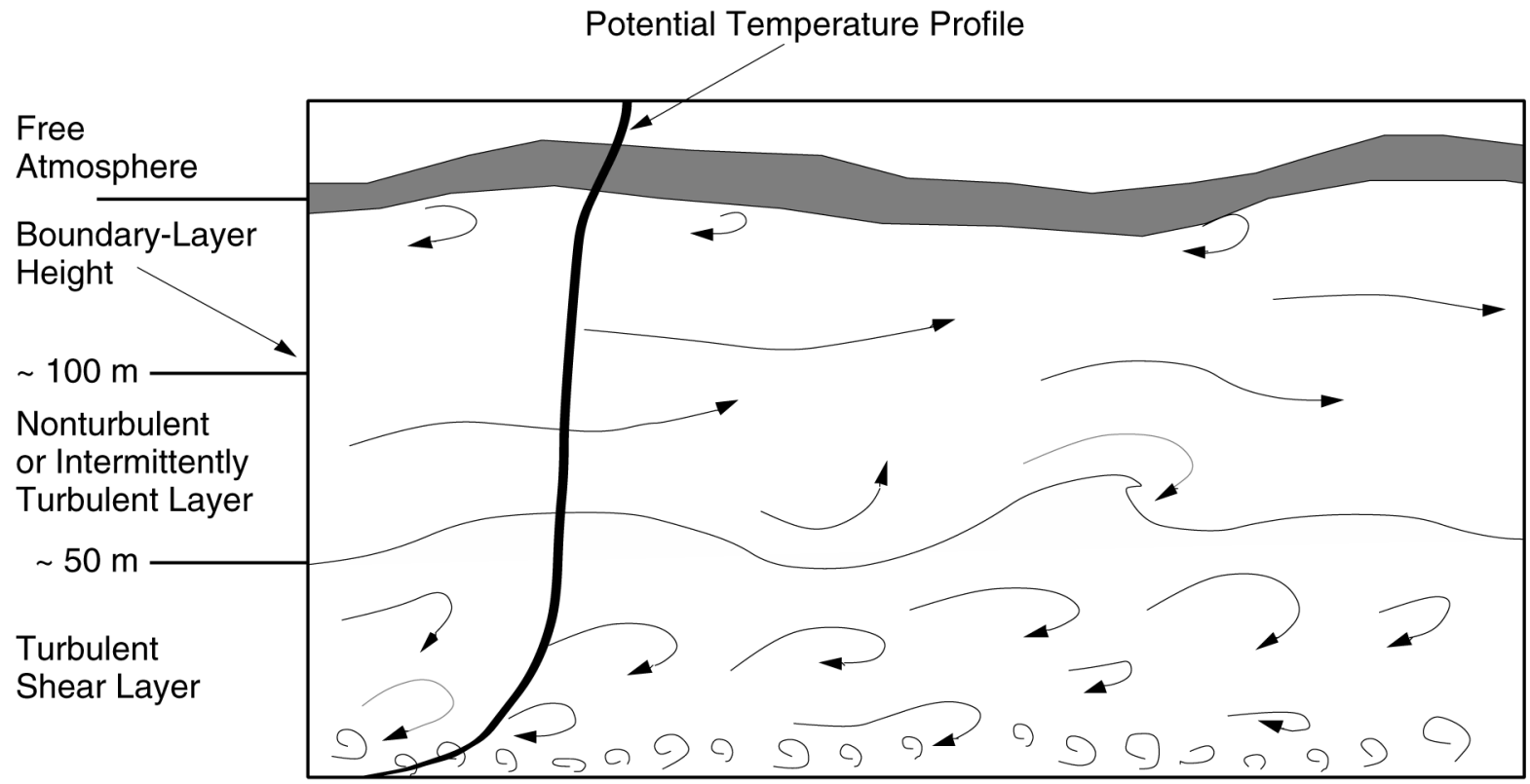

(a)

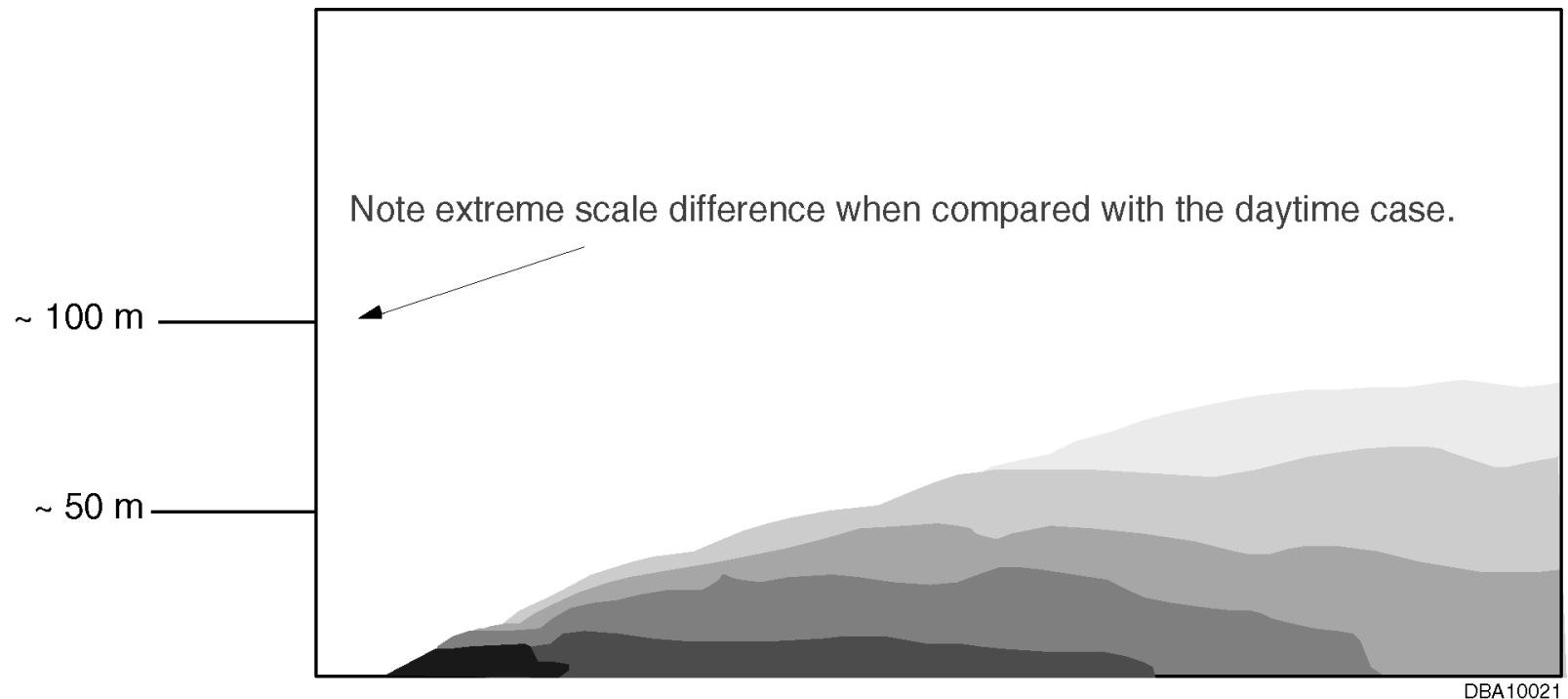

(b)

Figure 3.12 Typical Nighttime Stable Boundary Layer Showing (a) an Instantaneous Wind Field and (b) an Instantaneous Material Concentration Field from a Ground-Level Release (characteristic height of about $50 \mathrm{~m}$ for the surface shear layer and about $\mathbf{1 0 0} \mathrm{m}$ for the boundary layer provided for reference) 
to a thin layer near the ground. In very stable conditions, such as those represented in the 90-percentile level of safe distance distributions, the SBL is usually less than $50 \mathrm{~m}$ deep. When a contaminant is released into the SBL, it diffuses to its maximum vertical extent in a relatively a short distance, forcing most of the dispersion to occur two-dimensionally along the ground. This plume confinement allows comparatively high concentrations to be observed near the surface at considerable distances from the release site, leading to the PADs that are further from the source than are necessary for daytime incidents.

\subsubsection{Effects of Dense Gas on Plume Dispersion}

The discussion of atmospheric dispersion to this point has been confined to passive dispersion (i.e., cases in which the density of the ambient plume does not affect its dispersion). However, in many cases of practical interest, the effect of a high density (relative to air) of the hazardous chemical discharge becomes important in considering impacts within 1 to $2 \mathrm{~km}$ of the release point. So-called dense gas effects result not only from the properties of the material released but also from the methods of storage and the conditions of the release. Most cases of interest have focused on combustibles or toxic compounds that have boiling points below ambient temperature. These compounds are commonly transported or stored as liquids and then maintained in liquid phase (1) at or near their saturation temperature at atmospheric pressure by refrigeration and insulation (i.e., refrigerated liquid) or (2) at ambient temperature by pressurization (i.e., pressurized liquid or liquefied gas). For transportation incidents, cases that could lead to significant dense gas effects fall into one or more of the following broad categories:

- Chemicals with a high molecular weight when compared with air (e.g., chlorine, arsine) coupled with a large release quantity or high release rate (i.e., $>1 \mathrm{~kg} / \mathrm{s}$ );

- Refrigerated chemicals with a relatively low molecular weight when their temperature upon release is cold relative to the ambient temperature (e.g., a cold methane release evolving from the boiling of refrigerated liquefied natural gas);

- Pressurized liquids containing chemicals with a low to moderate molecular weight that, although they are less dense than air at their boiling point, cool rapidly and entrain aerosol generated in the release process, thereby creating a denser-than-air plume; and

- Chemicals that undergo molecular association (hydrogen fluoride [HF]) and/or transform to secondary hazardous compounds because of their ambient water-vapor reactivity (e.g., sulfur trioxide $\left[\mathrm{SO}_{3}\right] /$ oleum, nitrogen tetroxide $\left[\mathrm{N}_{2} \mathrm{O}_{4}\right]$ ). (These are not necessarily the same group of compounds that are water-reactive as defined in this report.)

Several major effects can be observed during the dispersion of a ground-level, dense gas cloud that do not occur during the dispersion of a neutrally buoyant cloud. One is that there is less vertical turbulent mixing between the dense gas cloud and the ambient atmosphere because of the stable density stratification of the cloud relative to the 
surrounding ambient air. Another is the presence of gravity-induced flow resulting from horizontal density gradients. These two effects result in a shallower and much wider cloud than the cloud that results from an analogous neutral density release. In addition, the movement of the dense gas cloud on uneven terrain can follow the downhill slope independent of the wind direction, and the cloud can become trapped in valleys or low spots. The magnitude of these dense gas effects depends on the size of the release, local meteorological conditions, and the physical properties of the chemical release.

\subsubsection{CASRAM Dispersion Model}

\subsubsection{Passive Dispersion}

Like many other dispersion models, CASRAM separates the dispersion calculation into two components: horizontal dispersion and vertical dispersion. In CASRAM, vertical turbulent dispersion is treated with a Lagrangian-integral model parameterized in terms of mean plume height, average advection velocity, and a dimensionless travel time. These parameters are expressed as integral equations written in terms of plume travel time and atmospheric boundary layer parameters. Continuous releases are treated as plumes, and instantaneous releases are treated as puffs. Horizontal turbulent dispersion is represented via Gaussian relationships that are parameterized in terms of the Lagrangian time scale and lateral wind direction fluctuations. Plume calculations are straight line in nature, since terrain effects are not currently considered in CASRAM.

The concentration relationship for continuous plume releases from point sources is represented in terms of the crosswind-integrated concentration (CWIC), chemical mass release rate $Q$, and traditional Gaussian expression for the horizontal plume spread. The ground-level concentration distribution is computed as follows:

$$
C(x, y, z=0)=\frac{Q \hat{C}_{y}(x, z=0)}{\sqrt{2 \pi} \sigma_{y}} \exp \left[-\left(\frac{y}{\sqrt{2} \sigma_{y}}\right)^{2}\right]
$$

where

$$
\begin{aligned}
& \hat{C}_{y}=\text { CWIC normalized by the release rate, } \\
& \sigma_{y}=\text { lateral plume spread, and } \\
& y=\text { lateral distance from the plume centerline. }
\end{aligned}
$$

For time-variant evaporative emissions, the release rate is taken to be the average over the exposure time corresponding with the toxicological value.

For releases with finite width, corresponding to large pools releases or dense gas releases as they become passive, the following expression is used: 


$$
C(x, y, z=0)=Q \hat{C}_{y}(x, z=0)\left(\operatorname{erf}\left[\frac{y_{o}-y}{\sqrt{2} \sigma_{y}}\right]+\operatorname{erf}\left[\frac{y_{o}+y}{\sqrt{2} \sigma_{y}}\right]\right) .
$$

Peak concentration averages resulting from instantaneous releases are calculated according to the relationship

$$
C(x, y, z=0)=\frac{M \hat{C}_{y}(x, z=0)}{\sqrt{2 \pi} \sigma_{y} T} \operatorname{erf}\left[\frac{\mathrm{U}}{2 \sqrt{2} \sigma_{y}}\right] \exp \left[-\left(\frac{y}{\sqrt{2} \sigma_{y}}\right)^{2}\right]
$$

where

$$
\begin{aligned}
& M=\text { total release amount }, \\
& T=\text { averaging time, and } \\
& U=10-\mathrm{m} \text { wind speed. }
\end{aligned}
$$

The subsections below first present the methodology for determining vertical dispersion (i.e., for determining $C_{y}$ as a function of downwind distance). They then discuss the determination of $\sigma_{y}$, thus providing horizontal dispersion.

\section{Vertical Dispersion}

This discussion of the vertical dispersion model begins with a review of the surfacelayer, similarity-based model of van Ulden (1978), since our approach represents a natural extension of this model. The van Ulden approach centered around writing an exact solution of the advection-diffusion equation. When written in terms of the CWIC form and neglecting stream-wise diffusion, it reads as follows:

$$
U(z) \frac{\partial C_{y}}{\partial z}=\frac{\partial}{\partial z}\left[K_{z}(z) \frac{\partial C_{y}}{\partial z}\right]
$$

where $K_{z}$ is the vertical diffusivity for a scalar. The solution van Ulden advances is written in terms of the mean plume height $\bar{z}$, the average plume advection velocity $\overline{U_{p}}$, and the power-law wind speed coefficient $m$ and diffusivity coefficient $n$. The coefficients $m$ and $n$ are defined such that

$$
U(z)=u_{o} z^{m}
$$

and 


$$
K_{z}(z)=k_{o} z^{n},
$$

where $u_{o}$ and $k_{o}$ are constants representing the wind speed and diffusivity at $1 \mathrm{~m}$. From the early work of Roberts (1923), it is well known that the advection-diffusion equation subject to the above power-law relationships yields an exact solution (see Calder 1949). The work of van Ulden (1978) extends this analysis by using the power-law coefficients to determine the concentration profile shape a priori (i.e., from the Roberts analysis) and then formulates integral relationships for the mean plume height and average advection velocity in terms of the more physically correct similarity functions for wind speed and diffusivity. The van Ulden (1978) solution reads as follows:

$$
\hat{C}_{y}(x, z)=\frac{A}{\bar{z} \bar{U}_{p}} \exp \left[-\left(\frac{B z}{\bar{z}}\right)^{s}\right],
$$

where

$$
\begin{gathered}
A=\frac{s \Gamma(2 / s)}{\Gamma(1 / s)^{2}}, \\
B=\frac{\Gamma(2 / s)}{\Gamma(1 / s)},
\end{gathered}
$$

and $s$ is a shape parameter given by $1-m-n$. In Equations 3.22 and 3.23, $\Gamma$ represents the gamma function.

In applying this model, van Ulden (1978) parameterized the mean plume height and average advection velocity by using surface-layer similarity functions for wind speed and diffusivity. In a subsequent study, Gryning et al. (1983) extended this analysis by adding a sophisticated relationship to determine the shape parameter $s$ as a function of stability and downwind distance. The relationships for $s$ were determined through analysis of numerical solutions for the advection-diffusion equation for a wide range of conditions. In a detailed model-data comparison that used CWIC data from the Prairie Grass experiments (Barad 1958), Gyning and colleagues demonstrated the utility of the Lagrangian empirical model in representing the concentration profile as well as in estimating ground-level concentrations. This model provided an excellent description of dispersion in the surface layer. However, its application is limited to dispersion problems in which the plume is mainly confined to the surface layer. When the plume rises above the surface layer, the concentration profile given by Equation 3.21 as well as the similarity relationships for $\bar{z}$ and $\overline{U_{p}}$ become invalid. For problems of practical interest, this rather severe constraint on the use of Equation 3.21 strongly limits the applicability of the model for problems of practical interest. 
Brown (1997) modified the original van Ulden work to correct this limitation. In this revised formulation, the normalized ground-level concentration is expressed as

$$
\hat{C}_{y}(x, z=0)=\frac{A^{\prime}(\tilde{s}) F\left(x ; u_{*}, z_{i}, H_{s}\right)}{z_{u} \bar{U}_{p}}
$$

where $z_{u}$ is defined such that

$$
U\left(z_{u}\right)=\overline{U_{p}},
$$

and

$$
A^{\prime}(\tilde{s})=\frac{1.6 \tilde{s} \Gamma(2 / \tilde{s})}{\Gamma(1 / \tilde{s})^{2}}
$$

Here, $A^{\prime}$ takes the same functional form as $A$ in van Ulden's model, except that it is multiplied by 1.6 to account for the ratio of $\bar{z}$ to $z_{u}$ and depends on a modified shape parameter denoted as $\tilde{s}$.

The main departure of this approach from the models of van Ulden and Gryning et al. is in the boundary-layer function $F$. This function is added to treat dispersion within the greater ABL outside the surface layer. As previously noted, the van Ulden model was developed by using the quasi-exponential concentration profile. For surface-layer dispersion, this assumed form for the concentration profile adequately represents the concentration profiles observed in field studies, most notably the Prairie Grass experiments. However, once the plume is influenced by boundary-layer effects outside of the surface layer, the concentration profiles depart significantly from the exponential form. In unstable conditions, this departure is particularly pronounced, since the plume centerline actually lifts off the ground, creating a maximum concentration aloft. In stable conditions, the opposite effect is observed, in which the concentration profile is flattened as a result of the rapid decrease in turbulent energy with height. The transition function $F$ allows us to adapt this methodology, which was originally developed to model surfacelayer dispersion, to treat dispersion throughout the entire ABL.

Brown (1997) developed relationships for $z_{u}, \widetilde{s}$, and $F$ by using a parametric analysis of a Langevin-equation Monte Carlo dispersion model validated with data from field and laboratory experiments. In applying the CASRAM vertical dispersion model, $\widetilde{s}$ is a function of meteorology and therefore does not vary with distance, and $F$ is represented as a function of travel time and meteorology. The heart of the calculation lies in $z_{u}$, which is calculated by using integral relationships represented as a function of travel time. Numerical integration of this relationship provides $z_{u}$ as a function of downwind 
distance, which, together with $\widetilde{s}$ and $F$, allows the evaluation of Equation 3.24 and ultimately Equation 3.15, 3.16, or 3.17.

\section{Horizontal Dispersion}

Under horizontal homogeneous conditions, the Gaussian model correctly represents lateral concentration distributions. In CASRAM, the lateral spread from nonbuoyant releases can be related to the standard deviation of the horizontal wind fluctuations and is determined by using relationships originally proposed by Draxler (1976). Here, $\sigma_{y}$ is given by

$$
\sigma_{y}=\sigma_{v} f_{y}\left(\frac{t}{T_{d}}\right),
$$

where

$$
\begin{aligned}
& \sigma_{v}=\text { standard deviation of transverse velocity, } \\
& t=\text { transit time (estimated by using wind speed at } 2 \mathrm{~m} \text { and distance), } \\
& T_{d}=\text { dispersion time scale related to the Lagrangian time scale, and } \\
& f_{y}=\text { a nondimensional function of travel time. }
\end{aligned}
$$

The empirical form of $f_{y}$ is estimated through evaluating field data. Several forms of $f_{y}$ have been proposed (Irwin 1983; Gryning and Lyck 1984), but the empirical expression that provides the best overall fit with available field data is the form proposed by Draxler (1976). His function is given by

$$
f_{y}=\frac{1}{1+0.9 \sqrt{t / T_{d}}}
$$

For surface releases, a $T_{d}$ of $300 \mathrm{~s}$ is used for unstable conditions and a maximum of $300 \mathrm{~s}$ or $0.001 t^{2} \mathrm{~s}$ is used for stable conditions. The appeal of Draxler's relation is that it is developed from diffusion data from many experiments and that it is consistent with Taylor's limit for both small $\left(\sigma_{y} \sim t\right)$ and large $\left(\sigma_{y} \sim t^{1 / 2}\right)$ travel times (Taylor 1921).

Equation 3.27 requires the standard deviation of transverse velocity $\sigma_{v}$. In the absence of observational data, $\sigma_{v}$ is determined by using the interpolation equation of Panofsky et al. (1977)

$$
\sigma_{v}=u_{*}\left(12-0.5 \frac{z_{i}}{L}\right)^{1 / 3}
$$


during unstable conditions and the proportionality relation of Panofsky and Dutton (1984)

$$
\sigma_{v}=1.92 u_{*}
$$

during stable conditions.

In very stable conditions, Equation 3.30 fails to adequately represent $\sigma_{v}$, since wind speed and friction velocity become very small. For instance, if the friction velocity is about $0.015 \mathrm{~m} / \mathrm{s}$, indicative of a wind speed of about $0.5 \mathrm{~m} / \mathrm{s}$ with $z_{O}=0.1 \mathrm{~m}$ on a clear night, Equation 3.30 predicts $\sigma_{v}=0.03 \mathrm{~m} / \mathrm{s}$. One kilometer from the source, this value of $\sigma_{v}$ yields $\sigma_{y}=36 \mathrm{~m}$ from Equation 3.27. Considering the 2,000-s travel time, such a narrow plume width is not realistic when the meandering nature of stable boundary layer flows is considered. To overcome this problem, we assign a minimum value of $0.15 \mathrm{~m} / \mathrm{s}$ for $\sigma_{v}$ on the basis of observations presented by Hanna and Chang (1992).

\subsubsection{Dense Gas Dispersion}

Early in development of CASRAM, consideration was given to the issue of treating or not treating dense gas effects. Our analysis at that time showed that although dense gas effects are indeed important for large releases of certain liquefied gases, the effects are less important than other factors in the overall analysis (meteorology, release amount and rate, etc.) for hazard zone prediction. Since that original unpublished work was done, several dense gas algorithms have been found to perform well when compared with available experimental data. Also, because dense gas submodels are now included in more than 100 models applicable to hazardous materials releases, CASRAM's omission of dense gas effects has been increasingly identified as a significant shortcoming of the model, thus blocking its broader acceptance in the scientific community.

To address these concerns, a dense gas algorithm was added to the CASRAM methodology as part of the 2000ERG study after a detailed review of available dense gas algorithms models. The review identified five dense gas models that were well documented and would be applicable within the CASRAM framework: DEGADIS (Havens 1988), HEGADAS (Post 1994), SLAB (Ermak 1990), SCIPUFF (Defense Threat Reduction Agency 1999), and TSCREEN (U.S. Environmental Protection Agency [EPA] 1992).

The Britter \& McQuaid Workbook dense gas nomogram formulation incorporated in the TSCREEN model was eliminated from further consideration because of the difficulty of incorporating its form (i.e., nomogram structure) into an integral model such as CASRAM. Although the SLAB model has some similarity parameterizations consistent with integral models, the shallow-layer approach adopted for SLAB did not allow a clean interface with the integral CASRAM passive gas formulation. The turbulent diffusion in SCIPUFF is based on a turbulence closure scheme. Also the model incorporates a concentration fluctuation variance equation upon which the formulations for mean flow 
dynamics for negatively buoyant dense gas are based. Although this approach is fundamentally consistent with the stochastic integral framework upon which CASRAM is based, its treatment of turbulence and description of dispersion through a second order closure approach scheme are not consistent.

The remaining models, DEGADIS and HEGADAS, have very similar origins and formulations as well as performance with field data. Both can also be easily adapted into the current CASRAM formulation. The model incorporated into CASRAM at this time, as discussed in the section below, relies heavily on the empirical entrainment parameterizations within the DEGADIS formulation. The HEGADAS model is similar in nature but is currently being revised, partially on the basis of extensive field data collected in the recent PERF-supported kit fox studies. Future modifications to the CASRAM dense gas dispersion model may involve incorporation of the HEGADAS formulation.

Like the passive gas dispersion model used in CASRAM, the dense gas algorithm is integral in nature. The initial conditions are specified by the vapor release rate $Q_{\nu}$ and aerosol release rate $Q_{a}$ from the container, which are calculated from the CASRAM emission rate model. The first step is evaluating the volumetric flow rate of vapor exiting the container $\dot{V}_{s v}$, which is given by

$$
\dot{V}_{s v}=\frac{Q_{v}}{\rho_{v}}
$$

where $\rho_{v}$ is the density of the chemical vapor at the boiling point. The initial volumetric flow rate of the cloud $\dot{V}_{c i}$ is taken as

$$
\dot{V}_{c i}=\left(1+\beta_{e i}\right) \dot{V}_{s v},
$$

where $\beta_{e i}$ is the entrainment parameter at the source taken as 2 . This is a rough estimate that depends on many factors. However, the model results at distances more than 10 to $20 \mathrm{~m}$ from the source are not sensitive to $\beta_{e i}$.

The initial cloud is assumed to have a flat, cylindrical shape (rectangular in two dimensions) with a width of $2 r_{i}$ and height $h_{i}$, where $r_{i}=h_{i}$. To estimate the cloud dimensions from the volumetric flow rate, one must solve the relationship

$$
h_{c i}=\frac{\dot{V}_{c i}}{2 \bar{U}_{p} r_{i}} \text {, }
$$

where

$$
\overline{U_{p}}=u\left(z=0.6 h_{c i}\right) \text {. }
$$


The solution of Equations 3.33 and 3.34 are necessarily iterative and subject to the constraint that $h_{c i}$ is more than $1.5 \mathrm{~m}$.

The initial cloud density is then defined in terms of the sum of the mass flow rates of the "flashed" vapor and aerosol plus the entrained air as

$$
\rho_{c i}=\frac{Q_{v}+Q_{a}+\beta_{e i} \dot{V}_{v} \rho_{a}}{\dot{V}_{c i}},
$$

where the last term on the right side of the numerator accounts for the mass of air initially entrained into the plume.

After release, the cloud spreads horizontally under the influence of its negative buoyancy while it grows vertically through entrainment of air from above. Note that dense gas plumes are marked by a much higher horizontal growth rate than vertical growth rate. The horizontal gravity spread is assumed to depend on the cloud advection speed and Richardson number for continuous releases and is computed in a form equivalent to the model of Raj (1985) such that

$$
\frac{d r}{d x}=\frac{\beta_{e} u_{*}}{\overline{U_{p}}} \sqrt{R i_{*}} .
$$

Here, $\beta_{e}$ is an entrainment parameter taken as 1.15 and $R i *$ is the local cloud Richardson number given by

$$
R i_{*}=\frac{g h_{c}\left(\rho_{c}-\rho_{a}\right)}{\rho_{a} u_{*}^{2}} .
$$

Vertical cloud growth is governed by vertical entrainment of air into the cloud, which can be conveniently defined in terms of cloud advection speed and entrainment velocity $\mathrm{v}_{\mathrm{e}}$ in the integral equation

$$
\frac{d h_{c}}{d x}=\frac{v_{e}}{\overline{U_{p}}}
$$

where the vertical entrainment velocity is as used in the DEGADIS model; namely,

$$
v_{e}=\frac{0.4 u_{*}}{0.88+0.099 R i_{*}^{1.04}} .
$$

Equations 3.36 and 3.38 make up a coupled set of differential equations that are solved at successive points downwind of the source. The solution proceeds until the 
critical Richardson number $R i$ is less than 50 . This critical Richardson number is defined differently than the local cloud Richardson number and is given by

$$
R i_{c}=\frac{U\left(h_{c}\right)\left(\rho_{c}-\rho_{a}\right) g h_{c}}{\rho_{a} u_{*}^{3}} .
$$

After this Richardson number criterion is met, we initialize the passive gas dispersion model by matching the cloud height and assuming a uniform concentration across the width of the cloud of $2 r$. Therefore, the parameter $y_{o}$ in Equation 3.16 is set to $r$. 


\section{Section 4 \\ Health Criteria}

Over the past 15 years, various health criteria have been used to develop Initial Isolation Zones and PADs. Early efforts employed occupational exposure guidelines such as threshold limit values (TLVs) established by the American Conference of Governmental Industrial Hygienists (ACGIH). In more recent work (e.g., the 1990 version of the ERG), Emergency Response Planning Guidelines (ERPGs) developed by the AIHA were identified as the best available health criteria for evaluating the health significance of accidental releases. This preference was based on a number of factors, including the high quality of documentation, the consensus approach upon which the values are derived, and the consideration of exposure to the general population.

In 1990, only a limited number of ERPGs were published. Therefore, DOT sought the advice of a panel of expert toxicologists on alternative health criteria to use and on the selection order for the alternative criteria. The alternative criteria recommended by the panel included adjusted occupational exposure guidelines, other emergency exposure guidelines, and acute inhalation toxicity data. The selection order hierarchy recommended was similar to the scheme recommended by Organization Resources Counselors, Inc. (1989).

In 1995, as part of a continuing effort to improve the ERG, an analysis of the various health criteria used to develop Initial Isolation and Protective Action Distances was performed. The analysis indicated that certain health criteria were stratified when compared with ERPG-2 values. For example, as demonstrated in Figure 4.1, use of ACGIH 8-h time-weighted average TLVs (TLVs-TWA) or ACGIH ceiling TLVs (TLVs-C) resulted in significant stratification. This stratification had a significant influence on the PADs calculated by using these health criteria. As a result, efforts were undertaken to further identify and minimize sources of stratification. These efforts, which are described below, included: (1) reviewing published studies on health criteria used to evaluate accidental releases, (2) performing an independent analysis of the ERPG values, and (3) convening an independent panel of expert toxicologists to recommend uses for health criteria and ways to minimize stratification.

For the 2000ERG analysis, we left the basic framework developed for the 1996 version of the ERG unchanged. The limited changes included incorporating several new ERPGs that became available between 1996 and 1999. In addition, we studied several new materials that had been added to the TIH list to determine appropriate health criteria. We also performed an extensive literature search to determine if any new acute toxicity information was published for the materials on the TIH list in the past several years that would be relevant to our analysis. Except for the ERPG values noted above, however, no new studies relevant to our analysis were identified. 

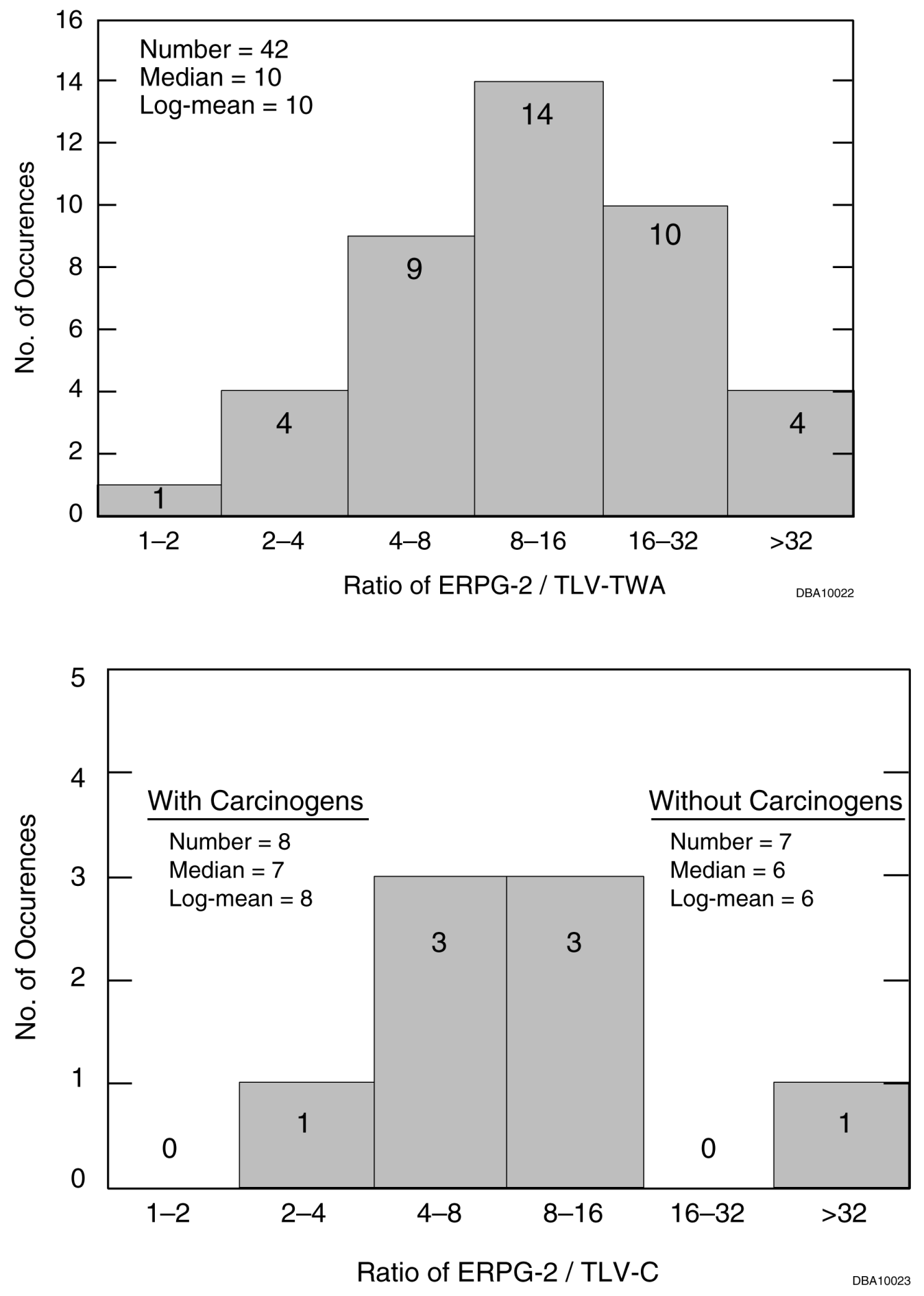

Figure 4.1 Histograms Comparing the Frequencies of ERPG-2 and TLV-TWA (both values were available for 22 chemicals) and Frequencies of ERPG-2 and TLV-C (values for 8 chemicals and a subset of 7 chemicals with the carcinogen removed) 
The remainder of this chapter describes the framework developed as part of the analysis done for the 1996 version of ERG. With minor changes, this material is taken from Dunn et al. (1996).

\subsection{Review of Past Development Efforts}

\subsubsection{Published Studies}

A number of published studies compare alternative health criteria for use in evaluating accidental releases. These studies have helped to resolve several questions on the relationship between ERPGs and alternative values, which include National Institute for Occupational Safety and Health (NIOSH) immediately dangerous to life and health (IDLH) levels, National Research Council emergency exposure guidance levels (EEGLs), and occupational health guidelines.

Craig et al. (1995) calculated the ratios of ERPG-2 values to other health criteria and examined the statistical relationship between them. The mean, coefficient of variation, and coefficient of determination of these ratios were calculated. The analysis included ERPG data for 35 chemicals. None of the existing values adequately estimated ERPG-3 values. For example, National Research Council 30-min EEGLs substantially underestimated ERPG-3 values (mean ratio $=0.55$ ), while NIOSH IDLHs overestimated ERPG-2 values (mean ratio $=2.48$ ).

A good correlation was observed between ERPG-2 values and National Research Council 60-min EEGLs and EPA levels of concern (LOCs) (mean ratios of 0.99 and 0.82, respectively). Similarly, good correlations were observed between ERPG-2 and Occupational Safety and Health Administration (OSHA) permissible exposure limit ceiling (PEL) values and 5 times the ACGIH 8-hour TLVs (mean ratios = 1.09 and 1.05, respectively). A poor correlation was observed between ERPG-2 and ACGIH TLV-C values (mean ratio $=0.2$ ). Data were not presented for the ratio of ERPG-2 and TLV values. However, on the basis of the good correlation with 5 times the 8-h TLVs, the correlation between ERPG-2 and unadjusted 8-h TLVs is probably very poor.

The study by Craig et al. (1995) confirms the stratification observed when unadjusted ACGIH TLV-C values, unadjusted 8-h TLV values, or 3 times the 8-h TLV values are used as surrogates for ERPG-2 values. Also, on the basis of the good correlation between the EPA LOC and ERPG-2, and since many EPA LOC values were derived by dividing the IDLH by 10 and many IDLHs were derived by dividing an $\mathrm{LC}_{50}$ value by 10 , a relationship between the ERPG-2 and $\mathrm{LC}_{50} / 100$ is inferred.

Woudenberg and Van Der Torn (1992) performed a number of nonparametric and parametric comparisons of various exposure limits including ERPGs (3, 2, and 1), IDLHs, ACGIH short-term exposure limits (STELs), 50\% decrease in mean respiratory rate (RD50) values, Health and Safety Executive (HSE) specified levels of toxicity (SLOTs), and National Research Council EEGLs. Woudenberg and Van Der Torn also 
calculated ratios of ERPG-3 to ERPG-2. At the time these analyses were performed, ERPG values were available for only 25 chemicals.

For ERPG-2, the nonparameteric comparison procedure identified a cluster with only EEGLs. This trend was confirmed by using parametric procedures. The ratio of mean EEGL to mean ERPG-2 was 1, with a range of 0.1 to $3.3(\mathrm{~N}=7)$. For ERPG-3, the nonparametric procedure identified a cluster with IDLHs. When the limits were scaled to a common time period, the $\mathrm{RD}_{50}$ was included in this cluster. The mean ERPG-3/IDLH ratio was 0.92 , with a range of 0.125 to $5(\mathrm{~N}=16)$. The mean $\mathrm{RD}_{50} / \mathrm{ERPG}-3$ ratio was 2 , with a range of 0.1 to $7.8(\mathrm{~N}=12)$. In the above ratios, the values are not scaled to a common time period. The ratio ERPG-2/ERPG-3 was 0.2, with a range of 0.01 to 0.4 , indicating a fivefold difference between ERPG-2 and ERPG-3.

Two additional analyses were performed as part of 1996 ERG study to further improve the values used in the Guidebook. Data from 65 ERPGs were used in the analyses $(\mathrm{N}=65)$. The relationship between the ratio of the key $\mathrm{LC}_{50}$ value and the ERPG-3 was analyzed. The key $\mathrm{LC}_{50}$ values were selected from the ERPG documentation, except where noted. With the exception of one chemical, dimethylamine, the $\mathrm{LC}_{50}$ values were for 30-min to 4-h exposure durations. Non-1-h values were adjusted to $1 \mathrm{~h}$. In this study, the ranking order described in Table 4.1 (see Section 4.2) was used. The ratio of mean $\mathrm{LC}_{50}$ to mean ERPG-3 was 25.7, with a median of 17 and range of 3 to 168. The ratio of ERPG-3 and ERPG-2 was also analyzed. The ratio of mean ERPG-3 to mean ERPG-2 was 6.6, with a median of 5 and range of 1 to 50.

For both ratios, the median values are slightly lower than the mean values, indicating that a few high values are influencing the means. For such data, the median values, which minimize the influence of extreme values, are the best estimate of central tendency. Considering the median value, the $1-\mathrm{h} \mathrm{LC}_{50} / 20$ value (i.e., $0.05 \times \mathrm{LC}_{50}$ ) is a reasonable approximation for the ERPG-3 value. Since ERPG-3 values are based on protection from life-threatening health effects, the relationship between $\mathrm{LC}_{50}$ and ERPG-3 has biological relevance. The product of the ratio of $\mathrm{LC}_{50} / \mathrm{ERPG}-3$ and ERPG-3/ERPG-2 is calculated as $17 \times 5=85$. Therefore, 1 - $\mathrm{h} \mathrm{LC}_{50} / 100$ values appear to be a reasonable and slightly conservative approximation for ERPG-2 values. Note that this relationship is empirical, since ERPG-2 values are based on a variety of serious health effects rather than lethality.

\subsubsection{Expert Panel Review}

On May 4, 1995, an independent panel of expert toxicologists convened to make recommendations on the use of health criteria for the 1996 version of the ERG. The panel made a number of recommendations for improving the consistency of criteria and for reducing stratification. They are presented below.

- Avoid using occupational health guidelines based on cancer since their use results in significant stratification. 
- Avoid using occupational health guidelines based on effects other than irritation since their use introduces a similar bias.

- Using acute inhalation toxicity data (e.g., $\mathrm{LC}_{50}$ values) in place of occupational health guidelines probably improves the consistency of the health criteria. However, the inconsistent use of these data has a high potential of introducing bias. To increase consistency, a scheme that considers species, exposure duration differences, and data sources should be developed and uniformly applied to data on individual chemicals.

In addition, the panel recommended identifying new potential sources of information for developing the health criteria. For example, additional acute toxicity data may be found in the documentation of the AIHA ERPGs. These documents site proprietary data not included in the open literature. Also, the panel recommended making more use of ERPG values by using existing ERPGs for closely related analogs that have limited toxicity data and no ERPGs.

The recommendations from the expert panel, and information gained from the studies and analyses described above, were incorporated into an updated procedure for developing the health criteria used to calculate Initial Isolation and Protective Action Distances.

\subsection{Overview of the Procedure Used to Develop Health Criteria}

Modeling considerations indicated a need for three values for each chemical. These values were a 1-h life-threatening value for determining the Initial Isolation Distances, and 1-h and 15-min protective action values for determining PADs. The procedure used to derive these values is described below.

\subsubsection{Use of ERPGs}

When published or approved ERPGs were available for the chemical of interest, ERPG-3 and ERPG-2 were used as the 1-h life-threatening and 1-h protective action criteria, respectively. ERPG- $2 \times 2$ was used to estimate 15 -min protective criteria. Use of the twofold factor is explained in Section 4.2.2 below. If ERPGs were available for a closely related structural analog, ERPG-3 and ERPG-2 values for the structural analog were used for the chemical of interest, as described above.

\subsubsection{Use of Acute Inhalation Lethality Data in Animals}

When ERPGs were not available, health criteria were derived by using median lethal concentration $\left(\mathrm{LC}_{50}\right)$ data and lowest reported lethal concentration $\left(\mathrm{LC}_{\mathrm{LO}}\right)$ data from acute inhalation studies on animals. When such data were not available for a chemical of interest, we used corresponding data for a structural analog. For example, for certain isocyanates for which there were no acute lethality data, data for methyl or butyl 
isocyanate could be used. Similarly, data for boron trichloride could be used for boron tribromide.

Several factors were considered in selecting and using the $\mathrm{LC}_{50}$ and $\mathrm{LC}_{\mathrm{LO}}$ data. These factors included species, time, data source, and structure activity considerations. These factors are discussed below and the resulting ranking of studies appears in Table 4.1.

\subsubsection{Species Considerations}

Data from studies using rats and mice were preferred for several reasons. Studies conducted with these species tend to use standardized protocols. Also, there is a wealth of comparative lethality data on rats and mice and much less comparative data on other species. Data on primates are rare, so using these data would limit the ability to compare responses across chemicals. However, acute lethal responses in this species might more closely simulate human responses. Therefore, when such data were available, they were generally included after the data for rats and mice but before data for other species, as presented in Table 4.1. The amount of comparative data on rabbits is limited. Results on this species are not as representative as data on primates, and so they appear lower in the ranking scheme.

Table 4.1 Order of Acute Lethality Data for Estimating Health Criteria

\begin{tabular}{|llll|}
\hline \multicolumn{1}{c}{ Rank } & \multicolumn{1}{c}{ Data } & \multicolumn{1}{c|}{ Rank } & \multicolumn{1}{c|}{ Data } \\
\hline 1 & 1-h $\mathrm{LC}_{50}$ in rats & 14 & 2- to 4-h $\mathrm{LC}_{50}$ in dogs \\
2 & 2- to 4-h $\mathrm{LC}_{50}$ in rats & 15 & 30 min $\mathrm{LC}_{50}$ in dogs \\
3 & 30-min $\mathrm{LC}_{50}$ in rats & 16 & 6- to 8-h $\mathrm{LC}_{50}$ in dogs \\
4 & 1-h $\mathrm{LC}_{50}$ in mice & 17 & 1-h $\mathrm{LC}_{50}$ in guinea pigs \\
5 & 2- to 4-h $\mathrm{LC}_{50}$ in mice & 18 & 2- to 4-h $\mathrm{LC}_{50}$ in guinea pigs \\
6 & 30-min $\mathrm{LC}_{50}$ in mice & 19 & 30 min $\mathrm{LC}_{50}$ in guinea pigs \\
7 & 6- to 8-h $\mathrm{LC}_{50}$ in rats & 20 & 6- to 8-h $\mathrm{LC}_{50}$ in guinea pigs \\
8 & 6- to 8-h $\mathrm{LC}_{50}$ in mice & 21 & 1-h $\mathrm{LC}_{50}$ in rabbits \\
9 & 1-h $\mathrm{LC}_{50}$ in primates & 22 & 2- to 4-h $\mathrm{LC}_{50}$ rabbits \\
10 & 2- to 4-h $\mathrm{LC}_{50}$ in primates & 23 & 30-min $\mathrm{LC}_{50}$ in rabbits \\
11 & 30-min $\mathrm{LC}_{50}$ in primates & 24 & 6- to 8-h $\mathrm{LC}_{50}$ in rabbits \\
12 & 6- to 8-h $\mathrm{LC}_{50}$ in primates & 25 & 1-h $\mathrm{LC}_{\mathrm{LO}}$ in rats \\
13 & 1-h $\mathrm{LC}_{50}$ in dogs & 26 & 2- to 4-h $\mathrm{LC}_{\mathrm{LO}}$ in rats, etc. ${ }^{\mathrm{a}}$ \\
\hline
\end{tabular}

a Rank 25 through 50 for $\mathrm{LC}_{\mathrm{LO}}$ data follow the same order as Rank 1 through 24 for $L_{50}$ data shown.

\subsubsection{Exposure Duration Considerations}

Data from 1-h exposures were preferred, since data from this duration require no adjustments. The most commonly reported acute lethality studies are for 1-h and 4-h exposure durations. Therefore, use of data from studies of this duration provides a 
measure of consistency in estimating health criteria. There is also a tendency for $1-\mathrm{h}$ and 4-h $\mathrm{LC}_{50}$ values to have been calculated by using standard protocols. For exposures less than 30 min long, concerns over chamber equilibration time $\left(\mathrm{T}_{99}\right)$ increased. For exposures more than $4 \mathrm{~h}$ long, concerns that effects other than acute lethal effects might influence the study results increased. Limited confidence was placed on data reported as $\mathrm{LC}_{\mathrm{LO}}$. In these studies, no information was available concerning the slope of the dose response curve. Also, in some studies that used $\mathrm{LC}_{\mathrm{LO}}$ values, $100 \%$ mortality was observed.

Data from non-1-h exposures were adjusted to predict results for 1-h exposures. To develop an approach for making the adjustments, various reports published by investigators who have examined the relationship between exposure duration and acute mortality response were reviewed (Doe and Milburn 1983; Haber 1924; Klimisch et al. 1987; Ten Berge et al. 1986).

In the simplest case, where the inhaled substance accumulates in the body and is not rapidly destroyed or excreted, the dose accumulated is directly proportional to the concentration $c$ and the exposure time $t$, and uptake is linear. This concept, known as Habers's rule or law, would result in the following relationship:

$$
W=c t,
$$

where $W$ is a constant dose specific for any given effect. This relationship is applicable for many reactive gases or highly lipid-soluble vapors over a limited range of concentrations and time.

However, many other relationships are possible. For example, for chemicals that are excreted as fast as they are inhaled and for which accumulation does not occur until a certain threshold concentration is reached, the following generalized dose-response equation applies:

$$
W=(c-a) t^{b}
$$

where $a$ is the threshold concentration and $b$ is derived from experimental data.

For a significant percentage of chemicals, the following relationship has been observed:

where

$$
L C_{50}\left(T_{1}\right)=L C_{50}\left(T_{o}\right)\left(\frac{T_{1}}{T_{o}}\right)^{1 / n},
$$

$T_{1}=$ actual exposure time,

$T_{\mathrm{o}}=$ experimental exposure time, and 
$n=$ constant.

Klimisch et al. (1987), citing Doe and Milburn (1983), found that for many chemicals, $n$ centers around a value of 0.5. Ten Berge et al. (1986) determined that for 18 of 20 chemicals studied, $n$ values were greater than 0.3 .

For deriving the health criteria, acute lethality data for exposure durations $T_{o}$ longer than $1 \mathrm{~h}$ were normalized by using the following quadratic dose-response function:

$$
L C_{50}(1 h r)=L C_{50}\left(T_{o}\right)\left(\frac{1 h r}{T_{o}}\right)^{0.5}
$$

This approach predicts lower $\mathrm{LC}_{50} / \mathrm{LC}_{\mathrm{LO}}$ values than does Habers's rule. Acute lethality data for exposure durations $T_{o}$ of less than $1 \mathrm{~h}$ were predicted by using a linear dose-response function (i.e., Habers's rule):

$$
L C_{50}(1 h r)=L C_{50}\left(T_{o}\right)\left(\frac{1 h r}{T_{o}}\right) .
$$

\subsubsection{Data Source Considerations}

The source of the data is critical. Information from main-stream, peer-reviewed toxicology and industrial hygiene journals is preferable to information from auxiliary, non-peer-reviewed sources. The publication date may also be important. Many studies conducted before 1950 did not include analytical verification of concentrations. Information from foreign journals tends to contain more transposition errors, especially as cited in the NIOSH Registry of Toxic Effects of Chemical Substances.

\subsubsection{Adjustment Factors}

As described in Section 4.1, the $1-\mathrm{h} \mathrm{LC}_{50}$ or adjusted $1-\mathrm{h} \mathrm{LC}_{50} / 100$ is a reasonable estimate of ERPG-2. Also, a fivefold factor is a reasonable central tendency adjustment factor between ERPG-2 and ERPG-3. Therefore, 1-h or adjusted 1-h $\mathrm{LC}_{50}$ or $\mathrm{LC}_{\mathrm{LO}}$ values were divided by 100 to estimate 1 -h protective health criteria, and this value was multiplied by 5 to estimate the 1-h life-threatening health criteria.

Members of the AIHA ERPG Committee indicate that when 1-h ERPGs are extrapolated to values of shorter duration, there is concern that the potential effects of peak, high-level exposures should be minimized. A default value of 2 was suggested for these purposes. Therefore, to estimate 15 -min protective health criteria from 1 -h values, a factor of 2 was employed in estimating the 15-min criteria from the 1-h criteria. 


\subsubsection{Use of Alternative Health Criteria}

For a few select chemicals, National Research Council EEGLs, Emergency Exposure Levels (EELs) published in the AIHA Journal, ACGIH 8-h TLVs, or ACGIH TLV-C values were used to develop health criteria. For one chemical, data on oral $\mathrm{LD}_{50}$ in animals were used to estimate an $\mathrm{LC}_{50}$ value and to derive health criteria. Standard assumptions of animal inhalation rate and body weight were used.

\subsubsection{Summary}

By building on past efforts, an updated procedure was developed to provide health criteria for use in determining Initial Isolation and Protective Action Distances. The new procedure incorporated additional ERPG values published since 1992 and expanded the use of existing ERPGs by applying them to structural analogs that otherwise had limited or no available acute toxicity data. A strategy was developed to reduce the stratification of PADs according to health criteria. The strategy involved minimizing the use of occupational health criteria through increased use of acute lethality data and more consistent selection and use of acute lethality data.

The updated procedure was used to develop health criteria for 163 chemicals. A summary of the basis for health criteria appears in Table 4.2. Documentation of the health criteria for individual chemicals is presented in Appendix B. For 56 chemicals (34\% of them), ERPGs or ERPGs for a structurally similar chemical formed the basis of the health criteria. For 90 chemicals $(55 \%), \mathrm{LC}_{50}$ values or $\mathrm{LC}_{50}$ values for a structurally similar chemical were used to develop the health criteria. For 11 chemicals $(7 \%), \mathrm{LC}_{50}$ or $\mathrm{LC}_{\mathrm{LO}}$ values for a structurally similar chemical formed the basis of the health criteria. Alternative health-based values, including National Research Council EEGLs, AIHA EELs, and ACGIH TLVs were used to develop criteria for only 5 chemicals (3\%). For 1 chemical, oral toxicity data were used to estimate an inhalation $\mathrm{LC}_{50}$ and to derive the health criteria.

The increased use of ERPGs and $\mathrm{LC}_{50}$ values and decreased reliance on alternative health-based values (e.g., TLVs) as a basis for the health criteria was consistent with the opinions of the expert panel. Use of the updated approach reduced the stratifications found as a result of previous efforts.

\subsection{Comparison to Other Procedures}

A number of other procedures have been developed for deriving health criteria used in evaluating accidental releases of chemicals. These include procedures developed by the EPA for deriving LOCs to evaluate releases of extremely hazardous substances (EPA 1991) and other procedures developed by the EPA for performing consequence analyses to comply with requirements of Section 112 R of the Clean Air Act (EPA 1996).

In the EPA LOC procedure, the NIOSH/OSHA IDLH/10 is the preferred value for deriving the LOC. Since IDLHs were developed during the Standards Completion 
Table 4.2 Summary of the Basis for Health Criteria Used to Prepare 2000ERG

\begin{tabular}{|c|c|c|}
\hline Basis of Health Criteria & $\begin{array}{c}\text { No. of } \\
\text { Chemicals }\end{array}$ & Percentage \\
\hline ERPG for chemical of concern & 37 & 23 \\
\hline ERPG for structurally similar chemical & 19 & 12 \\
\hline Subtotal for ERPGs & 56 & 34 \\
\hline $\mathrm{LC}_{50}$ for chemical of concern & 81 & 50 \\
\hline $\mathrm{LC}_{50}$ for structurally similar chemical & 9 & 6 \\
\hline Subtotal for $\mathrm{LC}_{50} \mathrm{~S}$ & 90 & 55 \\
\hline $\mathrm{LC}_{\mathrm{LO}}$ for chemical of concern & 10 & 6 \\
\hline $\mathrm{LC}_{\mathrm{LO}}$ for structurally similar chemical & 1 & $<1$ \\
\hline Subtotal for $L_{L_{L O}}$ & 11 & 7 \\
\hline AlHA EEL & 3 & 2 \\
\hline National Research Council EEGL & 1 & $<1$ \\
\hline ACGIH TLV for structurally similar chemical & 1 & $<1$ \\
\hline Subtotal for alternative health-based values & 5 & 3 \\
\hline Oral toxicity data & 1 & $<1$ \\
\hline Total & 163 & 100 \\
\hline
\end{tabular}

Program for the purpose of selecting respirators in the event of an emergency in the work place, the tenfold uncertainty factor is intended to account for the greater sensitivity of the general population versus the worker population. When IDLHs are unavailable, estimated IDLHs based on $\mathrm{LC}_{50} / 100, \mathrm{LC}_{\mathrm{LO}}, \mathrm{LD}_{50} / 100$, or $\mathrm{LD}_{\mathrm{LO}} / 100$ are used. As a third choice, ACGIH TLVs (8-h TLV-TWA, STEL, and TLV-C values) and National Research Council EEGLs are also used to derive a number of LOCs. AIHA ERPGs were cited as alternative criteria to use to develop LOCs. However, because only $15 \mathrm{draft}$ ERPGs were available at the time the LOC guidance was developed, ERPGs did not form the basis for any LOC.

In the procedure described by NIOSH to develop IDLHs, human data are preferred. However, since reliable human data are rarely available, many of the IDLHs are based on adjusting the results of acute inhalation lethality data in animals to a 30-min exposure duration by using the calculation $\mathrm{LC}_{50}(30 \mathrm{~min})=\mathrm{LC}_{50}(\mathrm{~T}) \times(\mathrm{T} / 0.5)^{1 / 3}$, then dividing by 10 . Therefore, many LOCs are based on adjusted $\mathrm{LC}_{50}$ or $\mathrm{LC}_{\mathrm{LO}}$ data divided by 100 .

Several similarities exist between the procedure used by the EPA to develop LOCs and the procedure used by DOT to develop health criteria for deriving Isolation and Protection Action Distances. Many LOC and DOT 1-h protective levels are based on adjusted $\mathrm{LC}_{50}$ or $\mathrm{LC}_{\mathrm{LO}}$ values divided by 100 . Also, various alternative values such as 
National Research Council EEGLs and ACGIH TLVs are considered as "last resort" criteria.

There are also several important differences in these two procedures. In the DOT approach, AIHA ERPGs are the preferred choice for deriving health criteria. We believe this to be a sounder approach, since ERPG values are considered by many authorities to be the best available criteria for evaluating accidental releases. Also, in the DOT procedure, when it was necessary to use acute lethality data in animals, a critical review of the available data was performed, which included a scheme for selecting the best study when multiple studies were available. In the DOT approach, when $\mathrm{LC}_{\mathrm{LO}}$ data were employed, use of a hundredfold instead of a tenfold uncertainty factor was maintained. This recommendation was based on the concept that a significant number of $\mathrm{LC}_{\mathrm{LO}}$ values represent concentrations that produced a significant percentage of mortality, including $100 \%$ mortality.

In the approach described in the guidance document for off-site consequence analysis (EPA 1996), ERPGs are recommended as the preferred values, followed by LOC values. Since ERPGs are recommended as first priority in the DOT scheme, followed by the time-adjusted $\mathrm{LC}_{50} / 100$, and many LOCs are based on $\mathrm{LC}_{50} / 100$, the two approaches are quite similar. However, as described above, there are differences in the methods used to select the acute lethality data.

\subsection{Future Modifications}

Through efforts of the AIHA ERPG Committee, ERPGs for additional chemicals will be provided in the future. The committee plans to publish approximately 10 new ERPGs per year. Not all of the chemicals on the ERPG list appear in the Table of Initial Isolation and Protective Action Distances, since many of the ERPG chemicals do not meet the specific toxicity and physical criteria for listing in the Table. However, when new ERPGs are available for chemicals on the DOT table, the values will be incorporated into the development of Isolation and Protective Action Distances in future additions of the ERG.

A National Advisory Committee for Acute Exposure Guidance Levels (AEGLs) was approved in 1995. Its first meeting was held on June 19-21, 1996. The committee is composed of scientists representing federal, state, and local agencies and organizations from the private sector with an interest in emergency planning, prevention, and response programs for acutely toxic chemicals. The purpose of the committee is to develop AEGLs that will meet the needs of various organizations (EPA, DOT, DOD, DOE, NIOSH, OSHA, Agency for Toxic Substances Disease Registry, industry). The National Research Council framework will be used to develop the AEGLs. Several draft AEGLs were available at the time of the 2000ERG work; however, no final values are available. When final consensus AEGL values are available, they will be incorporated into future ERG development. 


\subsection{Glossary for Chapter 4}

ACGIH 8-hour TLV: American Conference of Governmental Industrial Hygienists 8 -hour threshold limit value (ACGIH 1995). The time-weighted average concentration to which nearly all workers may be repeatedly exposed, day after day, without adverse effect.

ACGIH TLV STEL: American Conference of Governmental Industrial Hygienists short-term exposure limit (ACGIH 1995). The concentration to which workers can be exposed continuously for a short period of time without suffering from (1) irritation, (2) chronic or irreversible tissue damage, or (3) narcosis of sufficient degree to increase the likelihood of accidental injury, impair self-rescue, or materially reduce work efficiency, provided that the daily TLV-TWA is not exceeded.

ACGIH TLV Ceiling: American Conference of Governmental Industrial Hygienists threshold limit value ceiling (ACGIH 1995). The concentration that should not be exceeded during any part of the working exposure.

AIHA EEL: Emergency Exposure Level published in the American Industrial Hygiene Association Journal (Frawley et al. 1964). The concentrations of contaminant that can be tolerated without adversely affecting health but not necessarily without acute discomfort or other evidence of irritation or intoxication. The level is intended to provide guidance in managing single, brief exposures to airborne contaminants in the working environment.

AIHA ERPGs: American Industrial Hygiene Association Emergency Response Planning Guidelines (AIHA 1999).

ERPG-3: The maximum airborne concentration below which it is believed that nearly all individuals could be exposed for up to $1 \mathrm{~h}$ without experiencing or developing life-threatening health effects.

ERPG-2: The maximum airborne concentration below which it is believed nearly all individuals could be exposed for up to $1 \mathrm{~h}$ without experiencing or developing irreversible or other serious health effects, or symptoms that could impair an individual's ability to take protective action.

ERPG-1: The maximum airborne concentration below which it is believed nearly all individuals could be exposed for up to $1 \mathrm{~h}$ without experiencing other than mild, transient adverse health effects or perceiving a clearly defined objectionable odor.

EPA LOC: U.S. Environmental Protection Agency level of concern (EPA 1991). The concentration of an extremely hazardous substance in the air above which there may be serious irreversible health effects or death as a result of a single exposure for a relatively short period of time. 
HSE SLOT: Health and Safety Executive (England) specified level of toxicity (Turner and Fairhurst 1989).

$\mathbf{L C}_{50}$ : median (50\%) lethal concentration; lethal concentration to $50 \%$ of the exposed population.

$\mathbf{L C}_{\mathbf{L O}}$ : lowest reported lethal concentration.

NIOSH IDLH: National Institute for Occupational Safety and Health immediately dangerous to life and health level (NIOSH 1994). The maximum concentration from which, in the event of respirator failure, one could escape within 30 min without experiencing any escape-impairing (e.g., severe eye irritation) or irreversible health effects.

NRC EEGL: National Research Council emergency exposure guidance level (National Research Council, 1984-1987). A concentration of a substance in air (as gas, vapor, or aerosol) that will permit continued performance of specific tasks during rare emergency conditions lasting for periods of 1 to $24 \mathrm{~h}$.

OSHA PEL Ceiling: Occupational Safety and Health Administration permissible exposure limit ceiling (OSHA 1989). Concentration that should not be exceeded during any part of the workday.

$\mathbf{R D}_{\mathbf{5 0}}: 50 \%$ decrease in mean respiratory rate. 
$\Delta$ 


\section{Section 5 Summary}

Chapters 2 through 4 of this report detailed the statistical methodology for developing safe distance distributions, the consequence models used in this analysis, and the health criteria that define the safe distance. This chapter summarizes the results.

\subsection{Safe Distance Distributions and Protective Action Distances}

The statistical accident scenario and consequence analysis set forth here resulted in a set of up to 100,000 hypothetical incidents for each material appearing in the Table. This set of incidents accounts for variability in container type, incident type, accident severity (i.e., release amount), location, time of day, time of year, and meteorology. Each of these scenarios was evaluated by using detailed emission rate and atmospheric dispersion models to calculate downwind chemical concentration footprints. The safe distance for an incident is the distance downwind from the source at which the chemical concentration falls below the health criteria. The safe distance estimates for the entire set of hypothetical incidents considered in the analysis provide a distribution of safe distances corresponding to a wide spectrum of potential transportation-related releases. In the remainder of the analysis, these incidents are categorized according to whether they occur during the day or at night and whether they involve small ( $\leq 55$ gal) or large (>55 gal) spills.

Examples of safe distance distributions for two chemicals are given in Figures 5.15.8. The first four figures show safe distance distributions for chlorine, a Hazard Zone B gas. Distributions are separated according to spill size (large or small) and time of day (day or night). Figures 5.5 through 5.8 provide corresponding results for a water-reactive material, aluminum phosphide, which emits phosphine when spilled into water. In all eight figures, the 50, 70, 80, 90 and 95 percentiles are identified. The PADs in the guidebook correspond with the 90-percentile values for the individual categories.

Tables 5.1 and 5.2 provide safe distance estimates at several percentiles for the chlorine and aluminum phosphide distributions shown in the figures. Tables 5.3 and 5.4 provide corresponding data for two additional chemicals, phosphorous chloride (a Hazard Zone B liquid) and ethylene oxide (a Hazard Zone D gas). Results for phosphorous chloride in Table 5.3 are for land-based releases only. A separate set of safe distance distributions was developed for spills of phosphorous chloride into water.

As demonstrated in these examples, the safe distance distributions exhibit substantial tails, denoting the presence of low-probability/high consequence events. A comparison of the 50- and 90-percentile values reveals that the 90-percentile values are often a factor of 4 above the 50-percentile values. Clearly, use of the 90-percentile for the PAD affords a substantial level of protection for most incidents. The 95 and 99 percentiles do show that the PADs will not be sufficient for all incidents, however. The 99-percentile events, corresponding to worst-case releases in worst-case meteorology, can result in safe 


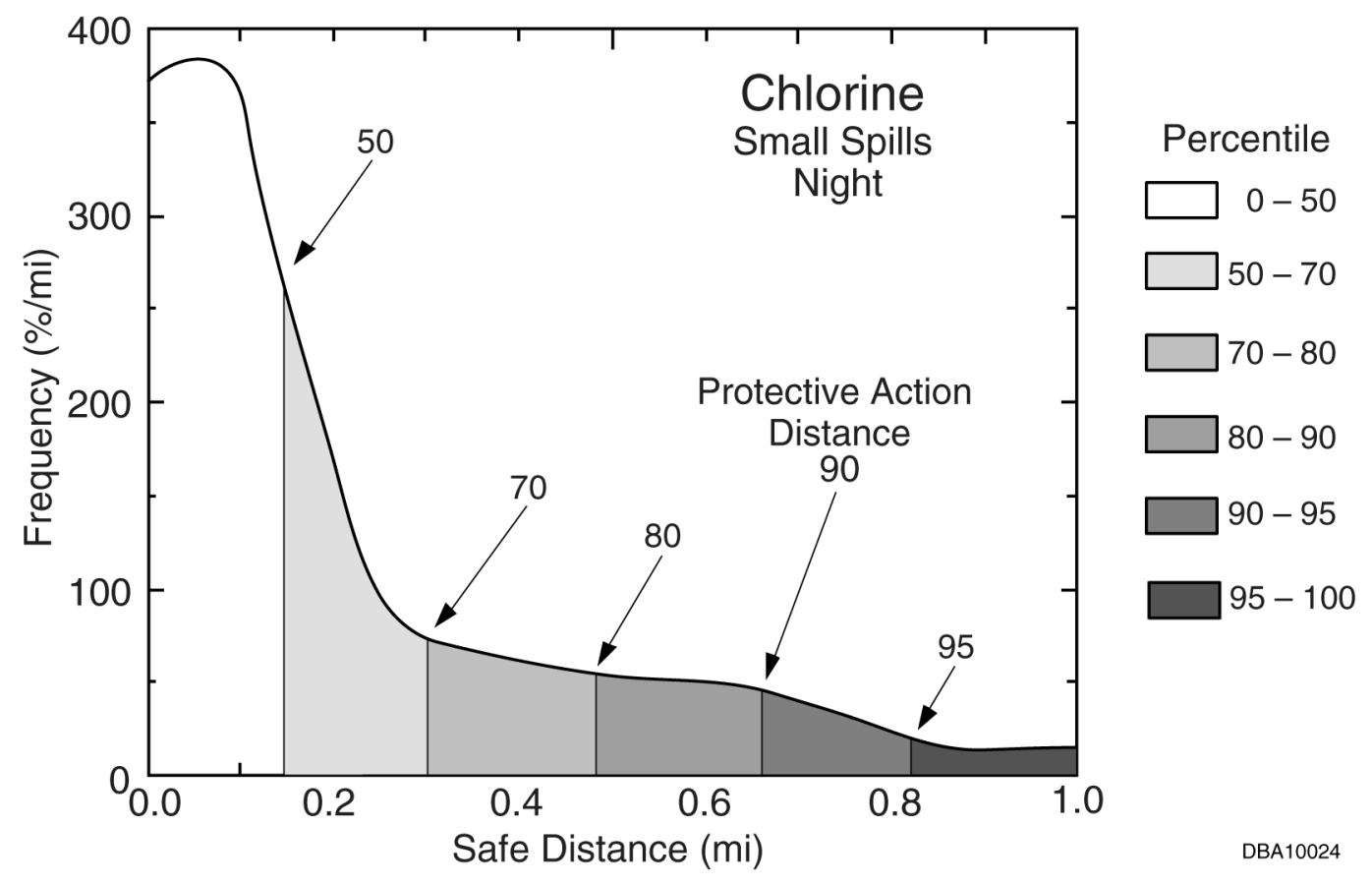

Figure 5.1 Frequency of Safe Distances for Small Nighttime Chlorine Spills as Determined in the 2000ERG Analysis

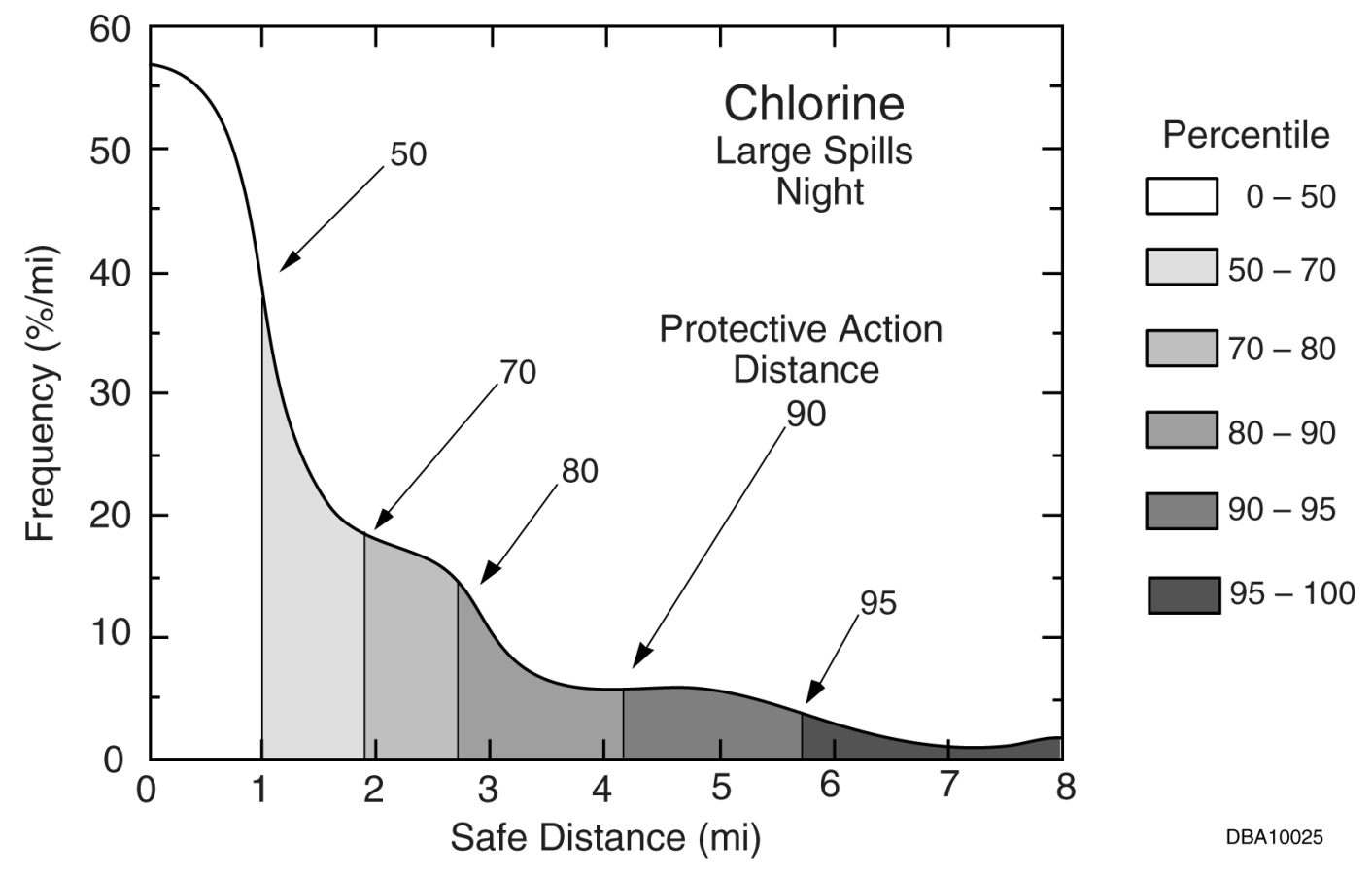

Figure 5.2 Frequency of Safe Distances for Large Nighttime Chlorine Spills as Determined in the 2000ERG Analysis 


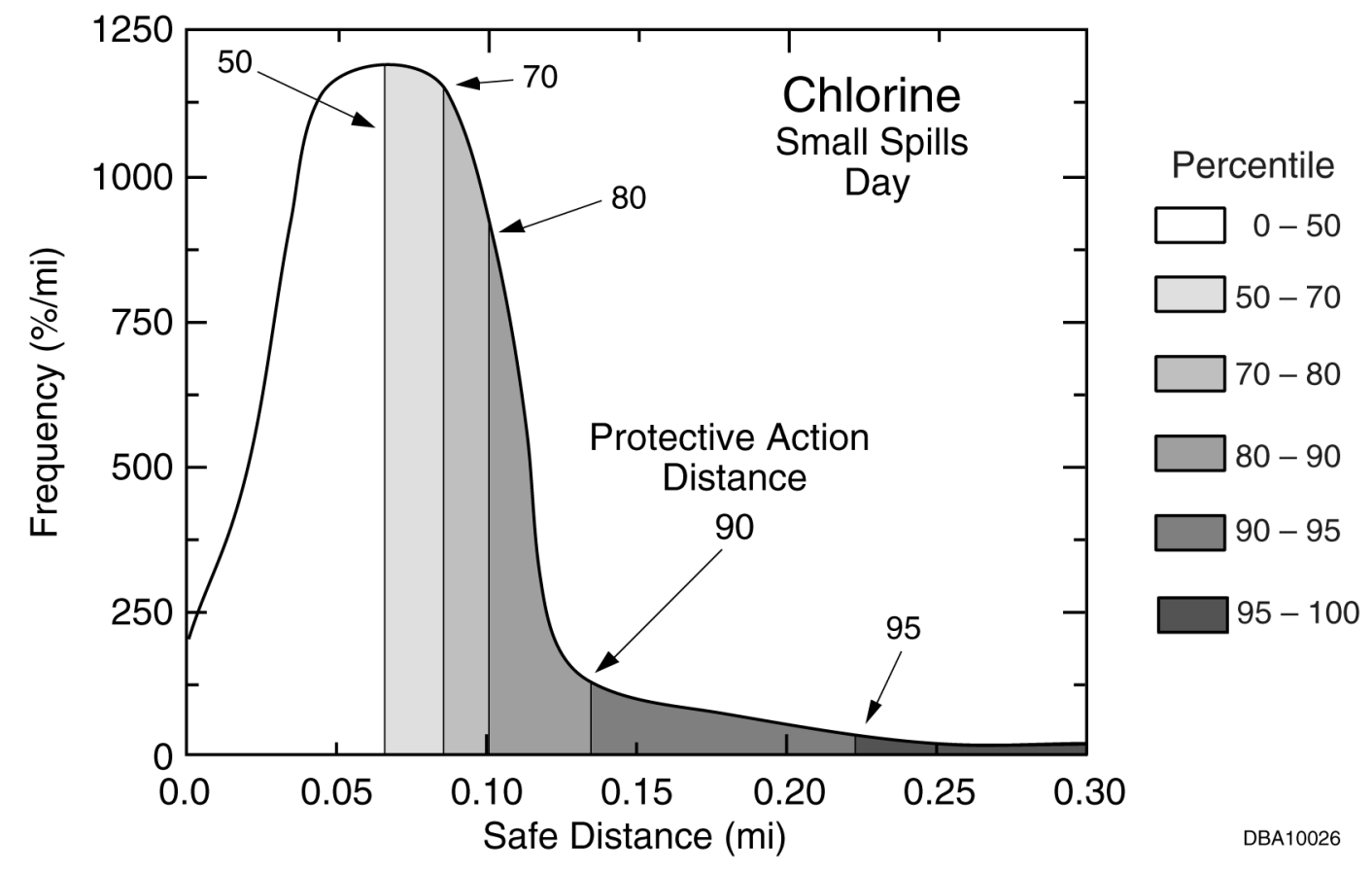

Figure 5.3 Frequency of Safe Distances for Small Daytime Chlorine Spills as Determined in the 2000ERG Analysis

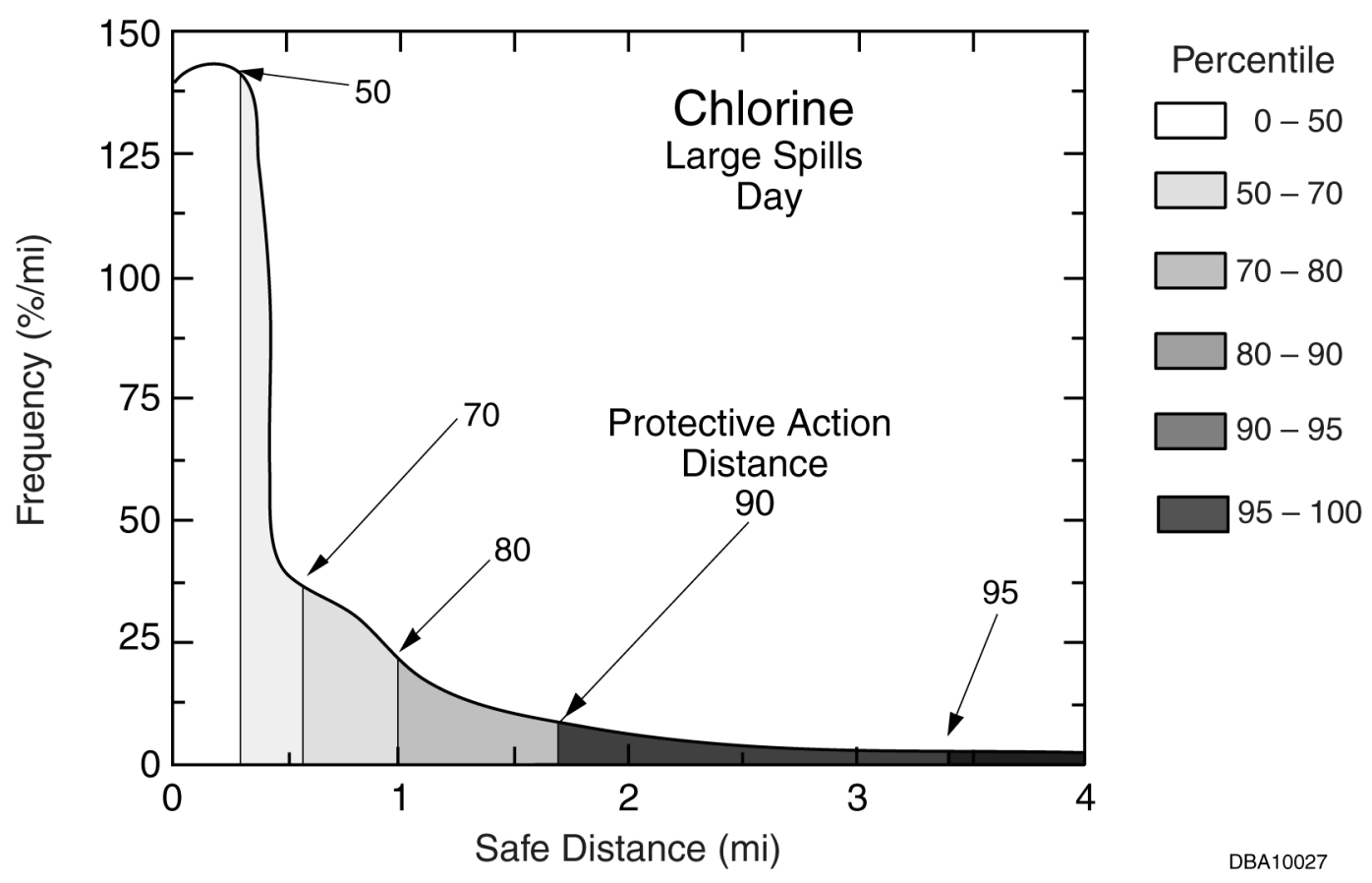

Figure 5.4 Frequency of Safe Distances for Large Daytime Chlorine Spills as Determined in the 2000ERG Analysis 


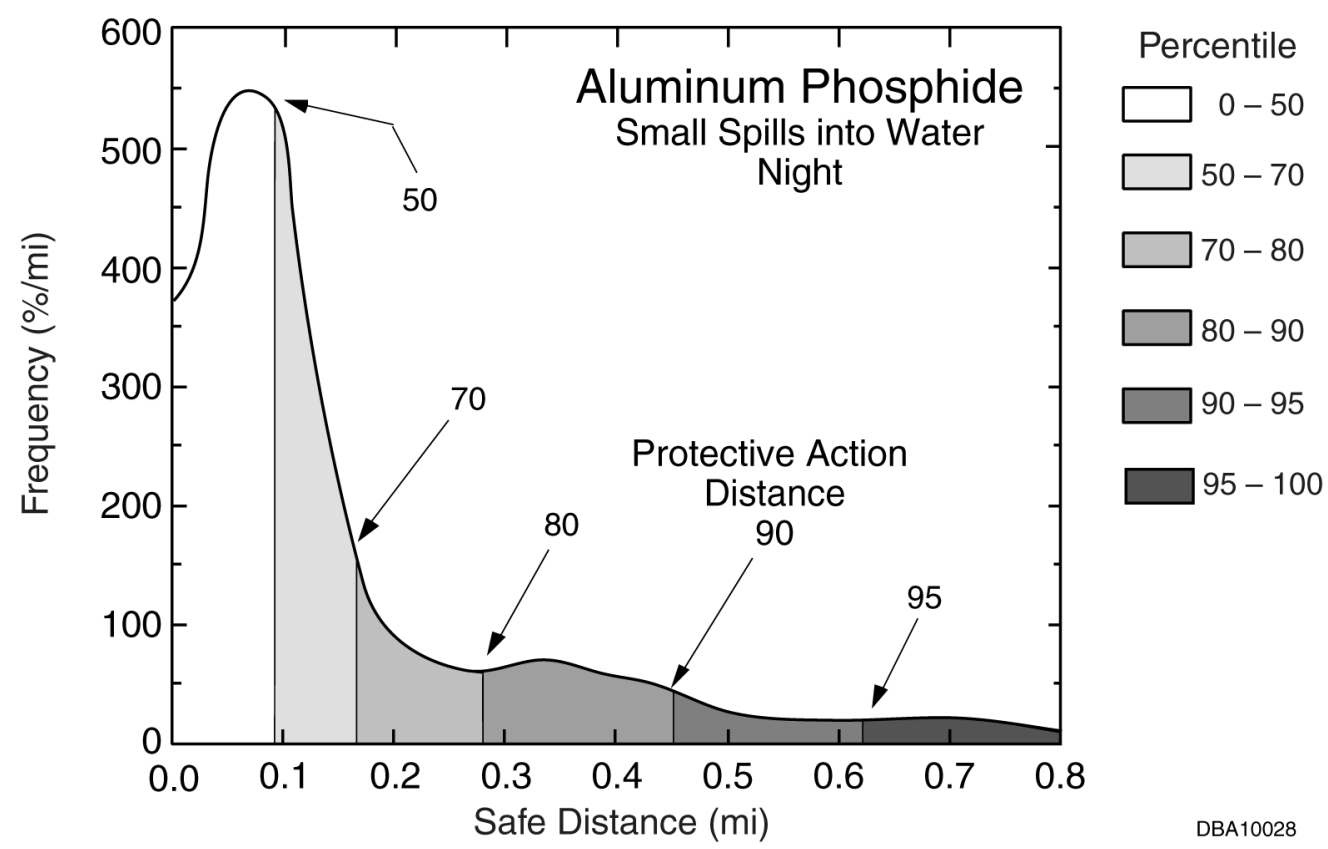

Figure 5.5 Frequency of Safe Distances for Small Nighttime Aluminum Phosphide Spills into Water as Determined in the 2000ERG Analysis

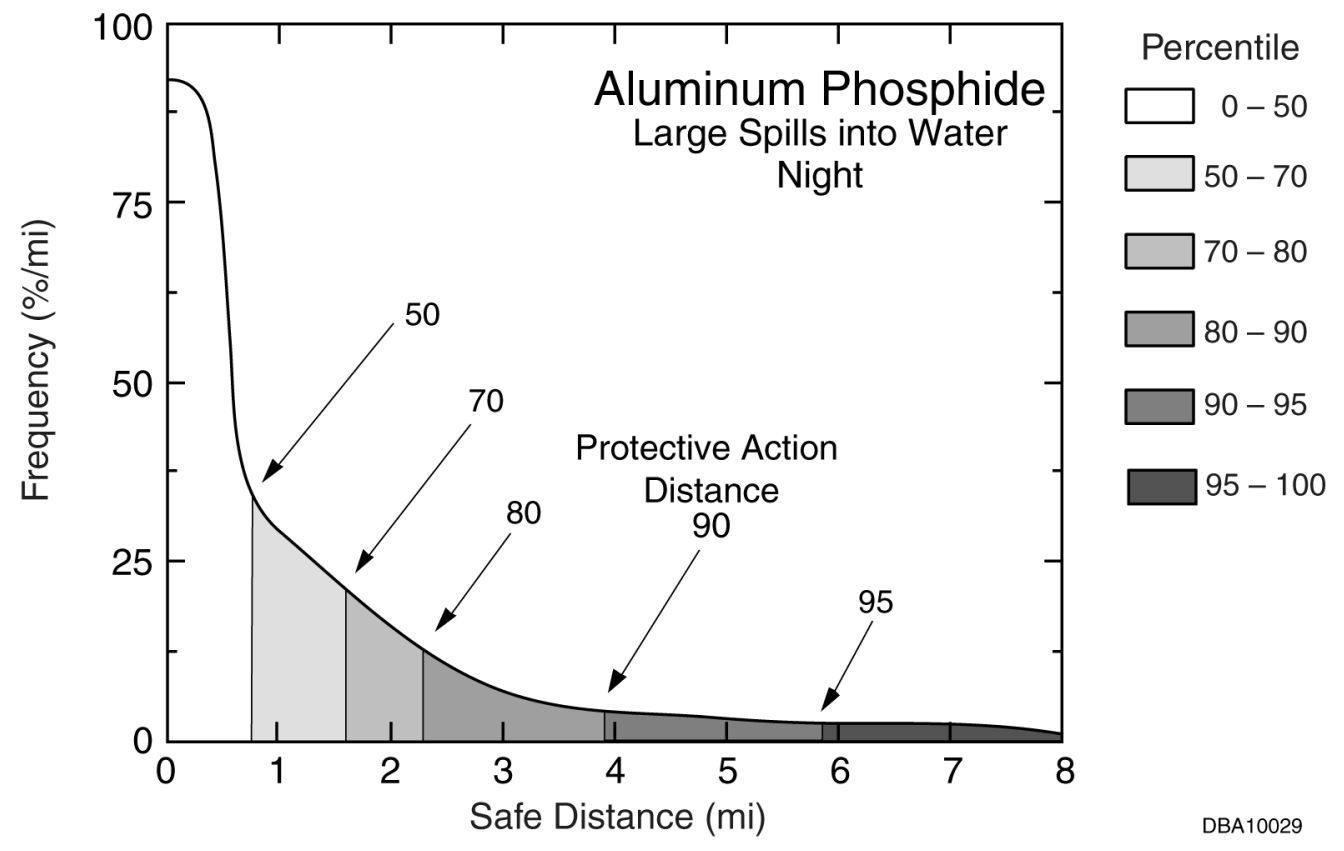

Figure 5.6 Frequency of Safe Distances for Large Nighttime Aluminum Phosphide Spills into Water as Determined in the 2000ERG Analysis 


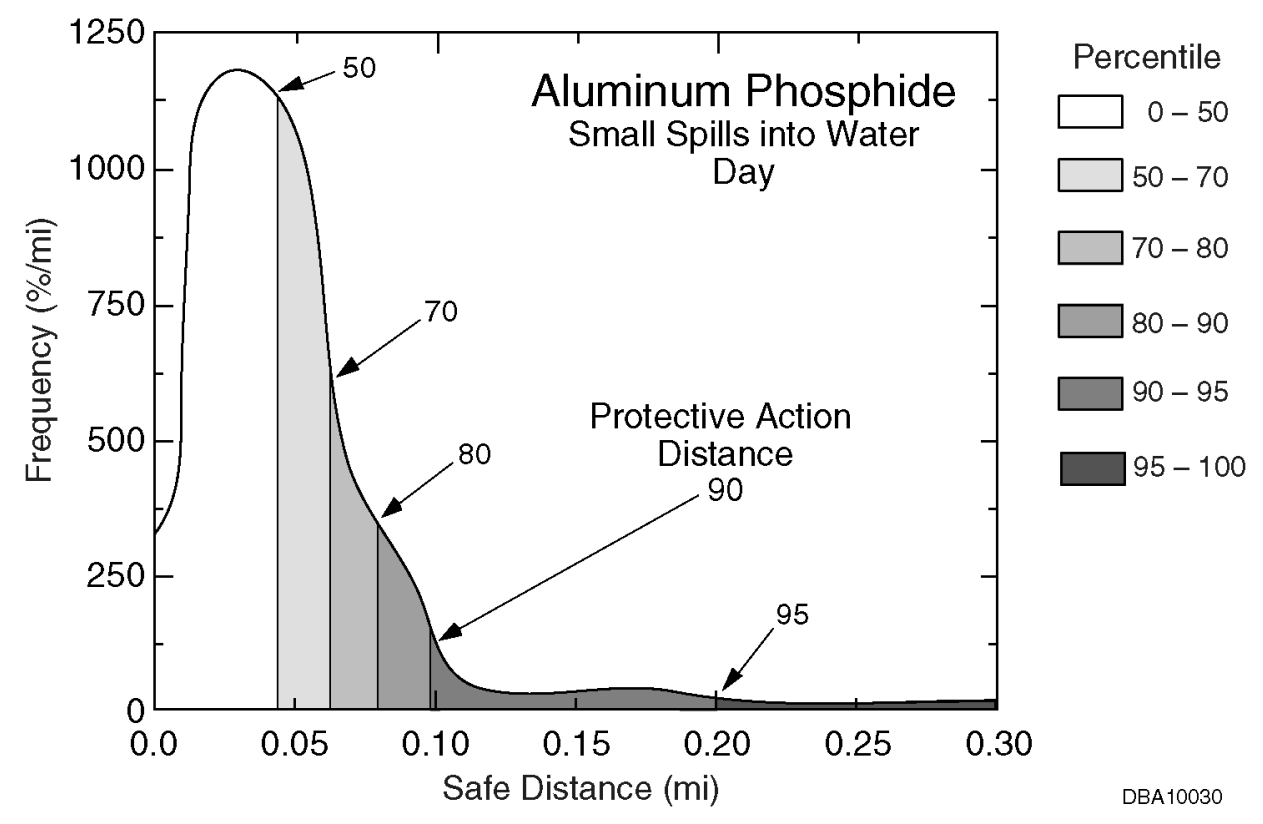

Figure 5.7 Frequency of Safe Distances for Small Daytime Aluminum Phosphide Spills into Water as Determined in the 2000ERG Analysis

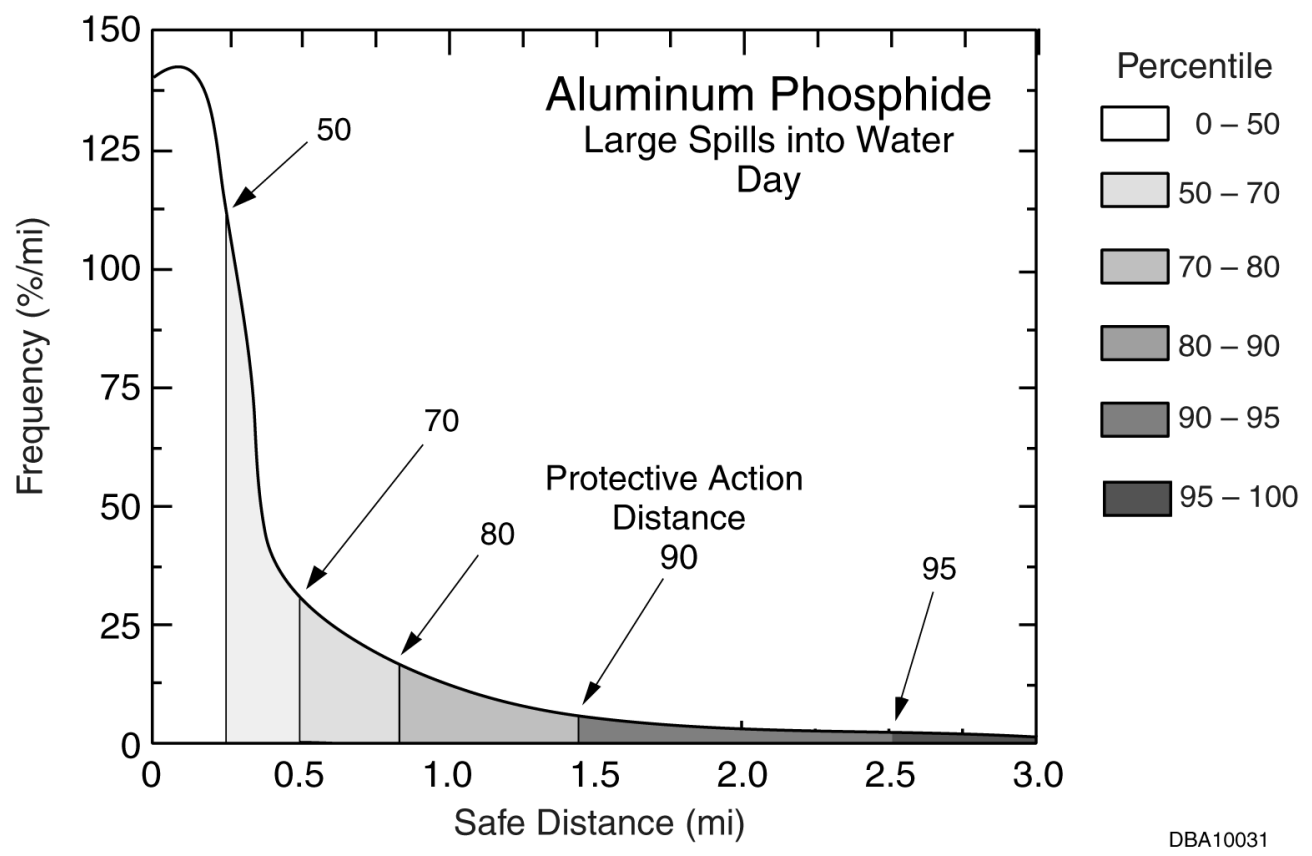

Figure 5.8 Frequency of Safe Distances for Large Daytime Aluminum Phosphide Spills into Water as Determined in the 2000ERG Analysis 
Table 5.1 Safe Distances at Several Percentiles for Chlorine (UN 1017) Releases as Determined in the 2000ERG Analysis

\begin{tabular}{|ccccccccc|}
\hline & & \multicolumn{6}{c|}{ Percentile } \\
\cline { 3 - 8 } Release Size & Time & $\mathbf{5 0}$ & $\mathbf{7 0}$ & $\mathbf{8 0}$ & $\mathbf{9 0}$ & $\mathbf{9 5}$ & $\mathbf{9 9}$ \\
\hline \multirow{2}{*}{ Small } & Day & 0.06 & 0.08 & 0.09 & $\mathbf{0 . 1 3}$ & 0.23 & 0.66 \\
& Night & 0.14 & 0.30 & 0.47 & $\mathbf{0 . 6 6}$ & 0.82 & 1.31 \\
& Large & Day & 0.28 & 0.56 & 0.98 & $\mathbf{1 . 6 9}$ & 3.37 & 7.01 \\
& Night & 0.99 & 1.96 & 2.92 & $\mathbf{4 . 1 6}$ & 5.80 & 8.46 \\
\hline
\end{tabular}

Table 5.2 Safe Distances at Several Percentiles for Aluminum Phosphide (UN 1397) Releases into Water as Determined in the 2000ERG Analysis

\begin{tabular}{|ccccccccc|}
\hline & & \multicolumn{6}{c|}{ Percentile } \\
\cline { 3 - 8 } Release Size & Time & $\mathbf{5 0}$ & $\mathbf{7 0}$ & $\mathbf{8 0}$ & $\mathbf{9 0}$ & $\mathbf{9 5}$ & $\mathbf{9 9}$ \\
\hline \multirow{2}{*}{ Small } & Day & 0.04 & 0.06 & 0.07 & $\mathbf{0 . 1 0}$ & 0.20 & 0.54 \\
& Night & 0.09 & 0.16 & 0.28 & $\mathbf{0 . 4 5}$ & 0.63 & 1.00 \\
& Large & Day & 0.23 & 0.51 & 0.82 & $\mathbf{1 . 4 2}$ & 2.51 & 6.46 \\
& Night & 0.79 & 1.61 & 2.31 & $\mathbf{3 . 9 1}$ & 5.84 & 8.38 \\
\hline
\end{tabular}

Table 5.3 Safe Distances at Several Percentiles for LandBased Phosphorous Trichloride (UN 1809) Releases as Determined in the 2000ERG Analysis

\begin{tabular}{|ccccccccc|}
\hline & & \multicolumn{6}{c|}{ Percentile } \\
\cline { 3 - 8 } Release Size & Time & $\mathbf{5 0}$ & $\mathbf{7 0}$ & $\mathbf{8 0}$ & $\mathbf{9 0}$ & $\mathbf{9 5}$ & $\mathbf{9 9}$ \\
\hline \multirow{2}{*}{ Small } & Day & 0.05 & 0.06 & 0.08 & $\mathbf{0 . 1 0}$ & 0.16 & 0.39 \\
& Night & 0.09 & 0.15 & 0.20 & $\mathbf{0 . 3 3}$ & 0.47 & 0.77 \\
Large & Day & 0.16 & 0.26 & 0.39 & $\mathbf{0 . 6 6}$ & 1.03 & 1.93 \\
& Night & 0.47 & 0.82 & 1.17 & $\mathbf{1 . 6 5}$ & 2.41 & 4.68 \\
\hline
\end{tabular}


Table 5.4 Safe Distances at Several Percentiles for Ethylene Oxide (UN 1040) Releases as Determined in the 2000ERG Analysis

\begin{tabular}{|ccccccccc|}
\hline & & \multicolumn{6}{c|}{ Percentile } \\
\cline { 3 - 8 } Release Size & Time & $\mathbf{5 0}$ & $\mathbf{7 0}$ & $\mathbf{8 0}$ & $\mathbf{9 0}$ & $\mathbf{9 5}$ & $\mathbf{9 9}$ \\
\hline \multirow{2}{*}{ Small } & Day & 0.01 & 0.01 & 0.02 & $\mathbf{0 . 0 2}$ & 0.03 & 0.09 \\
& Night & 0.02 & 0.04 & 0.06 & $\mathbf{0 . 0 9}$ & 0.13 & 0.22 \\
Large & Day & 0.06 & 0.11 & 0.19 & $\mathbf{0 . 3 0}$ & 0.41 & 1.03 \\
& Night & 0.19 & 0.39 & 0.60 & $\mathbf{1 . 0 3}$ & 1.50 & 2.94 \\
\hline
\end{tabular}

distances exceeding the PAD by a factor of 2 to 4 . However, using the 99-percentile criterion to define the PAD would result in extreme overreaction to the vast majority of incidents first responders face. The 90-percentile criterion was selected to strike a reasonable balance between adequately protecting the public from exposure to potentially harmful substances and avoiding the needless risks and expense associated with overreaction.

\subsection{Presentation of the Table in the Guidebook}

Appendix A provides the Table of Initial Isolation and Protective Action Distances as it appears in the 2000 Emergency Response Guidebook. The PADs in the Table are the 90 percentiles of the safe distance distributions as discussed in the previous section. The PADs have been rounded up the next $0.1 \mathrm{mi}$ and limited to $7 \mathrm{mi}$. Entries for which the calculated distances exceed $7 \mathrm{~m}$ are denoted as $7+\mathrm{mi}$ (or $11+\mathrm{km}$ ). Initial Isolation Distances are rounded up to the next $100 \mathrm{ft}$ for distances shorter than 2,000 ft and to the next $500 \mathrm{ft}$ for distances longer than 2,000 ft. Initial Isolation Distances are limited to $3,000 \mathrm{ft}$.

As discussed in Chapter 2, three distinct materials are listed in the Table. The first are TIH materials released in transportation-related incidents. The second are water-reactive materials that emit TIH gases when spilled into water. These entries are denoted by the phrase "when spilled in water." For TIH materials that emit a secondary TIH product when spilled in water, two entries are listed; they correspond to spills in water and on land. The third type of materials are chemical warfare agents released in a malicious manner. These entries are denoted by the phrase "when used as a weapon." Many TIH materials that are classical chemical warfare agents contain additional entries for weapons-related incidents. 
$\Delta$ 


\section{Section 6 References}

ACGIH, 1995, Threshold Limit Values for Chemical Substances and Physical Agents and Biological Exposure Indices, American Conference of Governmental Industrial Hygienists, Cincinnati, Ohio.

AIHA, 1999, The AIHA 1999 Emergency Response Planning Guidelines and Workplace Environmental Exposure Level Guidelines Handbook, American Industrial Hygiene Association, Fairfax, Va.

Barad, M.L. (editor), 1958, Project Prairie Grass: A Field Program in Diffusion, Vols. 1 and 2, part of Geophysical Research Papers No. 59 series; also Report AFCRL-58-235, Air Force Cambridge Research Center, July.

Brown, D.F., 1997, "Development of an Improved Meteorological Preprocessor and Atmospheric Dispersion Model," Ph.D. thesis, Department of Mechanical and Industrial Engineering, University of Illinois, Urbana, Ill.

Brown, D.F., and W.E. Dunn, 1998, The Surface Energy Budget Meteorological Model (SEBMET) for Atmospheric Boundary Layer Characterization, prepared by University of Illinois, Urbana, Ill., for U.S. Army Corps of Engineers, Construction and Research Laboratory, Champaign, Ill.

Brown, D.F., et al., 1999, unpublished information, prepared by Argonne National Laboratory, Argonne, Ill., for Research and Special Projects Administration, Office of Hazardous Materials Technology, U.S. Department of Transportation.

Calder, K.L., 1949, "Eddy Diffusion and Evaporation in Flow over Aerodynamically Smooth and Rough Surfaces: A Treatment Based on Laboratory Laws of Turbulent Flow with Special Reference to Conditions in the Lower Atmosphere," Quarterly Journal of Mechanical and Applied Math 92:153-176.

Carhart, R.A., et al., 1996, Technical Report Documentation to Support the 1996 North American Emergency Response Guidebook. Part II, Toxic Gases Produced from Reactions of Hazardous Materials Spilled into Natural Waters in Table "List of Dangerous Water-Reactive Materials," prepared by University of Chicago, Chicago, Ill., for Research and Special Projects Administration, Office of Hazardous Materials Technology, U.S. Department of Transportation.

Craig, D.K., et al., 1995, "Alternative Guideline Limits for Chemicals without Environmental Response Planning Guidelines," American Industrial Hygiene Association Journal 56:919-925. 
Defense Threat Reduction Agency, 1999, HPAC User's Guide (Ver. 3.2), HPACUGUIDE-01-U-RACO, prepared by SAIC for DTRA, Alexandria, Va., Oct. 4.

Doe, J.E., and G.M. Milburn, 1983, "The Relationship between Exposure Concentration, Duration of Exposure and Inhalation LC $_{50}$ Values," Human Toxicology 2:564.

DOT et al., 1999, 2000 Emergency Response Guidebook, prepared by U.S. Department of Transportation, Transport Canada, and Secretariat of Transport and Communications of Mexico, published by J.J. Keller \& Associates, Inc., Neenah, Wisc.

Draxler, R.R., 1976, "Determination of Atmospheric Diffusion Parameters," Atmospheric Environment 10:99-105.

Driedonks, A.G.M., 1982, "Models and Observations of the Growth of the Atmospheric Boundary Layer," Boundary Layer Meteorology 23:283-306.

Dunn, W.E., et al., 1996, Technical Documentation in Support of the 1996 North American Emergency Response Guidebook, prepared by University of Illinois, Urbana, Ill., for Research and Special Projects Administration, Office of Hazardous Materials Technology, U.S. Department of Transportation.

EPA: See U.S. Environmental Protection Agency.

Ermak, D.L., 1990, User's Manual for SLAB: An Atmospheric Dispersion Model for Denser-Than-Air Releases, ACRL-MA-105607, Lawrence Livermore National Laboratory, Livermore, Calif.

Frawley, J.P., et al., 1964, “Emergency Exposure Limits,” American Industrial Hygiene Association Journal 25:578-586.

Gryning, S.W., and E. Lyck, 1984, "Atmospheric Dispersion from Elevated Sources in an Urban Area: Comparison between Tracer Experiments and Model Calculations," Journal of Climate and Applied Meteorology 23:651-660.

Gryning, S., et al., 1983, "Dispersion from a Continuous Ground-Level Source Investigated by a K Model," Quarterly Journal of the Royal Meteorological Society 109, $355-364$.

Haber, F., 1924, Funf Vortrage Aus Den Jaren 1920-1923, Springer-Verlage, Berlin, Germany.

Hanna, S.R., and J.C. Chang, 1992, "Boundary Layer Parameterizations for Applied Dispersion Modeling over Urban Areas,” Boundary Layer Meteorology 58:229-259.

Hanna, S.R., and R.J. Paine, 1989, "Hybrid Plume Dispersion Model (HDPM) Development and Evaluation," Journal of Applied Meteorology 28:206-224. 
Havens, J., 1988, A Dispersion Model for Elevated Dense Gas Jet Chemical Releases, Volume I and II, EPA-450/4-88-006B, U.S. Environmental Protection Agency, Apr.

Iqbal, M., 1983, An Introduction to Solar Radiation, Academic Press, Toronto, Ontario, Canada.

Irwin, J.S., 1983, "Estimating Plume Dispersion - A Comparison of Several Sigma Schemes," Journal of Climate and Applied Meteorology 22:92-114.

Kapias, T., and R.F. Griffiths, 1999, "A New Model for Accidental Releases of Water Reactive Chemicals," Journal of Hazardous Materials 63:133-143.

Klimisch, H.J., et al., 1987, "Classification of Dangerous Substances and Pesticides in the European Economic Community Directives: A Proposed Revision of Criteria for Inhalation Toxicity," Regulatory Toxicology and Pharmacology 7:21-34.

Kroschwitz, J. (editor), 1991-1996, Kirk-Othmer's Encyclopedia of Chemical Technology, $4^{\text {th }}$ ed., Wiley-Interscience, New York, N.Y.

Lesht, B.M., and D.J. Brandner, 1992, "Functional Representation of Great Lakes Surface Temperatures," Journal of Great Lakes Research 18(1):98-107.

Lewis, R.J. (editor), 1966, Sax's Dangerous Properties of Industrial Materials, $9^{\text {th }}$ ed., Van Nostrand Reinhold, New York, N.Y.

National Renewable Energy Laboratory, 1992, User's Manual: National Solar Radiation Data Base, prepared by NREL, Golden, Colo., with data distributed by National Climatic Data Center, Asheville, N.C.

National Research Council, 1984-1987, Emergency and Continuous Exposure Guidance Levels for Selected Airborne Contaminants, Vol. I-VII, Committee on Toxicology, Board on Toxicology and Environmental Health Hazards, Commission on Life Sciences, National Research Council, Washington, D.C.

Nieuwstadt, F.T.M., 1981, "The Steady-State Height and Resistance Laws of the Nocturnal Boundary Layer: Theory Compared with Cabauw Observations," Boundary Layer Meteorology 20:3-17.

NIOSH, 1994, Documentation for Immediately Dangerous to Life or Health Concentrations, U.S. Department of Health and Human Services, Public Health Service, Centers for Disease Control and Prevention and National Institute for Occupational Safety and Health, Cincinnati, Ohio.

Organization Resources Counselors, Inc., 1989, letter from ORC (Washington, D.C.) to Office of Hazardous Materials Transportation (U.S. Department of Transportation, Washington, D.C.). 
OSHA, 1989, "Permissible Exposure Limits, Title 29 of the Code of Federal Regulations Part 1910.1000," U.S. Department of Labor, Occupational Safety and Health Administration, Federal Register, Jan. 19.

Panofsky, H.A., and J.A. Dutton, 1984, Atmospheric Turbulence - Models and Methods for Engineering Applications, John Wiley and Sons, New York, N.Y.

Panofsky, H.A., et al., 1977, "The Characteristics of Turbulent Velocity Components in the Surface Layer under Convective Conditions," Boundary Layer Meteorology 11:355361.

Perry, R.H., et al. (editors), 1984, Perry's Chemical Engineers Handbook, $6^{\text {th }}$ ed., McGraw-Hill, New York, N.Y.

Post, L., 1994, HGSystem 3.0 Technical Reference Manual, TNER.94.059, Shell Research Limited, Thornton Research Centre, Chester, England.

Raj, P.K., 1985, "Summary of Heavy Gas Spills Modeling Research,” pp. 51-75 in Proceedings of Heavy Gas (LNG/LPG) Workshop, Toronto, Ontario, Canada.

Raj, P.K., and C.K. Turner, 1993, Hazardous Materials Transportation in Tank Cars: Analysis of Risks Part 1, DOT/FRA/ORD-92/34, prepared by Technology \& Management Systems, Inc., Burlington, Mass., for the Federal Railroad Administration, Washington, D.C.

Roberts, O.F.T., 1923, "The Theoretical Scattering of Smoke in a Turbulent Atmosphere," pp. 640-654 in Proceedings of the Royal Society of London A, Vol. 104.

Sax, 1992, Dangerous Properties of Industrial Materials, $8^{\text {th }}$ ed., Van Nostrand Reinhold, New York, N.Y.

Taylor, G.I., 1921, “Diffusion by Continuous Movements,” pp. 196-212 in Proceedings of the London Math Society 20.

Ten Berge, W.F., et al., 1986, "Concentration-Time Mortality Response Relationship of Irritant and Systemically Acting Vapors and Gases," Journal of Hazardous Materials 13:301-309.

Turner, D., and S. Fairhurst, 1989, Assessment of the Toxicity of Major Hazard Substances, Report 21, Health and Safety Executive, London, England.

U.S. Environmental Protection Agency et al., 1991, Technical Guidance for Hazards Analysis, Emergency Planning for Extremely Hazardous Substances, EPA-OSWER-880001, Washington, D.C. 
U.S. Environmental Protection Agency, 1992, Workbook of Screening Techniques for Assessing Impacts of Toxic Air Pollutants (Revised), EPA-454/R-92-024, Dec.

U.S. Environmental Protection Agency, 1996, Offsite Consequence Analysis Guidance, Chemical Emergency Preparedness and Prevention Office, Washington, D.C.

van Ulden, A.P., 1978, "Simple Estimates for Vertical Diffusion from Sources near the Ground," Atmospheric Environment 12:2125-2129.

Willis, G.E., and J.W. Deardorff, 1976, "A Laboratory Model of Diffusion into the Convective Planetary Boundary Layer," Quarterly Journal of the Royal Meteorological Society 102:427-445.

Woudenberg, F., and P. Van Der Torn, 1992, "Emergency Exposure Limits: A Guide To Quality Assurance and Safety," Quality Assurance: Good Practice, Regulation, and Law 1:249-293. 
$\Delta$ 


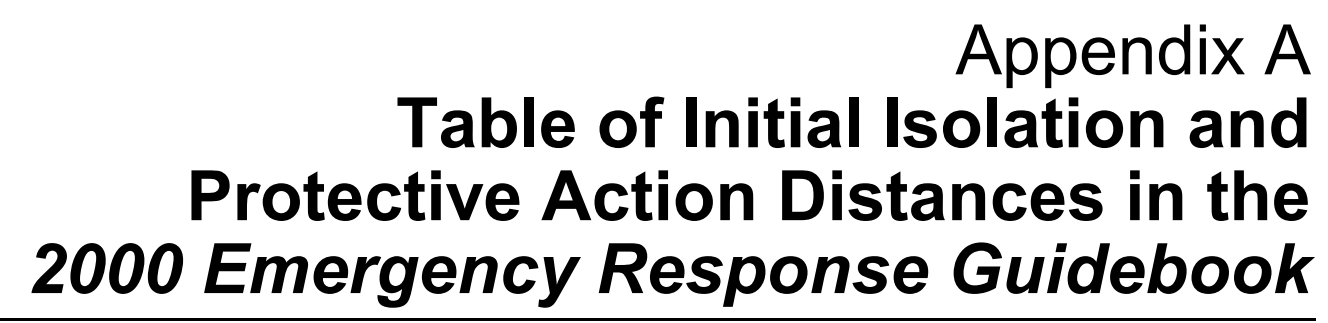


Table A.1 Table of Initial Isolation and Protective Action Distances

\begin{tabular}{|c|c|c|c|c|c|c|c|}
\hline \multirow[b]{3}{*}{ ID No. } & \multirow[b]{3}{*}{ Name of Material } & \multicolumn{3}{|c|}{ Small Spills } & \multicolumn{3}{|c|}{ Large Spills } \\
\hline & & \multirow{2}{*}{$\begin{array}{c}\text { First } \\
\text { Isolate } \\
\text { in All } \\
\text { Direc- } \\
\text { tions (ft) }\end{array}$} & \multicolumn{2}{|c|}{$\begin{array}{l}\text { Then Protect } \\
\text { Persons } \\
\text { Downwind } \\
\text { during }\end{array}$} & \multirow{2}{*}{\begin{tabular}{|c|} 
First \\
Isolate \\
in All \\
Direc- \\
tions (ft)
\end{tabular}} & \multicolumn{2}{|c|}{$\begin{array}{l}\text { Then Protect } \\
\text { Persons } \\
\text { Downwind } \\
\text { during }\end{array}$} \\
\hline & & & $\begin{array}{l}\text { Day } \\
\text { (mi) }\end{array}$ & $\begin{array}{c}\text { Night } \\
\text { (mi) }\end{array}$ & & $\begin{array}{l}\text { Day } \\
\text { (mi) }\end{array}$ & $\begin{array}{c}\text { Night } \\
\text { (mi) }\end{array}$ \\
\hline 1005 & Ammonia, anhydrous & 100 & 0.1 & 0.1 & 200 & 0.3 & 0.7 \\
\hline 1005 & Âmmonia, anhydrous, liquefied & 100 & 0.1 & $0.1^{-}$ & $200^{-\cdots}$ & $0.3^{-1}$ & $0.7^{-}$ \\
\hline 1005 & $\begin{array}{l}\text { Ammonia, solution, with more than } \\
50 \% \text { ammonia }\end{array}$ & 100 & $0.1^{-1}$ & $0.1^{-\cdots}$ & $200^{-\cdots}$ & $0.3^{-\cdots}$ & $0.7^{-}$ \\
\hline 1005 & Ānhydrous ammonia & 100 & 0.1 & $0.1^{-}$ & 200 & $0.3^{-}$ & $0.7^{-}$ \\
\hline 1005 & Ānhydrous ammonia, liquefied & 100 & 0.1 & $0.1^{-}$ & $200^{--}$ & $0.3^{-1}$ & $0.7^{--}$ \\
\hline 1008 & Boron trifluoride & 100 & 0.1 & 0.4 & 700 & 1.0 & 3.2 \\
\hline 1008 & Boron trifluoride, compressed & $100^{-1}$ & 0.1 & 0.4 & $700^{-}$ & $1.0^{-}$ & 3.2 \\
\hline 1016 & Carbon monoxide & 100 & 0.1 & 0.1 & 400 & 0.4 & 1.1 \\
\hline 1016 & Carbon monoxide, compressed & 100 & 0.1 & 0.1 & $400^{-\cdots}$ & $0.4^{-1}$ & 1.1 \\
\hline 1017 & Chlorine & 100 & 0.2 & 0.7 & 900 & 1.7 & 4.2 \\
\hline 1023 & Coal gas & 100 & 0.1 & 0.1 & 200 & 0.2 & 0.3 \\
\hline 1023 & Coal gas, compressed & $100^{-}$ & 0.1 & $0.1^{-}$ & 200 & $0.2^{-}$ & $0.3^{-}$ \\
\hline 1026 & Cyanogen & 100 & 0.2 & 0.7 & 1000 & 1.9 & 4.8 \\
\hline 1026 & Čanogen, liquefied & 100 & 0.2 & 0.7 & 1000 & $1.9^{-}$ & 4.8 \\
\hline 1026 & Cyanogen gas & 100 & 0.2 & 0.7 & 1000 & $1.9^{-\cdots}$ & $4.8^{-1}$ \\
\hline 1040 & Ethylene oxide & 100 & 0.1 & 0.1 & 200 & 0.3 & 1.1 \\
\hline 1040 & Éthylene oxide with nitrogen & 100 & 0.1 & 0.1 & $200^{-}$ & $0.3^{-1}$ & 1.1 \\
\hline 1045 & Fluorine & 100 & 0.1 & 0.3 & 600 & 0.9 & 2.5 \\
\hline 1045 & Fluorine, compressed & $100^{-1}$ & 0.1 & 0.3 & $600^{-}$ & 0.9 & 2.5 \\
\hline 1048 & Hydrogen bromide, anhydrous & 100 & 0.1 & 0.3 & 400 & 0.7 & 2.1 \\
\hline 1050 & Hydrogen chloride, anhydrous & 100 & 0.1 & 0.4 & 600 & 1.0 & 2.7 \\
\hline 1051 & $A C$ (when used as a weapon) & 200 & 0.1 & 0.3 & 1500 & 1.0 & 2.4 \\
\hline $1051^{-}$ & $\begin{array}{l}\text { Hydrocyanic acid, aqueous solutions, with more } \\
\text { than } 20 \% \text { hydrogen cyanide }\end{array}$ & 200 & $0.1^{--}$ & $0.3^{-\cdots}$ & $1300^{--}$ & $0.8^{-1}$ & $2.1^{-}$ \\
\hline 1051 & Hydrocyanic acid, liquefied & 200 & 0.1 & $0.3^{-1}$ & 1300 & $0.8^{-\cdots}$ & $2.1^{-}$ \\
\hline $1051^{-}$ & Hydrogen cyanide, anhydrous, stabilized & $200^{--}$ & 0.1 & $0.3^{-}$ & 1300 & 0.8 & 2.1 \\
\hline $1051^{-}$ & Hydrogen cyanide, stabilized & 200 & 0.1 & 0.3 & 1300 & 0.8 & 2.1 \\
\hline 1052 & Hydrogen fluoride, anhydrous & 100 & 0.1 & 0.4 & 400 & 0.7 & 1.8 \\
\hline 1053 & Hydrogen sulfide & 100 & 0.1 & 0.2 & 700 & 0.9 & 2.7 \\
\hline 1053 & Hydrogen sulfide, liquefied & 100 & 0.1 & 0.2 & $700^{-}$ & 0.9 & 2.7 \\
\hline 1053 & Hydrogen sulphide & 100 & 0.1 & $0.2^{-}$ & $700^{-\cdots}$ & 0.9 & 2.7 \\
\hline 1053 & Hydrogen sulphide, liquefied & 100 & 0.1 & $0.2^{--1}$ & $700^{--}$ & $0.9^{--}$ & $2.7^{--}$ \\
\hline 1062 & Methyl bromide & 100 & 0.1 & 0.2 & 300 & 0.3 & 0.9 \\
\hline 1064 & Methyl mercaptan & 100 & 0.1 & 0.2 & 300 & 0.5 & 1.7 \\
\hline
\end{tabular}


Table A.1 Table of Initial Isolation and Protective Action Distances (Cont.)

\begin{tabular}{|c|c|c|c|c|c|c|c|}
\hline \multirow[b]{3}{*}{ ID No. } & \multirow[b]{3}{*}{ Name of Material } & \multicolumn{3}{|c|}{ Small Spills } & \multicolumn{3}{|c|}{ Large Spills } \\
\hline & & \multirow{2}{*}{$\begin{array}{c}\text { First } \\
\text { Isolate } \\
\text { in All } \\
\text { Direc- } \\
\text { tions (ft) }\end{array}$} & \multicolumn{2}{|c|}{$\begin{array}{l}\text { Then Protect } \\
\text { Persons } \\
\text { Downwind } \\
\text { during }\end{array}$} & \multirow{2}{*}{$\begin{array}{c}\text { First } \\
\text { Isolate } \\
\text { in All } \\
\text { Direc- } \\
\text { tions (ft) }\end{array}$} & \multicolumn{2}{|c|}{$\begin{array}{l}\text { Then Protect } \\
\text { Persons } \\
\text { Downwind } \\
\text { during }\end{array}$} \\
\hline & & & $\begin{array}{l}\text { Day } \\
\text { (mi) }\end{array}$ & $\begin{array}{c}\text { Night } \\
\text { (mi) }\end{array}$ & & $\begin{array}{l}\text { Day } \\
\text { (mi) }\end{array}$ & $\begin{array}{l}\text { Night } \\
\text { (mi) }\end{array}$ \\
\hline 1067 & Dinitrogen tetroxide & 100 & 0.1 & 0.3 & 1000 & 0.8 & 2.4 \\
\hline 1067 & Dinitrogen tetroxide, liquefied & 100 & 0.1 & 0.3 & 1000 & 0.8 & 2.4 \\
\hline 1067 & Nitrogen dioxide & 100 & 0.1 & $0.3^{-}$ & 1000 & 0.8 & 2.4 \\
\hline 1067 & Nitrogen dioxide, liquefied & 100 & 0.1 & $0.3^{-1}$ & 1000 & 0.8 & 2.4 \\
\hline 1067 & Nitrogen peroxide, liquid & 100 & 0.1 & 0.3 & 1000 & 0.8 & 2.4 \\
\hline 1067 & Nitrogen tetroxide, liquid & 100 & 0.1 & 0.3 & 1000 & 0.8 & 2.4 \\
\hline 1069 & Nitrosyl chloride & 100 & 0.2 & 0.9 & 1200 & 2.2 & 6.1 \\
\hline 1071 & Oil gas & 100 & 0.1 & 0.1 & 100 & 0.2 & 0.3 \\
\hline 1071 & Öil gas, compressed & 100 & 0.1 & 0.1 & $100^{-}$ & 0.2 & 0.3 \\
\hline 1076 & CG (when used as a weapon) & 500 & 0.8 & 2.0 & 2500 & 4.5 & $7.0+$ \\
\hline 1076 & Döiphosgene & 200 & 0.1 & 0.3 & 300 & 0.6 & 1.2 \\
\hline 1076 & $\mathrm{DP}$ (when used as a weapon) & 200 & 0.2 & 0.6 & $600^{-}$ & $1.0^{-}$ & 2.8 \\
\hline 1076 & Phosgene & 300 & 0.5 & $1 . \overline{7}^{-}$ & 2500 & $4.1^{-}$ & 6.9 \\
\hline 1079 & Sulfur dioxide & 100 & 0.2 & 0.7 & 600 & 1.9 & 4.5 \\
\hline 1079 & Sulfur dioxide, liquefied & 100 & 0.2 & 0.7 & 600 & 1.9 & 4.5 \\
\hline 1079 & Süphur dioxide & 100 & 0.2 & $0 . \overline{7}$ & 600 & 1.9 & 4.5 \\
\hline 1079 & Sulphur dioxide, liquefied & 100 & 0.2 & 0.7 & $600^{-}$ & 1.9 & 4.5 \\
\hline 1082 & Trifluorochloroethylene & 100 & 0.1 & 0.1 & 100 & 0.2 & 0.5 \\
\hline 1082 & Trifluorochloroethylene, inhibited & 100 & 0.1 & 0.1 & $100^{-}$ & $0.2^{-}$ & 0.5 \\
\hline 1092 & Acrolein, inhibited & 200 & 0.3 & 1.0 & 1300 & 2.4 & 4.9 \\
\hline 1098 & Allyl alcohol & 100 & 0.1 & 0.1 & 100 & 0.2 & 0.4 \\
\hline 1135 & Ethylene chlorohydrin & 100 & 0.1 & 0.2 & 200 & 0.4 & 0.8 \\
\hline 1143 & Crotonaldehyde, inhibited & 100 & 0.1 & 0.1 & 100 & 0.2 & 0.5 \\
\hline 1143 & Črotonaldehyde, stabilized & 100 & 0.1 & 0.1 & 100 & $0.2^{-}$ & 0.5 \\
\hline 1162 & Dimethyldichlorosilane (when spilled in water) & 100 & 0.1 & 0.2 & 400 & 0.7 & 1.8 \\
\hline 1163 & 1,1-Dimethylhydrazine & 100 & 0.1 & 0.1 & 200 & 0.3 & 0.7 \\
\hline 1163 & Dimethylhydrazine, unsymmetrical & 100 & 0.1 & 0.2 & 200 & $0.3^{-}$ & 0.7 \\
\hline 1182 & Ethyl chloroformate & 100 & 0.1 & 0.2 & 200 & 0.4 & 0.9 \\
\hline 1185 & Ethyleneimine, inhibited & 100 & 0.2 & 0.5 & 500 & 0.9 & 2.2 \\
\hline 1238 & Methyl chloroformate & 100 & 0.2 & 0.7 & 500 & 1.0 & 2.1 \\
\hline 1239 & Methyl chloromethyl ether & 100 & 0.1 & 0.4 & 400 & 0.7 & 1.7 \\
\hline 1242 & Methyldichlorosilane (when spilled in water) & 100 & 0.1 & 0.1 & 200 & 0.3 & 1.0 \\
\hline 1244 & Methylhydrazine & 100 & 0.2 & 0.5 & 400 & 0.7 & 1.7 \\
\hline 1250 & Methyltrichlorosilane (when spilled in water) & 100 & 0.1 & 0.2 & 400 & 0.7 & 1.8 \\
\hline 1251 & Methyl vinyl ketone & 500 & 0.8 & 2.1 & 3000 & 5.4 & $7.0+$ \\
\hline 1251 & Methyl vinyl ketone, stabilized & 500 & 0.8 & 2.1 & 3000 & $5.4^{-}$ & $7.0+$ \\
\hline 1259 & Nickel carbonyl & 200 & 0.4 & 1.3 & 700 & 1.3 & 2.7 \\
\hline 1295 & Trichlorosilane (when spilled in water) & 100 & 0.1 & 0.2 & 400 & 0.8 & 2.0 \\
\hline 1298 & Trimethylchlorosilane (when spilled in water) & 100 & 0.1 & 0.1 & 300 & 0.5 & 1.4 \\
\hline
\end{tabular}


Table A.1 Table of Initial Isolation and Protective Action Distances (Cont.)

\begin{tabular}{|c|c|c|c|c|c|c|c|}
\hline \multirow[b]{3}{*}{ ID No. } & \multirow[b]{3}{*}{ Name of Material } & \multicolumn{3}{|c|}{ Small Spills } & \multicolumn{3}{|c|}{ Large Spills } \\
\hline & & \multirow{2}{*}{$\begin{array}{c}\text { First } \\
\text { Isolate } \\
\text { in All } \\
\text { Direc- } \\
\text { tions (ft) }\end{array}$} & \multicolumn{2}{|c|}{$\begin{array}{l}\text { Then Protect } \\
\text { Persons } \\
\text { Downwind } \\
\text { during }\end{array}$} & \multirow{2}{*}{$\begin{array}{c}\text { First } \\
\text { Isolate } \\
\text { in All } \\
\text { Direc- } \\
\text { tions (ft) }\end{array}$} & \multicolumn{2}{|c|}{$\begin{array}{l}\text { Then Protect } \\
\text { Persons } \\
\text { Downwind } \\
\text { during }\end{array}$} \\
\hline & & & $\begin{array}{l}\text { Day } \\
\text { (mi) }\end{array}$ & $\begin{array}{l}\text { Night } \\
\text { (mi) }\end{array}$ & & $\begin{array}{l}\text { Day } \\
\text { (mi) }\end{array}$ & $\begin{array}{l}\text { Night } \\
\text { (mi) }\end{array}$ \\
\hline 1340 & $\begin{array}{l}\text { Phosphorus pentasulfide, free from yellow or } \\
\text { white phosphorous (when spilled in water) }\end{array}$ & 100 & 0.1 & 0.3 & 500 & 0.8 & 2.0 \\
\hline 1340 & $\begin{array}{l}\text { Phosphorus pentasulphide, free from yellow or } \\
\text { white phosphorous (when spilled in water) }\end{array}$ & 100 & 0.1 & $0.3^{-1}$ & $500^{-\cdots}$ & $0.8^{-}$ & 2.0 \\
\hline 1360 & Calcium phosphide (when spilled in water) & 100 & 0.1 & 0.5 & 700 & 1.3 & 3.3 \\
\hline 1380 & Pentaborane & 500 & 0.8 & 2.3 & 2500 & 4.1 & 6.6 \\
\hline 1384 & Sodium dithionite (when spilled in water) & 100 & 0.1 & 0.1 & 100 & 0.2 & 0.7 \\
\hline 1384 & Sodium hydrosulfite (when spilled in water) & 100 & 0.1 & $0.1^{-}$ & $100^{-}$ & $0.2^{-}$ & $0 . \overline{7}$ \\
\hline 1384 & Sodium hydrosulphite (when spilled in water) & $100^{-1}$ & 0.1 & 0.1 & $100^{-}$ & $0.2^{-1}$ & 0.7 \\
\hline 1397 & Aluminum phosphide (when spilled in water) & 100 & 0.1 & 0.5 & 800 & 1.5 & 4.0 \\
\hline 1412 & Lithium amide (when spilled in water) & 100 & 0.1 & 0.1 & 300 & 0.5 & 1.2 \\
\hline 1419 & $\begin{array}{l}\text { Magnesium aluminum phosphide (when spilled } \\
\text { in water) }\end{array}$ & 100 & 0.1 & 0.5 & 700 & 1.3 & 3.4 \\
\hline 1432 & Sodium phosphide (when spilled in water) & 100 & 0.1 & 0.3 & 500 & 0.9 & 2.5 \\
\hline 1433 & Stannic phosphides (when spilled in water) & 100 & 0.1 & 0.5 & 600 & 1.0 & 2.9 \\
\hline 1510 & Tetranitromethane & 100 & 0.2 & 0.3 & 200 & 0.4 & 0.8 \\
\hline 1541 & $\begin{array}{l}\text { Acetone cyanohydrin, stabilized (when spilled in } \\
\text { water) }\end{array}$ & 100 & 0.1 & 0.1 & 300 & 0.5 & 1.3 \\
\hline 1556 & MD (when used as a weapon) & 100 & 0.2 & 0.5 & 400 & 0.8 & 2.2 \\
\hline 1556 & Methyldichloroarsine & $100^{-}$ & 0.1 & 0.2 & 200 & $0.3^{-}$ & 0.6 \\
\hline 1556 & PD (when used as a weapon) & 100 & 0.1 & $0 . \overline{1}$ & $100^{-}$ & $0.1^{-}$ & 0.2 \\
\hline 1560 & Arsenic chloride & 100 & 0.1 & 0.2 & 200 & 0.4 & 0.9 \\
\hline 1560 & Ârsenic trichloride & $100^{-}$ & 0.1 & 0.2 & $200^{-}$ & $0.4^{-}$ & 0.9 \\
\hline 1569 & Bromoacetone & 100 & 0.1 & 0.2 & 300 & 0.5 & 1.2 \\
\hline 1580 & Chloropicrin & 200 & 0.3 & 0.8 & 600 & 1.1 & 2.5 \\
\hline 1581 & Chloropicrin and methyl bromide mixture & 100 & 0.1 & 0.3 & 400 & 0.8 & 1.9 \\
\hline 1581 & Methyl bromide and chloropicrin mixtures & 100 & 0.1 & 0.3 & $400^{-}$ & $0.8^{-}$ & 1.9 \\
\hline 1581 & $\begin{array}{l}\text { Methyl bromide and more than } 2 \% \text { chloropicrin } \\
\text { mixture, liquid }\end{array}$ & 100 & 0.2 & 0.7 & $700^{-}$ & $1.3^{-}$ & 3.5 \\
\hline 1582 & Chloropicrin and methyl chloride mixture & 100 & 0.1 & 0.5 & 300 & 0.6 & 2.0 \\
\hline 1582 & Methyl chloride and chloropicrin mixtures & 100 & 0.1 & 0.5 & 300 & 0.6 & 2.0 \\
\hline 1583 & Chloropicrin, absorbed & 200 & 0.3 & 0.8 & 600 & 1.1 & 2.5 \\
\hline 1583 & Chiloropicrin mixture, n.o.s. & 100 & 0.2 & 0.7 & 700 & 1.3 & 3.5 \\
\hline 1589 & CK (when used as a weapon) & 200 & 0.4 & 1.5 & 1300 & 2.5 & 5.0 \\
\hline 1589 & Čyanogen chloride, inhibited & 200 & 0.3 & 1.1 & $900^{-\cdots}$ & $1.7^{-}$ & $4.2^{--}$ \\
\hline 1595 & Dimethyl sulfate & 100 & 0.1 & 0.1 & 100 & 0.2 & 0.4 \\
\hline 1595 & Dimethyl sulphate & 100 & 0.1 & 0.1 & $100^{-1}$ & $0.2^{--}$ & 0.4 \\
\hline 1605 & Ethylene dibromide & 100 & 0.1 & 0.1 & 100 & 0.2 & 0.3 \\
\hline 1612 & $\begin{array}{l}\text { Hexaethyl tetraphosphate and compressed gas } \\
\text { mixture }\end{array}$ & 100 & 0.1 & 0.1 & 100 & 0.2 & 0.9 \\
\hline
\end{tabular}


Table A.1 Table of Initial Isolation and Protective Action Distances (Cont.)

\begin{tabular}{|c|c|c|c|c|c|c|c|}
\hline \multirow[b]{3}{*}{ ID No. } & \multirow[b]{3}{*}{ Name of Material } & \multicolumn{3}{|c|}{ Small Spills } & \multicolumn{3}{|c|}{ Large Spills } \\
\hline & & \multirow{2}{*}{$\begin{array}{c}\text { First } \\
\text { Isolate } \\
\text { in All } \\
\text { Direc- } \\
\text { tions (ft) }\end{array}$} & \multicolumn{2}{|c|}{$\begin{array}{l}\text { Then Protect } \\
\text { Persons } \\
\text { Downwind } \\
\text { during }\end{array}$} & \multirow{2}{*}{$\begin{array}{c}\text { First } \\
\text { Isolate } \\
\text { in All } \\
\text { Direc- } \\
\text { tions (ft) }\end{array}$} & \multicolumn{2}{|c|}{$\begin{array}{l}\text { Then Protect } \\
\text { Persons } \\
\text { Downwind } \\
\text { during }\end{array}$} \\
\hline & & & $\begin{array}{l}\text { Day } \\
\text { (mi) }\end{array}$ & $\begin{array}{l}\text { Night } \\
\text { (mi) }\end{array}$ & & $\begin{array}{l}\text { Day } \\
\text { (mi) }\end{array}$ & $\begin{array}{l}\text { Night } \\
\text { (mi) }\end{array}$ \\
\hline 1613 & $\begin{array}{l}\text { Hydrocyanic acid, aqueous solution, with not } \\
\text { more than } 20 \% \text { hydrogen cyanide }\end{array}$ & 100 & 0.1 & 0.1 & 400 & 0.3 & 0.8 \\
\hline 1613 & $\begin{array}{l}\text { Hydrogen cyanide, aqueous solution, with not } \\
\text { more than } 20 \% \text { hydrogen cyanide }\end{array}$ & 100 & 0.1 & 0.1 & 400 & 0.3 & 0.8 \\
\hline 1614 & $\begin{array}{l}\text { Hydrogen cyanide, anhydrous, stabilized } \\
\text { (absorbed) }\end{array}$ & 200 & 0.1 & 0.3 & 1300 & 0.8 & 2.1 \\
\hline 1614 & Hydrogen cyanide, stabilized (absorbed) & 200 & 0.1 & $0.3^{-1}$ & 1300 & 0.8 & 2.1 \\
\hline 1647 & $\begin{array}{l}\text { Ethylene dibromide and methyl bromide mixture, } \\
\text { liquid }\end{array}$ & 100 & 0.1 & 0.1 & 100 & 0.2 & 0.3 \\
\hline $1647^{-1}$ & $\begin{array}{l}\text { Methyl bromide and ethylene dibromide mixture, } \\
\text { liquid }\end{array}$ & $100^{--}$ & 0.1 & $0.1^{--}$ & $100^{--}$ & $0.2^{--}$ & $0.3^{-1}$ \\
\hline 1660 & Nitric oxide & 100 & 0.2 & 0.8 & 500 & 0.8 & 2.2 \\
\hline $1660^{-}$ & Nitric oxide, compressed & 100 & 0.2 & 0.8 & $500^{-}$ & $0.8^{-}$ & 2.2 \\
\hline 1670 & Perchloromethyl mercaptan & 100 & 0.1 & 0.2 & 200 & 0.3 & 0.7 \\
\hline 1680 & Potassium cyanide (when spilled in water) & 100 & 0.1 & 0.2 & 300 & 0.5 & 1.6 \\
\hline 1689 & Sodium cyanide (when spilled in water) & 100 & 0.1 & 0.2 & 300 & 0.6 & 1.6 \\
\hline 1694 & CA (when used as a weapon) & 100 & 0.1 & 0.3 & 500 & 1.0 & 2.6 \\
\hline 1695 & Chloroacetone, stabilized & 100 & 0.1 & 0.2 & 200 & 0.4 & 0.8 \\
\hline 1697 & CN (when used as a weapon) & 100 & 0.1 & 0.3 & 400 & 0.7 & 2.0 \\
\hline 1698 & Adamsite (when used as a weapon) & 200 & 0.2 & 0.7 & 600 & 1.4 & 3.2 \\
\hline 1698 & $\overline{D M}$ (when used as a weapon) & 200 & 0.2 & 0.7 & $600^{-}$ & $1.4^{-}$ & 3.2 \\
\hline 1699 & DA (when used as a weapon) & 200 & 0.2 & 0.7 & 600 & 1.4 & 3.2 \\
\hline 1703 & $\begin{array}{l}\text { Tetraethyl dithiopyrophosphate and gases, in } \\
\text { solution }\end{array}$ & 100 & 0.2 & 0.7 & 1200 & 2.3 & 4.3 \\
\hline $1703^{-}$ & $\begin{array}{l}\text { Tetraethyl dithiopyrophosphate and gases, } \\
\text { mixtures }\end{array}$ & 100 & 0.2 & 0.7 & $1200^{-1}$ & $2.3^{-}$ & 4.3 \\
\hline 1703 & $\begin{array}{l}\text { Tetraethyl dithiopyrophosphate and gases, } \\
\text { mixtures, or in solution }\left(\mathrm{LC}_{50} \text { more than } 200 \mathrm{ppm}\right. \\
\text { but not more than } 5000 \mathrm{ppm})\end{array}$ & 100 & 0.1 & 0.3 & 400 & 0.5 & 1.8 \\
\hline 1703 & $\begin{array}{l}\text { Tetraethyl dithiopyrophosphate and gases, } \\
\text { mixtures, or in solution }\left(\mathrm{LC}_{50} \text { not more than }\right. \\
200 \mathrm{ppm})\end{array}$ & 100 & 0.2 & 0.7 & $1200^{-1}$ & $2.3^{2}$ & 4.3 \\
\hline 1705 & $\begin{array}{l}\text { Tetraethyl pyrophosphate and compressed gas } \\
\text { mixtures }\end{array}$ & 100 & 0.2 & 0.8 & 1300 & 2.5 & 4.5 \\
\hline $1705^{-1}$ & $\begin{array}{l}\text { Tetraethyl pyrophosphate and compressed gas } \\
\text { mixtures (LC50 more than } 200 \text { ppm but not more } \\
\text { than } 5000 \text { ppm) }\end{array}$ & 100 & 0.1 & 0.3 & $400^{-\cdots}$ & 0.5 & 1.8 \\
\hline $1705^{-}$ & $\begin{array}{l}\text { Tetraethyl pyrophosphate and compressed gas } \\
\text { mixtures (LC50 not more than } 200 \text { ppm) }\end{array}$ & $100^{-}$ & 0.2 & 0.8 & $1300^{-}$ & 2.5 & 4.5 \\
\hline 1714 & Zinc phosphide (when spilled in water) & 100 & 0.1 & 0.5 & 600 & 1.1 & 3.2 \\
\hline 1716 & Acetyl bromide (when spilled in water) & 100 & 0.1 & 0.2 & 300 & 0.5 & 1.4 \\
\hline 1717 & Acetyl chloride (when spilled in water) & 100 & 0.1 & 0.2 & 300 & 0.6 & 1.7 \\
\hline
\end{tabular}

Continued 
Table A.1 Table of Initial Isolation and Protective Action Distances (Cont.)

\begin{tabular}{|c|c|c|c|c|c|c|c|}
\hline \multirow[b]{3}{*}{ ID No. } & \multirow[b]{3}{*}{ Name of Material } & \multicolumn{3}{|c|}{ Small Spills } & \multicolumn{3}{|c|}{ Large Spills } \\
\hline & & \multirow{2}{*}{$\begin{array}{c}\text { First } \\
\text { Isolate } \\
\text { in All } \\
\text { Direc- } \\
\text { tions (ft) }\end{array}$} & \multicolumn{2}{|c|}{$\begin{array}{l}\text { Then Protect } \\
\text { Persons } \\
\text { Downwind } \\
\text { during }\end{array}$} & \multirow{2}{*}{$\begin{array}{c}\text { First } \\
\text { Isolate } \\
\text { in All } \\
\text { Direc- } \\
\text { tions (ft) }\end{array}$} & \multicolumn{2}{|c|}{$\begin{array}{l}\text { Then Protect } \\
\text { Persons } \\
\text { Downwind } \\
\text { during }\end{array}$} \\
\hline & & & $\begin{array}{l}\text { Day } \\
\text { (mi) }\end{array}$ & $\begin{array}{l}\text { Night } \\
\text { (mi) }\end{array}$ & & $\begin{array}{l}\text { Day } \\
\text { (mi) }\end{array}$ & $\begin{array}{l}\text { Night } \\
\text { (mi) }\end{array}$ \\
\hline 1722 & Allyl chlorocarbonate & 500 & 0.8 & 1.7 & 2000 & 3.8 & 6.7 \\
\hline 1722 & Álly̆ chloroformate & 500 & 0.8 & 1.7 & 2000 & 3.8 & $6.7^{-}$ \\
\hline 1724 & $\begin{array}{l}\text { Allyltrichlorosilane, stabilized (when spilled in } \\
\text { water) }\end{array}$ & 100 & 0.1 & 0.2 & 400 & 0.6 & 1.8 \\
\hline 1725 & $\begin{array}{l}\text { Aluminum bromide, anhydrous (when spilled in } \\
\text { water) }\end{array}$ & 100 & 0.1 & 0.2 & 300 & 0.6 & 1.7 \\
\hline 1726 & $\begin{array}{l}\text { Aluminum chloride, anhydrous (when spilled in } \\
\text { water) }\end{array}$ & 100 & 0.1 & 0.1 & 200 & 0.3 & 1.0 \\
\hline 1728 & Amyltrichlorosilane (when spilled in water) & 100 & 0.1 & 0.1 & 200 & 0.3 & 1.0 \\
\hline 1732 & Antimony pentafluoride (when spilled in water) & 100 & 0.1 & 0.4 & 500 & 1.0 & 2.3 \\
\hline 1736 & Benzoyl chloride (when spilled in water) & 100 & 0.1 & 0.1 & 100 & 0.2 & 0.7 \\
\hline 1741 & Boron trichloride & 100 & 0.1 & 0.2 & 200 & 0.4 & 1.0 \\
\hline 1744 & Bromine & 200 & 0.2 & 0.7 & 600 & 1.0 & 2.5 \\
\hline 1744 & Bromine, solution & 200 & 0.2 & 0.7 & $600^{-}$ & 1.0 & 2.5 \\
\hline 1745 & Bromine pentafluoride (when spilled on land) & 200 & 0.3 & 0.8 & 800 & 1.4 & 3.1 \\
\hline 1745 & Bromine pentafluoride (when spilled in water) & 100 & 0.1 & 0.5 & $700^{--}$ & 1.2 & 2.6 \\
\hline 1746 & Bromine trifluoride (when spilled on land) & 100 & 0.1 & 0.2 & 200 & 0.2 & 0.5 \\
\hline 1746 & Bromine trifluoride (when spilled in water) & $100^{-1}$ & 0.1 & 0.4 & $600^{--}$ & $1.3^{-}$ & 3.4 \\
\hline 1747 & Butyltrichlorosilane (when spilled in water) & 100 & 0.1 & 0.1 & 200 & 0.3 & 1.1 \\
\hline 1749 & Chlorine trifluoride & 200 & 0.3 & 1.0 & 1100 & 2.1 & 4.8 \\
\hline 1752 & Chloroacetyl chloride (when spilled on land) & 100 & 0.1 & 0.3 & 300 & 0.5 & 1.0 \\
\hline 1752 & Chloroacetyl chloride (when spilled in water) & $100^{-1}$ & 0.1 & 0.1 & 200 & 0.2 & 0.8 \\
\hline 1754 & Chlorosulfonic acid (when spilled on land) & 100 & 0.1 & 0.1 & 100 & 0.1 & 0.3 \\
\hline 1754 & Čhlorosulfonic acid (when spilled in water) & $100^{-1}$ & 0.1 & 0.1 & 200 & $0.3^{-}$ & 0.9 \\
\hline 1754 & $\begin{array}{l}\text { Chlorosulfonic acid and sulfur trioxide mixture } \\
\text { (when spilled on land) }\end{array}$ & 200 & 0.2 & 0.7 & 1000 & 1.3 & 3.5 \\
\hline 1754 & $\begin{array}{l}\text { Člorosulfonic acid and sulfur trioxide mixture } \\
\text { (when spilled in water) }\end{array}$ & 200 & 0.2 & 0.7 & 1000 & $1.3^{-1}$ & 3.5 \\
\hline $1754^{-}$ & Čhlorosulphonic acid (when spilled on land) & 100 & 0.1 & 0.1 & $100^{-1}$ & $0.1^{-}$ & 0.3 \\
\hline 1754 & Chlorosulphonic acid (when spilled in water) & 100 & 0.1 & $0.1^{-}$ & $200^{-1}$ & $0.3^{-1}$ & 0.9 \\
\hline 1754 & $\begin{array}{l}\text { Chlorosulphonic acid and sulphur trioxide mixture } \\
\text { (when spilled on land) }\end{array}$ & 200 & 0.2 & 0.7 & 1000 & $1.3^{-1}$ & 3.5 \\
\hline 1754 & $\begin{array}{l}\text { Chlorosulphonic acid and sulphur trioxide mixture } \\
\text { (when spilled in water) }\end{array}$ & 200 & 0.2 & 0.7 & 1000 & 1.3 & 3.5 \\
\hline 1754 & $\begin{array}{l}\text { Sulfur trioxide and chlorosulfonic acid mixture } \\
\text { (when spilled on land) }\end{array}$ & 200 & 0.2 & 0.7 & 1000 & $1.3^{-1}$ & 3.5 \\
\hline 1754 & $\begin{array}{l}\text { Sulfur trioxide and chlorosulfonic acid mixture } \\
\text { (when spilled in water) }\end{array}$ & 200 & 0.2 & 0.7 & 1000 & 1.3 & 3.5 \\
\hline 1754 & $\begin{array}{l}\text { Sulphur trioxide and chlorosulphonic acid mixture } \\
\text { (when spilled on land) }\end{array}$ & 200 & 0.2 & 0.7 & 1000 & $1.3^{-}$ & 3.5 \\
\hline 1754 & $\begin{array}{l}\text { Sulphur trioxide and chlorosulphonic acid mixture } \\
\text { (when spilled in water) }\end{array}$ & 200 & 0.2 & 0.7 & 1000 & 1.3 & $3.5^{-}$ \\
\hline
\end{tabular}


Table A.1 Table of Initial Isolation and Protective Action Distances (Cont.)

\begin{tabular}{|c|c|c|c|c|c|c|c|}
\hline \multirow[b]{3}{*}{ ID No. } & \multirow[b]{3}{*}{ Name of Material } & \multicolumn{3}{|c|}{ Small Spills } & \multicolumn{3}{|c|}{ Large Spills } \\
\hline & & \multirow{2}{*}{$\begin{array}{c}\text { First } \\
\text { Isolate } \\
\text { in All } \\
\text { Direc- } \\
\text { tions (ft) }\end{array}$} & \multicolumn{2}{|c|}{$\begin{array}{l}\text { Then Protect } \\
\text { Persons } \\
\text { Downwind } \\
\text { during }\end{array}$} & \multirow{2}{*}{\begin{tabular}{|c|} 
First \\
Isolate \\
in All \\
Direc- \\
tions (ft)
\end{tabular}} & \multicolumn{2}{|c|}{$\begin{array}{l}\text { Then Protect } \\
\text { Persons } \\
\text { Downwind } \\
\text { during }\end{array}$} \\
\hline & & & $\begin{array}{l}\text { Day } \\
\text { (mi) }\end{array}$ & $\begin{array}{l}\text { Night } \\
\text { (mi) }\end{array}$ & & $\begin{array}{l}\text { Day } \\
\text { (mi) }\end{array}$ & $\begin{array}{l}\text { Night } \\
\text { (mi) }\end{array}$ \\
\hline 1758 & Chromium oxychloride (when spilled in water) & 100 & 0.1 & 0.1 & 200 & 0.2 & 0.8 \\
\hline 1777 & Fluorosulfonic acid (when spilled in water) & 100 & 0.1 & 0.1 & 200 & 0.3 & 0.9 \\
\hline 1777 & Fluorosulphonic acid (when spilled in water) & 100 & 0.1 & 0.1 & $200^{-}$ & 0.3 & 0.9 \\
\hline 1801 & Octyltrichlorosilane (when spilled in water) & 100 & 0.1 & 0.2 & 300 & 0.5 & 1.5 \\
\hline 1806 & $\begin{array}{l}\text { Phosphorus pentachloride (when spilled in } \\
\text { water) }\end{array}$ & 100 & 0.1 & 0.2 & 400 & 0.6 & 1.8 \\
\hline 1809 & Phosphorus trichloride (when spilled on land) & 100 & 0.1 & 0.4 & 400 & 0.7 & 1.7 \\
\hline 1809 & Phosphorus trichloride (when spilled in water) & 100 & 0.1 & 0.2 & 400 & 0.7 & 1.6 \\
\hline 1810 & Phosphorus oxychloride (when spilled on land) & 100 & 0.1 & 0.3 & 300 & 0.5 & 1.1 \\
\hline 1810 & Phosphorus oxychloride (when spilled in water) & $100^{-1}$ & 0.1 & 0.2 & $300^{-}$ & 0.6 & 1.6 \\
\hline 1818 & Silicon tetrachloride (when spilled in water) & 100 & 0.1 & 0.2 & 400 & 0.8 & 2.1 \\
\hline 1828 & Sulfur chlorides (when spilled on land) & 100 & 0.1 & 0.2 & 200 & 0.3 & 0.6 \\
\hline 1828 & Sulfur chlorides (when spilled in water) & 100 & 0.1 & 0.1 & $200^{-}$ & $0 . \overline{4}$ & 1.4 \\
\hline 1828 & Sulphur chlorides (when spilled on land) & 100 & 0.1 & 0.2 & $200^{-}$ & $0.3^{-}$ & 0.6 \\
\hline 1828 & Sulphur chlorides (when spilled in water) & $100^{-1}$ & 0.1 & 0.1 & $200^{-}$ & $0.4^{-}$ & 1.4 \\
\hline 1829 & Sulfur trioxide & 200 & 0.2 & 0.7 & 1000 & 1.3 & 3.5 \\
\hline 1829 & Sulfur trioxide, inhibited & 200 & 0.2 & 0.7 & 1000 & $1.3^{-1}$ & 3.5 \\
\hline 1829 & Sulfur trioxide, stabilized & 200 & 0.2 & 0.7 & 1000 & $1.3^{-1}$ & 3.5 \\
\hline 1829 & Sulfur trioxide, uninhibited & 200 & 0.2 & 0.7 & 1000 & 1.3 & 3.5 \\
\hline 1829 & Sulphur trioxide & 200 & 0.2 & 0.7 & 1000 & 1.3 & 3.5 \\
\hline 1829 & Sulphur trioxide, inhibited & 200 & 0.2 & 0.7 & 1000 & $1.3^{-1}$ & 3.5 \\
\hline 1829 & Sulphur trioxide, stabilized & 200 & 0.2 & 0.7 & 1000 & $1.3^{--}$ & 3.5 \\
\hline $1829^{-}$ & Sulphur trioxide, uninhibited & 200 & 0.2 & $0 . \overline{7}$ & 1000 & $1.3^{-}$ & 3.5 \\
\hline 1831 & Oleum & 200 & 0.2 & 0.7 & 1000 & 1.3 & 3.5 \\
\hline $1831^{-}$ & Öleum, with not less than $30 \%$ free sulfur trioxide & 200 & 0.2 & 0.7 & 1000 & $1.3^{-1}$ & 3.5 \\
\hline $1831^{-}$ & $\begin{array}{l}\text { Ooleum, with not less than } 30 \% \text { free sulphur } \\
\text { trioxide }\end{array}$ & 200 & 0.2 & 0.7 & 1000 & 1.3 & 3.5 \\
\hline 1831 & Suülfuric acid, fuming & 200 & 0.2 & 0.7 & $1000-$ & $1.3^{-1}$ & 3.5 \\
\hline $1831^{-}$ & $\begin{array}{l}\text { Sulfuric acid, fuming, with not less than } 30 \% \text { free } \\
\text { sulfur trioxide }\end{array}$ & 200 & 0.2 & 0.7 & 1000 & $1.3^{--}$ & 3.5 \\
\hline $1831^{-}$ & Sulphuric acid, fuming & 200 & 0.2 & 0.7 & $1000^{-1}$ & $1.3^{-1}$ & $3.5^{--}$ \\
\hline $1831^{-}$ & $\begin{array}{l}\text { Sulphuric acid, fuming, with not less than } 30 \% \\
\text { free sulphur trioxide }\end{array}$ & 200 & 0.2 & 0.7 & 1000 & $1.3^{-1}$ & $3.5^{-}$ \\
\hline 1834 & Sulfuryl chloride (when spilled on land) & 100 & 0.1 & 0.1 & 100 & 0.2 & 0.4 \\
\hline 1834 & Sulfuryl chloride (when spilled in water) & 100 & 0.1 & 0.1 & $400^{-}$ & $0 . \overline{7}^{-}$ & 1.5 \\
\hline 1834 & Sulphuryl chloride (when spilled on land) & 100 & 0.1 & 0.1 & 100 & $0.2^{-}$ & 0.4 \\
\hline 1834 & Sulphuryl chloride (when spilled in water) & $100^{-1}$ & 0.1 & 0.1 & $400^{-}$ & $0 . \overline{7}^{-}$ & 1.5 \\
\hline 1836 & Thionyl chloride (when spilled on land) & 100 & 0.1 & 0.3 & 200 & 0.3 & 0.7 \\
\hline 1836 & Thionyl chloride (when spilled in water) & 100 & 0.1 & 0.6 & 1100 & 2.0 & 4.4 \\
\hline
\end{tabular}


Table A.1 Table of Initial Isolation and Protective Action Distances (Cont.)

\begin{tabular}{|c|c|c|c|c|c|c|c|}
\hline \multirow[b]{3}{*}{ ID No. } & \multirow[b]{3}{*}{ Name of Material } & \multicolumn{3}{|c|}{ Small Spills } & \multicolumn{3}{|c|}{ Large Spills } \\
\hline & & \multirow{2}{*}{$\begin{array}{c}\text { First } \\
\text { Isolate } \\
\text { in All } \\
\text { Direc- } \\
\text { tions (ft) }\end{array}$} & \multicolumn{2}{|c|}{$\begin{array}{l}\text { Then Protect } \\
\text { Persons } \\
\text { Downwind } \\
\text { during }\end{array}$} & \multirow{2}{*}{$\begin{array}{c}\text { First } \\
\text { Isolate } \\
\text { in All } \\
\text { Direc- } \\
\text { tions (ft) }\end{array}$} & \multicolumn{2}{|c|}{$\begin{array}{l}\text { Then Protect } \\
\text { Persons } \\
\text { Downwind } \\
\text { during }\end{array}$} \\
\hline & & & $\begin{array}{l}\text { Day } \\
\text { (mi) }\end{array}$ & $\begin{array}{l}\text { Night } \\
\text { (mi) }\end{array}$ & & $\begin{array}{l}\text { Day } \\
\text { (mi) }\end{array}$ & $\begin{array}{c}\text { Night } \\
\text { (mi) }\end{array}$ \\
\hline 1838 & Titanium tetrachloride (when spilled on land) & 100 & 0.1 & 0.1 & 100 & 0.2 & 0.5 \\
\hline 1838 & Titanium tetrachloride (when spilled in water) & 100 & 0.1 & 0.2 & $400^{--}$ & 0.7 & 1.8 \\
\hline 1859 & Silicon tetrafluoride & 100 & 0.1 & 0.3 & 200 & 0.3 & 1.0 \\
\hline 1859 & Silicon tetrafluoride, compressed & 100 & 0.1 & 0.3 & 200 & $0.3^{-1}$ & 1.0 \\
\hline 1892 & ED (when used as a weapon) & 100 & 0.2 & 0.5 & 400 & 0.8 & 1.6 \\
\hline 1892 & Éthyldichloroarsine & 100 & 0.1 & 0.2 & 200 & $0.3^{-1}$ & 0.6 \\
\hline 1898 & Acetyl iodide (when spilled in water) & 100 & 0.1 & 0.1 & 200 & 0.4 & 1.0 \\
\hline 1911 & Diborane & 100 & 0.1 & 0.2 & 300 & 0.6 & 1.7 \\
\hline $1911^{-}$ & Diborane, compressed & 100 & 0.1 & 0.2 & $300^{--}$ & 0.6 & $1.7^{-}$ \\
\hline 1923 & Calcium dithionite (when spilled in water) & 100 & 0.1 & 0.1 & 100 & 0.2 & 0.7 \\
\hline 1923 & Calcium hydrosulfite (when spilled in water) & 100 & 0.1 & 0.1 & $100^{-\cdots}$ & $0.2^{--}$ & $0.7^{-}$ \\
\hline 1923 & Calcium hydrosulphite (when spilled in water) & 100 & 0.1 & $0.1^{--}$ & $100^{---}$ & $0.2^{-\cdots}$ & $0.7^{-}$ \\
\hline 1939 & Phosphorus oxybromide (when spilled in water) & 100 & 0.1 & 0.2 & 300 & 0.4 & 1.2 \\
\hline $1939^{-}$ & $\begin{array}{l}\text { Phosphorus oxybromide, solid (when spilled in } \\
\text { water) }\end{array}$ & 100 & 0.1 & 0.2 & 300 & $0.4^{-}$ & $1.2^{--}$ \\
\hline 1953 & $\begin{array}{l}\text { Compressed gas, flammable, poisonous, n.o.s. } \\
\text { (Inhalation Hazard Zone A) }\end{array}$ & 600 & 1.1 & 3.5 & 3000 & 6.7 & $7.0+$ \\
\hline 1953 & $\begin{array}{l}\text { Compressed gas, flammable, poisonous, n.o.s. } \\
\text { (Inhalation Hazard Zone B) }\end{array}$ & 100 & 0.2 & 0.7 & 1000 & $1.9^{-1}$ & 4.8 \\
\hline 1953 & $\begin{array}{l}\text { Compressed gas, flammable, poisonous, n.o.s. } \\
\text { (Inhalation Hazard Zone C) }\end{array}$ & 100 & 0.1 & 0.6 & 700 & $1.3^{-1}$ & 3.5 \\
\hline 1953 & $\begin{array}{l}\text { Compressed gas, flammable, poisonous, n.o.s. } \\
\text { (Inhalation Hazard Zone D) }\end{array}$ & 100 & 0.1 & 0.4 & $600^{-\cdots}$ & $1.0^{-\cdots}$ & $2.7^{-}$ \\
\hline 1953 & $\begin{array}{l}\text { Compressed gas, flammable, toxic, n.o.s. } \\
\text { (Inhalation Hazard Zone A) }\end{array}$ & 600 & 1.1 & 3.5 & 3000 & 6.7 & $7.0+$ \\
\hline 1953 & $\begin{array}{l}\text { Compressed gas, flammable, toxic, n.o.s. } \\
\text { (Inhalation Hazard Zone B) }\end{array}$ & 100 & 0.2 & 0.7 & 1000 & $1.9^{-1}$ & 4.8 \\
\hline 1953 & $\begin{array}{l}\text { Compressed gas, flammable, toxic, n.o.s. } \\
\text { (Inhalation Hazard Zone C) }\end{array}$ & 100 & 0.1 & 0.6 & $700^{-1}$ & $1.3^{-1}$ & $3.5^{-}$ \\
\hline 1953 & $\begin{array}{l}\text { Compressed gas, flammable, toxic, n.o.s. } \\
\text { (Inhalation Hazard Zone D) }\end{array}$ & 100 & $0.1^{--}$ & 0.4 & $600^{-\cdots}$ & $1.0^{-\cdots}$ & 2.7 \\
\hline 1953 & Compressed gas, poisonous, flammable, n.o.s. & 600 & 1.1 & 3.5 & 3000 & $6.7^{-1}$ & $7.0+$ \\
\hline 1953 & $\begin{array}{l}\text { Compressed gas, poisonous, flammable, n.o.s. } \\
\text { (Inhalation Hazard Zone A) }\end{array}$ & 600 & 1.1 & 3.5 & 3000 & 6.7 & $7.0+$ \\
\hline 1953 & $\begin{array}{l}\text { Compressed gas, poisonous, flammable, n.o.s. } \\
\text { (Inhalation Hazard Zone B) }\end{array}$ & $100^{-1}$ & 0.2 & 0.7 & 1000 & 1.9 & 4.8 \\
\hline 1953 & $\begin{array}{l}\text { Compressed gas, poisonous, flammable, n.o.s. } \\
\text { (Inhalation Hazard Zone C) }\end{array}$ & 100 & 0.1 & 0.6 & $700^{-}$ & $1.3^{-}$ & 3.5 \\
\hline 1953 & $\begin{array}{l}\text { Compressed gas, poisonous, flammable, n.o.s. } \\
\text { (Inhalation Hazard Zone D) }\end{array}$ & 100 & 0.1 & 0.4 & 600 & 1.0 & 2.7 \\
\hline 1953 & Compressed gas, toxic, flammable, n.o.s. & 600 & 1.1 & 3.5 & 3000 & 6.7 & $7.0+$ \\
\hline
\end{tabular}


Table A.1 Table of Initial Isolation and Protective Action Distances (Cont.)

\begin{tabular}{|c|c|c|c|c|c|c|c|}
\hline \multirow[b]{3}{*}{ ID No. } & \multirow[b]{3}{*}{ Name of Material } & \multicolumn{3}{|c|}{ Small Spills } & \multicolumn{3}{|c|}{ Large Spills } \\
\hline & & \multirow{2}{*}{$\begin{array}{c}\text { First } \\
\text { Isolate } \\
\text { in All } \\
\text { Direc- } \\
\text { tions (ft) }\end{array}$} & \multicolumn{2}{|c|}{$\begin{array}{l}\text { Then Protect } \\
\text { Persons } \\
\text { Downwind } \\
\text { during }\end{array}$} & \multirow{2}{*}{$\begin{array}{c}\text { First } \\
\text { Isolate } \\
\text { in All } \\
\text { Direc- } \\
\text { tions (ft) }\end{array}$} & \multicolumn{2}{|c|}{$\begin{array}{l}\text { Then Protect } \\
\text { Persons } \\
\text { Downwind } \\
\text { during }\end{array}$} \\
\hline & & & $\begin{array}{l}\text { Day } \\
\text { (mi) }\end{array}$ & $\begin{array}{l}\text { Night } \\
\text { (mi) }\end{array}$ & & $\begin{array}{l}\text { Day } \\
(\mathrm{mi})\end{array}$ & $\begin{array}{l}\text { Night } \\
\text { (mi) }\end{array}$ \\
\hline 1953 & $\begin{array}{l}\text { Compressed gas, toxic, flammable, n.o.s. } \\
\text { (Inhalation Hazard Zone A) }\end{array}$ & 600 & 1.1 & 3.5 & 3000 & 6.7 & $7.0+$ \\
\hline 1953 & $\begin{array}{l}\text { Compressed gas, toxic, flammable, n.o.s. } \\
\text { (Inhalation Hazard Zone B) }\end{array}$ & $100^{--}$ & 0.2 & 0.7 & 1000 & $1.9^{-}$ & 4.8 \\
\hline 1953 & $\begin{array}{l}\text { Compressed gas, toxic, flammable, n.o.s. } \\
\text { (Inhalation Hazard Zone C) }\end{array}$ & $100^{--}$ & 0.1 & 0.6 & $700^{-\cdots}$ & $1.3^{-\cdots}$ & 3.5 \\
\hline 1953 & $\begin{array}{l}\text { Compressed gas, toxic, flammable, n.o.s. } \\
\text { (Inhalation Hazard Zone D) }\end{array}$ & 100 & $0.1^{-1}$ & 0.4 & $600^{-\cdots}$ & $1.0^{--}$ & $2.7^{-}$ \\
\hline 1953 & Liquefied gas, flammable, poisonous, n.o.s. & 600 & 1.1 & 3.5 & 3000 & $6.7^{-1}$ & $7.0+$ \\
\hline $1953^{-1}$ & $\begin{array}{l}\text { Liquefied gas, flammable, poisonous, n.o.s. } \\
\text { (Inhalation Hazard Zone A) }\end{array}$ & 600 & $1.1^{-1}$ & 3.5 & 3000 & $6.7^{-}$ & $7.0+$ \\
\hline 1953 & $\begin{array}{l}\text { Liquefied gas, flammable, poisonous, n.o.s. } \\
\text { (Inhalation Hazard Zone B) }\end{array}$ & 100 & 0.2 & 0.7 & 1000 & $1.9^{-1}$ & 4.8 \\
\hline $1953^{-}$ & $\begin{array}{l}\text { Liquefied gas, flammable, poisonous, n.o.s. } \\
\text { (Inhalation Hazard Zone C) }\end{array}$ & 100 & 0.1 & 0.6 & $700^{--}$ & 1.3 & 3.5 \\
\hline 1953 & $\begin{array}{l}\text { Liquefied gas, flammable, poisonous, n.o.s. } \\
\text { (Inhalation Hazard Zone D) }\end{array}$ & 100 & 0.1 & $0.4^{--}$ & $600^{-\cdots}$ & 1.0 & 2.7 \\
\hline 1953 & Liquefied gas, flammable, toxic, n.o.s. & 600 & 1.1 & 3.5 & $3000^{-1}$ & 6.7 & $7.0+$ \\
\hline $1953^{-1}$ & $\begin{array}{l}\text { Liquefied gas, flammable, toxic, n.o.s. (Inhalation } \\
\text { Hazard Zone A) }\end{array}$ & 600 & 1.1 & 3.5 & 3000 & $6.7^{-1}$ & $7.0+$ \\
\hline 1953 & $\begin{array}{l}\text { Liquefied gas, flammable, toxic, n.o.s. (Inhalation } \\
\text { Hazard Zone B) }\end{array}$ & 100 & 0.2 & 0.7 & $1000^{-\cdots}$ & $1.9^{-\cdots}$ & 4.8 \\
\hline 1953 & $\begin{array}{l}\text { Liquefied gas, flammable, toxic, n.o.s. (Inhalation } \\
\text { Hazard Zone C) }\end{array}$ & 100 & 0.1 & 0.6 & $700^{-\cdots}$ & 1.3 & 3.5 \\
\hline 1953 & $\begin{array}{l}\text { Liquefied gas, flammable, toxic, n.o.s. (Inhalation } \\
\text { Hazard Zone D) }\end{array}$ & $100^{--1}$ & $0.1^{-1}$ & 0.4 & $600^{-1}$ & $1.0^{-\cdots}$ & 2.7 \\
\hline $1953^{--}$ & Póisonous gas, flammable, n.o.s. & 600 & 1.1 & 3.5 & 3000 & $6.7^{--1}$ & $7.0+$ \\
\hline 1953 & Poisonous liquid, flammable, n.o.s. & 500 & 0.8 & 2.1 & 3000 & $5.4^{--}$ & $7.0+$ \\
\hline 1955 & Compressed gas, poisonous, n.o.s. & 1400 & 2.6 & 5.2 & 3000 & $7.0+$ & $7.0+$ \\
\hline $1955^{-}$ & $\begin{array}{l}\text { Compressed gas, poisonous, n.o.s. (Inhalation } \\
\text { Hazard Zone A) }\end{array}$ & $1400^{-}$ & 2.6 & 5.2 & 3000 & $7.0+$ & $7.0+$ \\
\hline 1955 & $\begin{array}{l}\text { Compressed gas, poisonous, n.o.s. (Inhalation } \\
\text { Hazard Zone B) }\end{array}$ & 200 & 0.3 & 1.0 & 1400 & 2.5 & 6.1 \\
\hline 1955 & $\begin{array}{l}\text { Compressed gas, poisonous, n.o.s. (Inhalation } \\
\text { Hazard Zone C) }\end{array}$ & 100 & 0.2 & 0.8 & $700^{-1}$ & 1.9 & 4.5 \\
\hline $1955^{-}$ & $\begin{array}{l}\text { Compressed gas, poisonous, n.o.s. (Inhalation } \\
\text { Hazard Zone D) }\end{array}$ & 100 & 0.1 & $0.4^{-}$ & $600^{--}$ & 1.0 & $2.7^{-}$ \\
\hline $1955^{-1}$ & Compressed gas, toxic, n.o.s. & $1400^{--}$ & 2.6 & 5.2 & 3000 & $7.0+$ & $7.0+$ \\
\hline 1955 & $\begin{array}{l}\text { Compressed gas, toxic, n.o.s. (Inhalation Hazard } \\
\text { Zone A) }\end{array}$ & $1400^{--1}$ & 2.6 & 5.2 & 3000 & $7.0+$ & $7.0+$ \\
\hline 1955 & $\begin{array}{l}\text { Compressed gas, toxic, n.o.s. (Inhalation Hazard } \\
\text { Zone B) }\end{array}$ & 200 & $0.3^{-1}$ & 1.0 & $1400^{--}$ & $2.5^{-}$ & $6.1^{-}$ \\
\hline
\end{tabular}

Continued 
Table A.1 Table of Initial Isolation and Protective Action Distances (Cont.)

\begin{tabular}{|c|c|c|c|c|c|c|c|}
\hline \multirow[b]{3}{*}{ ID No. } & \multirow[b]{3}{*}{ Name of Material } & \multicolumn{3}{|c|}{ Small Spills } & \multicolumn{3}{|c|}{ Large Spills } \\
\hline & & \multirow{2}{*}{$\begin{array}{c}\text { First } \\
\text { Isolate } \\
\text { in All } \\
\text { Direc- } \\
\text { tions (ft) }\end{array}$} & \multicolumn{2}{|c|}{$\begin{array}{l}\text { Then Protect } \\
\text { Persons } \\
\text { Downwind } \\
\text { during }\end{array}$} & \multirow{2}{*}{\begin{tabular}{|c|} 
First \\
Isolate \\
in All \\
Direc- \\
tions (ft)
\end{tabular}} & \multicolumn{2}{|c|}{$\begin{array}{l}\text { Then Protect } \\
\text { Persons } \\
\text { Downwind } \\
\text { during }\end{array}$} \\
\hline & & & $\begin{array}{l}\text { Day } \\
\text { (mi) }\end{array}$ & $\begin{array}{l}\text { Night } \\
\text { (mi) }\end{array}$ & & $\begin{array}{l}\text { Day } \\
(\mathrm{mi})\end{array}$ & $\begin{array}{l}\text { Night } \\
\text { (mi) }\end{array}$ \\
\hline 1955 & $\begin{array}{l}\text { Compressed gas, toxic, n.o.s. (Inhalation Hazard } \\
\text { Zone C) }\end{array}$ & 100 & 0.2 & 0.8 & 700 & 1.9 & 4.5 \\
\hline 1955 & $\begin{array}{l}\text { Compressed gas, toxic, n.o.s. (Inhalation Hazard } \\
\text { Zone D) }\end{array}$ & 100 & 0.1 & 0.4 & $600^{-1}$ & $1.0^{-\cdots}$ & 2.7 \\
\hline 1955 & Liquefied gas, poisonous, n.o.s. & 1400 & 2.6 & 5.2 & 3000 & $7.0+$ & $7.0+$ \\
\hline $1955^{-}$ & $\begin{array}{l}\text { Liquefied gas, poisonous, n.o.s. (Inhalation } \\
\text { Hazard Zone A) }\end{array}$ & $1400^{--}$ & 2.6 & 5.2 & 3000 & $7.0+$ & $7.0+$ \\
\hline $1955^{-}$ & $\begin{array}{l}\text { Liquefied gas, poisonous, n.o.s. (Inhalation } \\
\text { Hazard Zone B) }\end{array}$ & 200 & 0.3 & 1.0 & 1400 & 2.5 & $6.1^{-1}$ \\
\hline 1955 & $\begin{array}{l}\text { Liquefied gas, poisonous, n.o.s. (Inhalation } \\
\text { Hazard Zone C) }\end{array}$ & 100 & 0.2 & 0.8 & $700^{--}$ & $1.9^{--}$ & 4.5 \\
\hline $1955^{-}$ & $\begin{array}{l}\text { Liquefied gas, poisonous, n.o.s. (Inhalation } \\
\text { Hazard Zone D) }\end{array}$ & 100 & 0.1 & 0.4 & $600^{--}$ & $1.0^{--}$ & $2.7^{-}$ \\
\hline 1955 & Liquefied gas, toxic, n.o.s. & $1400^{-}$ & 2.6 & 5.2 & 3000 & $7.0+$ & $7.0+$ \\
\hline 1955 & $\begin{array}{l}\text { Liquefied gas, toxic, n.o.s. (Inhalation Hazard } \\
\text { Zone A) }\end{array}$ & $1400^{-}$ & 2.6 & 5.2 & 3000 & $7.0+$ & $7.0+$ \\
\hline 1955 & $\begin{array}{l}\text { Liquefied gas, toxic, n.o.s. (Inhalation Hazard } \\
\text { Zone B) }\end{array}$ & 200 & 0.3 & 1.0 & 1400 & 2.5 & 6.1 \\
\hline 1955 & $\begin{array}{l}\text { Liquefied gas, toxic, n.o.s. (Inhalation Hazard } \\
\text { Zone C) }\end{array}$ & 100 & 0.2 & 0.8 & $700^{--}$ & $1.9^{--}$ & $4.5^{-}$ \\
\hline $1955^{-}$ & $\begin{array}{l}\text { Liquefied gas, toxic, n.o.s. (Inhalation Hazard } \\
\text { Zone D) }\end{array}$ & 100 & 0.1 & 0.4 & $600^{-1}$ & $1.0^{-\cdots}$ & 2.7 \\
\hline $1955^{-}$ & $\begin{array}{l}\text { Methyl bromide and nonflammable, nonliquefied } \\
\text { compressed gas mixture }\end{array}$ & 100 & 0.1 & 0.2 & $300^{--}$ & $0.3^{-1}$ & 0.9 \\
\hline $1955^{-1}$ & $\begin{array}{l}\text { Organic phosphate compound mixed with } \\
\text { compressed gas }\end{array}$ & $100^{--}$ & $0.2^{-}$ & 0.8 & $1300^{---}$ & 2.5 & $4.5^{-}$ \\
\hline 1955 & Örganic phosphate mixed with compressed gas & 100 & 0.2 & 0.8 & $1300^{-}$ & $2.5^{-1}$ & 4.5 \\
\hline 1955 & $\begin{array}{l}\text { Organic phosphorus compound mixed with } \\
\text { compressed gas }\end{array}$ & 100 & $0.2^{-}$ & 0.8 & 1300 & 2.5 & $4.5^{-}$ \\
\hline 1967 & Insecticide gas, poisonous, n.o.s. & 100 & 0.2 & 0.8 & 1300 & 2.5 & 4.5 \\
\hline 1967 & Insecticide gas, toxic, n.o.s. & $100^{-1}$ & 0.2 & 0.8 & 1300 & $2.5^{-}$ & 4.5 \\
\hline 1967 & Parathion and compressed gas mixture & $100^{-1}$ & 0.1 & 0.2 & 300 & 0.6 & 2.0 \\
\hline 1975 & Dinitrogen tetroxide and nitric oxide mixture & 100 & 0.2 & 0.8 & 500 & 0.8 & 2.2 \\
\hline $1975^{-}$ & Nitric oxide and dinitrogen tetroxide mixture & $100^{-1}$ & 0.2 & 0.8 & $500^{-}$ & 0.8 & 2.2 \\
\hline 1975 & Nitric oxide and nitrogen dioxide mixture & 100 & 0.2 & 0.8 & $500^{-\cdots}$ & 0.8 & 2.2 \\
\hline 1975 & Nitric oxide and nitrogen tetroxide mixture & 100 & 0.2 & 0.8 & $500^{-}$ & 0.8 & 2.2 \\
\hline 1975 & Nitrogen dioxide and nitric oxide mixture & $100^{-1}$ & 0.2 & 0.8 & $500^{-}$ & $0.8^{-}$ & 2.2 \\
\hline 1975 & Nitrogen tetroxide and nitric oxide mixture & 100 & 0.2 & 0.8 & $500^{--}$ & 0.8 & 2.2 \\
\hline 1994 & Iron pentacarbonyl & 100 & 0.2 & 0.4 & 400 & 0.7 & 1.5 \\
\hline 2004 & Magnesium diamide (when spilled in water) & 100 & 0.1 & 0.1 & 200 & 0.3 & 0.8 \\
\hline 2011 & Magnesium phosphide (when spilled in water) & 100 & 0.1 & 0.5 & 800 & 1.4 & 3.7 \\
\hline 2012 & Potassium phosphide (when spilled in water) & 100 & 0.1 & 0.3 & 500 & 0.8 & 2.5 \\
\hline
\end{tabular}


Table A.1 Table of Initial Isolation and Protective Action Distances (Cont.)

\begin{tabular}{|c|c|c|c|c|c|c|c|}
\hline \multirow[b]{3}{*}{ ID No. } & \multirow[b]{3}{*}{ Name of Material } & \multicolumn{3}{|c|}{ Small Spills } & \multicolumn{3}{|c|}{ Large Spills } \\
\hline & & \multirow{2}{*}{$\begin{array}{c}\text { First } \\
\text { Isolate } \\
\text { in All } \\
\text { Direc- } \\
\text { tions (ft) }\end{array}$} & \multicolumn{2}{|c|}{$\begin{array}{l}\text { Then Protect } \\
\text { Persons } \\
\text { Downwind } \\
\text { during }\end{array}$} & \multirow{2}{*}{$\begin{array}{c}\text { First } \\
\text { Isolate } \\
\text { in All } \\
\text { Direc- } \\
\text { tions (ft) }\end{array}$} & \multicolumn{2}{|c|}{$\begin{array}{l}\text { Then Protect } \\
\text { Persons } \\
\text { Downwind } \\
\text { during }\end{array}$} \\
\hline & & & $\begin{array}{l}\text { Day } \\
\text { (mi) }\end{array}$ & $\begin{array}{c}\text { Night } \\
\text { (mi) }\end{array}$ & & $\begin{array}{l}\text { Day } \\
\text { (mi) }\end{array}$ & $\begin{array}{c}\text { Night } \\
\text { (mi) }\end{array}$ \\
\hline 2013 & Strontium phosphide (when spilled in water) & 100 & 0.1 & 0.3 & 500 & 0.8 & 2.3 \\
\hline 2032 & Nitric acid, fuming & 300 & 0.2 & 0.3 & 1300 & 0.8 & 2.2 \\
\hline 2032 & Nitric acid, red fuming & $300^{-1}$ & 0.2 & 0.3 & 1300 & 0.8 & 2.2 \\
\hline 2186 & Hydrogen chloride, refrigerated liquid & 100 & 0.1 & 0.4 & 600 & 1.0 & 2.7 \\
\hline 2188 & Arsine & 200 & 0.3 & 1.3 & 1100 & 2.0 & 4.1 \\
\hline 2188 & SA (when used as a weapon) & 200 & 0.5 & 1.5 & 1300 & 2.5 & $5.0^{--}$ \\
\hline 2189 & Dichlorosilane & 100 & 0.2 & 0.6 & 800 & 1.5 & 3.9 \\
\hline 2190 & Oxygen difluoride & 1400 & 2.6 & 5.2 & 3000 & $7.0+$ & $7.0+$ \\
\hline 2190 & Oxygen difluoride, compressed & 1400 & 2.6 & 5.2 & 3000 & $7.0+$ & $7.0+$ \\
\hline 2191 & Sulfuryl fluoride & 100 & 0.1 & 0.2 & 300 & 0.5 & 1.4 \\
\hline 2191 & Sulphuryl fluoride & $100^{-1}$ & 0.1 & 0.2 & 300 & $0.5^{-}$ & 1.4 \\
\hline 2192 & Germane & 100 & 0.1 & 0.5 & 900 & 1.7 & 4.1 \\
\hline 2194 & Selenium hexafluoride & 100 & 0.2 & 0.8 & 800 & 1.4 & 3.7 \\
\hline 2195 & Tellurium hexafluoride & 200 & 0.4 & 1.4 & 1200 & 2.2 & 4.7 \\
\hline 2196 & Tungsten hexafluoride & 100 & 0.2 & 0.8 & 500 & 0.8 & 2.3 \\
\hline 2197 & Hydrogen iodide, anhydrous & 100 & 0.1 & 0.3 & 300 & 0.5 & 1.6 \\
\hline 2198 & Phosphorus pentafluoride & 100 & 0.2 & 0.7 & 400 & 0.7 & 2.2 \\
\hline 2198 & Phosphorus pentafluoride, compressed & 100 & 0.2 & $0 . \overline{7}$ & 400 & 0.7 & 2.2 \\
\hline 2199 & Phosphine & 300 & 0.2 & 0.8 & 1600 & 1.1 & 3.4 \\
\hline 2202 & Hydrogen selenide, anhydrous & 600 & 1.1 & 3.5 & 3000 & 6.7 & $7.0+$ \\
\hline 2204 & Carbonyl sulfide & 100 & 0.1 & 0.4 & 700 & 1.2 & 3.5 \\
\hline 2204 & Carbonyl sulphide & $100^{-1}$ & 0.1 & 0.4 & $700^{-}$ & 1.2 & 3.5 \\
\hline 2232 & Chloroacetaldehyde & 100 & 0.1 & 0.3 & 200 & 0.4 & 1.0 \\
\hline 2232 & 2-Čhorouethanăl & 100 & 0.1 & 0.3 & 200 & $0.4^{-}$ & $1.0^{--}$ \\
\hline 2334 & Allylamine & 100 & 0.1 & 0.3 & 300 & 0.6 & 1.5 \\
\hline 2337 & Phenyl mercaptan & 100 & 0.1 & 0.1 & 100 & 0.2 & 0.4 \\
\hline 2382 & 1,2-Dimethylhydrazine & 100 & 0.1 & 0.2 & 200 & 0.3 & 0.7 \\
\hline 2382 & Dimethylhydrazine, symmetrical & $100^{-1}$ & 0.1 & 0.2 & $200^{-}$ & $0.3^{-1}$ & $0.7^{-}$ \\
\hline 2407 & Isopropyl chloroformate & 100 & 0.1 & 0.2 & 300 & 0.5 & 1.2 \\
\hline 2417 & Carbonyl fluoride & 100 & 0.1 & 0.7 & 400 & 0.6 & 1.9 \\
\hline 2417 & Carbonyl fluoride, compressed & $100^{-}$ & 0.1 & 0.7 & $400^{-}$ & 0.6 & 1.9 \\
\hline 2418 & Sulfur tetrafluoride & 200 & 0.3 & 1.2 & 1000 & 1.8 & 4.3 \\
\hline 2418 & Sülphur tetrafluoride & 200 & 0.3 & 1.2 & 1000 & 1.8 & 4.3 \\
\hline 2420 & Hexafluoroacetone & 100 & 0.2 & 0.9 & 1200 & 2.3 & 5.3 \\
\hline 2421 & Nitrogen trioxide & 100 & 0.1 & 0.1 & 500 & 0.4 & 1.3 \\
\hline 2438 & Trimethylacetyl chloride & 100 & 0.1 & 0.1 & 100 & 0.2 & 0.5 \\
\hline 2442 & Trichloroacetyl chloride (when spilled on land) & 100 & 0.1 & 0.2 & 200 & 0.4 & 0.9 \\
\hline 2442 & Trichloroacetyl chloride (when spilled in water) & 100 & 0.1 & 0.1 & $100^{--}$ & $0.2^{-1}$ & 0.8 \\
\hline 2474 & Thiophosgene & 200 & 0.4 & 1.1 & 900 & 1.6 & 3.1 \\
\hline
\end{tabular}


Table A.1 Table of Initial Isolation and Protective Action Distances (Cont.)

\begin{tabular}{|c|c|c|c|c|c|c|c|}
\hline \multirow[b]{3}{*}{ ID No. } & \multirow[b]{3}{*}{ Name of Material } & \multicolumn{3}{|c|}{ Small Spills } & \multicolumn{3}{|c|}{ Large Spills } \\
\hline & & \multirow{2}{*}{$\begin{array}{c}\text { First } \\
\text { Isolate } \\
\text { in All } \\
\text { Direc- } \\
\text { tions (ft) }\end{array}$} & \multicolumn{2}{|c|}{$\begin{array}{l}\text { Then Protect } \\
\text { Persons } \\
\text { Downwind } \\
\text { during }\end{array}$} & \multirow{2}{*}{$\begin{array}{c}\text { First } \\
\text { Isolate } \\
\text { in All } \\
\text { Direc- } \\
\text { tions (ft) }\end{array}$} & \multicolumn{2}{|c|}{$\begin{array}{c}\text { Then Protect } \\
\text { Persons } \\
\text { Downwind } \\
\text { during }\end{array}$} \\
\hline & & & $\begin{array}{l}\text { Day } \\
\text { (mi) }\end{array}$ & $\begin{array}{c}\text { Night } \\
\text { (mi) }\end{array}$ & & $\begin{array}{l}\text { Day } \\
\text { (mi) }\end{array}$ & $\begin{array}{c}\text { Night } \\
\text { (mi) }\end{array}$ \\
\hline 2477 & Methyl isothiocyanate & 100 & 0.1 & 0.2 & 200 & 0.3 & 0.7 \\
\hline 2480 & Methyl isocyanate & 300 & 0.5 & 1.7 & 1600 & 3.0 & 6.1 \\
\hline 2481 & Ethyl isocyanate & 700 & 1.2 & 2.7 & 3000 & $7.0+$ & $7.0+$ \\
\hline 2482 & n-Propyl isocyanate & 400 & 0.7 & 1.5 & 2500 & 3.9 & 6.6 \\
\hline 2483 & Isopropyl isocyanate & 600 & 1.1 & 2.4 & 1400 & 2.6 & 4.6 \\
\hline 2484 & tert-Butyl isocyanate & 400 & 0.6 & 1.5 & 1800 & 3.3 & 6.4 \\
\hline 2485 & n-Butyl isocyanate & 300 & 0.5 & 1.0 & 1100 & 1.9 & 3.9 \\
\hline 2486 & Isobutyl isocyanate & 200 & 0.4 & 0.9 & 500 & 1.0 & 2.0 \\
\hline 2487 & Phenyl isocyanate & 100 & 0.2 & 0.5 & 500 & 0.8 & 1.6 \\
\hline 2488 & Cyclohexyl isocyanate & 100 & 0.1 & 0.2 & 300 & 0.5 & 0.9 \\
\hline 2495 & Iodine pentafluoride (when spilled in water) & 100 & 0.1 & 0.3 & 400 & 0.7 & 1.9 \\
\hline 2521 & Diketene, inhibited & 100 & 0.1 & 0.1 & 100 & 0.2 & 0.3 \\
\hline 2534 & Methylchlorosilane & 100 & 0.1 & 0.6 & 700 & 1.3 & 3.5 \\
\hline 2548 & Chlorine pentafluoride & 100 & 0.2 & 0.6 & 1200 & 2.3 & 5.4 \\
\hline 2576 & $\begin{array}{l}\text { Phosphorus oxybromide, molten (when spilled } \\
\text { in water) }\end{array}$ & 100 & 0.1 & 0.2 & 300 & 0.4 & 1.2 \\
\hline 2600 & Carbon monoxide and hydrogen mixture & 100 & 0.1 & 0.1 & 400 & 0.4 & 1.1 \\
\hline 2600 & $\begin{array}{l}\text { Carbon monoxide and hydrogen mixture, } \\
\text { compressed }\end{array}$ & $100^{-1}$ & 0.1 & 0.1 & $400^{-}$ & $0 . \overline{4}$ & 1.1 \\
\hline 2600 & Hydrogen and carbon monoxide mixture & 100 & 0.1 & 0.1 & 400 & 0.4 & 1.1 \\
\hline 2600 & $\begin{array}{l}\text { Hydrogen and carbon monoxide mixture, } \\
\text { compressed }\end{array}$ & $100^{-1}$ & 0.1 & $0.1^{-}$ & $400^{-}$ & $0.4^{-}$ & 1.1 \\
\hline 2605 & Methoxymethyl isocyanate & 200 & 0.2 & 0.5 & 400 & 0.8 & 1.6 \\
\hline 2606 & Methyl orthosilicate & 100 & 0.1 & 0.1 & 100 & 0.2 & 0.4 \\
\hline 2644 & Methyl iodide & 100 & 0.1 & 0.2 & 200 & 0.2 & 0.6 \\
\hline 2646 & Hexachlorocyclopentadiene & 100 & 0.1 & 0.1 & 100 & 0.1 & 0.2 \\
\hline 2668 & Chloroacetonitrile & 100 & 0.1 & 0.1 & 100 & 0.2 & 0.3 \\
\hline 2676 & Stibine & 100 & 0.2 & 1.0 & 800 & 1.4 & 3.7 \\
\hline 2691 & $\begin{array}{l}\text { Phosphorus pentabromide (when spilled in } \\
\text { water) }\end{array}$ & 100 & 0.1 & 0.2 & 300 & 0.5 & 1.5 \\
\hline 2692 & Boron tribromide (when spilled on land) & 100 & 0.1 & 0.2 & 200 & 0.4 & 0.9 \\
\hline 2692 & Boron tribromide (when spilled in water) & 100 & 0.1 & 0.1 & 200 & $0.3^{-1}$ & 1.0 \\
\hline 2740 & n-Propyl chloroformate & 100 & 0.1 & 0.2 & 200 & 0.3 & 0.9 \\
\hline 2742 & sec-Butyl chloroformate & 100 & 0.1 & 0.1 & 100 & 0.2 & 0.4 \\
\hline 2742 & Isobutyl chloroformate & 100 & 0.1 & 0.1 & 200 & 0.2 & 0.5 \\
\hline 2743 & n-Butyl chloroformate & 100 & 0.1 & 0.1 & 100 & 0.2 & 0.3 \\
\hline 2806 & Lithium nitride (when spilled in water) & 100 & 0.1 & 0.1 & 300 & 0.5 & 1.3 \\
\hline
\end{tabular}


Table A.1 Table of Initial Isolation and Protective Action Distances (Cont.)

\begin{tabular}{|c|c|c|c|c|c|c|c|}
\hline \multirow[b]{3}{*}{ ID No. } & \multirow[b]{3}{*}{ Name of Material } & \multicolumn{3}{|c|}{ Small Spills } & \multicolumn{3}{|c|}{ Large Spills } \\
\hline & & \multirow{2}{*}{$\begin{array}{c}\text { First } \\
\text { Isolate } \\
\text { in All } \\
\text { Direc- } \\
\text { tions (ft) }\end{array}$} & \multicolumn{2}{|c|}{$\begin{array}{l}\text { Then Protect } \\
\text { Persons } \\
\text { Downwind } \\
\text { during }\end{array}$} & \multirow{2}{*}{\begin{tabular}{|c|} 
First \\
Isolate \\
in All \\
Direc- \\
tions (ft)
\end{tabular}} & \multicolumn{2}{|c|}{$\begin{array}{l}\text { Then Protect } \\
\text { Persons } \\
\text { Downwind } \\
\text { during }\end{array}$} \\
\hline & & & $\begin{array}{l}\text { Day } \\
\text { (mi) }\end{array}$ & $\begin{array}{l}\text { Night } \\
\text { (mi) }\end{array}$ & & $\begin{array}{l}\text { Day } \\
\text { (mi) }\end{array}$ & $\begin{array}{l}\text { Night } \\
\text { (mi) }\end{array}$ \\
\hline 2810 & Bis-(2-chloroethyl) ethylamine & 100 & 0.1 & 0.1 & 100 & 0.1 & 0.2 \\
\hline 2810 & Bis-(2-chloroethyl) methylamine & 100 & 0.1 & 0.1 & $100^{--}$ & $0.1^{-}$ & $0.2^{--}$ \\
\hline 2810 & Bis-(2-chloroethyli) sulfide & 100 & 0.1 & 0.1 & $100^{-\cdots}$ & $0.1^{-1}$ & $0.2^{--}$ \\
\hline $2810^{-}$ & Bis-(2-chloroethyl) sulphide & 100 & 0.1 & 0.1 & 100 & $0.1^{-}$ & $0.2^{-2}$ \\
\hline 2810 & Buzz (when used as a weapon) & 100 & 0.1 & 0.3 & 200 & $0.3^{-1}$ & $1.2^{-}$ \\
\hline $2810^{-}$ & $B Z$ (when used as a weapon) & 100 & 0.1 & 0.3 & $200^{-}$ & $0.3^{-1}$ & $1.2^{-}$ \\
\hline 2810 & $\overline{C S}$ (when used as a weapon) & 200 & 0.2 & 0.7 & $800^{-}$ & 1.6 & 3.5 \\
\hline 2810 & DC (when used as a weapon) & 100 & 0.1 & 0.5 & $800^{---}$ & $1.4^{-}$ & 3.3 \\
\hline 2810 & $\begin{array}{l}\text { Ö-Ëthyi S-(2-diisopropylaminoethyl) } \\
\text { methylphosphonothiolate }\end{array}$ & 100 & 0.1 & 0.1 & $100^{-\cdot-}$ & $0.1^{-1}$ & $0.1^{-}$ \\
\hline 2810 & Ėthyl $\mathrm{N}, \mathrm{N}$-dimethylphosphoramidocyanidate & 100 & $0.1^{-1}$ & $0.1^{--}$ & $200^{--}$ & 0.3 & 0.6 \\
\hline $2810^{-}$ & $\mathrm{GA}$ (when used as a weapon) & 100 & 0.2 & 0.4 & 500 & $1.0^{-}$ & 1.9 \\
\hline 2810 & GB (when used as a weapon) & 500 & 1.0 & 2.1 & 3000 & $7.0+$ & $7.0+$ \\
\hline 2810 & $G \bar{D}$ (when used as a weapon) & 300 & 0.5 & $1.1^{-}$ & 2500 & 4.2 & 6.5 \\
\hline $2810^{-}$ & GF (when used as a weapon) & 100 & 0.2 & 0.4 & 800 & 1.4 & 3.2 \\
\hline 2810 & $\mathrm{H}$ (when used as a weapon) & 100 & 0.1 & $0.1^{-}$ & 200 & $0.4^{-}$ & 0.7 \\
\hline 2810 & $\mathrm{HD}$ (when used as a weapon) & 100 & 0.1 & 0.1 & 200 & $0 . \overline{4}$ & 0.7 \\
\hline 2810 & $\mathrm{HL}$ (when used as a weapon) & 100 & 0.1 & 0.2 & $300^{-}$ & 0.6 & 1.1 \\
\hline 2810 & $\mathrm{HN}-1$ (when used as a weapon) & 100 & 0.1 & 0.1 & $200^{-}$ & $0 . \overline{4}$ & 0.8 \\
\hline 2810 & $\mathrm{HN}-2$ (when used as a weapon) & 100 & 0.1 & 0.1 & 200 & $0.3^{-}$ & 0.7 \\
\hline 2810 & $\mathrm{HN}-3$ (when used as a weapon) & 100 & 0.1 & 0.1 & $100^{--}$ & 0.1 & 0.2 \\
\hline 2810 & Isopropyl methylphosphonofluoridate & 400 & 0.8 & 1.4 & $1800^{-}$ & $3.3^{-1}$ & 5.4 \\
\hline 2810 & $\mathrm{~L}$ (Lewisite) (when used as a weapon) & 100 & 0.1 & 0.2 & 300 & $0 . \overline{6}$ & 1.1 \\
\hline 2810 & Lewisite (when used as a weapon) & 100 & 0.1 & 0.2 & $300^{--}$ & 0.6 & 1.1 \\
\hline 2810 & Mustard (when used as a weapon) & 100 & $0.1^{-1}$ & 0.1 & 100 & $0.1^{-1}$ & 0.2 \\
\hline 2810 & Mustard Lewisite (when used as a weapon) & 100 & 0.1 & 0.2 & $300^{--}$ & 0.6 & 1.1 \\
\hline $2810^{-}$ & Pinacolyl methylphosphonofluoridate & 200 & 0.3 & 0.5 & $700^{--}$ & $1.3^{-1}$ & 1.9 \\
\hline 2810 & Poisonous liquid, n.o.s. & 700 & 1.2 & 2.7 & 3000 & $7.0+$ & $7.0+$ \\
\hline 2810 & $\begin{array}{l}\text { Poisonous liquid, n.o.s. (Inhalation Hazard } \\
\text { Zone A) }\end{array}$ & 700 & 1.2 & 2.7 & 3000 & $7.0+$ & $7.0+$ \\
\hline 2810 & $\begin{array}{l}\text { Poisonous liquid, n.o.s. (Inhalation Hazard } \\
\text { Zone B) }\end{array}$ & $200^{--}$ & 0.3 & 0.8 & 800 & $1 . \overline{4}$ & 3.1 \\
\hline 2810 & Poisonous liquid, organic, n.o.s. & 700 & 1.2 & 2.7 & 3000 & $7.0+$ & $7.0+$ \\
\hline 2810 & $\begin{array}{l}\text { Poisonous liquid, organic, n.o.s. (Inhalation } \\
\text { Hazard Zone A) }\end{array}$ & 700 & 1.2 & 2.7 & 3000 & $7.0+$ & $7.0+$ \\
\hline $2810^{-}$ & $\begin{array}{l}\text { Póisonous liquid, organic, n.o.s. (Inhalation } \\
\text { Hazard Zone B) }\end{array}$ & 200 & 0.2 & 0.7 & $600^{-\cdots}$ & $1.0^{-}$ & $2.5^{-}$ \\
\hline 2810 & Sarin (when used as a weapon) & 500 & 1.0 & $2.1^{--}$ & 3000 & $7.0+$ & $7.0+$ \\
\hline 2810 & Soman (when used as a weapon) & 300 & 0.5 & $1.1^{-\cdots}$ & 2500 & 4.2 & 6.5 \\
\hline 2810 & Tabun (when used as a weapon) & 100 & $0.2^{-}$ & $0.4^{-\cdots}$ & $500^{--1}$ & $1.0^{-1}$ & 1.9 \\
\hline
\end{tabular}

Continued 
Table A.1 Table of Initial Isolation and Protective Action Distances (Cont.)

\begin{tabular}{|c|c|c|c|c|c|c|c|}
\hline \multirow[b]{3}{*}{ ID No. } & \multirow[b]{3}{*}{ Name of Material } & \multicolumn{3}{|c|}{ Small Spills } & \multicolumn{3}{|c|}{ Large Spills } \\
\hline & & \multirow{2}{*}{$\begin{array}{c}\text { First } \\
\text { Isolate } \\
\text { in All } \\
\text { Direc- } \\
\text { tions (ft) }\end{array}$} & \multicolumn{2}{|c|}{$\begin{array}{l}\text { Then Protect } \\
\text { Persons } \\
\text { Downwind } \\
\text { during }\end{array}$} & \multirow{2}{*}{\begin{tabular}{|c|} 
First \\
Isolate \\
in All \\
Direc- \\
tions (ft)
\end{tabular}} & \multicolumn{2}{|c|}{$\begin{array}{l}\text { Then Protect } \\
\text { Persons } \\
\text { Downwind } \\
\text { during }\end{array}$} \\
\hline & & & $\begin{array}{l}\text { Day } \\
\text { (mi) }\end{array}$ & $\begin{array}{l}\text { Night } \\
\text { (mi) }\end{array}$ & & $\begin{array}{l}\text { Day } \\
\text { (mi) }\end{array}$ & $\begin{array}{l}\text { Night } \\
\text { (mi) }\end{array}$ \\
\hline 2810 & Thickened GD (when used as a weapon) & 300 & 0.5 & 1.1 & 2500 & 4.2 & 6.5 \\
\hline 2810 & Toxic liquid, n.o.s. & 700 & 1.2 & 2.7 & 3000 & $7.0+$ & $7.0+$ \\
\hline 2810 & Toxic liquid, n.o.s. (Inhalation Hazard Zone A) & 700 & 1.2 & 2.7 & 3000 & $7.0+$ & $7.0+$ \\
\hline 2810 & Toxic liquid, n.o.s. (Inhalation Hazard Žone B) & 200 & 0.3 & 0.8 & $800^{--}$ & 1.4 & $3.1^{-1}$ \\
\hline 2810 & Toxic liquid, organic, n.o.s. & 700 & 1.2 & 2.7 & 3000 & $7.0+$ & $7.0+$ \\
\hline $2810^{-}$ & $\begin{array}{l}\text { Toxic liquid, organic, n.o.s. (Inhalation Hazard } \\
\text { Zone A) }\end{array}$ & $700^{--1}$ & 1.2 & 2.7 & 3000 & $7.0+$ & $7.0+$ \\
\hline 2810 & $\begin{array}{l}\text { Toxic liquid, organic, n.o.s. (Inhalation Hazard } \\
\text { Zone B) }\end{array}$ & $200^{--}$ & 0.2 & $0 . \overline{7}^{--}$ & $600^{---}$ & $1.0^{-1}$ & 2.5 \\
\hline 2810 & Tris-(2-chloroethyl) amine & 100 & 0.1 & 0.1 & $100^{-}$ & $0.1^{-}$ & 0.1 \\
\hline 2810 & $\mathrm{VX}$ (when used as a weapon) & 100 & 0.1 & 0.1 & $200^{-}$ & $0.4^{-}$ & 0.6 \\
\hline 2811 & $\mathrm{CX}$ (when used as a weapon) & 100 & 0.1 & 0.3 & 300 & 0.6 & 1.9 \\
\hline 2826 & Ethyl chlorothioformate & 100 & 0.1 & 0.1 & 200 & 0.3 & 0.5 \\
\hline 2845 & Ethyl phosphonous dichloride, anhydrous & 200 & 0.3 & 0.8 & 500 & 1.0 & 2.1 \\
\hline 2845 & Methyl phosphonous dichloride & 200 & 0.3 & 0.8 & 800 & $1 . \overline{4}$ & 3.1 \\
\hline 2901 & Bromine chloride & 100 & 0.2 & 0.6 & 500 & 1.0 & 2.5 \\
\hline 2927 & Ethyl phosphonothioic dichloride, anhydrous & 100 & 0.1 & 0.1 & 100 & 0.1 & 0.1 \\
\hline 2927 & Éthyl phosphorodichloridate & $100^{-1}$ & 0.1 & 0.1 & $100^{-}$ & $0.1^{-1}$ & 0.2 \\
\hline 2927 & Poisonous liquid, corrosive, n.o.s. & $700^{-1}$ & 1.2 & 2.7 & 3000 & $7.0+$ & $7.0+$ \\
\hline 2927 & $\begin{array}{l}\text { Poisonous liquid, corrosive, n.o.s. (Inhalation } \\
\text { Hazard Zone A) }\end{array}$ & 700 & 1.2 & 2.7 & 3000 & $7.0+$ & $7.0+$ \\
\hline 2927 & $\begin{array}{l}\text { Poisonous liquid, corrosive, n.o.s. (Inhalation } \\
\text { Hazard Zone B) }\end{array}$ & 200 & 0.2 & 0.7 & $800^{-1}$ & 1.0 & 2.5 \\
\hline 2927 & Toxic liquid, corrosive, organic, n.o.s. & $700^{-1}$ & 1.2 & 2.7 & 3000 & $7.0+$ & $7.0+$ \\
\hline 2927 & $\begin{array}{l}\text { Toxic liquid, corrosive, organic, n.o.s. (Inhalation } \\
\text { Hazard Zone A) }\end{array}$ & 700 & 1.2 & 2.7 & 3000 & $7.0+$ & $7.0+$ \\
\hline 2927 & $\begin{array}{l}\text { Toxic liquid, corrosive, organic, n.o.s. (Inhalation } \\
\text { Hazard Zone B) }\end{array}$ & 100 & 0.2 & 0.5 & $500^{-}$ & 0.9 & 2.2 \\
\hline 2929 & Poisonous liquid, flammable, n.o.s. & 500 & 0.8 & 2.1 & 3000 & 5.4 & $7.0+$ \\
\hline 2929 & $\begin{array}{l}\text { Poisonous liquid, flammable, n.o.s. (Inhalation } \\
\text { Hazard Zone A) }\end{array}$ & 500 & 0.8 & $2.1^{-1}$ & 3000 & 5.4 & $7.0+$ \\
\hline 2929 & $\begin{array}{l}\text { Poisonous liquid, flammable, n.o.s. (Inhalation } \\
\text { Hazard Zone B) }\end{array}$ & 100 & 0.1 & $0.4^{-}$ & $400^{--}$ & 0.7 & $1.7^{--}$ \\
\hline 2929 & Poisonous liquid, flammable, organic, n.o.s. & 500 & 0.8 & 2.1 & 3000 & 5.4 & $7.0+$ \\
\hline 2929 & $\begin{array}{l}\text { Poisonous liquid, flammable, organic, n.o.s. } \\
\text { (Inhalation Hazard Zone A) }\end{array}$ & 500 & 0.8 & 2.1 & 3000 & 5.4 & $7.0+$ \\
\hline 2929 & $\begin{array}{l}\text { Poisonous liquid, flammable, organic, n.o.s. } \\
\text { (Inhalation Hazard Zone B) }\end{array}$ & 100 & 0.1 & 0.4 & $400^{--}$ & 0.7 & $1.7^{--}$ \\
\hline 2929 & Tơxic liquid, flammäble, n.o.s. & 500 & 0.8 & 2.1 & 3000 & $5.4^{-}$ & $7.0+$ \\
\hline 2929 & $\begin{array}{l}\text { Toxic liquid, flammable, n.o.s. (Inhalation Hazard } \\
\text { Zone A) }\end{array}$ & 500 & $0.8^{-}$ & $2.1^{-}$ & 3000 & 5.4 & $7.0+$ \\
\hline
\end{tabular}


Table A.1 Table of Initial Isolation and Protective Action Distances (Cont.)

\begin{tabular}{|c|c|c|c|c|c|c|c|}
\hline \multirow[b]{3}{*}{ ID No. } & \multirow[b]{3}{*}{ Name of Material } & \multicolumn{3}{|c|}{ Small Spills } & \multicolumn{3}{|c|}{ Large Spills } \\
\hline & & \multirow{2}{*}{$\begin{array}{c}\text { First } \\
\text { Isolate } \\
\text { in All } \\
\text { Direc- } \\
\text { tions (ft) }\end{array}$} & \multicolumn{2}{|c|}{$\begin{array}{l}\text { Then Protect } \\
\text { Persons } \\
\text { Downwind } \\
\text { during }\end{array}$} & \multirow{2}{*}{$\begin{array}{c}\text { First } \\
\text { Isolate } \\
\text { in All } \\
\text { Direc- } \\
\text { tions (ft) }\end{array}$} & \multicolumn{2}{|c|}{$\begin{array}{l}\text { Then Protect } \\
\text { Persons } \\
\text { Downwind } \\
\text { during }\end{array}$} \\
\hline & & & $\begin{array}{l}\text { Day } \\
\text { (mi) }\end{array}$ & $\begin{array}{l}\text { Night } \\
\text { (mi) }\end{array}$ & & $\begin{array}{l}\text { Day } \\
\text { (mi) }\end{array}$ & $\begin{array}{l}\text { Night } \\
\text { (mi) }\end{array}$ \\
\hline 2929 & $\begin{array}{l}\text { Toxic liquid, flammable, n.o.s. (Inhalation Hazard } \\
\text { Zone B) }\end{array}$ & 100 & 0.1 & 0.4 & 400 & 0.7 & 1.7 \\
\hline 2929 & Toxic liquid, flammable, organic, n.o.s. & 500 & 0.8 & 2.1 & 3000 & $5.4^{-}$ & $7.0+$ \\
\hline 2929 & $\begin{array}{l}\text { T̄oxic liquid, flammable, organic, n.o.s. } \\
\text { (Inhalation Hazard Zone A) }\end{array}$ & 500 & 0.8 & $2.1^{-}$ & 3000 & $5.4^{--}$ & $7.0+$ \\
\hline 2929 & $\begin{array}{l}\text { Toxic liquid, flammable, organic, n.o.s. } \\
\text { (Inhalation Hazard Zone B) }\end{array}$ & 100 & 0.1 & 0.4 & $400^{---}$ & $0.7^{--}$ & $1.7^{-}$ \\
\hline 2977 & $\begin{array}{l}\text { Radioactive material, Uranium hexafluoride, } \\
\text { fissile (when spilled in water) }\end{array}$ & 100 & 0.1 & 0.3 & 300 & 0.6 & 1.9 \\
\hline 2977 & $\begin{array}{l}\text { Uranium hexafluoride, fissile containing more } \\
\text { than } 1 \% \text { uranium-235 (when spilled in water) }\end{array}$ & 100 & 0.1 & $0.3^{-\cdots}$ & $300^{---}$ & 0.6 & $1.9^{--}$ \\
\hline 2978 & $\begin{array}{l}\text { Radioactive material, uranium hexafluoride, non } \\
\text { fissile or fissile-excepted (when spilled in water) }\end{array}$ & 100 & 0.1 & 0.3 & 300 & 0.6 & 1.9 \\
\hline 2978 & $\begin{array}{l}\text { Uranium hexafluoride, fissile excepted (when } \\
\text { spilled in water) }\end{array}$ & 100 & 0.1 & 0.3 & 300 & 0.6 & $1.9^{-1}$ \\
\hline 2978 & $\begin{array}{l}\text { Uranium hexafluoride, low specific activity } \\
\text { (when spilled in water) }\end{array}$ & 100 & 0.1 & 0.3 & 300 & 0.6 & $1.9^{-}$ \\
\hline 2978 & $\begin{array}{l}\text { Uranium hexafluoride, non-fissile (when spilled } \\
\text { in water) }\end{array}$ & $100^{-1}$ & 0.1 & 0.3 & $300^{-}$ & $0.6^{-}$ & 1.9 \\
\hline 2985 & $\begin{array}{l}\text { Chlorosilanes, flammable, corrosive, n.o.s. } \\
\text { (when spilled in water) }\end{array}$ & 100 & 0.1 & 0.2 & 400 & 0.7 & 1.8 \\
\hline 2985 & Chlorosilanes, n.o.s (when spilled in water) & 100 & 0.1 & 0.2 & 400 & $0.7^{-}$ & 1.8 \\
\hline 2986 & $\begin{array}{l}\text { Chlorosilanes, corrosive, flammable, n.o.s. } \\
\text { (when spilled in water) }\end{array}$ & 100 & 0.1 & 0.2 & 400 & 0.7 & 1.8 \\
\hline 2986 & Chlorosilanes, n.o.s. (when spilled in water) & $100^{-1}$ & 0.1 & 0.2 & $400^{-}$ & $0.7^{--}$ & 1.8 \\
\hline 2987 & $\begin{array}{l}\text { Chlorosilanes, corrosive, n.o.s. (when spilled in } \\
\text { water) }\end{array}$ & 100 & 0.1 & 0.2 & 400 & 0.7 & 1.8 \\
\hline 2987 & Chilorosilanes, n.o.s (when spilled in water) & 100 & 0.1 & 0.2 & $400^{--}$ & $0.7^{-1}$ & 1.8 \\
\hline 2988 & Chlorosilanes, n.o.s. (when spilled in water) & 100 & 0.1 & 0.2 & 400 & 0.7 & 1.8 \\
\hline 2988 & $\begin{array}{l}\text { Čhlorosilanes, water-reactive, flammable, } \\
\text { corrosive, n.o.s. (when spilled in water) }\end{array}$ & 100 & 0.1 & 0.2 & $400^{-\cdots}$ & $0.7^{-}$ & 1.8 \\
\hline 3023 & 2-Methyl-2-hepthanethiol & 100 & 0.1 & 0.1 & 200 & 0.3 & 0.7 \\
\hline 3023 & tert-Öctyl mercaptan & 100 & 0.1 & 0.1 & 200 & 0.3 & 0.7 \\
\hline 3048 & $\begin{array}{l}\text { Aluminum phosphide pesticide (when spilled in } \\
\text { water) }\end{array}$ & 100 & 0.1 & 0.5 & 700 & 1.2 & 3.3 \\
\hline 3049 & $\begin{array}{l}\text { Metal alkyl halides, n.o.s. (when spilled in } \\
\text { water) }\end{array}$ & 100 & 0.1 & 0.1 & 100 & 0.2 & 0.8 \\
\hline 3049 & $\begin{array}{l}\text { Metal alkyl halides, water-reactive, n.o.s. (when } \\
\text { spilled in water) }\end{array}$ & 100 & 0.1 & 0.1 & $10 \overline{0}$ & 0.2 & 0.8 \\
\hline 3049 & Metal aryl halides, n.o.s. (when spilled in water) & 100 & 0.1 & 0.1 & $100^{-}$ & 0.2 & 0.8 \\
\hline 3049 & $\begin{array}{l}\text { Metal aryl halides, water-reactive, n.o.s. (when } \\
\text { spilled in water) }\end{array}$ & 100 & 0.1 & 0.1 & 100 & 0.2 & 0.8 \\
\hline
\end{tabular}

Continued 
Table A.1 Table of Initial Isolation and Protective Action Distances (Cont.)

\begin{tabular}{|c|c|c|c|c|c|c|c|}
\hline \multirow[b]{3}{*}{ ID No. } & \multirow[b]{3}{*}{ Name of Material } & \multicolumn{3}{|c|}{ Small Spills } & \multicolumn{3}{|c|}{ Large Spills } \\
\hline & & \multirow{2}{*}{$\begin{array}{c}\text { First } \\
\text { Isolate } \\
\text { in All } \\
\text { Direc- } \\
\text { tions (ft) }\end{array}$} & \multicolumn{2}{|c|}{$\begin{array}{l}\text { Then Protect } \\
\text { Persons } \\
\text { Downwind } \\
\text { during }\end{array}$} & \multirow{2}{*}{$\begin{array}{c}\text { First } \\
\text { Isolate } \\
\text { in All } \\
\text { Direc- } \\
\text { tions (ft) }\end{array}$} & \multicolumn{2}{|c|}{$\begin{array}{l}\text { Then Protect } \\
\text { Persons } \\
\text { Downwind } \\
\text { during }\end{array}$} \\
\hline & & & $\begin{array}{l}\text { Day } \\
\text { (mi) }\end{array}$ & $\begin{array}{c}\text { Night } \\
\text { (mi) }\end{array}$ & & $\begin{array}{l}\text { Day } \\
\text { (mi) }\end{array}$ & $\begin{array}{c}\text { Night } \\
\text { (mi) }\end{array}$ \\
\hline 3052 & Aluminum alkyl halides (when spilled in water) & 100 & 0.1 & 0.1 & 100 & 0.2 & 0.8 \\
\hline 3057 & Trifluoroacetyl chloride & 100 & 0.2 & 0.9 & 1400 & 2.5 & 5.3 \\
\hline 3079 & Methacrylonitrile, inhibited & 100 & 0.1 & 0.3 & 200 & 0.4 & 1.0 \\
\hline 3083 & Perchloryl fluoride & 100 & 0.1 & 0.6 & 700 & 1.4 & 3.5 \\
\hline 3122 & Poisonous liquid, oxidizing, n.o.s. & 500 & 0.8 & 2.1 & 3000 & 5.4 & $7.0+$ \\
\hline 3122 & $\begin{array}{l}\text { Poisonous liquids, oxidizing, n.o.s. (Inhalation } \\
\text { Hazard Zone A) }\end{array}$ & $500^{--}$ & 0.8 & 2.1 & 3000 & $5.4^{-1}$ & $7.0+$ \\
\hline 3122 & $\begin{array}{l}\text { Poisonous liquids, oxidizing, n.o.s. (Inhalation } \\
\text { Hazard Zone B) }\end{array}$ & $100^{--}$ & $0.1^{--}$ & 0.4 & $400^{-1}$ & 0.7 & 1.7 \\
\hline 3122 & T̄oxic liquid, oxidizing, n.o.s. & 500 & 0.8 & 2.1 & $3000^{-}$ & $5.4^{-}$ & $7.0+$ \\
\hline 3122 & $\begin{array}{l}\text { Toxic liquid, oxidizing, n.o.s. (Inhalation Hazard } \\
\text { Zone A) }\end{array}$ & 500 & 0.8 & 2.1 & 3000 & 5.4 & $7.0+$ \\
\hline 3122 & $\begin{array}{l}\text { Toxic liquid, oxidizing, no.s. (Inhalation Hazard } \\
\text { Zone B) }\end{array}$ & 100 & 0.1 & 0.4 & 400 & $0 . \overline{7}$ & 1.7 \\
\hline 3123 & Poisonous liquid, water-reactive, n.o.s. & 700 & 1.2 & 2.7 & 3000 & $7.0+$ & $7.0+$ \\
\hline 3123 & $\begin{array}{l}\text { Poisonous liquid, water-reactive, n.o.s. } \\
\text { (Inhalation Hazard Zone A) }\end{array}$ & 700 & 1.2 & 2.7 & 3000 & $7.0+$ & $7.0+$ \\
\hline 3123 & $\begin{array}{l}\text { Poisonous liquid, water-reactive, n.o.s. } \\
\text { (Inhalation Hazard Zone B) }\end{array}$ & 200 & $0.3^{-}$ & 0.8 & 800 & 1.4 & 3.1 \\
\hline 3123 & $\begin{array}{l}\text { Poisonous liquid, which in contact with water } \\
\text { emits flammable gases, n.o.s. }\end{array}$ & 700 & 1.2 & $2.7^{-}$ & 3000 & $7.0+$ & $7.0+$ \\
\hline 3123 & $\begin{array}{l}\text { emits flammable gases, n.o.s. (Inhalation Hazard } \\
\text { Zone A) }\end{array}$ & 700 & 1.2 & 2.7 & 3000 & $7.0+$ & $7.0+$ \\
\hline 3123 & $\begin{array}{l}\text { Poisonous liquid, which in contact with water } \\
\text { Zonits flammable gases, n.o.s. (Inhalation Hazard }\end{array}$ & 200 & 0.3 & 0.8 & $800^{-}$ & $1.4^{-}$ & 3.1 \\
\hline 3123 & Toxic liquid, water-reactive, n.o.s. & $700^{-1}$ & 1.2 & 2.7 & 3000 & $7.0+$ & $7.0+$ \\
\hline 3123 & $\begin{array}{l}\text { Toxic liquid, water-reactive, n.o.s. (Inhalation } \\
\text { Hazard Zone A) }\end{array}$ & $700^{-1}$ & 1.2 & 2.7 & $3000^{-}$ & $7.0+$ & $7.0+$ \\
\hline 3123 & $\begin{array}{l}\text { Toxic liquid, water-reactive, n.o.s. (Inhalation } \\
\text { Hazard Zone B) }\end{array}$ & 200 & 0.3 & 0.8 & $800^{-}$ & $1.4^{-}$ & 3.1 \\
\hline 3123 & $\begin{array}{l}\text { Toxic liquid, which in contact with water emits } \\
\text { flammable gases, n.o.s. }\end{array}$ & 700 & 1.2 & 2.7 & 3000 & $7.0+$ & $7.0+$ \\
\hline 3123 & $\begin{array}{l}\text { Toxic liquid, which in contact with water emits } \\
\text { flammable gases, n.o.s. (Inhalation Hazard } \\
\text { Zone A) }\end{array}$ & $700^{-1}$ & 1.2 & 2.7 & 3000 & $7.0+$ & $7.0+$ \\
\hline 3123 & $\begin{array}{l}\text { Tlamic liquid, which in contact with water emits } \\
\text { Zone B) }\end{array}$ & 200 & $0.3^{-}$ & 0.8 & $800^{-1}$ & 1.4 & 3.1 \\
\hline
\end{tabular}


Table A.1 Table of Initial Isolation and Protective Action Distances (Cont.)

\begin{tabular}{|c|c|c|c|c|c|c|c|}
\hline \multirow[b]{3}{*}{ ID No. } & \multirow[b]{3}{*}{ Name of Material } & \multicolumn{3}{|c|}{ Small Spills } & \multicolumn{3}{|c|}{ Large Spills } \\
\hline & & \multirow{2}{*}{$\begin{array}{c}\text { First } \\
\text { Isolate } \\
\text { in All } \\
\text { Direc- } \\
\text { tions (ft) }\end{array}$} & \multicolumn{2}{|c|}{$\begin{array}{l}\text { Then Protect } \\
\text { Persons } \\
\text { Downwind } \\
\text { during }\end{array}$} & \multirow{2}{*}{$\begin{array}{c}\text { First } \\
\text { Isolate } \\
\text { in All } \\
\text { Direc- } \\
\text { tions (ft) }\end{array}$} & \multicolumn{2}{|c|}{$\begin{array}{l}\text { Then Protect } \\
\text { Persons } \\
\text { Downwind } \\
\text { during }\end{array}$} \\
\hline & & & $\begin{array}{l}\text { Day } \\
\text { (mi) }\end{array}$ & $\begin{array}{l}\text { Night } \\
\text { (mi) }\end{array}$ & & $\begin{array}{l}\text { Day } \\
\text { (mi) }\end{array}$ & $\begin{array}{l}\text { Night } \\
\text { (mi) }\end{array}$ \\
\hline 3160 & Liquefied gas, poisonous, flammable, n.o.s. & 600 & 1.1 & 3.5 & 3000 & 6.7 & $7.0+$ \\
\hline 3160 & $\begin{array}{l}\text { Liquefied gas, poisonous, flammable, n.o.s. } \\
\text { (Inhalation Hazard Zone A) }\end{array}$ & 600 & 1.1 & $3.5^{-}$ & 3000 & $6.7^{--}$ & $7.0+$ \\
\hline 3160 & $\begin{array}{l}\text { Liquefied gas, poisonous, flammabie, n.o.s. } \\
\text { (Inhalation Hazard Zone B) }\end{array}$ & 100 & 0.2 & 0.7 & 1000 & $1.9^{-\cdots}$ & 4.8 \\
\hline 3160 & $\begin{array}{l}\text { Liquefied gas, poisonous, flammable, n.o.s. } \\
\text { (Inhalation Hazard Zone C) }\end{array}$ & $100^{--}$ & $0.1^{--}$ & 0.6 & $700^{--}$ & $1.3^{--}$ & 3.5 \\
\hline $3160^{-}$ & $\begin{array}{l}\text { Liquefied gas, poisonous, flammable, n.o.s. } \\
\text { (Inhalation Hazard Zone D) }\end{array}$ & 100 & 0.1 & $0.4^{--}$ & $600^{--}$ & $1.0^{--}$ & $2.7^{-}$ \\
\hline 3160 & Liquefied gas, toxic, flammable, no.s. & 600 & 1.1 & 3.5 & 3000 & 6.7 & $7.0+$ \\
\hline $3160^{-}$ & $\begin{array}{l}\text { Liquefied gas, toxic, flammable, n.o.s. (Inhalation } \\
\text { Hazard Zone A) }\end{array}$ & 600 & 1.1 & 3.5 & 3000 & 6.7 & $7.0+$ \\
\hline $3160^{-}$ & $\begin{array}{l}\text { Liquefied gas, toxic, flammable, n.o.s. (Inhalation } \\
\text { Hazard Zone B) }\end{array}$ & 100 & 0.2 & 0.7 & $1000^{-1}$ & 1.9 & 4.8 \\
\hline $3160^{-}$ & $\begin{array}{l}\text { Liquefied gas, toxic, flammable, n.o.s. (Inhalation } \\
\text { Hazard Zone C) }\end{array}$ & 100 & 0.1 & 0.6 & 700 & 1.3 & 3.5 \\
\hline 3160 & $\begin{array}{l}\text { Liquefied gas, toxic, flammable, n.o.s. (Inhalation } \\
\text { Hazard Zone D) }\end{array}$ & 100 & 0.1 & 0.4 & 600 & 1.0 & 2.7 \\
\hline 3162 & Liquefied gas, poisonous, n.o.s. & 1400 & 2.6 & 5.2 & 3000 & $7.0+$ & $7.0+$ \\
\hline 3162 & $\begin{array}{l}\text { Liquefied gas, poisonous, n.o.s. (Inhalation } \\
\text { Hazard Zone A) }\end{array}$ & $1400^{--1}$ & 2.6 & 5.2 & 3000 & $7.0+$ & $7.0+$ \\
\hline 3162 & $\begin{array}{l}\text { Liquefied gas, poisonous, n.o.s. (Inhalation } \\
\text { Hazard Zone B) }\end{array}$ & 200 & $0.3^{-}$ & 1.0 & $1400^{--1}$ & 2.5 & 6.1 \\
\hline 3162 & $\begin{array}{l}\text { Liquefied gas, poisonous, n.o.s. (Inhalation } \\
\text { Hazard Zone C) }\end{array}$ & $100^{--1}$ & $0.2^{-1}$ & 0.8 & $700^{--}$ & $1.9^{-1}$ & $4.5^{-}$ \\
\hline 3162 & $\begin{array}{l}\text { Liquefied gas, poisonous, n.o.s. (Inhalation } \\
\text { Hazard Zone D) }\end{array}$ & 100 & $0.1^{-1}$ & 0.4 & $600^{--}$ & $1.0^{--}$ & $2.7^{-}$ \\
\hline 3162 & Liquefied gas, toxic, n.o.s. & $1400^{--}$ & 2.6 & 5.2 & 3000 & $7.0+$ & $7.0+$ \\
\hline 3162 & $\begin{array}{l}\text { Liquefied gas, toxic, n.o.s. (Inhalation Hazard } \\
\text { Zone A) }\end{array}$ & $1400^{--}$ & 2.6 & 5.2 & 3000 & $7.0+$ & $7.0+$ \\
\hline 3162 & $\begin{array}{l}\text { Liquefied gas, toxic, n.o.s. (Inhalation Hazard } \\
\text { Zone B) }\end{array}$ & 200 & 0.3 & 1.0 & 1400 & 2.5 & 6.1 \\
\hline 3162 & $\begin{array}{l}\text { Liquefied gas, toxic, n.o.s. (Inhalation Hazard } \\
\text { Zone C) }\end{array}$ & 100 & 0.2 & 0.8 & 700 & 1.9 & 4.5 \\
\hline 3162 & $\begin{array}{l}\text { Liquefied gas, toxic, n.o.s. (Inhalation Hazard } \\
\text { Zone D) }\end{array}$ & 100 & 0.1 & 0.4 & 600 & $1.0^{-}$ & 2.7 \\
\hline 3246 & Methanesulfonyl chloride & 300 & 0.4 & 1.5 & 800 & 1.4 & 3.2 \\
\hline 3246 & Methanesulphonyl chloride & 300 & 0.4 & 1.5 & 800 & 1.4 & 3.2 \\
\hline 3275 & Nitriles, poisonous, flammable, n.o.s. & 100 & 0.1 & 0.3 & 200 & 0.4 & 1.0 \\
\hline $3275^{-}$ & Nitriles, toxic, flammable, n.o.s. & 100 & 0.1 & $0.3^{--}$ & 200 & $0.4^{-}$ & 1.0 \\
\hline 3276 & Nitriles, poisonous, n.o.s. & 100 & 0.1 & 0.3 & 200 & 0.4 & 1.0 \\
\hline 3276 & Nitriles, toxic, n.o.s. & 100 & 0.1 & 0.3 & 200 & $0.4^{-1}$ & 1.0 \\
\hline
\end{tabular}

Continued 
Table A.1 Table of Initial Isolation and Protective Action Distances (Cont.)

\begin{tabular}{|c|c|c|c|c|c|c|c|}
\hline \multirow[b]{3}{*}{ ID No. } & \multirow[b]{3}{*}{ Name of Material } & \multicolumn{3}{|c|}{ Small Spills } & \multicolumn{3}{|c|}{ Large Spills } \\
\hline & & \multirow{2}{*}{$\begin{array}{c}\text { First } \\
\text { Isolate } \\
\text { in All } \\
\text { Direc- } \\
\text { tions (ft) }\end{array}$} & \multicolumn{2}{|c|}{$\begin{array}{l}\text { Then Protect } \\
\text { Persons } \\
\text { Downwind } \\
\text { during }\end{array}$} & \multirow{2}{*}{$\begin{array}{c}\text { First } \\
\text { Isolate } \\
\text { in All } \\
\text { Direc- } \\
\text { tions (ft) }\end{array}$} & \multicolumn{2}{|c|}{$\begin{array}{l}\text { Then Protect } \\
\text { Persons } \\
\text { Downwind } \\
\text { during }\end{array}$} \\
\hline & & & $\begin{array}{l}\text { Day } \\
\text { (mi) }\end{array}$ & $\begin{array}{c}\text { Night } \\
\text { (mi) }\end{array}$ & & $\begin{array}{l}\text { Day } \\
\text { (mi) }\end{array}$ & $\begin{array}{l}\text { Night } \\
\text { (mi) }\end{array}$ \\
\hline 3278 & Organophosphorus compound, poisonous, n.o.s. & 200 & 0.3 & 0.8 & 800 & 1.4 & 3.1 \\
\hline 3278 & Örganophosphorus compound, toxic, no.s. & 200 & 0.3 & 0.8 & $800^{-}$ & 1.4 & 3.1 \\
\hline 3279 & $\begin{array}{l}\text { Organophosphorus compound, poisonous, } \\
\text { flammable, n.o.s. }\end{array}$ & 200 & 0.3 & 0.8 & 800 & 1.4 & 3.1 \\
\hline 3279 & $\begin{array}{l}\text { Organophosphorus compound, toxic, flammable, } \\
\text { n.o.s. }\end{array}$ & 200 & 0.3 & 0.8 & $800^{-1}$ & $1 . \overline{4}$ & 3.1 \\
\hline 3280 & Organoarsenic compound, n.o.s. & 100 & 0.1 & 0.5 & 600 & 1.1 & 2.7 \\
\hline 3281 & Metal carbonyls, n.o.s. & 200 & 0.4 & 1.3 & 700 & 1.3 & 2.7 \\
\hline 3287 & Poisonous liquid, inorganic, n.o.s. & 500 & 0.8 & 2.3 & 2500 & 4.1 & 6.6 \\
\hline 3287 & $\begin{array}{l}\text { Poisonous liquid, inorganic, n.o.s. (Inhalation } \\
\text { Hazard Zone A) }\end{array}$ & 500 & 0.8 & 2.3 & 2500 & 4.1 & 6.6 \\
\hline 3287 & $\begin{array}{l}\text { Poisonous liquid, inorganic, n.o.s. (Inhalation } \\
\text { Hazard Zone B) }\end{array}$ & 200 & 0.3 & 0.8 & 800 & $1.4^{-}$ & 3.1 \\
\hline 3287 & Toxic liquid, inorganic, n.o.s. & 500 & 0.8 & 2.3 & 2500 & $4.1^{-1}$ & 6.6 \\
\hline 3287 & $\begin{array}{l}\text { Toxic liquid, inorganic, n.o.s. (Inhalation Hazard } \\
\text { Zone A) }\end{array}$ & 500 & 0.8 & 2.3 & 2500 & $4.1^{-1}$ & 6.6 \\
\hline 3287 & $\begin{array}{l}\text { Toxic liquid, inorganic, n.o.s. (Inhalation Hazard } \\
\text { Zone B) }\end{array}$ & 200 & 0.3 & 0.8 & $800^{-\cdots}$ & $1 . \overline{4}$ & $3.1^{-1}$ \\
\hline 3289 & Poisonous liquid, corrosive, inorganic, n.o.s. & 300 & 0.4 & 1.1 & 1300 & 1.6 & 3.1 \\
\hline 3289 & $\begin{array}{l}\text { Poisonous liquid, corrosive, inorganic, n.o.s. } \\
\text { (Inhalation Hazard Zone A) }\end{array}$ & 300 & 0.4 & 1.1 & 1300 & 1.6 & 3.1 \\
\hline 3289 & $\begin{array}{l}\text { Poisonous liquid, corrosive, inorganic, n.o.s. } \\
\text { (Inhalation Hazard Zone B) }\end{array}$ & 200 & 0.2 & 0.7 & 600 & 1.0 & 2.5 \\
\hline 3289 & Toxic liquid, corrosive, inorganic, n.o.s. & 300 & 0.4 & 1.1 & 1300 & 1.6 & 3.1 \\
\hline 3289 & $\begin{array}{l}\text { Toxic liquid, corrosive, inorganic, n.o.s. } \\
\text { (Inhalation Hazard Zone A) }\end{array}$ & 300 & 0.4 & 1.1 & 1300 & 1.6 & 3.1 \\
\hline 3289 & $\begin{array}{l}\text { Toxic liquid, corrosive, inorganic, n.o.s. } \\
\text { (Inhalation Hazard Zone B) }\end{array}$ & 200 & 0.2 & 0.7 & 600 & 1.0 & 2.5 \\
\hline 3294 & $\begin{array}{l}\text { Hydrogen cyanide, solution in alcohol, with not } \\
\text { more than } 45 \% \text { hydrogen cyanide }\end{array}$ & 100 & 0.1 & 0.2 & 700 & 0.4 & 1.2 \\
\hline 3300 & $\begin{array}{l}\text { Carbon dioxide and ethylene oxide mixture, with } \\
\text { more than } 87 \% \text { ethylene oxide }\end{array}$ & 100 & 0.1 & 0.1 & 200 & 0.3 & 1.1 \\
\hline 3300 & $\begin{array}{l}\text { Ethylene oxide and carbon dioxide mixture, with } \\
\text { more than } 87 \% \text { ethylene oxide }\end{array}$ & 100 & 0.1 & 0.1 & $200^{-}$ & $0.3^{-}$ & 1.1 \\
\hline
\end{tabular}


Table A.1 Table of Initial Isolation and Protective Action Distances (Cont.)

\begin{tabular}{|c|c|c|c|c|c|c|c|}
\hline \multirow[b]{3}{*}{ ID No. } & \multirow[b]{3}{*}{ Name of Material } & \multicolumn{3}{|c|}{ Small Spills } & \multicolumn{3}{|c|}{ Large Spills } \\
\hline & & \multirow{2}{*}{$\begin{array}{c}\text { First } \\
\text { Isolate } \\
\text { in All } \\
\text { Direc- } \\
\text { tions (ft) }\end{array}$} & \multicolumn{2}{|c|}{$\begin{array}{l}\text { Then Protect } \\
\text { Persons } \\
\text { Downwind } \\
\text { during }\end{array}$} & \multirow{2}{*}{$\begin{array}{c}\text { First } \\
\text { Isolate } \\
\text { in All } \\
\text { Direc- } \\
\text { tions (ft) }\end{array}$} & \multicolumn{2}{|c|}{$\begin{array}{l}\text { Then Protect } \\
\text { Persons } \\
\text { Downwind } \\
\text { during }\end{array}$} \\
\hline & & & $\begin{array}{l}\text { Day } \\
\text { (mi) }\end{array}$ & $\begin{array}{l}\text { Night } \\
\text { (mi) }\end{array}$ & & $\begin{array}{l}\text { Day } \\
(\mathrm{mi})\end{array}$ & $\begin{array}{l}\text { Night } \\
\text { (mi) }\end{array}$ \\
\hline 3303 & Compressed gas, poisonous, oxidizing, n.o.s. & 1400 & 2.6 & 5.2 & 3000 & $7.0+$ & $7.0+$ \\
\hline 3303 & $\begin{array}{l}\text { Compressed gas, poisonous, oxidizing, n.o.s. } \\
\text { (Inhalation Hazard Zone A) }\end{array}$ & 1400 & 2.6 & 5.2 & 3000 & $7.0+$ & $7.0+$ \\
\hline 3303 & $\begin{array}{l}\text { Compressed gas, poisonous, oxidizing, n.o.s. } \\
\text { (Inhalation Hazard Zone B) }\end{array}$ & 200 & $0.3^{-1}$ & $1.0^{--}$ & 1100 & $2.1^{--}$ & 4.8 \\
\hline 3303 & $\begin{array}{l}\text { Compressed gas, poisonous, oxidizing, n.o.s. } \\
\text { (Inhalation Hazard Zone C) }\end{array}$ & 100 & $0.2^{-1}$ & $0.8^{--}$ & $700^{--}$ & $1.9^{--}$ & 4.5 \\
\hline $3303^{-}$ & $\begin{array}{l}\text { Compressed gas, poisonous, oxidizing, n.o.s. } \\
\text { (Inhalation Hazard Zone D) }\end{array}$ & 100 & 0.1 & $0.4^{--}$ & $600^{--}$ & 1.0 & 2.7 \\
\hline 3303 & Compressed gas, toxic, oxidizing, n.o.s. & $1400^{-}$ & 2.6 & $5.2^{--}$ & 3000 & $7.0+$ & $7.0+$ \\
\hline 3303 & $\begin{array}{l}\text { Compressed gas, toxic, oxidizing, n.o.s. } \\
\text { (Inhalation Hazard Zone A) }\end{array}$ & $1400^{--}$ & 2.6 & $5.2^{--}$ & 3000 & $7.0+$ & $7.0+$ \\
\hline 3303 & $\begin{array}{l}\text { Compressed gas, toxic, oxidizing, n.o.s. } \\
\text { (Inhalation Hazard Zone B) }\end{array}$ & 200 & $0.3^{-1}$ & 1.0 & $1100^{--}$ & $2.1^{--1}$ & 4.8 \\
\hline 3303 & $\begin{array}{l}\text { Compressed gas, toxic, oxidizing, n.o.s. } \\
\text { (Inhalation Hazard Zone C) }\end{array}$ & 100 & 0.2 & 0.8 & $700^{---}$ & 1.9 & 4.5 \\
\hline 3303 & $\begin{array}{l}\text { Compressed gas, toxic, oxidizing, n.o.s. } \\
\text { (Inhalation Hazard Zone D) }\end{array}$ & $100^{-\cdots}$ & 0.1 & 0.4 & $600^{-\cdots}$ & 1.0 & 2.7 \\
\hline 3304 & Compressed gas, poisonous, corrosive, n.o.s. & 1400 & 2.6 & 5.2 & 3000 & $7.0+$ & $7.0+$ \\
\hline 3304 & $\begin{array}{l}\text { Compressed gas, poisonous, corrosive, n.o.s. } \\
\text { (Inhalation Hazard Zone A) }\end{array}$ & $1400^{-}$ & 2.6 & 5.2 & 3000 & $7.0+$ & $7.0+$ \\
\hline 3304 & $\begin{array}{l}\text { Compressed gas, poisonous, corrosive, n.o.s. } \\
\text { (Inhalation Hazard Zone B) }\end{array}$ & 200 & 0.3 & 1.0 & 1400 & 2.5 & 6.1 \\
\hline 3304 & $\begin{array}{l}\text { Compressed gas, poisonous, corrosive, n.o.s. } \\
\text { (Inhalation Hazard Zone C) }\end{array}$ & 100 & 0.2 & 0.8 & $600^{-1}$ & 1.9 & 4.5 \\
\hline 3304 & $\begin{array}{l}\text { Compressed gas, poisonous, corrosive, n.o.s. } \\
\text { (Inhalation Hazard Zone D) }\end{array}$ & 100 & 0.1 & 0.4 & 600 & 1.0 & 2.7 \\
\hline 3304 & Compressed gas, toxic, corrosive, n.o.s. & $1400^{-}$ & 2.6 & 5.2 & 3000 & $7.0+$ & $7.0+$ \\
\hline $3304^{-}$ & $\begin{array}{l}\text { Compressed gas, toxic, corrosive, n.o.s. } \\
\text { (Inhalation Hazard Zone A) }\end{array}$ & $1400^{-1}$ & 2.6 & 5.2 & $3000^{-1}$ & $7.0+$ & $7.0+$ \\
\hline 3304 & $\begin{array}{l}\text { Compressed gas, toxic, corrosive, n.o.s. } \\
\text { (Inhalation Hazard Zone B) }\end{array}$ & 200 & 0.3 & 1.0 & $1400^{-1}$ & 2.5 & 6.1 \\
\hline 3304 & $\begin{array}{l}\text { Compressed gas, toxic, corrosive, n.o.s. } \\
\text { (Inhalation Hazard Zone C) }\end{array}$ & 100 & $0.2^{-2}$ & $0.8^{-}$ & 600 & 1.9 & 4.5 \\
\hline 3304 & $\begin{array}{l}\text { Compressed gas, toxic, corrosive, n.o.s. } \\
\text { (Inhalation Hazard Zone D) }\end{array}$ & $100^{-}$ & $0.1^{-1}$ & $0.4^{-}$ & 600 & $1.0^{\circ}$ & 2.7 \\
\hline
\end{tabular}

Continued 
Table A.1 Table of Initial Isolation and Protective Action Distances (Cont.)

\begin{tabular}{|c|c|c|c|c|c|c|c|}
\hline \multirow[b]{3}{*}{ ID No. } & \multirow[b]{3}{*}{ Name of Material } & \multicolumn{3}{|c|}{ Small Spills } & \multicolumn{3}{|c|}{ Large Spills } \\
\hline & & \multirow{2}{*}{$\begin{array}{c}\text { First } \\
\text { Isolate } \\
\text { in All } \\
\text { Direc- } \\
\text { tions (ft) }\end{array}$} & \multicolumn{2}{|c|}{$\begin{array}{l}\text { Then Protect } \\
\text { Persons } \\
\text { Downwind } \\
\text { during }\end{array}$} & \multirow{2}{*}{$\begin{array}{c}\text { First } \\
\text { Isolate } \\
\text { in All } \\
\text { Direc- } \\
\text { tions (ft) }\end{array}$} & \multicolumn{2}{|c|}{$\begin{array}{l}\text { Then Protect } \\
\text { Persons } \\
\text { Downwind } \\
\text { during }\end{array}$} \\
\hline & & & $\begin{array}{l}\text { Day } \\
\text { (mi) }\end{array}$ & $\begin{array}{l}\text { Night } \\
\text { (mi) }\end{array}$ & & $\begin{array}{l}\text { Day } \\
\text { (mi) }\end{array}$ & $\begin{array}{l}\text { Night } \\
\text { (mi) }\end{array}$ \\
\hline 3305 & $\begin{array}{l}\text { Compressed gas, poisonous, flammable, } \\
\text { corrosive, n.o.s. }\end{array}$ & 1400 & 2.6 & 5.2 & 3000 & $7.0+$ & $7.0+$ \\
\hline 3305 & $\begin{array}{l}\text { Compressed gas, poisonous, flammable, } \\
\text { corrosive, n.o.s. (Inhalation Hazard Zone A) }\end{array}$ & $1400^{-}$ & 2.6 & 5.2 & 3000 & $7.0+$ & $7.0+$ \\
\hline 3305 & $\begin{array}{l}\text { Compressed gas, poisonous, flammable, } \\
\text { corrosive, n.o.s. (Inhalation Hazard Zone B) }\end{array}$ & 200 & 0.3 & 1.0 & 1400 & 2.5 & 6.1 \\
\hline 3305 & $\begin{array}{l}\text { Compressed gas, poisonous, flammable, } \\
\text { corrosive, n.o.s. (Inhalation Hazard Zone C) }\end{array}$ & 100 & 0.2 & 0.8 & 600 & 1.9 & 4.5 \\
\hline $3305^{-}$ & $\begin{array}{l}\text { Compressed gas, poisonous, flammable, } \\
\text { corrosive, n.o.s. (Inhalation Hazard Zone D) }\end{array}$ & 100 & $0.1^{-}$ & $0.4^{-}$ & $600^{--}$ & $1.0^{-1}$ & 2.7 \\
\hline 3305 & $\begin{array}{l}\text { Compressed gas, toxic, flammable, corrosive, } \\
\text { n.o.s. }\end{array}$ & $1400^{-}$ & 2.6 & 5.2 & 3000 & $7.0+$ & $7.0+$ \\
\hline 3305 & $\begin{array}{l}\text { Compressed gas, toxic, flammable, corrosive, } \\
\text { n.o.s. (Inhalation Hazard Zone A) }\end{array}$ & $1400^{-}$ & 2.6 & 5.2 & 3000 & $7.0+$ & $7.0+$ \\
\hline 3305 & $\begin{array}{l}\text { Compressed gas, toxic, flammable, corrosive, } \\
\text { n.o.s. (Inhalation Hazard Zone B) }\end{array}$ & 200 & 0.3 & 1.0 & 1400 & 2.5 & 6.1 \\
\hline 3305 & $\begin{array}{l}\text { Compressed gas, toxic, flammable, corrosive, } \\
\text { n.o.s. (Inhalation Hazard Zone C) }\end{array}$ & $100^{-1}$ & 0.2 & 0.8 & $600^{-}$ & 1.9 & 4.5 \\
\hline 3305 & $\begin{array}{l}\text { Compressed gas, toxic, flammable, corrosive, } \\
\text { n.o.s. (Inhalation Hazard Zone D) }\end{array}$ & 100 & 0.1 & 0.4 & $600^{-}$ & 1.0 & 2.7 \\
\hline 3306 & $\begin{array}{l}\text { Compressed gas, poisonous, oxidizing, } \\
\text { corrosive, n.o.s. }\end{array}$ & 1400 & 2.6 & 5.2 & 3000 & $7.0+$ & $7.0+$ \\
\hline 3306 & $\begin{array}{l}\text { Compressed gas, poisonous, oxidizing, } \\
\text { corrosive, n.o.s. (Inhalation Hazard Zone A) }\end{array}$ & $1400^{-}$ & 2.6 & 5.2 & 3000 & $7.0+$ & $7.0+$ \\
\hline 3306 & $\begin{array}{l}\text { Compressed gas, poisonous, oxidizing, } \\
\text { corrosive, n.o.s. (Inhalation Hazard Zone B) }\end{array}$ & 200 & 0.3 & 1.0 & 1100 & 2.1 & 4.8 \\
\hline 3306 & $\begin{array}{l}\text { Compressed gas, poisonous, oxidizing, } \\
\text { corrosive, n.o.s. (Inhalation Hazard Zone C) }\end{array}$ & 100 & 0.2 & 0.8 & 600 & 1.9 & $4.5^{-}$ \\
\hline 3306 & $\begin{array}{l}\text { Compressed gas, poisonous, oxidizing, } \\
\text { corrosive, n.o.s. (Inhalation Hazard Zone D) }\end{array}$ & 100 & $0.1^{-1}$ & 0.4 & 600 & 1.0 & $2.7^{-}$ \\
\hline 3306 & $\begin{array}{l}\text { Compressed gas, toxic, oxidizing, corrosive, } \\
\text { n.o.s. }\end{array}$ & $1400^{--}$ & 2.6 & 5.2 & 3000 & $7.0+$ & $7.0+$ \\
\hline 3306 & $\begin{array}{l}\text { Compressed gas, toxic, oxidizing, corrosive, } \\
\text { n.o.s. (Inhalation Hazard Zone A) }\end{array}$ & 1400 & 2.6 & 5.2 & 3000 & $7.0+$ & $7.0+$ \\
\hline 3306 & $\begin{array}{l}\text { Compressed gas, toxic, oxidizing, corrosive, } \\
\text { n.o.s. (Inhalation Hazard Zone B) }\end{array}$ & 200 & $0.3^{-1}$ & 1.0 & 1100 & $2.1^{1}$ & 4.8 \\
\hline 3306 & $\begin{array}{l}\text { Compressed gas, toxic, oxidizing, corrosive, } \\
\text { n.o.s. (Inhalation Hazard Zone C) }\end{array}$ & $100^{-}$ & 0.2 & 0.8 & $600^{-}$ & 1.9 & $4.5^{-}$ \\
\hline 3306 & $\begin{array}{l}\text { Compressed gas, toxic, oxidizing, corrosive, } \\
\text { n.o.s. (Inhalation Hazard Zone D) }\end{array}$ & 100 & 0.1 & $0.4^{-}$ & $600^{-1}$ & 1.0 & $2.7^{-}$ \\
\hline
\end{tabular}


Table A.1 Table of Initial Isolation and Protective Action Distances (Cont.)

\begin{tabular}{|c|c|c|c|c|c|c|c|}
\hline \multirow[b]{3}{*}{ ID No. } & \multirow[b]{3}{*}{ Name of Material } & \multicolumn{3}{|c|}{ Small Spills } & \multicolumn{3}{|c|}{ Large Spills } \\
\hline & & \multirow{2}{*}{$\begin{array}{c}\text { First } \\
\text { Isolate } \\
\text { in All } \\
\text { Direc- } \\
\text { tions (ft) }\end{array}$} & \multicolumn{2}{|c|}{$\begin{array}{l}\text { Then Protect } \\
\text { Persons } \\
\text { Downwind } \\
\text { during }\end{array}$} & \multirow{2}{*}{$\begin{array}{c}\text { First } \\
\text { Isolate } \\
\text { in All } \\
\text { Direc- } \\
\text { tions (ft) }\end{array}$} & \multicolumn{2}{|c|}{$\begin{array}{l}\text { Then Protect } \\
\text { Persons } \\
\text { Downwind } \\
\text { during }\end{array}$} \\
\hline & & & $\begin{array}{l}\text { Day } \\
\text { (mi) }\end{array}$ & $\begin{array}{l}\text { Night } \\
\text { (mi) }\end{array}$ & & $\begin{array}{l}\text { Day } \\
\text { (mi) }\end{array}$ & $\begin{array}{l}\text { Night } \\
\text { (mi) }\end{array}$ \\
\hline 3307 & Liquefied gas, poisonous, oxidizing, n.o.s. & 1400 & 2.6 & 5.2 & 3000 & $7.0+$ & $7.0+$ \\
\hline 3307 & $\begin{array}{l}\text { Liquefied gas, poisonous, oxidizing, n.o.s. } \\
\text { (Inhalation Hazard Zone A) }\end{array}$ & 1400 & 2.6 & 5.2 & 3000 & $7.0+$ & $7.0+$ \\
\hline 3307 & $\begin{array}{l}\text { Liquefied gas, poisonous, oxidizing, n.o.s. } \\
\text { (Inhalation Hazard Zone B) }\end{array}$ & 200 & $0.3^{-1}$ & $1.0^{--}$ & 1100 & $2.1^{1}$ & 4.8 \\
\hline 3307 & $\begin{array}{l}\text { Liquefied gas, poisonous, oxidizing, n.o.s. } \\
\text { (Inhalation Hazard Zone C) }\end{array}$ & $100^{--}$ & $0.2^{-1}$ & $0.8^{--}$ & $700^{--}$ & 1.9 & 4.5 \\
\hline $3307^{-}$ & $\begin{array}{l}\text { Liquefied gas, poisonous, oxidizing, n.o.s. } \\
\text { (Inhalation Hazard Zone D) }\end{array}$ & 100 & 0.1 & $0.4^{--}$ & 600 & $1.0^{-}$ & 2.7 \\
\hline $3307^{-}$ & Liquefied gas, toxic, oxidizing, n.o.s. & 1400 & 2.6 & $5.2^{--}$ & 3000 & $7.0+$ & $7.0+$ \\
\hline $3307^{-1}$ & $\begin{array}{l}\text { Liquefied gas, toxic, oxidizing, n.o.s. (Inhalation } \\
\text { Hazard Zone A) }\end{array}$ & $1400^{--}$ & 2.6 & $5.2^{--}$ & 3000 & $7.0+$ & $7.0+$ \\
\hline $3307^{-1}$ & $\begin{array}{l}\text { Liquefied gas, toxic, oxidizing, n.o.s. (Inhalation } \\
\text { Hazard Zone B) }\end{array}$ & 200 & $0.3^{-1}$ & 1.0 & 1100 & $2.1^{-1}$ & 4.8 \\
\hline 3307 & $\begin{array}{l}\text { Liquefied gas, toxic, oxidizing, n.o.s. (Inhalation } \\
\text { Hazard Zone C) }\end{array}$ & 100 & 0.2 & 0.8 & $700^{---}$ & $1.9^{-1}$ & 4.5 \\
\hline 3307 & $\begin{array}{l}\text { Liquefied gas, toxic, oxidizing, n.o.s. (Inhalation } \\
\text { Hazard Zone D) }\end{array}$ & $100^{-\cdots}$ & 0.1 & 0.4 & 600 & 1.0 & 2.7 \\
\hline 3308 & Liquefied gas, poisonous, corrosive, n.o.s. & 1400 & 2.6 & 5.2 & 3000 & $7.0+$ & $7.0+$ \\
\hline 3308 & $\begin{array}{l}\text { Liquefied gas, poisonous, corrosive, n.o.s. } \\
\text { (Inhalation Hazard Zone A) }\end{array}$ & $1400^{-}$ & 2.6 & 5.2 & 3000 & $7.0+$ & $7.0+$ \\
\hline 3308 & $\begin{array}{l}\text { Liquefied gas, poisonous, corrosive, n.o.s. } \\
\text { (Inhalation Hazard Zone B) }\end{array}$ & 200 & 0.3 & 1.0 & 1400 & 2.5 & 6.1 \\
\hline 3308 & $\begin{array}{l}\text { Liquefied gas, poisonous, corrosive, n.o.s. } \\
\text { (Inhalation Hazard Zone C) }\end{array}$ & 100 & 0.2 & 0.8 & $600^{-1}$ & 1.9 & 4.5 \\
\hline 3308 & $\begin{array}{l}\text { Liquefied gas, poisonous, corrosive, n.o.s. } \\
\text { (Inhalation Hazard Zone D) }\end{array}$ & 100 & 0.1 & 0.4 & 600 & $1.0^{-}$ & 2.7 \\
\hline 3308 & Liquefied gas, toxic, corrosive, n.o.s. & $1400^{-}$ & 2.6 & 5.2 & 3000 & $7.0+$ & $7.0+$ \\
\hline 3308 & $\begin{array}{l}\text { Liquefied gas, toxic, corrosive, n.o.s. (Inhalation } \\
\text { Hazard Zone A) }\end{array}$ & $1400^{-1}$ & 2.6 & 5.2 & $3000^{-1}$ & $7.0+$ & $7.0+$ \\
\hline 3308 & $\begin{array}{l}\text { Liquefied gas, toxic, corrosive, n.o.s. (Inhalation } \\
\text { Hazard Zone B) }\end{array}$ & 200 & 0.3 & 1.0 & $1400^{-1}$ & $2.5^{\circ}$ & 6.1 \\
\hline 3308 & $\begin{array}{l}\text { Liquefied gas, toxic, corrosive, n.o.s. (Inhalation } \\
\text { Hazard Zone C) }\end{array}$ & 100 & $0.2^{-2}$ & $0.8^{-}$ & 600 & $1.9^{-1}$ & 4.5 \\
\hline 3308 & $\begin{array}{l}\text { Liquefied gas, toxic, corrosive, n.o.s. (Inhalation } \\
\text { Hazard Zone D) }\end{array}$ & $100^{-}$ & $0.1^{-1}$ & $0.4^{-}$ & 600 & 1.0 & 2.7 \\
\hline
\end{tabular}

Continued 
Table A.1 Table of Initial Isolation and Protective Action Distances (Cont.)

\begin{tabular}{|c|c|c|c|c|c|c|c|}
\hline \multirow[b]{3}{*}{ ID No. } & \multirow[b]{3}{*}{ Name of Material } & \multicolumn{3}{|c|}{ Small Spills } & \multicolumn{3}{|c|}{ Large Spills } \\
\hline & & \multirow{2}{*}{$\begin{array}{c}\text { First } \\
\text { Isolate } \\
\text { in All } \\
\text { Direc- } \\
\text { tions (ft) }\end{array}$} & \multicolumn{2}{|c|}{$\begin{array}{l}\text { Then Protect } \\
\text { Persons } \\
\text { Downwind } \\
\text { during }\end{array}$} & \multirow{2}{*}{$\begin{array}{c}\text { First } \\
\text { Isolate } \\
\text { in All } \\
\text { Direc- } \\
\text { tions (ft) }\end{array}$} & \multicolumn{2}{|c|}{$\begin{array}{l}\text { Then Protect } \\
\text { Persons } \\
\text { Downwind } \\
\text { during }\end{array}$} \\
\hline & & & $\begin{array}{l}\text { Day } \\
\text { (mi) }\end{array}$ & $\begin{array}{l}\text { Night } \\
\text { (mi) }\end{array}$ & & $\begin{array}{l}\text { Day } \\
\text { (mi) }\end{array}$ & $\begin{array}{l}\text { Night } \\
\text { (mi) }\end{array}$ \\
\hline 3309 & $\begin{array}{l}\text { Liquefied gas, poisonous, flammable, corrosive, } \\
\text { n.o.s. }\end{array}$ & 1400 & 2.6 & 5.2 & 3000 & $7.0+$ & $7.0+$ \\
\hline 3309 & $\begin{array}{l}\text { Liquefied gas, poisonous, flammable, corrosive, } \\
\text { n.o.s. (Inhalation Hazard Zone A) }\end{array}$ & 1400 & 2.6 & 5.2 & 3000 & $7.0+$ & $7.0+$ \\
\hline 3309 & $\begin{array}{l}\text { Liquefied gas, poisonous, flammable, corrosive, } \\
\text { n.o.s. (Inhalation Hazard Zone B) }\end{array}$ & 200 & 0.3 & 1.0 & 1400 & 2.5 & 6.1 \\
\hline 3309 & $\begin{array}{l}\text { Liquefied gas, poisonous, flammable, corrosive, } \\
\text { n.o.s. (Inhalation Hazard Zone C) }\end{array}$ & 100 & 0.2 & 0.8 & $600^{--1}$ & 1.9 & 4.5 \\
\hline 3309 & $\begin{array}{l}\text { Liquefied gas, poisonous, flammable, corrosive, } \\
\text { n.o.s. (Inhalation Hazard Zone D) }\end{array}$ & 100 & 0.1 & $0.4^{--}$ & $600^{--}$ & 1.0 & 2.7 \\
\hline 3309 & Liquefied gas, toxic, flammable, corrosive, n.o.s. & $1400^{--}$ & 2.6 & 5.2 & 3000 & $7.0+$ & $7.0+$ \\
\hline 3309 & $\begin{array}{l}\text { Liquefied gas, toxic, flammable, corrosive, n.o.s. } \\
\text { (Inhalation Hazard Zone A) }\end{array}$ & $1400^{-}$ & 2.6 & 5.2 & 3000 & $7.0+$ & $7.0+$ \\
\hline 3309 & $\begin{array}{l}\text { Liquefied gas, toxic, flammable, corrosive, n.o.s. } \\
\text { (Inhalation Hazard Zone B) }\end{array}$ & $200^{-}$ & 0.3 & 1.0 & 1400 & 2.5 & 6.1 \\
\hline 3309 & $\begin{array}{l}\text { Liquefied gas, toxic, flammable, corrosive, n.o.s. } \\
\text { (Inhalation Hazard Zone C) }\end{array}$ & $100^{-1}$ & 0.2 & 0.8 & 600 & $1.9^{-1}$ & 4.5 \\
\hline 3309 & $\begin{array}{l}\text { Liquefied gas, toxic, flammable, corrosive, n.o.s. } \\
\text { (Inhalation Hazard Zone D) }\end{array}$ & 100 & 0.1 & 0.4 & 600 & 1.0 & 2.7 \\
\hline 3310 & $\begin{array}{l}\text { Liquefied gas, poisonous, oxidizing, corrosive, } \\
\text { n.o.s. }\end{array}$ & 1400 & 2.6 & 5.2 & 3000 & $7.0+$ & $7.0+$ \\
\hline 3310 & $\begin{array}{l}\text { Liquefied gas, poisonous, oxidizing, corrosive, } \\
\text { n.o.s. (Inhalation Hazard Zone A) }\end{array}$ & 1400 & 2.6 & 5.2 & 3000 & $7.0+$ & $7.0+$ \\
\hline 3310 & $\begin{array}{l}\text { Liquefied gas, poisonous, oxidizing, corrosive, } \\
\text { n.o.s. (Inhalation Hazard Zone B) }\end{array}$ & 200 & 0.3 & 1.0 & 1100 & 2.1 & 4.8 \\
\hline 3310 & $\begin{array}{l}\text { Liquefied gas, poisonous, oxidizing, corrosive, } \\
\text { n.o.s. (Inhalation Hazard Zone C) }\end{array}$ & $100^{-}$ & 0.2 & 0.8 & 600 & $1.9^{9}$ & 4.5 \\
\hline $3310^{-}$ & $\begin{array}{l}\text { Liquefied gas, poisonous, oxidizing, corrosive, } \\
\text { n.o.s. (Inhalation Hazard Zone D) }\end{array}$ & $100^{-1}$ & 0.1 & 0.4 & $600^{-}$ & $1.0^{-}$ & 2.7 \\
\hline $3310^{-}$ & Ĺiquefied gas, toxic, oxidizing, corrosive, n.o.s. & $1400^{--}$ & 2.6 & 5.2 & 3000 & $7.0+$ & $7.0+$ \\
\hline $3310^{-}$ & $\begin{array}{l}\text { Liquefied gas, toxic, oxidizing, corrosive, n.o.s. } \\
\text { (Inhalation Hazard Zone A) }\end{array}$ & $1400^{--}$ & 2.6 & $5.2^{--}$ & 3000 & $7.0+$ & $7.0+$ \\
\hline $3310^{-}$ & $\begin{array}{l}\text { Liquefied gas, toxic, oxidizing, corrosive, n.o.s. } \\
\text { (Inhalation Hazard Zone B) }\end{array}$ & 200 & $0.3^{-1}$ & 1.0 & 1100 & $2.1^{--}$ & 4.8 \\
\hline 3310 & $\begin{array}{l}\text { Liquefied gas, toxic, oxidizing, corrosive, n.o.s. } \\
\text { (Inhalation Hazard Zone C) }\end{array}$ & 100 & 0.2 & 0.8 & $600^{--}$ & $1.9^{-1}$ & 4.5 \\
\hline $3310^{-}$ & $\begin{array}{l}\text { Liquefied gas, toxic, oxidizing, corrosive, n.o.s. } \\
\text { (Inhalation Hazard Zone D) }\end{array}$ & 100 & $0.1^{-}$ & 0.4 & $600^{---}$ & 1.0 & $2.7^{-}$ \\
\hline 3318 & Ammonia solution, with more than $50 \%$ ammonia & 100 & 0.1 & 0.1 & 200 & 0.3 & 0.7 \\
\hline
\end{tabular}

Continued 
Table A.1 Table of Initial Isolation and Protective Action Distances (Cont.)

\begin{tabular}{|c|c|c|c|c|c|c|c|}
\hline \multirow[b]{3}{*}{ ID No. } & \multirow[b]{3}{*}{ Name of Material } & \multicolumn{3}{|c|}{ Small Spills } & \multicolumn{3}{|c|}{ Large Spills } \\
\hline & & \multirow{2}{*}{$\begin{array}{c}\text { First } \\
\text { Isolate } \\
\text { in All } \\
\text { Direc- } \\
\text { tions (ft) }\end{array}$} & \multicolumn{2}{|c|}{$\begin{array}{l}\text { Then Protect } \\
\text { Persons } \\
\text { Downwind } \\
\text { during }\end{array}$} & \multirow{2}{*}{$\begin{array}{c}\text { First } \\
\text { Isolate } \\
\text { in All } \\
\text { Direc- } \\
\text { tions (ft) }\end{array}$} & \multicolumn{2}{|c|}{$\begin{array}{l}\text { Then Protect } \\
\text { Persons } \\
\text { Downwind } \\
\text { during }\end{array}$} \\
\hline & & & $\begin{array}{l}\text { Day } \\
\text { (mi) }\end{array}$ & $\begin{array}{l}\text { Night } \\
\text { (mi) }\end{array}$ & & $\begin{array}{l}\text { Day } \\
\text { (mi) }\end{array}$ & $\begin{array}{l}\text { Night } \\
\text { (mi) }\end{array}$ \\
\hline 3355 & Insecticide gas, poisonous, flammable, n.o.s & 1400 & 2.6 & 5.2 & 3000 & $7.0+$ & $7.0+$ \\
\hline 3355 & $\begin{array}{l}\text { Insecticide gas, poisonous, flammable, n.o.s. } \\
\text { (Inhalation Hazard Zone A) }\end{array}$ & $1400^{-1}$ & 2.6 & 5.2 & 3000 & $7.0+$ & $7.0+$ \\
\hline 3355 & $\begin{array}{l}\text { Insecticide gas, poisonous, flammable, n.o.s. } \\
\text { (Inhalation Hazard Zone B) }\end{array}$ & 200 & $0.3^{-1}$ & 1.0 & $1400^{-1}$ & 2.5 & 6.1 \\
\hline 3355 & $\begin{array}{l}\text { Insecticide gas, poisonous, flammable, n.o.s. } \\
\text { (Inhalation Hazard Zone C) }\end{array}$ & $100^{--1}$ & 0.2 & 0.8 & $700^{--}$ & 1.9 & 4.5 \\
\hline $3355^{-}$ & $\begin{array}{l}\text { Insecticide gas, poisonous, flammable, n.o.s. } \\
\text { (Inhalation Hazard Zone D) }\end{array}$ & 100 & 0.1 & 0.4 & $600^{-}$ & $1.0^{-}$ & 2.7 \\
\hline $3355^{-}$ & Insecticide gas, toxic, flammable, n.o.s & $1400^{-}$ & 2.6 & 5.2 & 3000 & $7.0+$ & $7.0+$ \\
\hline 3355 & $\begin{array}{l}\text { Insecticide gas, toxic, flammable, n.o.s. } \\
\text { (Inhalation Hazard Zone A) }\end{array}$ & $1400^{-}$ & 2.6 & 5.2 & 3000 & $7.0+$ & $7.0+$ \\
\hline 3355 & $\begin{array}{l}\text { Insecticide gas, toxic, flammable, n.o.s. } \\
\text { (Inhalation Hazard Zone B) }\end{array}$ & 200 & 0.3 & 1.0 & 1400 & $2.5^{-}$ & 6.1 \\
\hline $3355^{-1}$ & $\begin{array}{l}\text { Insecticide gas, toxic, flammable, n.o.s. } \\
\text { (Inhalation Hazard Zone C) }\end{array}$ & $100^{-1}$ & 0.2 & 0.8 & $700^{-}$ & 1.9 & 4.5 \\
\hline 3355 & $\begin{array}{l}\text { Insecticide gas, toxic, flammable, n.o.s. } \\
\text { (Inhalation Hazard Zone D) }\end{array}$ & 100 & 0.1 & 0.4 & $600^{-1}$ & 1.0 & 2.7 \\
\hline 9191 & $\begin{array}{l}\text { Chlorine dioxide, hydrate, frozen (when spilled } \\
\text { in water) }\end{array}$ & 100 & 0.1 & 0.1 & 100 & 0.1 & 0.4 \\
\hline 9192 & Fluorine, refrigerated liquid (cryogenic liquid) & 100 & 0.1 & 0.3 & 600 & 0.9 & 2.5 \\
\hline 9202 & $\begin{array}{l}\text { Carbon monoxide, refrigerated liquid (cryogenic } \\
\text { liquid) }\end{array}$ & 100 & 0.1 & 0.1 & 400 & 0.4 & 1.1 \\
\hline 9206 & Methyl phosphonic dichloride & 100 & 0.1 & 0.1 & 100 & 0.1 & 0.2 \\
\hline 9263 & Chloropivaloyl chloride & 100 & 0.1 & 0.1 & 100 & 0.2 & 0.3 \\
\hline 9264 & 3,5-Dichloro-2,4,6-trifluoropyridine & 100 & 0.1 & 0.1 & 100 & 0.2 & 0.3 \\
\hline 9269 & Trimethoxysilane & 100 & 0.2 & 0.6 & 700 & 1.3 & 2.6 \\
\hline
\end{tabular}


$\Delta$ 


\section{Appendix B \\ Chemicals Analyzed in the 2000 Emergency Response Guidebook Analysis}

Table B. 1 lists the chemicals analyzed in the 2000 Emergency Response Guidebook (2000ERG) analysis in alphabetical order by U.S. Department of Transportation (DOT) name. Most of these materials are toxic by inhalation (TIH) materials; however, several are surrogates for generic table entries (e.g., 2-amino-2-methylpropanenitrile) or mildly toxic components of mixtures (e.g., benzene). For reference, the Chemical Abstract Services (CAS) number, boiling point, vapor pressure at $20^{\circ} \mathrm{C}$, and toxicological data are provided. Additional chemical data used in the analysis include critical temperature, critical volume, melting point, heat of vaporization, liquid density, and specific heat of the liquid. For vapor pressure, heat of vaporization, liquid density, and specific heat of the liquid, temperature-dependent relationships were used. 
Table B.1 Chemicals Analyzed in the 2000ERG Analysisa

\begin{tabular}{|c|c|c|c|c|c|c|c|c|}
\hline DOT Name & CAS No. & $\begin{array}{l}\text { Molecular } \\
\text { Weight }\end{array}$ & $\begin{array}{l}\text { Boiling } \\
\text { Point } \\
\left({ }^{\circ} \mathrm{C}\right)\end{array}$ & $\begin{array}{l}\text { Vapor } \\
\text { Pressure at } \\
20^{\circ} \mathrm{C}(\mathrm{kPa})\end{array}$ & $\begin{array}{c}L^{L C_{50}} \text { or } L C_{L O} \\
(\mathrm{ppm})\end{array}$ & $\begin{array}{c}\text { 1-h } \\
\text { Protective } \\
\text { (ppm) }\end{array}$ & $\begin{array}{l}\text { 15-min } \\
\text { Protective } \\
\text { (ppm) }\end{array}$ & Basis \\
\hline Acrolein & 107-02-8 & 56.1 & 52.7 & 29.69 & 62 & 0.5 & 1 & ERPG \\
\hline Äldicarín & $116-06-3$ & Ni $/ \bar{A}$ & $\mathrm{~N} / \mathrm{A}^{-}$ & $\mathrm{N} / \mathrm{A}$ & $\bar{i}$ & 0.01 & 0.02 & $\mathrm{LC}_{50}$ \\
\hline 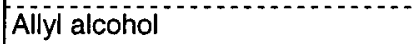 & $107-18-6$ & $58.1^{\circ}$ & 97.1 & 2.491 & $1060^{\circ}$ & $10^{-1}$ & $20^{-}$ & {$\left[\mathrm{LC}_{50}^{--}\right.$} \\
\hline Állyí chiloroformate- & $2937-50-0$ & 120.5 & $112.9^{-1}$ & 6.194 & $\dddot{5}$ & 0.05 & 0.2 & $\mathrm{LC}_{50}$ \\
\hline Ällyl isothiocyanate & $57-06-7$ & 99.2 & 150.7 & 0.516 & $28-\bar{s}$ & $i$ & 2 & ERPG-S \\
\hline Ällylamine & $107-11-9$ & 57.1 & 53.4 & 25.69 & 572 & 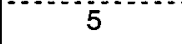 & 10 & $\mathrm{LC}_{50}$ \\
\hline 2-Amino-2-methylpropanenitrile & $19355-69-2$ & 84.1 & 159.5 & $0.099^{\circ}$ & 112 & $\pi$ & 2 & $\mathrm{LC}_{50}$ \\
\hline Ámmonia & $7664-41-7$ & 17 & -33.5 & 854.5 & 7,338 & 200 & $400^{\circ}$ & ERPG \\
\hline Arsenic trichloride & $7784-34-1$ & 181.2 & 130.1 & 1.113 & 56 & 0.5 & $1.0^{-}$ & $\mathrm{LC}_{\mathrm{LO}}$ \\
\hline Ärsine & $7784-42-1$ & $77.9^{-}$ & -62.5 & 1475 & 30 & 0.5 & 0.6 & ERPG \\
\hline Benzene & $71-43-2$ & 78.1 & 80.1 & 9.983 & 26,458 & 150 & 300 & ERPG \\
\hline Bis-(2-chloroethyl) ethylamine & $538-07-8$ & 170.1 & 193.9 & 0.023 & 3.6 & 0.036 & 0.144 & $\mathrm{LC}_{50}$ \\
\hline Bis-(2-chioroethyl) methylamine & $51-75-2$ & 156.1 & $174.9^{-}$ & 0.039 & 7.8 & 0.078 & 0.312 & $\mathrm{LC}_{50}$ \\
\hline Bis-(2-chloroethyl) sulfide & $505-60-2$ & 159.1 & 216.9 & 0.010 & 2.3 & 0.023 & 0.092 & $\mathrm{LC}_{50}$ \\
\hline Boron tribromide & $10294-33-4$ & 251.5 & $89.0^{\circ}$ & 7.336 & $387-5$ & $\dddot{3}$ & $\because 6$ & $\mathrm{LC}_{50}-\mathrm{S}$ \\
\hline Boron trichloride & $10294-34-5$ & 117.2 & 12.5 & 132.2 & 2541 & 25 & $50^{-}$ & $\mathrm{LC}_{50}$ \\
\hline Boron trifluoride & $7637-07-2$ & 67.8 & -99.8 & 4264 & $387^{\circ}$ & $\ddot{3}$ & 16 & ERPG \\
\hline Bromine & $7726-95-6$ & 159.8 & 58.8 & 22.87 & $310^{-}$ & $\overline{1}$ & 2 & ERPG \\
\hline Bromine choride & $13863-41-7$ & 115.4 & 4.9 & 220.0 & 290 & 3 & $\dddot{6}$ & $\mathrm{LC}_{50} \mathrm{~S}$ \\
\hline Bromine pentafluoride & $7789-30-2$ & 174.9 & 40.9 & 42.88 & $299-\mathrm{s}$ & $i$ & 2 & ERPG-S \\
\hline Bromine trifluoride & $7787-71-5$ & 136.9 & 125.9 & 0.774 & $299-\mathrm{s}$ & 1 & 2 & ERPG-S \\
\hline Bromoacetone & $598-31-2$ & 137 & 135.9 & 11.431 & 95 & 1 & 2 & $\mathrm{LC}_{\mathrm{LO}}$ \\
\hline n-Butyl chloroformate & $592-34-7$ & 136.6 & $137.9^{-}$ & 0.765 & $323-\mathrm{s}$ & 3 & 6 & $\mathrm{LC}_{50}$ \\
\hline sec-Butyl chloroformate & $17462-58-7$ & 136.6 & $127.9-E^{-}$ & $1.051-E$ & 323 & 3 & 6 & $\mathrm{LC}_{50} \mathrm{~S}$ \\
\hline n-Butylisocyanate & $111-36-4$ & 99.1 & $115.0-\mathrm{s}^{-}$ & $1.755-\mathrm{s}$ & 28 & 0.05 & $0.1^{\circ}$ & ERPG \\
\hline tert-Butylisocyanate & $1609-86-5$ & (99.1 & 86.0 & $4.888-E$ & 22 & 0.05 & 0.1 & ERPG-S \\
\hline tert-Butylarsine & $117791-53-4$ & 134 & $44.4-E$ & $40.35-E$ & $140^{-}$ & 1.5 & 3 & $\mathrm{LC}_{50}$ \\
\hline
\end{tabular}

Continued 
Table B.1 Chemicals Analyzed in the 2000ERG Analysis (Cont.)

\begin{tabular}{|c|c|c|c|c|c|c|c|c|}
\hline DOT Name & CAS No. & $\begin{array}{c}\text { Molecular } \\
\text { Weight }\end{array}$ & $\begin{array}{l}\text { Boiling } \\
\text { Point } \\
\left({ }^{\circ} \mathrm{C}\right)\end{array}$ & $\begin{array}{c}\text { Vapor } \\
\text { Pressure at } \\
20^{\circ} \mathrm{C}(\mathrm{kPa})\end{array}$ & $\begin{array}{l}\mathrm{LC}_{50} \text { or } L C_{\mathrm{LO}} \\
\quad(\mathrm{ppm})\end{array}$ & $\begin{array}{c}1-\mathrm{h} \\
\text { Protective } \\
\text { (ppm) }\end{array}$ & $\begin{array}{l}\text { 15-min } \\
\text { Protective } \\
\text { (ppm) }\end{array}$ & Basis \\
\hline Carbon monoxide & $630-08-0$ & 28 & -191.5 & 2792 & 4590 & 350 & 500 & ERPG \\
\hline Carbon tetrachioride & $56-23-5$ & 153.8 & 76.7 & 12.138 & 19,000 & 100 & 200 & $\mathrm{ERPG}$ \\
\hline Carbonyl fluoride & $353-50-4$ & 66 & -84.6 & 5211 & 360 & 3 & 6 & $\mathrm{LC}_{50}$ \\
\hline Carbonyl sulfide & $463-58-1$ & $60.1^{\circ}$ & -50.2 & 1124 & 924 & 10 & 20 & $\mathrm{LC}_{50}$ \\
\hline Čhiorine & $7782-50-5$ & 70.9 & -34.1 & $679.7^{-}$ & 293 & 3 & 6 & ERPG \\
\hline Ćhiorine pentafluoride & $13637-63-3$ & 130.4 & -13.9 & 332.1 & 122 & 1 & 2 & ERPG-S \\
\hline Chiorine trifluoride & $7790-91-2$ & 92.4 & 11.8 & 148.0 & 299 & 1 & 2 & ERPG \\
\hline Chloroacetaldehyde & $107-20-0^{--}$ & 78.5 & $84.9^{-}$ & 3.522 & $200^{-\cdots}$ & 2 & 4 & $\mathrm{LC}_{50}$ \\
\hline Chioroacetone & $78-95-5$ & 92.5 & 120.1 & 1.567 & 262 & 2 & 4 & $\mathrm{LC}_{50}$ \\
\hline Ćhioroacetonitrile & $107-14-2$ & 75.5 & 126.0 & $1.087^{\circ}$ & $500^{-\cdots}$ & 5 & 10 & $\mathrm{LC}_{50}$ \\
\hline Čhioroacetyl chloride & $79-04-9$ & 112.9 & 106.0 & 2.522 & $660^{-1}$ & 1 & 2 & ERPG \\
\hline Chioromethyl methyl ether & $107-30-2$ & 80.5 & 59.5 & 21.14 & 441 & 3 & 6 & $\mathrm{LC}_{50}$ \\
\hline $\mathrm{p}$-Chiorophenyl isocyanate & $104-12-1$ & 153.6 & $199.0^{-}$ & $0.069^{\circ}$ & 18 & 0.15 & 0.3 & $\mathrm{LC}_{50}$ \\
\hline Ćhloropicrin & $76-06-2$ & 164.4 & $111.9^{-}$ & $3.190^{-}$ & 28 & 0.2 & 0.4 & ERPG \\
\hline Chloropivaloyl chloride & $4300-97-4$ & 155 & $147.9^{-1}$ & $0.189-E^{-}$ & 126 & 1 & 2 & $\mathrm{LC}_{50}$ \\
\hline Ćhiorosulfonic acid & $7790-94-5$ & 116.5 & $153.9^{-}$ & 0.309 & $929 \mathrm{mg} / \mathrm{m}^{3}$ & $10 \mathrm{mg} / \mathrm{m}^{3}$ & $20 \mathrm{mg} / \mathrm{m}^{3}$ & $\overline{E R P G}$ \\
\hline Ċrotonaldehyde & $4170-30-3$ & 70.1 & 104.9 & 3.121 & $380^{-\cdots}$ & $10^{-\cdots}$ & 20 & ERPG \\
\hline Cyanogen & $460-19-5$ & 52 & $-21.2^{-1}$ & 489.7 & $350^{-1}$ & 3 & 6 & $\mathrm{LC}_{50}$ \\
\hline Cyanogen chloride & $506-77-4$ & 61.5 & $12.9^{-}$ & $135.0^{-}$ & $80^{-}$ & 0.4 & 1.0 & $\mathrm{ERPG}$ \\
\hline Cyclohexyl isocyanate & $3173-53-3$ & 125.2 & 169.0 & 0.094 & 15 & 0.05 & 0.1 & ERPG-S \\
\hline Cyclohexyl methyiphosphonofluoridate & $\mathrm{N} / \mathrm{A}$ & 180.2 & $238.9^{--}$ & $0.006^{-1}$ & $0.08^{-1}$ & $0.0008^{-1}$ & $0.0032^{2}$ & $\mathrm{LC}_{50}$ \\
\hline
\end{tabular}

Continued 
Table B.1 Chemicals Analyzed in the 2000ERG Analysis ${ }^{a}$ (Cont.)

\begin{tabular}{|c|c|c|c|c|c|c|c|c|}
\hline DOT Name & CAS No. & $\begin{array}{l}\text { Molecular } \\
\text { Weight }\end{array}$ & $\begin{array}{l}\text { Boiling } \\
\text { Point } \\
\left({ }^{\circ} \mathrm{C}\right)\end{array}$ & $\begin{array}{c}\text { Vapor } \\
\text { Pressure at } \\
20^{\circ} \mathrm{C}(\mathrm{kPa})\end{array}$ & $\begin{array}{l}L_{50} \text { or } L C_{L O} \\
\quad(p p m)\end{array}$ & $\begin{array}{c}1-h \\
\text { Protective } \\
\text { (ppm) }\end{array}$ & $\begin{array}{l}\text { 15-min } \\
\text { Protective } \\
\text { (ppm) }\end{array}$ & Basis \\
\hline Diamylamine & $2050-92-2$ & 157.3 & 203.0 & 0.013 & 126 & 1 & 2 & $\mathrm{LC}_{\mathrm{LO}}$ \\
\hline Diborane & $19287 \cdot 45 \cdot 7$ & 27.7 & -92.6 & 3438 & $80^{-}$ & 1 & 2 & $\overline{E R} \overline{P G}$ \\
\hline Dichlorosilane & $4109-96-0$ & 101 & 8.4 & $154.2^{2}$ & 215 & 2 & 4 & $\mathrm{LC}_{50}$ \\
\hline 3,5 -Dichloro-2,4,6-trifluoropyridine & $1737-93-5$ & 202 & $177.5-5$ & $0.104-\mathrm{S}$ & 62 & 0.5 & 1 & $\mathrm{LC}_{50}$ \\
\hline Diketene & $674-82-8$ & 84.1 & 126.1 & 1.064 & 612 & 5 & $10^{\circ}$ & $E R P G$ \\
\hline $1,1-$ Dimethyl hydrazine & $57-14-7$ & 60.1 & 63.4 & 16.38 & 1410 & 15 & 30 & $\mathrm{LC}_{50}$ \\
\hline 1,2 -Dimethyl hydrazine & $540-73-8$ & 60.1 & 87.1 & 7.230 & $680^{--}$ & 7 & 15 & $\mathrm{LG}_{50}$ \\
\hline Dimethyl sulfate & $77-78-1$ & 126.1 & 188.9 & $0.069^{\circ}$ & 17 & 0.15 & 0.3 & $\mathrm{LC}_{50}$ \\
\hline Diphosgene & $503-38-8$ & 197.8 & $127.9^{-1}$ & $0.553^{-1}$ & $50-5^{-1}$ & $0.1^{-}$ & 0.2 & ERPG-S \\
\hline Ethyl chloroformate & $541-41-3$ & 108.5 & 92.9 & 2.121 & 145 & 1 & 2 & $\mathrm{LC}_{50}-\mathrm{S}$ \\
\hline Ethylchlorothioformate & $2812-73-9$ & 124.6 & 131.9 & $0.685-E^{-1}$ & $138-S^{-1}$ & 1 & 2 & $\mathrm{LC}_{50}-\mathrm{S}$ \\
\hline Ethylchlorothiolformate & $2941-64-2$ & $124.6-5$ & $131.9-\mathrm{s}$ & $0.685-\mathrm{s}^{-1}$ & $138-s^{-1}$ & 1 & 2 & $\mathrm{LC}_{50}-\mathrm{S}$ \\
\hline Ethyl dichloroarsine & $598-14-1$ & $174.9^{-}$ & 155.9 & 0.281 & 36 & 0.3 & 0.6 & $\mathrm{LC}_{50}$ \\
\hline $\begin{array}{l}\text { Ethyl } \mathrm{N}, \mathrm{N}- \\
\text { dimethylphosphoramidocyanidate }\end{array}$ & $N / A$ & 162.3 & $239.9-\mathrm{E}^{-}$ & $0.005-E^{-1}$ & 0.18 & 0.0018 & $0.0072^{-1}$ & $\mathrm{C}_{50}$ \\
\hline Ethyl isocyanate & $109-90=0$ & $71.1^{-1}$ & 61.6 & 24.50 & $28-S^{-}$ & 0.05 & 0.1 & ERPG \\
\hline Ethyl phosphonothionic dichloride & $993-43-1$ & 162.9 & 176.9 & $0.026-E^{-1}$ & $62-5$ & 0.5 & 1 & $\mathrm{LC}_{50}$ \\
\hline Éthyl phosphonous dichloride & $1498-40-4$ & 130.9 & $113.0-E^{-}$ & $4.762-\mathrm{E}^{-}$ & $62^{-1}$ & 0.5 & 1 & $\mathrm{LC}_{\mathrm{LO}}$ \\
\hline Ethyl phosphorodichloridate & $1498-51-7$ & $162.9^{-}$ & 166.9 & $0.040-\mathrm{E}^{-}$ & 43 & $0.3^{-1}$ & 0.6 & $\mathrm{LC}_{50}^{-}$ \\
\hline Ethylacrolein & $922-63-4$ & 84.1 & 92.9 & $5.392-\mathrm{E}$ & 578 & 5 & $10^{\circ}$ & $\mathrm{LC}_{50}$ \\
\hline Ethylene chlorohydrin & $107-07-3$ & 80.5 & 128.7 & $0.699^{-}$ & 74 & $0.5^{\circ}$ & 1 & $\mathrm{LC}_{50}$ \\
\hline Ethylene dibromide & $106-93-4$ & 187.9 & 131.4 & 1.357 & $697^{-1}$ & 5 & $10^{-1}$ & $\mathrm{LC}_{50}$ \\
\hline Ethylene oxide & $75-21-8$ & $44.1^{-1}$ & 10.5 & 146.3 & $5840^{-}$ & $50^{-1}$ & $100^{-1}$ & $E R P G$ \\
\hline Éthylenimine & $151-56-4$ & $43.1^{-}$ & $55.9^{-}$ & 22.18 & 250 & 2 & 4 & $\mathrm{LC}_{50}$ \\
\hline Fluorine & $7782-41-4$ & 38 & -188.3 & 4160 & 185 & 5 & 15 & ERPG \\
\hline Germanium tetrachloride & $10038-98-9$ & 214.4 & 83.9 & 9.51 & 150 & 1 & 2 & $\mathrm{LC}_{\text {LO }}$ \\
\hline Germanium tetrahydride & $7782-65-2$ & 76.6 & $-88.2^{-}$ & 3870 & 622 & 5 & $10^{-}$ & $\mathrm{LC}_{50}$ \\
\hline
\end{tabular}


Table B.1 Chemicals Analyzed in the 2000ERG Analysis ${ }^{a}$ (Cont.)

\begin{tabular}{|c|c|c|c|c|c|c|c|c|}
\hline DOT Name & CAS No. & $\begin{array}{c}\text { Molecular } \\
\text { Weight }\end{array}$ & $\begin{array}{l}\text { Boiling } \\
\text { Point } \\
\left({ }^{\circ} \mathrm{C}\right)\end{array}$ & $\begin{array}{c}\text { Vapor } \\
\text { Pressure at } \\
20^{\circ} \mathrm{C}(\mathrm{kPa})\end{array}$ & $\begin{array}{c}L_{50} \text { or } L C_{L O} \\
(\mathrm{ppm})\end{array}$ & $\begin{array}{c}1-\mathrm{h} \\
\text { Protective } \\
\text { (ppm) }\end{array}$ & $\begin{array}{c}\text { 15-min } \\
\text { Protective } \\
\text { (ppm) }\end{array}$ & Basis \\
\hline Hexachlorocyclopentadiene & $77-47-4$ & 272.8 & 239.1 & 0.0052 & 3 & 0.03 & 0.06 & $\mathrm{LC}_{50}$ \\
\hline Hexaethyltetraphosphate & $757-58-4$ & 506.2 & -195.9 & 2644 & $24-E$ & 0.5 & 1 & $\mathrm{LC}_{50}-\mathrm{E}$ \\
\hline Hexafluoroacetone & $684-16-2$ & 166 & -27.3 & 584.19 & 476 & 1 & 2 & $E R P G$ \\
\hline Hydrogen bromide & $10035-10-6$ & 80.9 & -66.8 & 2182 & 2860 & 20 & 40 & ERPG-S \\
\hline Hydrogen chloride & $7647-01-0$ & 36.5 & -85.1 & 4206 & 3124 & 20 & 40 & ERPG \\
\hline Hydrogen cyanide & $74-90-8$ & 27 & 25.8 & 81.63 & 71 & 10 & 20 & ERPG \\
\hline Hydrogen fluoride & $7664-39-3$ & 20 & 19.6 & 102.7 & 1300 & $20^{\circ}$ & 40 & $\mathrm{ERPG}$ \\
\hline Hydrogen iodide & $10034-85-2$ & 127.9 & -35.6 & 691.0 & 2860 & 20 & $40^{\circ}$ & ERPG-S \\
\hline Hydrogen selenide & $7783-07-5$ & 81 & -42.1 & 911.1 & $4-6$ & 0.05 & 0.1 & $\mathrm{LC}_{50}$ \\
\hline Hydrogen sulfide & $7783-06-4$ & 34.1 & -60.4 & 1781 & 712 & 30 & 60 & ERPG \\
\hline Iron pentacarbonyl & $13463-40-6$ & 195.9 & 102.8 & 3.142 & 57 & 0.5 & 1 & $L C_{50}$ \\
\hline Isobutyl chloroformate & $543-27-1$ & 136.6 & 128.1 & $0 . \overline{751}$ & 299 & 3 & 6 & $\mathrm{LC}_{50}$ \\
\hline Isobutyl isocyanate & $1873-29-6$ & 99.1 & 115.0 & 1.755 & $28-5$ & 0.05 & 0.1 & ERPG-S \\
\hline isopropyl chloroformate & $108-23-6$ & 122.6 & $104.9-\mathrm{s}$ & $4.698-5$ & 299 & 3 & 6 & $\mathrm{LC}_{50}$ \\
\hline Isopropyl isocyanate & $1795-48-8$ & 85.1 & 82.9 & 7.372 & $28-5$ & 0.05 & $0.1^{-1}$ & ERPG-S \\
\hline Isopropyl methylphosphonofluoridate & $107-44-8$ & 140.1 & $157.9^{\circ}$ & 0.283 & 0.1 & 0.001 & 0.004 & $\mathrm{LC}_{50}$ \\
\hline Methacrylonitrile & $126-98-7$ & 67.1 & 90.4 & 7.541 & 656 & 5 & 10 & $\mathrm{LC}_{50}$ \\
\hline Methanesulfonyl monochioride & $124-63-0$ & 114.6 & 162.4 & 0.190 & $5-\bar{s}$ & 0.05 & 0.01 & $\mathrm{LC}_{50} \mathrm{~S}$ \\
\hline Methoxymethyl isocyanate & $6427-21-0$ & 87.1 & $165.7-\mathrm{E}$ & $0.250-E$ & $28-S$ & 0.05 & 0.1 & ERPG-S \\
\hline Methyl bromide & $74-83-9$ & 94.9 & 3.6 & 184.3 & 1007 & 50 & 100 & ERPG \\
\hline Methyl chioride & $74-87-3$ & 50.5 & -24.3 & 495.4 & 11,040 & 400 & 1500 & ERPG \\
\hline Methyl chloroformate & $79-22-1$ & 94.5 & 70.9 & 11.20 & 88 & 1 & 2 & $\mathrm{LC}_{50}$ \\
\hline Methyl hydrazine & $60-34-4$ & $46.1^{\circ}$ & 87.6 & 4.997 & 148 & 1 & 2 & $\mathrm{LC}_{50}$ \\
\hline Methyl iodide & $74-88-4$ & 141.9 & 42.5 & 44.33 & 1600 & 50 & 100 & ERPG \\
\hline Methyl isocyanate & $624-83-9$ & 57.1 & 38.9 & 50.18 & 41 & 0.5 & 1 & ERPG \\
\hline Methyl isothiocyanate & $556-61-6$ & 73.1 & 118.9 & 3.205 & 635 & 5 & 10 & $\mathrm{LC}_{50}$ \\
\hline Methyl mercaptan & $74-93-1$ & 48.1 & $6.0^{-}$ & 169.8 & 1340 & 25 & 50 & $\mathrm{ERPG}$ \\
\hline
\end{tabular}

Continued 
Table B.1 Chemicals Analyzed in the 2000ERG Analysisa (Cont.)

\begin{tabular}{|c|c|c|c|c|c|c|c|c|}
\hline DOT Name & CAS No. & $\begin{array}{l}\text { Molecular } \\
\text { Weight }\end{array}$ & $\begin{array}{c}\text { Boiling } \\
\text { Point } \\
\left({ }^{\circ} \mathrm{C}\right)\end{array}$ & $\begin{array}{c}\text { Vapor } \\
\text { Pressure at } \\
20^{\circ} \mathrm{C}(\mathrm{kPa})\end{array}$ & $\begin{array}{c}\mathrm{LC}_{50} \text { or } L C_{\mathrm{LO}} \\
(\mathrm{ppm})\end{array}$ & $\begin{array}{c}1-h \\
\text { Protective } \\
\text { (ppm) }\end{array}$ & $\begin{array}{l}\text { 15-min } \\
\text { Protective } \\
\text { (ppm) }\end{array}$ & Basis \\
\hline Methyl phosphonic dichloride & $676-97-1$ & 132.9 & $162.9-\mathrm{E}$ & $0.040-E$ & 52 & 0.5 & 1.0 & $\mathrm{LC}_{50}$ \\
\hline Methyl phosphonous dichloride & $676-83-5$ & 116.9 & 81.9-E & $11.89-\mathrm{E}$ & $52-5$ & 0.5 & 1.0 & $\mathrm{LC}_{50}-\mathrm{S}$ \\
\hline Methyl silicate & $681-84-5$ & 152.2 & 120.9 & $1.613^{-}$ & 300 & 3 & 6 & $\mathrm{LC}_{\mathrm{LO}}$ \\
\hline Methyl vinyl ketone & $78-94-4$ & $70.1^{-1}$ & 81.5 & 9.274 & 5 & 0.05 & 0.1 & $\mathrm{LC}_{50}$ \\
\hline Methylamine & $74-89-5$ & 31.1 & -6.3 & 295.7 & 5000 & 100 & 200 & ERPG \\
\hline Methylchlorosilane & $993-00-0$ & 80.6 & 8.8 & 149.6 & $1547-\mathrm{S}$ & 3 & 6 & ERPG-S \\
\hline Methyldichloroarsine & $593-89-5$ & 160.9 & 135.9 & 1.034 & 68 & 0.5 & 1 & $\mathrm{LC}_{50}$ \\
\hline Nickel carbonyl & $13463-39-3$ & 170.8 & 42.5 & 43.50 & 18 & 0.15 & 0.3 & $\mathrm{LC}_{50}$ \\
\hline Nitric acid & $7697-37.2$ & 63 & $83.0^{-}$ & 6.401 & 67 & 1.3 & 2.6 & ${ }^{L} C_{50}$ \\
\hline Nitric oxide & $10102-43-9$ & $30^{-}$ & -151.8 & 5093 & $1708^{\circ}$ & 15 & $30^{-}$ & $\mathrm{LC}_{50}^{--}$ \\
\hline Nitrogen dioxide & $10102-44-0^{-}$ & 46 & 21.0 & 96.04 & $11 \overline{5}$ & 10 & 20 & ËÉ'- \\
\hline Nitrogen fluoride oxide & $13847-65-9$ & 87.1 & $-129.1-\mathrm{E}$ & 3979-E & 48 & 0.5 & 1.0 & $\mathrm{LC}_{50}$ \\
\hline Nitrogen trioxide & $10544-73-7$ & 76 & 2.0 & 218.3 & $115-S^{-}$ & 10 & $20^{-}$ & EEL \\
\hline Nitrosyl chioride & $2696-92-6$ & 65.5 & -5.3 & 270.4 & $293-s$ & 3 & 6 & ERPG-S \\
\hline tert-Octyl mercaptan & $141-59-3$ & 146.3 & 155.9 & 0.488 & 102 & 1 & 2 & $\mathrm{LC}_{50}$ \\
\hline $\begin{array}{l}\text { O-Ethyl S-(2-diisopropylaminoethyl) } \\
\text { methylphosphonothiolate }\end{array}$ & $50782-69-9$ & 267.4 & $297.9^{-}$ & .00005 & 0.023 & 0.00023 & $0.0009^{-}$ & $\mathrm{LC}_{50}$ \\
\hline Oxygen difluoride & $7783-41-7$ & 54 & -145.0 & 2789 & 2.6 & 0.03 & 0.06 & $\mathrm{LC}_{50}$ \\
\hline Parathion & $56-38-2$ & 291.3 & -195.9 & 2644 & 14 & 0.15 & 0.3 & $\mathrm{LC}_{50}$ \\
\hline Pentaborane & $19624-22-7$ & 63.2 & 58.4 & $22.70-E$ & 10 & 0.1 & 0.2 & $\mathrm{LC}_{50}$ \\
\hline Perchioromethyl mercaptan & $594-42-3$ & 185.9 & $148.0^{-}$ & 0.642 & 69 & 0.5 & $1.0^{\circ}$ & $\mathrm{LC}_{50}^{-}$ \\
\hline Perchioryl fluoride & $7616-94-6$ & 102.4 & -46.7 & 1060 & $770^{\circ}$ & 5 & 10 & $\mathrm{LC}_{50}$ \\
\hline Phenyl isocyanate & $103-79-9$ & 119.1 & 165.7 & 0.250 & 16 & 0.05 & $0.9^{-1}$ & ERPG-S \\
\hline Phenyl mercaptan & $108-98-5$ & 110.2 & 169.2 & 0.142 & 66 & 0.5 & 1.0 & $\mathrm{LC}_{50}$ \\
\hline Phosgene & $75-44-5$ & 98.9 & 7.6 & 159.3 & 1000 & 0.2 & 0.4 & EAPG \\
\hline Phosphine & $7803-51-2$ & 34 & -87.8 & 3517 & 22 & 2.5 & 5 & ERPG \\
\hline Phosphorous oxychloride & $10025-87-3$ & 153.3 & 105.5 & 3.273 & 96 & 1 & 2 & $\mathrm{LC}_{50}$ \\
\hline Phosphorous pentafluoride & $7647-19-0$ & 126 & -84.6 & $19990-E^{-}$ & $260^{\circ}$ & 2 & 4 & $\mathrm{LC}_{50}-\mathrm{S}^{-}$ \\
\hline
\end{tabular}

Continued 
Table B.1 Chemicals Analyzed in the 2000ERG Analysisa (Cont.)

\begin{tabular}{|c|c|c|c|c|c|c|c|c|}
\hline DOT Name & CAS No. & $\begin{array}{l}\text { Molecular } \\
\text { Weight }\end{array}$ & $\begin{array}{c}\text { Boiling } \\
\text { Point } \\
\left({ }^{\circ} \mathrm{C}\right)\end{array}$ & $\begin{array}{c}\text { Vapor } \\
\text { Pressure at } \\
20^{\circ} \mathrm{C}(\mathrm{kPa})\end{array}$ & $\begin{array}{c}\mathrm{LC}_{50} \text { or } L C_{\mathrm{LO}} \\
\quad(\mathrm{ppm})\end{array}$ & $\begin{array}{c}1-\mathbf{h} \\
\text { Protective } \\
\text { (ppm) }\end{array}$ & $\begin{array}{l}\text { 15-min } \\
\text { Protective } \\
\text { (ppm) }\end{array}$ & Basis \\
\hline Phosphorous trichloride & $7719-12-2$ & 137.3 & 76.1 & 12.82 & 208 & 2 & 4 & $\mathrm{LC}_{50}$ \\
\hline Phosphorous trifluoride & $7783-55-3$ & 88 & -101.3 & 6902 & 433 & 3 & $\ddot{6}$ & $\mathrm{LC}_{50}$ \\
\hline Pinacolyl methylphosphonofluoridate & $96-64-0^{-}$ & 182.2 & 197.9 & 0.037 & 0.08 & 0.0008 & 0.0032 & $\mathrm{LC}_{50}$ \\
\hline n-Propyl chloroformate & $109-61-5$ & 122.6 & 104.9 & $4.698^{-}$ & 319 & 3 & 2 & $\mathrm{LC}_{50}$ \\
\hline$n$-Propyl isocyanate & $110-78-1$ & $85.1^{-1}$ & 82.9 & $5.274^{-}$ & 44 & 0.05 & $0.1^{--}$ & $\ddot{E R P G ̈-S}$ \\
\hline Selenium hexafluoride & $7783-79-1$ & 193 & -34.7 & 2854 & 50 & 0.5 & 1 & $\mathrm{LC}_{50}$ \\
\hline Silicon tetrafluoride & $7783-61-1$ & 104.1 & -95.2 & 3205 & 922 & $10^{-1}$ & $20^{-}$ & $\mathrm{LC}_{50}$ \\
\hline Stibine & $7803-52 \cdot 3$ & 124.8 & -18.5 & $286.1-\mathrm{E}$ & $20^{-1}$ & 0.5 & 1 & ERPG \\
\hline Sulfur chloride pentafluoride & $13780-57-9$ & 162.5 & -21.2 & $442.0-\mathrm{s}$ & 100 & 1 & 2 & $\mathrm{LC}_{\mathrm{LO}}$ \\
\hline Sulfur dioxide & $7446-09-5$ & 64.1 & -10.1 & 336.5 & $2520^{-}$ & 0.2 & 0.4 & ERPG \\
\hline Sulfur monochioride & $10025-67-9$ & 135 & 137.9 & 0.944 & $150^{*}$ & 1 & 2 & $\mathrm{LC}_{50}$ \\
\hline Sulfur tetrafluoride & $7783-60-0$ & 108.1 & -40.4 & 1785 & $40^{-1}$ & 0.4 & 0.8 & $\mathrm{LC}_{50}$ \\
\hline Sulfur trioxide & $7446-11-9$ & 80.1 & 44.8 & 25.73 & $106 \mathrm{mg} / \mathrm{m}^{3}$ & $10 \mathrm{mg} / \mathrm{m}^{3}$ & $20 \mathrm{mg} / \mathrm{m}^{3}$ & ERPG \\
\hline Sulfuryl chloride & $7791-25-5$ & 135 & 69.4 & 14.811 & $3020-\mathrm{s}$ & 30 & $60^{-1}$ & $\mathrm{LC}_{50}-\mathrm{S}$ \\
\hline Sulfuryl fluoride & $2699-79-8$ & 102.1 & -55.4 & $1964^{-}$ & 3020 & $30^{-1}$ & $60^{-1}$ & $\mathrm{LC}_{50}$ \\
\hline Tellurium hexafluoride & $7783-80-4$ & 241.6 & -38.2 & 709.6 & 20 & 0.2 & 0.4 & $\mathrm{LC}_{\mathrm{LO}}$ \\
\hline Tetraethyl dithiopyrophosphate & $3689-24-5$ & 322.3 & -195.9 & 2644 & 1.5 & 0.015 & 0.02 & $\mathrm{LC}_{50}$ \\
\hline Tetraethyl pyrophosphate & $107-49-3$ & 290.1 & -195.9 & 2644 & $1.5-S^{-}$ & 0.015 & 0.02 & $\mathrm{LC}_{50}-\mathrm{S}$ \\
\hline Tetrafluorohydrazine & $10036-47-2$ & 104 & -74.3 & 2515 & 950 & $10^{-}$ & $20^{-\cdots}$ & $\mathrm{LC}_{50}$ \\
\hline Tetramethyl tin & $594-27-4$ & 178.8 & 77.9 & $17.92-\mathrm{E}^{-}$ & 58 & 0.6 & $1.2^{-1}$ & $\mathrm{LC}_{\mathrm{LO}}^{--}$ \\
\hline Tetranitromethane & $509-14-8$ & 196 & 125.8 & 1.121 & 36 & 0.3 & 0.6 & $\mathrm{LC}_{50}$ \\
\hline Thionyl chloride & $7719-09-7$ & 119 & 75.7 & 12.77 & 500 & 5 & $10^{-\cdots}$ & $\mathrm{LC}_{50}$ \\
\hline Thiophosgene & $463-71-8$ & 115 & 72.9 & 15.04 & $25-\mathrm{S}$ & 0.2 & 0.4 & ERPG-S \\
\hline Titanium tetrachioride & $7550-45-0$ & 189.7 & 135.9 & 1.253 & $1300 \mathrm{mg} / \mathrm{m}^{3}$ & $20 \mathrm{mg} / \mathrm{m}^{3}$ & $40 \mathrm{mg} / \mathrm{m}^{3}$ & ERPG \\
\hline Trichloroacetyl chloride & $76-02-8$ & 181.8 & 118.0 & $2.189^{-1}$ & 128 & 1 & 2 & ERPG-S \\
\hline Trifluoroacetyl chloride & $354-32 \cdot 5$ & 132.5 & -17.9 & $356.2-5$ & 208 & 1 & 2 & ERPG-S \\
\hline
\end{tabular}

Continued 
Table B.1 Chemicals Analyzed in the 2000ERG Analysisa (Cont.)

\begin{tabular}{|c|c|c|c|c|c|c|c|c|}
\hline DOT Name & CAS No. & $\begin{array}{c}\text { Molecular } \\
\text { Weight }\end{array}$ & $\begin{array}{c}\text { Boiling } \\
\text { Point } \\
\left({ }^{\circ} \mathrm{C}\right)\end{array}$ & $\begin{array}{c}\text { Vapor } \\
\text { Pressure at } \\
20^{\circ} \mathrm{C}(\mathrm{kPa})\end{array}$ & $\begin{array}{c}\mathrm{LC}_{50} \text { or } \mathrm{LC}_{\mathrm{LO}} \\
(\mathrm{ppm})\end{array}$ & $\begin{array}{c}\text { 1-h } \\
\text { Protective } \\
\text { (ppm) }\end{array}$ & $\begin{array}{l}\text { 15-min } \\
\text { Protective } \\
\text { (ppm) }\end{array}$ & Basis \\
\hline Trifluorochloroethylene & $79-38-9$ & 116.5 & -27.9 & 531.4 & 8568 & 100 & 200 & ERPG \\
\hline Trimethoxy silane & $2487-90-3$ & 122.3 & 80.9 & $20.40-E$ & 84 & 2 & 4 & $\mathrm{EAPG}$ \\
\hline Trimethylacetyl chloride & $3282-30-2$ & 120.6 & 106.9 & 2.866 & $250^{-}$ & 5 & $10^{-}$ & $\mathrm{LC}_{50}$ \\
\hline Tris-(2-chloroethyl) amine & $817-09-4$ & 204.5 & $255.9^{-}$ & 0.00094 & 3 & 0.03 & 12 & $\mathrm{LC}_{50}^{-}$ \\
\hline Tungsten hexafluoride & $7783-82-6$ & 297.8 & 17.4 & 111.8 & 207 & 2 & 4 & $\mathrm{LC}_{50}$ \\
\hline
\end{tabular}

a The abbreviations used in this table are defined as follows:

ERPG = Emergency Response Planning Guideline established by the American Industrial Hygiene Association (AlHA).

$\mathrm{EEL} \quad=$ Emergency Exposure Level published in the AlHA Journal.

$\mathrm{LC}_{50}=$ median lethal concentration in animals exposed via inhalation.

$L C_{L O}=$ lowest lethal concentration reported in an animal study.

$\mathrm{LC}_{50}-\mathrm{E}=\mathrm{LC}_{50}$ estimated from oral toxicity data.

$\mathrm{E} \quad=$ estimated value.

$\mathrm{S} \quad=$ data are for a structurally similar chemical.

N/A not applicable. 


\section{Appendix C Experimental Program Conducted to Support the Water Reactivity Analysis}

To supply an empirical basis for the amount of toxic by inhalation (TIH) gas emitted upon the reaction of a substance with water, we carried out a series of small-scale experiments with representative materials. Experimental data were needed since quantitative data from observations of TIH gas evolving from hazardous chemicals added to water do not exist in the chemical literature. We examined a total of 21 substances, a few of which we were seeking to rule out as TIH by water reactivity (TIHWR) substances. We examined about a quarter of our TIHWR list, with an emphasis on the large class of hydrochloride $(\mathrm{HCl})$ emitters.

\section{C.1 Apparatus and Experimental Method}

We tested water-reactive materials for their ability to generate gases by mixing small amounts (about 1 millimole [mmol]) of the material with water in a closed system. A diagram of the apparatus used is shown in Figure C.1. We followed the release of gas over time by observing the displacement of a manometric fluid. For example, when gaseous $\mathrm{HCl}$ was generated, $\mathrm{HCl}$ vapor (saturated) was evolved into a burette that contained HCl-saturated octane and was held at an angle of about 15 degrees from the horizontal. This arrangement allowed the volume of the closed system to increase substantially yet limited the increase in the pressure in the system to less than 10 to $15 \mathrm{~cm}$ of octane (less than $0.015 \mathrm{~atm}$ ).

The apparatus was calibrated by reacting concentrated sulfuric acid with a known mass of potassium chloride; this reaction yielded the predicted volume of gaseous $\mathrm{HCl}$. All reactions were carried out at room temperature $\left(24^{\circ} \mathrm{C}\right)$. Although the reactions were all exothermic, the small volume of the reacting system led to efficient cooling; the temperature of the gas remained at $24^{\circ} \mathrm{C}$.

Two experiments, using different methods, were carried out with each substance.

- Method A: Stoichiometric amounts of water and the water-reactive material were used. The reaction flask was purged with dry nitrogen, the water-reactive material was injected through a side arm sealed with a rubber cap, and the water was then injected over a period of about $10 \mathrm{~s}$. The reaction mixture was magnetically stirred. As an example of a typical experiment, $0.121 \mathrm{~mL}(0.129 \mathrm{~g}=1.00 \mathrm{mmol})$ of dimethyldichlorosilane $\left(\mathrm{CH}_{3}\right)_{2} \mathrm{SiCl}_{2}$ was reacted with $0.018 \mathrm{~mL}(1.00 \mathrm{mmol})$ of water to yield $\mathrm{HCl}$ and a polymeric siloxane. With this method, we sought to verify the possible evolution of the TIH material, to measure the fraction of the stoichiometric yield that actually resulted, and to estimate the primary rate constant for the reaction. 


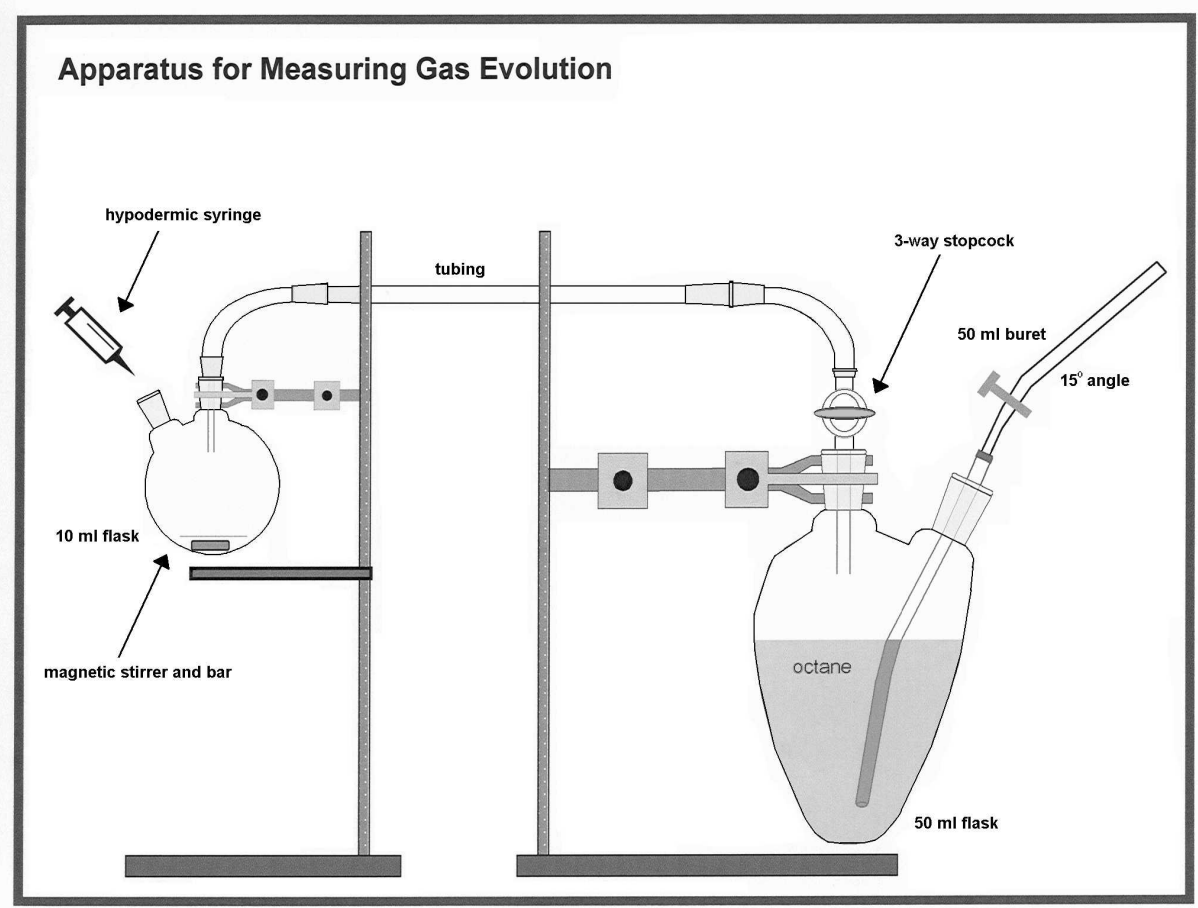

Figure C.1 Diagram of the Apparatus for Measuring the Rate and Amount of TIH Gases Released When a Material Reacts with Water

- Method B: The water-reactive material was added to the water, which was present in fivefold molar excess. Again, the reaction system was pre-purged with dry nitrogen. As an example, to study dimethyldichlorosilane, $0.090 \mathrm{~mL}(0.090 \mathrm{~g}=$ $5.00 \mathrm{mmol})$ of water was put in the reaction flask, and then $0.121 \mathrm{~mL}(0.129 \mathrm{~g}=$ $1.00 \mathrm{mmol})$ of $\left(\mathrm{CH}_{3}\right)_{2} \mathrm{SiCl}_{2}$ was injected through a side arm over a period of about $10 \mathrm{~s}$. With this experimental method, we sought to reproduce a more likely scenario for an actual spill. We usually found differences between this method and Method A.

\section{C.2 Experimental Results}

The following subsections detail the experimental procedures, the observed results, and our interpretation of what was observed. All masses are given in grams. 


\section{C.2.1 Tetrachlorosilane $(0.170 \mathrm{~g}=1.00 \mathrm{mmol}), \mathrm{SiCl}_{4}$}

$\mathrm{SiCl}_{4}+2 \mathrm{H}_{2} \mathrm{O} \longrightarrow 4 \mathrm{HCl}+\mathrm{SiO}_{2}$
\begin{tabular}{ccc}
\hline & \multicolumn{3}{c}{ Mass of HCl (g) } \\
\cline { 2 - 4 }$\left(\begin{array}{c}\text { Time } \\
\text { (min) }\end{array}\right.$ & Method A & Method B \\
\hline 1 & 0.034 & 0.046 \\
5 & 0.041 & 0.050 \\
10 & 0.043 & 0.048 \\
20 & 0.046 & 0.043 \\
\hline
\end{tabular}

Comments: The balance equation predicts that the theoretical yield of $\mathrm{HCl}$ would be $0.146 \mathrm{~g}(4.00 \mathrm{mmol})$ from $0.170 \mathrm{~g}$ of tetrachlorosilane (silicon tetrachloride), $\mathrm{SiCl}_{4}$. In the experiment, after $20 \mathrm{~min}$, only about 30 to $33 \%$ of the theoretical amount of $\mathrm{HCl}$ had been generated. Both methods indicated that a considerable portion of the theoretical yield of $\mathrm{HCl}$ gas had not evolved. On contact with water, the tetrachlorosilane immediately formed a white, solid, polymeric silicon oxide. This product undoubtedly sequestered some water, preventing it from reacting promptly with the $\mathrm{SiCl}_{4}$.

\section{C.2.2 Trichloromethylsilane $(0.299 \mathrm{~g}=2.00 \mathrm{mmol}), \mathrm{CH}_{3} \mathrm{SiCl}_{3}$}

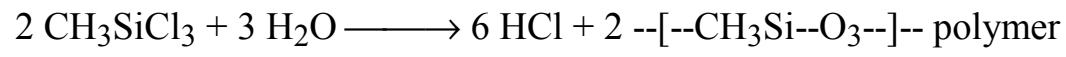

\begin{tabular}{|ccc|}
\hline & \multicolumn{2}{c|}{ Mass of $\mathbf{H C l}(\mathbf{g})$} \\
\cline { 2 - 3 } Time & & \\
$(\boldsymbol{m i n})$ & Method A & Method B \\
\hline & & \\
1 & 0.023 & 0.050 \\
5 & 0.041 & 0.064 \\
10 & 0.055 & 0.068 \\
20 & 0.059 & 0.073 \\
\hline
\end{tabular}

Comments: The balance equation predicts a theoretical yield of $0.219 \mathrm{~g}(6.00 \mathrm{mmol})$ of $\mathrm{HCl}$. Only $27 \%$ and $33 \%$ of this amount was actually generated in Methods A and B, respectively. On contact with water, the trichloromethylsilane immediately formed a white, solid, polymeric siloxane, which undoubtedly sequestered a considerable portion of the water, preventing its reaction. 


\section{C.2.3 Dichlorodimethylsilane $(0.129 \mathrm{~g}=1.00 \mathrm{mmol}),\left(\mathrm{CH}_{3}\right)_{2} \mathrm{SiCl}_{2}$}

$$
\left.\left(\mathrm{CH}_{3}\right)_{2} \mathrm{SiCl}_{2}+\mathrm{H}_{2} \mathrm{O} \longrightarrow 2 \mathrm{HCl}+\text {--[-- }\left(\mathrm{CH}_{3}\right)_{2} \mathrm{Si}-\text {-O-- }\right]-- \text { polymer }
$$

\begin{tabular}{|ccc|}
\hline & \multicolumn{2}{c|}{ Mass of $\mathbf{~ H C l ~}(\mathbf{g})$} \\
\cline { 2 - 3 } Time & & \\
$(\mathbf{m i n})$ & Method A & Method B \\
\hline & & \\
1 & 0.0113 & 0.0182 \\
5 & 0.043 & 0.027 \\
10 & 0.068 & 0.030 \\
20 & 0.073 & 0.030 \\
\hline
\end{tabular}

Comments: In Method $\mathrm{A}$, the theoretical amount of $\mathrm{HCl}$ gas, $0.073 \mathrm{~g}$ based on the equation, was generated. In Method $\mathrm{B}$, over half of the $\mathrm{HCl}$ apparently dissolved in the excess water. In the free atmosphere, advection of the gas that would be produced would tend to reduce dissolution, increasing the yield.

\section{C.2.4 Chlorotrimethylsilane $(0.109 \mathrm{~g}=1.00 \mathrm{mmol}),\left(\mathrm{CH}_{3}\right)_{3} \mathrm{SiCl}$}

$$
2\left(\mathrm{CH}_{3}\right)_{3} \mathrm{SiCl}+\mathrm{H}_{2} \mathrm{O} \longrightarrow 2 \mathrm{HCl}+\left(\mathrm{CH}_{3}\right)_{3} \mathrm{SiOSi}\left(\mathrm{CH}_{3}\right)_{3}
$$

\begin{tabular}{|ccc|}
\hline & \multicolumn{2}{c|}{ Mass of $\mathbf{H C l} \mathbf{( g )}$} \\
\cline { 2 - 3 } Time & & \\
$(\mathbf{m i n})$ & Method A & Method B \\
\hline & & \\
1 & 0.0046 & 0.0102 \\
5 & 0.0102 & 0.0125 \\
10 & 0.0114 & 0.0137 \\
20 & 0.0125 & 0.0137 \\
\hline
\end{tabular}

Comments: The balance equation predicts a theoretical yield of $0.0365 \mathrm{~g}(1.00 \mathrm{mmol})$ of $\mathrm{HCl}$. However, only $34 \%$ and $38 \%$ was generated in Methods A and B, respectively. Apparently, the majority of the $\mathrm{HCl}$ that was produced was absorbed in solution to form hydrochloric acid. 


\section{C.2.5 Titanium Tetrachloride $(0.190 \mathrm{~g}=1.00 \mathrm{mmol}), \mathrm{TiCl}_{4}$}

$$
\mathrm{TiCl}_{4}+2 \mathrm{H}_{2} \mathrm{O} \longrightarrow 4 \mathrm{HCl}+\mathrm{TiO}_{2}
$$

\begin{tabular}{|ccc|}
\hline & \multicolumn{2}{c|}{ Mass of $\mathbf{H C l}(\mathbf{g})$} \\
\cline { 2 - 3 } Time & & \\
(min) & Method A & Method B \\
\hline & & \\
1 & 0.023 & 0.023 \\
5 & 0.039 & 0.0114 \\
10 & 0.039 & 0.0091 \\
20 & 0.039 & 0.0091 \\
\hline
\end{tabular}

Comments: $\mathrm{TiCl}_{4}$ is explosively reactive. In Method A, the injected water was immediately covered with a white crust of titanium dioxide. This cover seemed to prevent the full reaction of water with the remaining $\mathrm{TiCl}_{4}$. Only $27 \%$ of the predicted theoretical yield occurred. In Method B, it appeared that in addition, some $\mathrm{HCl}$ that initially escaped as a gas dissolved in the excess water. The yield peaked at $16 \%$ of maximum after $1 \mathrm{~min}$ and dropped to $6 \%$ within $10 \mathrm{~min}$. In the free atmosphere, a smaller fraction of the $\mathrm{HCl}$ produced would dissolve in the excess water as a result of advection.

\section{C.2.6 Calcium Hypochlorite $(0.143 \mathrm{~g}=1.00 \mathrm{mmol}), \mathrm{Ca}(\mathrm{OCl})_{2}$}

$$
\mathrm{Ca}(\mathrm{OCl})_{2}+\mathrm{H}_{2} \mathrm{O} \longrightarrow \text { no reaction }
$$

\begin{tabular}{ccc|}
\hline & \multicolumn{2}{c|}{ Mass of $\mathrm{Cl}_{\mathbf{2}} \mathbf{( g )}$} \\
\cline { 2 - 3 } $\begin{array}{c}\text { Time } \\
\text { (min) }\end{array}$ & Method A & Method B \\
\hline & 0 & 0 \\
1 & 0 & 0 \\
5 & 0 & 0 \\
10 & 0 & 0 \\
20 & 0 & \\
\hline
\end{tabular}

Comments: The experiment showed decisively that no $\mathrm{Cl}_{2}$ release occurs when calcium hypochlorite is mixed with water under these conditions. No formation of any gaseous product was detected, but the dissolution of the material in water may have produced some heat, causing the slight volume change that was observed (on the order of $0.5 \mathrm{~mL}$ ). 


\section{C.2.7 Oleum (fuming sulfuric acid, $0.122 \mathrm{~g} \approx 1 \mathrm{mmol}$ ) \\ $\mathrm{H}_{2} \mathrm{SO}_{4} *\left(\mathrm{SO}_{3}\right)_{\mathrm{n}}+\mathrm{n} \mathrm{H}_{2} \mathrm{O} \longrightarrow \mathrm{H}_{2} \mathrm{SO}_{4}+$ heat}

\begin{tabular}{ccc|}
\hline & \multicolumn{2}{c|}{ Mass of $\mathbf{H C l}(\mathbf{g})$} \\
\cline { 2 - 3 } Time & Method A & Method B \\
\hline & & \\
1 & 0 & 0 \\
5 & 0 & 0 \\
10 & 0 & 0 \\
20 & 0 & 0 \\
\hline
\end{tabular}

Comments: Little formation of any gaseous product was detected. The dissolution in water produced a large amount of heat, which caused a slight observable volume change (on the order of $1 \mathrm{~mL}$ ). Also, the formation of additional sulfuric acid from sulfur trioxide is highly exothermic. The TIH concern associated with this material is the production of an acidic mist. However, neither Method A nor Method B simulated conditions that might generate an acidic mist.

\section{C.2.8 Aluminum Bromide (anhydrous, $0.267 \mathrm{~g}=1.00 \mathrm{mmol}$ ), $\mathrm{AlBr}_{3}$}

$\mathrm{AlBr}_{3}+\mathrm{x} \mathrm{H}_{2} \mathrm{O} \longrightarrow \mathrm{AlBr}_{3} *\left(\mathrm{x} \mathrm{H}_{2} \mathrm{O}\right)$ (hydration)
\begin{tabular}{ccc} 
Time & \multicolumn{2}{c|}{ Mass of $\mathbf{H B r}(\mathbf{g})$} \\
\cline { 2 - 4 }$(\mathbf{m i n})$ & Method A & Method B \\
\hline 1 & 0 & 0 \\
5 & 0 & 0 \\
10 & 0 & 0 \\
20 & 0 & 0 \\
\hline
\end{tabular}

Comments: Gaseous product did not appear. The hydration reaction was rapid and quite exothermic. The observed small change in volume (on the order of $1 \mathrm{~mL}$ ) was attributed to this heating. The production of an acidic mist by the intense heating of a restricted quantity of water should not be ruled out as the result of a natural spill of large quantities of aluminum bromide. 


\section{C.2.9 Aluminum Chloride (anhydrous, $0.133 \mathrm{~g}=1.00 \mathrm{mmol}$ ), $\mathrm{AlCl}_{3}$}

$$
\mathrm{AlCl}_{3}+\mathrm{x} \mathrm{H}_{2} \mathrm{O} \longrightarrow \mathrm{AlCl}_{3} *\left(\mathrm{x} \mathrm{H}_{2} \mathrm{O}\right) \text { (hydration) }
$$

\begin{tabular}{|ccc|}
\hline & \multicolumn{2}{c|}{ Mass of $\mathbf{H C l}(\mathbf{g})$} \\
\cline { 2 - 3 } $\begin{array}{c}\text { Time } \\
(\mathbf{m i n})\end{array}$ & Method A & Method B \\
\hline & 0 & 0 \\
1 & 0 & 0 \\
5 & 0 & 0 \\
10 & 0 & 0 \\
20 & 0 &
\end{tabular}

Comments: Gaseous product did not appear. The hydration reaction was rapid and quite exothermic. The observed small change in volume (on the order of $1 \mathrm{~mL}$ ) was attributed to this heating. The production of an acidic mist by intense heating of a restricted quantity of water should not be ruled out as the result of a natural spill of large quantities of aluminum chloride.

\section{C.2.10 Tin Tetrachloride $(0.260 \mathrm{~g}=1.00 \mathrm{mmol}), \mathrm{SnCl}_{4}$}

$$
\mathrm{SnCl}_{4}+4 \mathrm{H}_{2} \mathrm{O} \longrightarrow \mathrm{SnO}_{2} \cdot 2 \mathrm{H}_{2}+4 \mathrm{HCl}
$$

\begin{tabular}{|ccc|}
\hline & \multicolumn{2}{c|}{ Mass of $\mathbf{H C l} \mathbf{( g )}$} \\
\cline { 2 - 3 } Time & & \\
(min) & Method A & Method B \\
\hline & & \\
1 & 0.0023 & 0.0023 \\
5 & 0.0023 & 0.0023 \\
10 & 0.0023 & 0.0023 \\
20 & 0.0023 & 0.0023 \\
\hline
\end{tabular}

Comments: Less than $2 \%$ of the theoretical maximum gaseous $\mathrm{HCl}(0.146 \mathrm{~g})$ was generated. 


\section{C.2.11 Nitrosylsulfuric Acid (0.127 g= $1.00 \mathrm{mmol}), \mathrm{HO}_{3} \mathrm{SONO}$}

$$
\begin{aligned}
& \mathrm{HO}_{3} \mathrm{SONO}+\mathrm{H}_{2} \mathrm{O} \longrightarrow \mathrm{H}_{2} \mathrm{SO}_{4}+\mathrm{HONO} \\
& \mathrm{HONO} \longrightarrow(2 / 3) \mathrm{NO}+(1 / 3) \mathrm{HNO}_{3}+(1 / 3) \mathrm{H}_{2} \mathrm{O} \\
& (2 / 3) \mathrm{NO}+(1 / 3) \mathrm{O}_{2} \longrightarrow(2 / 3) \mathrm{NO}_{2} \\
& \begin{array}{|ccc|}
\hline & \multicolumn{2}{c|}{\text { Mass of } \mathbf{N O}_{\mathbf{2}} \mathbf{( g )}} \\
\cline { 2 - 3 } \text { Time } & & \\
(\mathbf{m i n}) & \text { Method A } & \text { Method B } \\
\hline & & \\
1 & 0.086 & 0.0316 \\
5 & 0.0028 & 0.0302 \\
10 & 0.0014 & 0.0273 \\
20 & 0.0 & 0.0244 \\
\hline
\end{array}
\end{aligned}
$$

Comments: The theoretical yield of $\mathrm{NO}_{2}$ according to the equations above would be $0.0307 \mathrm{~g}$. The nitrogen purge was omitted because oxygen is required for the production of the $\mathrm{TIH} \mathrm{NO} \mathrm{N}_{2}$. The red $\mathrm{NO}_{2}$ appeared immediately. Conversion of $\mathrm{NO}$ to $\mathrm{NO}_{2}$ (as represented in the last of the three chemical equations above) was rapid and complete. One mole of oxygen was removed from the closed test system for every two moles of $\mathrm{NO}_{2}$ that were generated. Therefore, the number of moles of $\mathrm{NO}_{2}$ that were produced was $3 / 2$ times larger than indicated by the volume changes. This factor was included in computing the masses in the table. In Method $\mathrm{B}$, the mass of $\mathrm{NO}_{2}$ produced after $1 \mathrm{~min}$ slightly exceeded (by about 3\%) the theoretical maximum because reactions in addition to those represented above occurred. Dissolution of the gaseous $\mathrm{NO}_{2}$ in the acidic water after the first minute accounted for the reduction in the amount of gaseous $\mathrm{NO}_{2}$ in the system after the first minute. 


\section{C.2.12 Thionyl Chloride $(0.119 \mathrm{~g}=1.00 \mathrm{mmol}), \mathrm{SOCl}_{2}$}

$$
\mathrm{SOCl}_{2}+\mathrm{H}_{2} \mathrm{O} \longrightarrow 2 \mathrm{HCl}+\mathrm{SO}_{2}
$$

\begin{tabular}{|cccccc|}
\hline & \multicolumn{2}{c}{ Method A } & & \multicolumn{2}{c|}{ Method B } \\
\cline { 2 - 3 } \cline { 5 - 6 } $\begin{array}{c}\text { Time } \\
(\mathbf{m i n})\end{array}$ & Mass HCI & Mass $\mathbf{S O}_{\mathbf{2}}$ & & Mass HCl & Mass $\mathbf{S O}_{\mathbf{2}}$ \\
\hline & & & & & \\
1 & 0.023 & 0.020 & & 0.041 & 0.060 \\
2 & 0.053 & 0.047 & & 0.043 & 0.064 \\
3 & 0.070 & 0.061 & & 0.040 & 0.064 \\
5 & 0.073 & 0.064 & & 0.039 & 0.060 \\
10 & 0.073 & 0.056 & & 0.039 & 0.052 \\
20 & 0.073 & 0.052 & & 0.039 & 0.048 \\
\hline
\end{tabular}

Comments: This case was unusual in that two TIH gases were emitted at the same time in a fixed ratio. The maximum theoretical yield of $\mathrm{HCl}$ according to this equation would be $0.0730 \mathrm{~g}$ of $\mathrm{HCl}$ and $0.064 \mathrm{~g}$ of $\mathrm{SO}_{2}$. The two gases were generated concurrently. The experiment measured the total volume of evolved gas and not the separate volumes. In Method A, in which $1.00 \mathrm{mmol}$ of water was mixed with $\mathrm{SOCl}_{2}$, the theoretical amount of $\mathrm{HCl}$ and $\mathrm{SO}_{2}$ (as shown in the "yield" column) appeared within 5 min as all the water was consumed. The assignment into masses of $\mathrm{HCl}$ and $\mathrm{SO}_{2}$ assumed no dissolution of either gas in the unreacted water. The reduction in the amount of gases after 5 min was ascribed to the loss of $\mathrm{SO}_{2}$, because $\mathrm{SO}_{2}$ (but not $\mathrm{HCl}$ ) can be absorbed by the manometric fluid (octane previously saturated with $\mathrm{HCl}$ ). In Method $\mathrm{B}$, the partition into mass of $\mathrm{HCl}$ and mass of $\mathrm{SO}_{2}$ was estimated by assuming that the rate-course of the reaction was the same as that in Method A. It is clear that about $40 \%$ of the $\mathrm{HCl}$ dissolved in the excess water or was produced in solution as hydrochloric acid. 


\section{C.2.13 Phosphoryl Chloride (phosphorus oxychloride, $0.153 \mathrm{~g}=1.00 \mathrm{mmol}), \mathrm{POCl}_{3}$}

$$
\begin{aligned}
& \mathrm{POCl}_{3}+3 \mathrm{H}_{2} \mathrm{O} \longrightarrow 3 \mathrm{HCl}+\mathrm{H}_{3} \mathrm{PO}_{4} \text { (Total) } \\
& \mathrm{POCl}_{3}+\mathrm{H}_{2} \mathrm{O} \longrightarrow \mathrm{HCl}+\mathrm{POCl}_{2} \mathrm{OH} \text { (First step) }
\end{aligned}
$$

\begin{tabular}{|ccc|}
\hline & \multicolumn{2}{c|}{ Mass of $\mathbf{H C l}(\mathbf{g})$} \\
\cline { 2 - 3 } Time & & \\
$(\mathbf{m i n})$ & Method A & Method B \\
\hline & & \\
1 & 0.016 & 0.0228 \\
2 & 0.0171 & 0.0103 \\
3 & 0.0182 & 0.0068 \\
5 & 0.0194 & 0.0046 \\
10 & 0.0205 & 0.0043 \\
20 & 0.0228 & 0.0043 \\
30 & 0.0251 & ---- \\
60 & 0.0274 & ---- \\
180 & 0.0297 & ---- \\
\hline
\end{tabular}

Comments: The maximum theoretical yield of $\mathrm{HCl}$ according to the first equation would be $0.1095 \mathrm{~g}$ of $\mathrm{HCl}$. In Method A, the reaction was incomplete. Essentially just one chlorine atom was hydrolyzed, as indicated by the second equation. Over a period of several hours, the additional slow formation of $\mathrm{HCl}$ gas was observed. In Method $\mathrm{B}$, most $\mathrm{HCl}$ gas was absorbed in the excess water to form a solution of hydrochloric acid. In the free atmosphere, advection would prevent much of the absorption, causing the release of a substantial amount of $\mathrm{HCl}$ gas. 


\section{C.2.14 Fumaryl Chloride $(0.153 \mathrm{~g}=1.00 \mathrm{mmol}), \mathrm{ClCOCH}=\mathrm{CHCOCI}$}

$$
\mathrm{ClCOCH}=\mathrm{CHCOCl}+2 \mathrm{H}_{2} \mathrm{O} \longrightarrow 2 \mathrm{HCl}+\mathrm{HOOCCH}=\mathrm{CHCOOH}
$$

\begin{tabular}{|ccc|}
\hline & \multicolumn{2}{c|}{ Mass of $\mathbf{H C l}(\mathbf{g})$} \\
\cline { 2 - 3 } Time & & \\
$(\mathbf{m i n})$ & Method A & Method B \\
\hline & & \\
1 & 0 & 0 \\
2 & 0 & 0 \\
5 & 0 & 0 \\
10 & 0 & 0 \\
20 & 0 & 0 \\
\hline
\end{tabular}

Comments: Essentially no $\mathrm{HCl}$ gas formation was observed $(<0.3 \mathrm{~mL})$; the material was quite unreactive. Fumaryl chloride should be removed from the list of TIHWR compounds. 


\section{C.2.15 Chloroacetyl Chloride $(0.113 \mathrm{~g}=1.00 \mathrm{mmol}), \mathrm{ClCH}_{2} \mathrm{COCl}$ \\ $\mathrm{ClCH}_{2} \mathrm{COCl}+\mathrm{H}_{2} \mathrm{O} \longrightarrow \mathrm{HCl}+\mathrm{ClCH}_{2} \mathrm{COOH}$}

\begin{tabular}{ccc|}
\hline & \multicolumn{2}{c|}{ Mass of HCI $(\mathbf{g})$} \\
\cline { 2 - 3 } Time & Method A & Method B \\
\hline & & \\
1 & 0.00046 & 0.00046 \\
2 & 0.00068 & 0.00114 \\
3 & 0.00114 & 0.00230 \\
4 & 0.0014 & 0.00114 \\
5 & 0.0018 & 0.00046 \\
10 & 0.0062 & 0 \\
20 & 0.014 & 0 \\
30 & 0.023 & ---- \\
40 & 0.027 & ---- \\
50 & 0.030 & ---- \\
60 & 0.032 & ---- \\
90 & 0.035 & ---- \\
120 & 0.036 & ---- \\
150 & 0.036 & ---- \\
\hline
\end{tabular}

Comments: The maximum theoretical yield of $\mathrm{HCl}$ according to the equation would be $0.0364 \mathrm{~g}$. In Method A, there was a slow initial period followed by a speed up, which suggested autocatalysis. Ultimately, the theoretical amount of gaseous $\mathrm{HCl}$ appeared. In Method $\mathrm{B}$, most of the $\mathrm{HCl}$ was absorbed in the excess water to form a hydrochloric acid. However, in the free atmosphere, the several minutes of contact between $\mathrm{HCl}$ and water required would not be available, causing substantial emission. 


\section{C.2.16 Phosphorus Tribromide $(0.271 \mathrm{~g}=1.00 \mathrm{mmol}), \mathrm{PBr}_{3}$}

$$
\mathrm{PBr}_{3}+3 \mathrm{H}_{2} \mathrm{O} \longrightarrow 3 \mathrm{HBr}+\mathrm{H}_{3} \mathrm{PO}_{3}
$$

\begin{tabular}{|ccc|}
\hline & \multicolumn{2}{c|}{ Mass of $\mathbf{H B r}(\mathbf{g})$} \\
\cline { 2 - 3 } Time & Method A & Method B \\
\hline (min) & Meth \\
1 & 0.0081 & 0 \\
2 & 0.0202 & 0 \\
3 & 0.0405 & 0 \\
5 & 0.0809 & 0 \\
10 & 0.162 & 0 \\
20 & 0.217 & 0 \\
25 & 0.228 & 0 \\
30 & 0.233 & 0 \\
60 & 0.238 & 0 \\
\hline
\end{tabular}

Comments: The maximum theoretical yield of $\mathrm{HBr}$ according to the equation would be $0.243 \mathrm{~g}$. This case is quite interesting. In Method A, the reaction slowly generated $\mathrm{HBr}$ and eventually released an amount of $\mathrm{HBr}$ close to the theoretical maximum. However, in Method B, in the presence of excess water, the solubility of $\mathrm{HBr}$ was sufficiently high that the gas dissolved before it could be released. Therefore, the material is not considered a TIHWR chemical, even though in the exothermic, violent conditions of a large spill, some $\mathrm{HBr}$ would probably be released as a gas. 


\section{C.2.17 Phosphorus Pentabromide (0.430 $\mathrm{g}=1.00 \mathrm{mmol}), \mathrm{PBr}_{5}$}

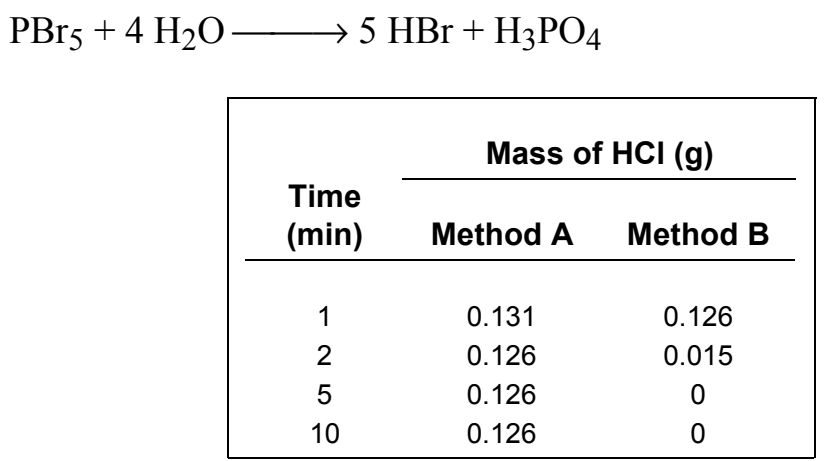

Comments: The maximum theoretical yield of $\mathrm{HBr}$ according to the equation would be $0.405 \mathrm{~g}$. The high solubility of $\mathrm{HBr}$ was evidenced in this experiment also, but the reaction rate was much higher, leading to a different conclusion than that for the tribromide form. In Method A, the reaction was so violent that some water was spattered as droplets onto the walls of the container and out of contact with the $\mathrm{PBr}_{5}$. In Method $\mathrm{B}$, $\mathrm{HBr}$ gas formed rapidly (in much less time than $1 \mathrm{~min}$ ) in a similarly violent fashion. All of the $\mathrm{HBr}$ then dissolved in the excess water within the first $2 \mathrm{~min}$. In an actual spill, the $\mathrm{HBr}$ would be emitted into the atmosphere and advected away before it would have a chance to dissolve in the water. Therefore, phosphorus pentabromide is included as a TIHWR, and phosphorus tribromide is not, because of the different relationships between reaction rate and the rate at which $\mathrm{HBr}$ dissolves. 


\section{C.2.18 Calcium Phosphide (0.182 $\mathrm{g}=1.00 \mathrm{mmol}), \mathrm{Ca}_{3} \mathrm{P}_{2}$}

$$
\mathrm{Ca}_{3} \mathrm{P}_{2}+6 \mathrm{H}_{2} \mathrm{O} \longrightarrow 2 \mathrm{PH}_{3}+3 \mathrm{Ca}(\mathrm{OH})_{2}
$$

\begin{tabular}{|ccc|}
\hline & \multicolumn{2}{c|}{ Mass of $\mathrm{PH}_{\mathbf{3}} \mathbf{( g )}$} \\
\cline { 2 - 3 } Time & & \\
$(\mathbf{m i n})$ & Method A & Method B \\
\hline & & \\
1 & 0.00212 & 0.00425 \\
2 & 0.00425 & 0.0106 \\
5 & 0.00425 & 0.0170 \\
10 & 0.00425 & 0.0191 \\
20 & 0.00425 & 0.0191 \\
\hline
\end{tabular}

Comments: This case is very interesting as a representative of the class of metallic phosphides, which can emit the very deadly phosphine gas upon reaction with water. The maximum theoretical yield of $\mathrm{PH}_{3}$ according to the equation would be $0.0680 \mathrm{~g}$. In both methods, the hydrolysis stopped short of completion. With a limited amount of water, the production reached nearly $7 \%$ of maximum; but with a fivefold excess water supply, it reached $28 \%$ of maximum. Samples of other metallic phosphides proved difficult to obtain, and the class clearly deserves careful further study. Some metallic phosphides among those listed in 2000ERG will not react, according to the literature; others, like calcium phosphide, will react substantially. 


\section{C.2.19 Phosphorus Trichloride $(0.137 \mathrm{~g}=1.00 \mathrm{mmol}), \mathrm{PCl}_{3}$}

$$
\mathrm{PCl}_{3}+3 \mathrm{H}_{2} \mathrm{O} \longrightarrow 3 \mathrm{HCl}+\mathrm{H}_{3} \mathrm{PO}_{3}
$$

\begin{tabular}{|ccc|}
\hline & \multicolumn{2}{c|}{ Mass of $\mathbf{H C l}(\mathbf{g})$} \\
\cline { 2 - 3 } Time & Method A & Method B \\
\hline min) & Mer \\
1 & 0.059 & 0.036 \\
2 & 0.091 & 0.021 \\
3 & 0.100 & 0.0114 \\
5 & 0.107 & 0.0046 \\
10 & 0.109 & 0.0023 \\
20 & 0.109 & 0.0011 \\
\hline
\end{tabular}

Comments: The maximum theoretical yield of $\mathrm{HCl}$ according to the equation would be $0.109 \mathrm{~g}$. In Method A, the reaction generated the theoretical maximum amount of gaseous $\mathrm{HCl}$. In Method $\mathrm{B}$, a substantial portion of the $\mathrm{HCl}$ gas dissolved in the excess water. In the free atmosphere, probably close to one-third of the maximum yield of $\mathrm{HCl}$ would occur, because the gas would not remain in contact with the water for enough time (on the order of $1 \mathrm{~min}$ ) to permit dissolution. 


\section{C.2.20 Sulfuryl Chloride $(0.135 \mathrm{~g}=1.00 \mathrm{mmol}), \mathrm{SO}_{2} \mathrm{Cl}_{2}$}

\begin{tabular}{|c|c|c|}
\hline & \multicolumn{2}{|c|}{ Mass of $\mathrm{HCl}(\mathrm{g})$} \\
\hline (min) & Method A & Method B \\
\hline 1 & 0.0068 & 0.0091 \\
\hline 2 & 0.0114 & 0.0114 \\
\hline 3 & 0.015 & 0.0125 \\
\hline 5 & 0.023 & 0.0137 \\
\hline 10 & 0.041 & 0.0148 \\
\hline 15 & 0.055 & 0.0125 \\
\hline 20 & 0.059 & 0.0114 \\
\hline 30 & 0.064 & 0.0114 \\
\hline 60 & 0.068 & ----- \\
\hline 90 & 0.071 & ----- \\
\hline 120 & 0.071 & ----- \\
\hline
\end{tabular}

Comments: The maximum theoretical yield of $\mathrm{HCl}$ according to the equation would be $0.0729 \mathrm{~g}$. In Method A, essentially the stoichiometric amount of gaseous $\mathrm{HCl}$ was generated, but slowly, requiring over $1 \mathrm{~h}$ for completion. In Method B, a substantial portion of the $\mathrm{HCl}$ dissolved in the excess water, but $16 \%$ of the maximum was generated. In an unenclosed spill, somewhat more than $16 \%$ would be released to the atmosphere, with at least one-third of the maximum amount probably appearing in the first $5 \mathrm{~min}$.

\section{C.2.21 Methanesulfonyl Chloride $(0.114 \mathrm{~g}=1.00 \mathrm{mmol}), \mathrm{CH}_{3} \mathrm{SO}_{2} \mathrm{Cl}$}

$$
\mathrm{CH}_{3} \mathrm{SO}_{2} \mathrm{Cl}+\mathrm{H}_{2} \mathrm{O} \longrightarrow \mathrm{HCl}+\mathrm{CH}_{3} \mathrm{SO}_{2} \mathrm{OH}
$$

\begin{tabular}{|ccc|}
\hline & \multicolumn{2}{c|}{ Mass of $\mathbf{H C l}(\mathbf{g})$} \\
\cline { 2 - 3 } Time & & \\
$(\boldsymbol{m i n})$ & Method A & Method B \\
\hline & 0 & 0 \\
5 & 0 & 0 \\
10 & 0 & 0 \\
20 & 0 & 0 \\
\hline
\end{tabular}

Comments: No gases were generated from contact of methanesulfonyl chloride with water. The material is not a TIHWR chemical. 
$\Delta$ 


\section{Appendix D Additional Details on Water-Reactive Materials}

Appendix D provides detailed information on the water-reactive materials listed in the Table of Initial Isolation and Protective Action Distances. Supplementary information on all water-reactive materials in the toxic by inhalation by water reactivity (TIHWR) list is provided in Table D.1. In addition, for the 37 new materials added to the TIHWR list, a brief summary of reasons supporting their inclusion is provided. 
Table D.1 Supplementary Information on Water-Reactive Materials in the 2000 Emergency Response Guidebook ${ }^{\mathrm{a}}$

\begin{tabular}{|c|c|c|c|c|c|c|c|c|c|}
\hline UN No. & TIH & Exp & Name & Prod. & St & Dens & S.Y. & $\varepsilon$ & C \\
\hline 1162 & & $\mathrm{X}$ & Dimethyldichlorosilane & $\mathrm{HCl}$ & $\mathrm{L}$ & 1.10 & 0.565 & 0.41 & 0.96 \\
\hline 1242 & & & Methyldichlorosilane & $\mathrm{HCl}$ & $\mathrm{L}$ & 1.11 & 0.634 & 0.1 & 0.33 \\
\hline 1250 & & $X$ & Methyltrichlorosilane & $\mathrm{HCl}$ & $L$ & 1.27 & 0.732 & 0.33 & 1.31 \\
\hline 1295 & & & Trichlorosilane & $\mathrm{HCl}$ & $L$ & 1.34 & 0.808 & 0.33 & 1.5 \\
\hline 1298 & & $\mathrm{X}$ & Trimethylchlorosilane & $\mathrm{HCl}$ & $L$ & 0.85 & 0.336 & 0.37 & 1.45 \\
\hline 1340 & & & Phosphorus pentasulfide & $\mathrm{H}_{2} \mathrm{~S}$ & $S$ & 2.09 & 0.766 & 0.6 & 0.2 \\
\hline 1360 & & $\mathrm{X}$ & Calcium phosphide & $\mathrm{PH}_{3}$ & $S$ & 2.51 & 0.373 & 0.29 & 0.36 \\
\hline 1397 & & & Aluminum phosphide & $\mathrm{PH}_{3}$ & $S$ & 2.40 & 0.587 & 0.3 & 0.1 \\
\hline 1412 & & & Lithium amide & $\mathrm{NH}_{3}$ & $S$ & 1.18 & 0.740 & 0.1 & 5 \\
\hline 1419 & & & Magnesium aluminum phosphide & $\mathrm{PH}_{3}$ & $\mathrm{~S}$ & 2.20 & 0.529 & 0.3 & 0.1 \\
\hline 1432 & & & Sodium phosphide & $\mathrm{PH}_{3}$ & $S$ & 1.74 & 0.283 & 0.3 & 0.1 \\
\hline 1433 & & & Stannic phosphide & $\mathrm{PH}_{3}$ & $\mathrm{~S}$ & 5.18 & 0.239 & 0.3 & 0.1 \\
\hline 1541 & & & Acetone cyanohydrin & $\mathrm{HCN}$ & L & 0.93 & 0.317 & 0.2 & 0.2 \\
\hline 1680 & & & Potassium cyanide & $\mathrm{HCN}$ & $S$ & 1.52 & 0.415 & 0.2 & 0.1 \\
\hline 1689 & & & Sodium cyanide & $\mathrm{HCN}$ & S & 1.52 & 0.552 & 0.2 & 0.1 \\
\hline 1714 & & & Zinc phosphide & $\mathrm{PH}_{3}$ & $S$ & 4.55 & 0.263 & 0.3 & 0.2 \\
\hline 1716 & & & Acetyl bromide & $\mathrm{HBr}$ & L & 1.66 & 0.658 & 0.4 & 5 \\
\hline 1717 & & & Acetyl chloride & $\mathrm{HCl}$ & L & 1.11 & 0.464 & 0.4 & 5 \\
\hline 1724 & & & Allyl trichlorosilane, stabilized & $\mathrm{HCl}$ & L & 1.21 & 0.623 & 0.33 & 1.5 \\
\hline 1725 & & & Aluminum bromide, anhydrous & $\mathrm{HBr}$ & $\mathrm{S}$ & 2.54 & 0.910 & 0.6 & 0.1 \\
\hline 1726 & & & Aluminum chloride, anhydrous & $\mathrm{HCl}$ & $S$ & 2.44 & 0.820 & 0.1 & 0.2 \\
\hline 1728 & & & Amyltrichlorosilane & $\mathrm{HCl}$ & $L$ & 1.16 & 0.532 & 0.1 & 0.7 \\
\hline 1732 & & & Antimony pentafluoride & $\mathrm{HF}$ & L & 2.99 & 0.461 & 0.4 & 5 \\
\hline 1736 & & & Benzoyl chloride & $\mathrm{HCl}$ & L & 1.21 & 0.259 & 0.1 & 0.33 \\
\hline 1745 & $\mathrm{X}$ & & Bromine pentafluoride & $\mathrm{Br}_{2}$ & $L$ & 2.47 & 0.456 & 0.04 & 0.2 \\
\hline 1745 & $\bar{x}$ & & Bromine pentafluoride & $\mathrm{HF}$ & L & 2.47 & 0.572 & 0.4 & 5 \\
\hline 1746 & $\mathrm{X}$ & & Bromine trifluoride & $\mathrm{Br}_{2}$ & L & 2.80 & 0.591 & 0.02 & 0.2 \\
\hline 1746 & $\bar{x}$ & & Bromine trifluoride & $\mathrm{HF}$ & $\ddot{L}$ & 2.80 & 0.438 & 0.6 & 5 \\
\hline 1747 & & & Butyltrichlorosilane & $\mathrm{HCl}$ & $L$ & 1.16 & 0.571 & 0.1 & 0.7 \\
\hline 1749 & $\mathrm{X}$ & & Chlorine trifluoride & $\mathrm{Cl}_{2}$ & G & 1.77 & 0.383 & 0.05 & 1 \\
\hline 1749 & $\bar{x}$ & & Chlorine trifluoride & $\mathrm{HF}$ & $\ddot{L}$ & 1.77 & 0.649 & 0.6 & 5 \\
\hline 1752 & & $\mathrm{X}$ & Chloroacetyl chloride & $\mathrm{HCl}$ & $L$ & 1.50 & 0.323 & 0.1 & 0.33 \\
\hline 1754 & & & Chlorosulfonic acid & $\mathrm{HCl}$ & $L$ & 1.76 & 0.313 & 0.2 & 0.1 \\
\hline 1758 & & & Chromium oxychloride & $\mathrm{HCl}$ & L & 1.91 & 0.471 & 0.1 & 0.1 \\
\hline 1777 & & & Fluorosulfonic acid & $\mathrm{HF}$ & L & 1.73 & 0.200 & 0.1 & 5 \\
\hline 1801 & & & Octyltrichlorosilane & $\mathrm{HCl}$ & L & 1.33 & 0.442 & 0.33 & 1.5 \\
\hline 1806 & & & Phosphorus pentachloride & $\mathrm{HCl}$ & $S$ & 1.60 & 0.875 & 0.2 & 5 \\
\hline
\end{tabular}


Table D.1 Supplementary Information on Water-Reactive Materials in the 2000 Emergency Response Guidebook ${ }^{\mathrm{a}}$ (Cont.)

\begin{tabular}{|c|c|c|c|c|c|c|c|c|c|}
\hline UN No. & TIH & Exp & Name & Prod. & St & Dens & S.Y. & $\varepsilon$ & C \\
\hline 1807 & & & Phosphorus pentoxide & $\mathrm{H}_{2} \mathrm{PO}_{4}$ & $S$ & 1.50 & 1.410 & 0.05 & 0.2 \\
\hline 1809 & & $\mathrm{X}$ & Phosphorus trichloride & $\mathrm{HCl}$ & $\mathrm{L}$ & 1.57 & 0.796 & 0.33 & 3 \\
\hline 1810 & & $X$ & Phosphorus oxychloride & $\mathrm{HCl}$ & L & 1.67 & 0.713 & 0.21 & 10 \\
\hline 1816 & & $X$ & Silicon tetrachloride & $\mathrm{HCl}$ & L & 1.48 & 0.858 & 0.34 & 0.83 \\
\hline 1828 & $\mathrm{X}$ & & Sulfur chlorides & $\mathrm{SO}_{2}$ & $\mathrm{~L}$ & 1.62 & 0.252 & 0.12 & 0.2 \\
\hline 1828 & $\bar{x}$ & & Sulfur chlorides & $\mathrm{HCl}$ & L & 1.62 & 0.540 & 0.08 & 0.6 \\
\hline 1828 & $\bar{x}$ & & Sulfur chlorides & $\mathrm{H}_{2} \mathrm{~S}$ & L & 1.62 & 0.474 & 0.1 & 0.6 \\
\hline 1829 & $X$ & & Sulfur trioxide & $\mathrm{H}_{2} \mathrm{SO}_{4}$ & $S$ & 1.92 & 1.230 & 0.2 & 0.2 \\
\hline 1831 & $\mathrm{X}$ & $\mathrm{X}$ & Oleum & $\mathrm{H}_{2} \mathrm{SO}_{4}$ & $L$ & 1.80 & 1.500 & 0.07 & 10 \\
\hline 1834 & $\mathrm{X}$ & $\mathrm{X}$ & Sulfuryl chloride & $\mathrm{HCl}$ & L & 1.66 & 0.540 & 0.2 & 0.92 \\
\hline 1834 & $\bar{x}$ & & Sulfuryl chloride & $\mathrm{H}_{2} \mathrm{SO}_{4}$ & L & 1.66 & 0.726 & 0.05 & 0.2 \\
\hline 1836 & & $X$ & Thionyl chloride & $\mathrm{SO}_{2}$ & $L$ & 1.63 & 0.538 & 1 & 2.71 \\
\hline 1836 & $x$ & $x^{-}$ & Thionyl chloride & $\mathrm{HCl}$ & L & 1.63 & 0.613 & 0.08 & 0.59 \\
\hline 1838 & $\mathrm{X}$ & $\mathrm{X}$ & Titanium tetrachloride & $\mathrm{HCl}$ & L & 1.73 & 0.769 & 0.27 & 0.89 \\
\hline 1898 & & & Acetyl iodide & $\mathrm{HI}$ & $L$ & 2.07 & 0.753 & 0.4 & 0.2 \\
\hline 1939 & & $\mathrm{X}$ & Phosphorus oxybromide, molten2 & $\mathrm{HBr}$ & $\mathrm{L}$ & 2.82 & 0.847 & 0.21 & 20 \\
\hline 2004 & & & Magnesium diamide & $\mathrm{NH}_{3}$ & $S$ & 1.39 & 0.604 & 0.1 & 0.1 \\
\hline 2011 & & & Magnesium phosphide & $\mathrm{PH}_{3}$ & $S$ & 2.06 & 0.504 & 0.3 & 0.15 \\
\hline 2012 & & & Potassium phosphide & $\mathrm{PH}_{3}$ & S & 2.50 & 0.229 & 0.3 & 0.1 \\
\hline 2013 & & & Strontium phosphide & $\mathrm{PH}_{3}$ & $S$ & 2.68 & 0.209 & 0.3 & 0.1 \\
\hline 2442 & & & Trichloroacetyl chloride & $\mathrm{HCl}$ & $\mathrm{L}$ & 1.63 & 0.314 & 0.1 & 0.33 \\
\hline 2495 & & & lodine pentafluoride & $\mathrm{HF}$ & $\mathrm{L}$ & 3.75 & 0.450 & 0.2 & 5 \\
\hline 2691 & & $\mathrm{X}$ & Phosphorus pentabromide & $\mathrm{HBr}$ & S & 2.00 & 0.940 & 0.31 & 3 \\
\hline 2692 & $\mathrm{X}$ & & Boron tribromide & $\mathrm{HBr}$ & $\mathrm{L}$ & 2.65 & 0.971 & 0.1 & 0.8 \\
\hline 2806 & & & Lithium nitride & $\mathrm{NH}_{3}$ & $S$ & 1.27 & 0.489 & 0.2 & 1 \\
\hline 2977 & & & Uranium hexafluoride, fissile & $\mathrm{HF}$ & $S$ & 4.68 & 0.341 & 0.2 & 5 \\
\hline 2978 & & & Uranium hexafluoride, non-fissile & HF & $\mathrm{S}$ & 4.68 & 0.341 & 0.2 & 5 \\
\hline 2985 & & $\mathrm{X}$ & Chlorosilanes, n.o.s. & $\mathrm{HCl}$ & L & 1.10 & 0.565 & 0.41 & 0.96 \\
\hline 2986 & & $\mathrm{X}$ & Chlorosilanes, flam., corr, n.o.s. & $\mathrm{HCl}$ & $\mathrm{L}$ & 1.10 & 0.565 & 0.41 & 0.96 \\
\hline 2987 & & & Chlorosilanes, corrosive, n.o.s. & $\mathrm{HCl}$ & L & 1.10 & 0.565 & 0.41 & 0.96 \\
\hline 2988 & & & Chlorosilanes, wtr-rctv, flam., corr.,n.o.s. & $\mathrm{HCl}$ & $\mathrm{L}$ & 1.10 & 0.565 & 0.41 & 0.96 \\
\hline 3048 & & & Aluminum phosphide pesticide & $\mathrm{PH}_{3}$ & $\mathrm{~S}$ & 2.40 & 0.587 & 0.3 & 0.05 \\
\hline 3049 & & & Metal alkyl halides n.o.s. & $\mathrm{HCl}$ & & 1.60 & 0.500 & 0.05 & 5 \\
\hline 3052 & & & Aluminum alkyl halides & $\mathrm{HCl}$ & & 1.60 & 0.500 & 0.05 & 5 \\
\hline 9191 & & & Chlorine dioxide, hydrate, frozen & $\mathrm{Cl}_{2}$ & $\mathrm{~S}$ & 1.40 & 0.084 & 0.05 & 5 \\
\hline $\mathrm{N} / \mathrm{A}$ & & & Sodium methylcarbamodithioate) & $\mathrm{H}_{2} \mathrm{~S}$ & $\mathrm{~L}$ & 1.00 & 0.000 & 0 & 0 \\
\hline $\mathrm{N} / \mathrm{A}$ & & & Sodium methylcarbamodithioate & $\mathrm{CH}_{5} \mathrm{~N}$ & $\mathrm{~L}$ & 1.00 & 0.000 & 0 & 0 \\
\hline
\end{tabular}

a $\operatorname{Exp}=$ experiment performed, $\mathrm{St}=$ normal state during shipment (solid, liquid, gas), Dens $=$ density $\left(\mathrm{g} / \mathrm{cm}^{3}\right)$,

S.Y. = stoichiometric yield of $\mathrm{TIH}(\mathrm{kg} \mathrm{TIH} / \mathrm{kg}$ spilled parent), $\varepsilon=$ efficiency factor (average fraction of S.Y. produced), and $\mathrm{C}=$ primary rate constant at $20^{\circ} \mathrm{C}$. 


\section{Reasons to Support Why Materials Were Added to the TIHWR List}

UN\#1162 dimethyldichlorosilane: Experiment established a substantial rate of evolution of $\mathrm{HCl}$ when the chemical was mixed with water.

UN\#1340 phosphorus pentasulfide: The material "Readily liberates toxic hydrogen sulfide and phosphorus pentaoxide and evolves heat on contact with moisture" (Lewis 1966).

UN\#1384 sodium hydrosulfite: The compound is soluble in water and would dissolve smoothly with no evolution of gases in most spills. However, large spills into restricted amounts of water cause heating with subsequent decomposition and evolution of $\mathrm{SO}_{2}$ and possibly $\mathrm{H}_{2} \mathrm{~S}$.

UN\#1541 acetone cyanohydrin: This compound readily decomposes to $\mathrm{HCN}$ and acetone. The protective action distance is greater when spilled into water because of likely evolution of $\mathrm{HCN}$.

UN\#1724 allyl trichlorosilane, stabilized: This compound generates $\mathrm{HCl}$ when mixed with water. Experimental results on the related compound methyltrichlorosilane suggested a higher rate of evolution than previously considered.

UN\#1728 amyltrichlorosilane: It generates $\mathrm{HCl}$ when mixed with water. Experimental results on the related compound methyltrichlorosilane suggested a higher rate of evolution than previously considered.

UN\#1736 benzoyl chloride: The compound generates $\mathrm{HCl}$ when spilled into water. Large spills, especially into restricted amounts of water, could cause a medium to large hazard.

UN\#1745 bromine pentafluoride: It explodes or ignites on contact with many hydrogen-containing materials (including water). Products of reaction include $\mathrm{HF}$ and possibly $\mathrm{Br}_{2}$. This material was recommended for inclusion on the 1996 North American ERG list.

UN\#1746 bromine trifluoride: It reacts explosively or violently with water to generate $\mathrm{HF}$ and possibly $\mathrm{Br}_{2}$. It was recommended for inclusion in the NAERG96 list.

UN\#1747 butyltrichlorosilane: This chemical generates $\mathrm{HCl}$ when mixed with water. Experimental results on the related compound methyltrichlorosilane suggested a higher rate of evolution than previously considered.

UN\#1749 chlorine trifluoride: The compound reacts explosively with water to generate $\mathrm{HF}$ and possibly $\mathrm{Cl}_{2}$. It was recommended for inclusion on the NAERG96 list. 
UN\#1752 chloroacetyl chloride: Experiment established a substantial rate of evolution of $\mathrm{HCl}$ when the material was mixed with water. The chemical was recommended for inclusion on the NAERG96 list.

UN\#1754 chlorosulfonic acid: This acid is a source of very toxic fumes. It decomposes explosively on contact with water to generate $\mathrm{HCl}$. This product is a less serious $\mathrm{TIH}$ than chlorosulfonic acid itself.

UN\#1801 octyltrichlorosilane: This compound generates $\mathrm{HCl}$ when mixed with water. Experimental results on the related compound methyltrichlorosilane suggested a higher rate of evolution than previously considered.

UN\#1807 phosphorus pentoxide: The chemical reacts violently with water, generating much heat. It is capable of raising an acidic mist of phosphoric acid.

UN\#1809 phosphorus trichloride: Experiment established a substantial rate of evolution of $\mathrm{HCl}$ when the material was mixed with water.

UN\#1810 phosphorus oxychloride: Experiment established a substantial rate of evolution of $\mathrm{HCl}$ when the material was mixed with water.

UN\#1828 sulfur chloride: The compound was included on the basis of descriptions of its reactivity in standard references.

UN\#1829 sulfur trioxide: This compound reacts exothermically with water to generate sulfuric acid. Local heating is known to raise a persistent acidic mist.

UN\#1831 oleum: No gaseous emission was observed in the millimole experiment. However, the reaction of this chemical with water is very exothermic, and it is known to raise a mist of droplets of sulfuric acid, which gave rise to its alternate name, "fuming sulfuric acid."

UN\#1834 sulfuryl chloride: Experiment established a substantial rate of evolution of $\mathrm{HCl}$ when the compound was mixed with water.

UN\#1838 titanium tetrachloride: Experiment established a substantial rate of evolution of $\mathrm{HCl}$ when the chemical was mixed with water.

UN\#1923 calcium hydrosulfite: The compound dissolves smoothly in water under many conditions. In an industrial accident, the reaction of the related compound sodium hydrosulfite with a restricted amount of water at a larger scale generated enough heat to start decomposition in the undissolved portion and evolution of toxic gases.

UN\#1939 phosphorus oxybromide, solid: Experiment with the related compound phosphorus oxychloride established a substantial rate of evolution of a hydrogen halide. 
UN\#2308 nitrosylsulfuric acid: Experiment established a substantial rate of evolution of $\mathrm{NO}_{2}$ when the material was mixed with water.

UN\#2442 trichloroacetyl chloride: Experiment established with the related compound chloroacetyl chloride a substantial rate of evolution of $\mathrm{HCl}$.

UN\#2495 iodine pentafluoride: The literature reports "Violent reaction with water" (Sax 1992).

UN\#2576 phosphorus oxybromide, molten: Experiment established a substantial rate of evolution of a hydrogen halide in the case of the related compound phosphorus oxychloride.

UN\#2691 phosphorus pentabromide: Experiment established a substantial rate of evolution of $\mathrm{HBr}$ when the material was mixed with water.

UN\#2692 boron tribromide: The chemical literature suggested that water reaction would cause evolution of toxic gases at rates comparable to those of the related compound $\mathrm{BCl}_{3}$.

UN\#2985 chlorosilanes n.o.s.: Most chlorosilanes generate $\mathrm{HCl}$ at some rate if spilled into water.

UN\#2986 chlorosilanes, flammable, corrosive n.o.s.: Most chlorosilanes generate $\mathrm{HCl}$ at some rate if spilled into water.

UN\#2987 chlorosilanes, corrosive n.o.s.: Most chlorosilanes generate $\mathrm{HCl}$ at some rate if spilled into water.

UN\#2988 chlorosilanes, water reactive, flammable, corrosive, n.o.s.: Most chlorosilanes generate $\mathrm{HCl}$ at some rate if spilled into water.

UN\#3049 metal alkyl halides n.o.s.: Most metal alkyl halides generate hydrogen halides at some rate if spilled into water.

UN\#3052 aluminum alkyl halides: Most aluminum alkyl halides generate hydrogen halides at some rate if spilled into water.

UN\#N/A metam sodium (sodium methylcarbamodithioate): This pesticide is known to have generated TIH gases at a toxic level when spilled into a river. 